Universidade de São Paulo

Instituto de Física

\title{
FORÇANTE RADIATIVA, PROPRIEDADES ÓPTICAS E FÍSICAS DAS NUVENS CIRRUS NA AMAZÔNIA
}

\author{
Diego Alves Gouveia
}

\author{
Tese de doutorado apresentada ao Instituto \\ de Física como requisito parcial para a ob- \\ tenção do título de Doutor em Ciências.
}

\section{Orientador:}

Prof. Dr. Henrique de Melo Jorge Barbosa

\section{Banca Examinadora:}

Prof. Dr. Henrique de Melo Jorge Barbosa (IFUSP)

Prof. Dr. Vito Roberto Vanin (IFUSP)

Profa. Dra. Marcia Yamasoe (IAGUSP)

Profa. Dra. Elisa Sena (UNIFESP)

Prof. Dr. Juan Luis Guerrero Rascado (UG) 
FICHA CATALOGRÁFICA

Preparada pelo Serviço de Biblioteca e Informação do Instituto de Física da Universidade de São Paulo

\section{Gouveia, Diego Alves}

Forçante radiativa, propriedades ópticas e físicas das nuvens cirrus na Amazônia. São Paulo, 2018.

Tese (Doutorado) - Universidade de São Paulo, Instituto de Física, Depto. de Física Aplicada.

Orientador: Prof. Dr. Henrique de Melo Jorge Barbosa

Área de Concentração: Física

Unitermos: 1. Cirrus; 2. Amazônia; 3. Lidar; 4.Propriedades ópticas; 5. Efeito radiativo. 


\title{
RADIATIVE FORCING, PHYSICAL AND OPTICAL PROPERTIES OF CIRRUS CLOUDS OVER AMAZON
}

\author{
Diego Alves Gouveia
}

\author{
Thesis submitted to the Physics Institute of \\ the University of São Paulo in partial fulfill- \\ ment of the requirements for the degree of \\ Doctor of Science.
}

\section{Supervisor:}

Prof. Dr. Henrique de Melo Jorge Barbosa

\section{Examining Committee:}

Prof. Dr. Henrique de Melo Jorge Barbosa (IFUSP)

Prof. Dr. Vito Roberto Vanin (IFUSP)

Profa. Dra. Marcia Yamasoe (IAGUSP)

Profa. Dra. Elisa Sena (UNIFESP)

Prof. Dr. Juan Luis Guerrero Rascado (UG) 



\section{AGRADECIMENTOS}

Agradeço imensamente ao prof. Henrique de Melo Jorge Barbosa, pela oportunidade, confiança, preocupação com o desenvolvimento deste projeto, cuidado com minha formação e, principalmente, dedicação. Com certeza um exemplo de profissional a ser seguido.

Agradeço ao professor Boris Barja, por todas as lições, discussões, auxilio na implementação do algoritmo automatizado de detecção de nuvens e pela atenção especial dada a este projeto.

Agradeço ao professor Albert Ansmann, do Leibniz Institute for Tropospheric Research (TROPOS), por ter aceitado ser supervisor do meu projeto de estágio no exterior, pela recepção e importantes lições. Agradeço também a todos os membros de seu grupo, em especial ao Patrick, Holger, Heike, Birgit e prof. Dietrich, pelas importantes lições sobre a técnica lidar e sobre o estudo de nuvens. As contribuições de vocês foram cruciais para o sucesso deste trabalho.

Agradeço também ao professor Vito Vanin, pelas inúmeras discussões sobre análise estatística.

Ao professor Eduardo Landulfo, do IPEN, e a todos que contribuem para o desenvolvimento da LALINET, em especial ao Fábio, Gregori, Marcos e ao prof. Juan Luiz Gerrero-Rascado.

Gostaria de agradecer a todos do laboratório de física atmosférica pelas discussões, dicas e colaborações.

Agradeço aos amigos e familiares pelo suporte, preocupação e amizade. Em especial, agradeço à minha namorada Daniela, pela paciência, companheirismo e dedicação, e à sua família, pelas caronas, marmitas e carinho.

Agradeço ao CPNq (Processo: 141941/2014-6, Doutorado - GD), à CAPES (Processo: Programa de Doutorado Sanduíche no Exterior -88881.133433/2016-01), à FAPESP e à USP pelo suporte financeiro para a realização deste trabalho. 



\section{RESUMO}

As nuvens cirrus cobrem uma grande fração das latitudes tropicais e desempenham um papel importante no balanço de radiação da Terra. As propriedades ópticas, altitude, extensão vertical e cobertura horizontal de nuvens controlam sua forçante radiativa. Além disso, nuvens cirrus tropicais podem influenciar a distribuição vertical do aquecimento radiativo na tropopausa tropical e pesquisas recentes também apontam para um aumento do vapor de água estratosférico ligado principalmente à ocorrência de nuvens cirrus na camada da tropopausa tropical (TTL). Apesar de sua importância, estudos relatando propriedades de nuvens cirrus sobre florestas tropicais como a Amazônia são ainda escassos. A maioria estão baseados em imagens de satélites de órbita polar que não fornecem informações sobre o ciclo diurno, nem sobre a estrutura vertical destas nuvens. Ao mesmo tempo, os estudos com lidar em solo são restritos a poucos estudos de caso, em geral associados a campanhas de campo de curta duração.

Este panorama começou a mudar em 2011 com a instalação do sistema lidar do Laboratório de Física Atmosférica do IF-USP próximo à cidade de Manaus, Brasil. Neste trabalho, um conjunto de um ano de dados (de julho de 2011 a junho de 2012) foi utilizado para caracterizar as propriedades macro, microfísicas e ópticas das nuvens cirrus sobre a região amazônica e, posteriormente, calcular o papel que essas nuvens têm no balanço radiativo do planeta. Para tanto, foi desenvolvido um algoritmo automático para detectar as nuvens e para obter as propriedades ópticas, incluindo a correção de múltiplo-espalhamento. As forçantes radiativas foram estimadas com dois modelos diferentes, a partir dos perfis de extinção medido com o lidar e de uma parametrização para estimar o raio efetivo dos cristais de gelo.

Nossos resultados mostraram que as nuvens cirrus na alta troposfera foram mais frequentes na Amazônia do que relatado previamente em outras regiões tropicais. A frequência de ocorrência foi de $88 \%$ durante a estação chuvosa e não inferior a 50 \% durante a estação seca. O ciclo diurno mostrou um mínimo ao redor do meio-dia local e máximo durante o final da tarde, associado ao ciclo diurno de precipitação. Os valores médios das alturas de topo e base da nuvem, da espessura da nuvem e da profundidade óptica da nuvem foram de 14,3 $\pm 1,9$ (desv. pad.) $\mathrm{km}, 12,9 \pm 2,2$ $\mathrm{km}, 1,4 \pm 1,1 \mathrm{~km}$ e $0,25 \pm 0,46$, respectivamente. As nuvens cirrus foram encontradas em temperaturas de até $-90{ }^{\circ} \mathrm{C}$, com $6 \%$ ocorrendo acima da tropopausa. A distribuição vertical não se mostrou uniforme, e nuvens cirrus finas $(0,03<\tau$ $<0,3)$ e subvisuais $(\tau<0,03)$ ocorreram mais frequentemente nas proximidades da tropopausa. A razão lidar média foi de 23,3 \pm 8,0 sr. Contudo, para as nuvens cirrus subvisuais foi encontrada uma distribuição bimodal com um pico secundário em torno de 44 sr, sugerindo uma composição mista dos cristais de gelo. Não foi encontrada uma dependência da razão lidar com a temperatura da nuvem (altitude), indicando que as nuvens estão verticalmente bem misturadas. A frequência de ocorrência relativa das camadas de nuvens cirrus classificadas como subvisuais foi de $41,6 \%$, enquanto que $37,8 \%$ foram cirrus finos e $20,5 \%$ de cirrus opacos $(\tau>0,3)$, 
com uma superposição média de 1,41 $\pm 0,63$ camadas por perfil. Assim, na Amazônia central não ocorre apenas uma alta frequência de nuvens cirrus, mas também uma grande fração de nuvens cirrus subvisuais, o que pode estar contaminando as medidas de fotômetros solares e sensores orbitais.

As propriedades medidas foram utilizadas no cálculo da forçante radiativa das nuvens cirrus (CRF) e dos perfis da taxa de aquecimento da atmosfera, em detalhe pelo libRadtran e aproximadamente pelo modelo de Corti e Peter (modelo CP). Com tamanha frequência de ocorrência e residindo tão alto sobre a intocada floresta Amazônica (albedo $\approx 0,12$ ), essas nuvens produziram uma CRF líquida no topo da atmosfera e na superfície (TOA e BOA) de $+15,3 \pm 0,4 W m^{-2}$ e $-3,7 \pm 0,2$ $W m^{-2}$, respectivamente, muito mais intenso do que o estimado sobre a Europa (0,9 a 1,7 $W m^{-2}$ no TOA). Cirrus opticamente mais espessas, em geral, apresentaram CRF líquido maior, com CRF instantâneo atingindo valores máximos (mínimos) de $140(-65) W m^{-2}$ para o período noturno (diurno) no TOA. Juntos, os perfis verticais com $\tau_{\text {Coluna }}>0,3$ foram responsáveis por cerca de $72 \%$ (62\%) do CRF líquido no TOA (BOA), o que significa que uma importante fração do CRF é gerada por cirrus opticamente mais finos $\left(\tau_{\text {Coluna }}<0,3\right)$, que são mais difíceis de se serem detectados por radares e instrumentos passivos a bordo de satélites. O ciclo diurno da profundidade óptica das nuvens cirrus teve reflexo em sua forçante radiativa. Observamos um ciclo diurno do valor médio da CRF líquida no TOA (BOA), que vaiou entre $1,7(-23) W m^{-2}$ à tarde e $47(3,1) W m^{-2}$ durante a noite. As nuvens cirrus promovem um aquecimento aproximadamente constante de 1,2 $\mathrm{K}$ dia $^{-1}$ no perfil vertical entre 8 e $18 \mathrm{~km}$ (dentro da nuvem), mas com valores instantâneos superiores a $10 \mathrm{~K}$ dia $^{-1}$ para porções da nuvem com alto $I W C$. Acredita-se que esse perfil de aquecimento gerado pelas nuvens cirrus tenha um papel importante na circulação da alta troposfera/baixa estratosfera, gerando um fluxo ascendente médio de massa de ar entre 2 e $15 \mathrm{~kg} \mathrm{~m}^{-2}$ dia $^{-1}$ para altitudes entre 13 e 16,5 $\mathrm{km}$, contribuindo para a manutenção da camada de cirrus próximo da tropopausa tropical.

Palavras-chave: Cirrus; Amazônia; Lidar; Propriedades ópticas; Efeito radiativo 


\title{
RADIATIVE FORCING, PHYSICAL AND OPTICAL PROPERTIES OF CIRRUS CLOUDS OVER AMAZON
}

\begin{abstract}
Cirrus clouds cover a large fraction of tropical latitudes and play an important role in the Earth's radiation balance. Their optical properties, altitude, vertical extension and horizontal cover control their radiative effect. In addition, tropical cirrus clouds can influence the vertical distribution of radiative heating near the tropopause, and recent research associate the moistening of the lower stratosphere with the occurrence of cirrus clouds in the tropical tropopause layer (TTL). Despite their importance, studies describing the properties of cirrus clouds over tropical forests like the Amazon are still scarce. Most studies are based on images from polar orbiting satellites, which do not give information on the diurnal cycle nor on the vertical structure of these clouds. At the same time, the studies based on ground based lidar are restricted to a few case studies, based on short-term field campaigns.

This panorama started to change in 2011 with the installation of a lidar system from the Laboratory of Atmospheric Physics of IF-USP near the city of Manaus, Brazil. In this study, data from July 2011 to June 2012 was used to characterize the macro, microphysical and optical properties of cirrus clouds over the Amazon region, and then to calculate the role of those clouds in the radiative balance of the planet. An automatic algorithm was developed to detect the cloud layers and to obtain the optical properties, already considering the multiple-scattering correction. Two different models, using as input the measured extinction profiles and a parameterization for the ice crystals effective radius, were used to estimate the cirrus radiative effect.
\end{abstract}

Our results showed that cirrus clouds are more frequent in Amazonia than in other tropical regions. The frequency of occurrence was $88 \%$ during the rainy season and not less than $50 \%$ during the dry season. The diurnal cycle showed a minimum around local noon and a maximum around late afternoon, associated with the diurnal cycle of precipitation. The average values of the top and cloud base heights, thickness, and optical depth were $14.3 \pm 1.9 \mathrm{~km}, 12.9 \pm 2.2 \mathrm{~km}, 1.4 \pm 1.1 \mathrm{~km}$, and $0.25 \pm 0.46$, respectively. Cirrus clouds were found at temperatures as low as $-90{ }^{\circ} \mathrm{C}$, with $6 \%$ occurring above the tropopause. The vertical distribution was not uniform, and thin cirrus $(0.03<\tau<0.3)$ and subvisible $(\tau<0.03)$ were more frequent in the vicinity of the tropopause. The mean lidar-ratio was $23.3 \pm 8.0 \mathrm{sr}$. However, for the subvisible clouds a bimodal distribution with a secondary peak at about 44 sr was found, suggesting a mixture of ice crystals habits. No dependence of the lidar-ratio with temperature (altitude) was found, suggesting these clouds are well mixed vertically. The relative frequency of occurrence of cirrus layers classified as subvisible was $41.6 \%$, while $37.8 \%$ were thin cirrus and $20.5 \%$ opaque cirrus $(\tau>0.3)$, with an average overlap of $1.41 \pm 0.63$ layers per profile. Therefore, in central Amazonia, there is not only a high incidence of cirrus clouds, but also a large fraction of subvisible clouds, which may be contaminating the measurements of sunphotometers and satellite sensors. 
These measured properties were used for the calculation of the cirrus radiative forcing $(\mathrm{CRF})$ and the heating rate profiles, in detail with libRadtran, and approximately with the model of Corti and Peter (CP model). Given their high frequency of occurrence and location at high altitude over the pristine Amazon forest (albedo $\approx 0,12$ ), these clouds produced a net CRF at the top and bottom of the atmosphere (TOA and BOA) of $+15.3 \pm 0.4 \mathrm{~W} \mathrm{~m}^{-2}$ and $-3.7 \pm 0.2 \mathrm{~W} \mathrm{~m}^{-2}$, respectively. This is greater than what was found over Europe (0.9, to $1.7 \mathrm{~W} \mathrm{~m}^{-2}$ at TOA). Optically thicker cirrus usually had larger CRF, with instantaneous CRF reaching peak (minimum) values of $140(-65) W m^{-2}$ for the nocturnal (diurnal) period at TOA. The vertical profiles with $\tau_{\text {Column }}>0.3$ were responsible for about $72 \%(62 \%)$ of the net $\mathrm{CRF}$ at TOA (BOA), which means that a significant fraction of the cirrus CRF is generated by optically thin cirrus $\left(\tau_{\text {Column }}<0.3\right)$, which are more difficult to detect by radars and passive instruments on satellites. The diurnal cycle of the cirrus clouds optical depth had influence in its radiative forcing. We observed a diurnal cycle of the mean value of net CRF at TOA (BOA), which ranged from $1.7(-23)$ $W m^{-2}$ in the afternoon to $47(3.1) W m^{-2}$ at night. The heating rates associated with these cirrus clouds were approximately constant, with $1.2 \mathrm{~K} \mathrm{day}^{-1}$ from 8 to $18 \mathrm{~km}$ (within the cloud), but with instantaneous values that reached values higher than $10 \mathrm{~K} d a y^{-1}$ for portions with higher $I W C$. It is believed that this warming profile plays an important role in the circulation of the upper troposphere / low stratosphere, generating an average air mass flux between 2 and $15 \mathrm{~kg} \mathrm{~m}^{-2}$ day $^{-1}$ for altitudes between 13 and $16.5 \mathrm{~km}$, a positive feedback for the maintenance of the cirrus layer near the tropical tropopause.

Keywords: Cirrus; Amazon; Lidar; Optical properties; Radiative effect 


\section{LISTA DE FIGURAS}

Pág.

1.1 Diferente do que ocorre em nuvens baixas e que possuem grande albedo, nuvens cirrus são mais translucidas e deixam passar grande parte da radiação solar, ao mesmo tempo em que impedem que parte da radiação emitida pela terra se perca para o espaço (Figura retirada de http://mynasadata.larc.nasa.gov/oyw/scool-featured-lessonclassification-of-clouds $/$ ) . . . . . . . . . . . . . . .

2.1 Mapa por satélite (Google Earth) mostrando a localização do lidar (ACONVEX T0e, $2.89^{\circ} \mathrm{S}$ $\left.59.97^{\circ} \mathrm{W}\right), 30 \mathrm{~km}$ vento acima (norte) do centro de Manaus-AM, Brasil. . . . . . . . . . 8

2.2 Exemplo de medidas com o sistema lidar do LFA-IFUSP e a detecção de nuvens cirrus. Painel superior: logaritmo do sinal (elástico) do lidar corrigido pela distância, com média temporal de 5 min. Os pontos vermelhos e pretos mostram a base e o topo da nuvem para cada perfil vertical, dados pela máscara de nuvens. Painel inferior: Coeficiente de extinção por partículas calculado com o método descrito na seção 2.3 . . . . . . . . . . . . . .

2.3 Exemplo de uma nuvem cirrus detectada com o algoritmo automatizado. (painel superior): $\mathrm{S}(\mathrm{z})$ com as alturas de base e de topo (linhas tracejadas verdes e magentas), o $\mathrm{S}(\mathrm{z})$ molecular ajustado abaixo da base da nuvem (linha preta), e a região acima da nuvem utilizado para calcular o fator de transmissão. (painel inferior): O fator de transmissão da equação do lidar para essa nuvem, com o valor médio e a profundidade óptica $\tau_{c}$ obtido com o método de transmitância descrito acima. . . . . . . . . . . . . . . . . . . . . . . . .

2.4 (Esquerda): Perfil vertical do coeficiente de retroespalhamento para uma nuvem cirrus derivado pelos métodos Raman e de Klett para 3 valores diferentes de razão lidar. (Direita): Profundidade óptica da nuvem cirrus em função da altitude calculado para os 3 valores de razão lidar. A linha vertical em verde representa o valor da profundidade óptica obtido pelo método da transmitância. . . . . . . . . . . . . . . . . . . . . . . . . . . . 18

2.5 (esquerda) Sinal lidar simulado com e sem os efeitos de espalhamento múltiplo. (centro esquerda) Razão entre sinais com espalhamento único e múltiplo (SS/MS). Convergência da profundidade óptica recuperada (centro direita) e da razão lidar (direita) quando corrigida pelo método iterativo. A curva cheia são os resultados calculados com o valor correto do raio efetivo do cristal de gelo simulado $(20 \mu \mathrm{m})$ e as pontilhadas quando calculadas com $\pm 10 \mu \mathrm{m} . \quad 19$

2.6 Fluxograma do método de correção dos efeitos de espalhamento múltiplo. ...... . 20 
2.7 Exemplos de sinais corrigidos pelo background e pela distância (topo) e a correspondente relação S/N (abaixo). A curva azul é um perfil de lidar medido com média temporal de 5 min e resolução vertical de 7,5 m, enquanto a curva vermelha é um perfil simulado com uma relação $\mathrm{S} / \mathrm{N}$ semelhante na base da nuvem cirrus simulada com profundidade óptica de 0,12 . A curva preta é o mesmo perfil medido, mas com um média vertical de 5 bins $(37,5 \mathrm{~m})$ e, portanto, uma relação $\mathrm{S} / \mathrm{N}$ mais elevada. . . . . . . . . . . . . . . . . . . . . . . . 21

2.8 COD calculado pelo método da transmitância em função do COD real para diferentes razões S/N. As barras de erro são o desvio padrão dos valores médios. As diferenças absolutas (painel inferior) são todas compatíveis com zero (isto é, o COD médio calculado é compatível com o COD verdadeiro). . . . . . . . . . . . . . . . . . . . . . . .

2.9 COD calculado pelo método de Klett, assumindo o verdadeiro LR $=20 \mathrm{sr}$, em função do COD real para diferentes razões $\mathrm{S} / \mathrm{N}$. As barras de erro são o desvio padrão dos valores médios. As diferenças absolutas (painel inferior) são todas compatíveis com zero (isto é, o COD médio calculado é compatível com o COD verdadeiro). . . . . . . . . . . . . . .

2.10 COD calculada pelo método de Klett, para $\mathrm{LR}=10,20$ (verdadeiro) e 30 sr, é mostrada como um função do $\mathrm{COD}$ verdadeiro para $\mathrm{S} / \mathrm{N}=50$. Pontos em verde são o método de transmissão para $\mathrm{S} / \mathrm{N}=10$. As barras de erro são o desvio padrão dos valores médios.

2.11 São mostrados os erros relativos (em \%) na determinação do COD para ambos os métodos em função do COD verdadeiro para as diferentes relações sinal/ruído. . . . . . . . . . . 26

2.12 LR calculado a partir da combinação dos métodos de transmitância e Klett, em função do COD verdadeiro para diferentes relações S/N. As barras de erro são o desvio padrão dos valores médios. As diferenças absolutas (painel inferior) são todas compatíveis com zero (isto é, a média do LR calculada é compatível com o LR verdadeiro). . . . . . . . . . . 27

2.13 Os histogramas de LR calculados a partir da combinação dos métodos de transmitância e Klett para $\mathrm{S} / \mathrm{N}=5$ (esquerda) e $\mathrm{S} / \mathrm{N}=10$ (direita) são mostrados apenas para COD> 0.02. 28

2.14 Fração de nuvens detectadas em função da razão sinal ruído logo abaixo da base, do coeficiente de retroespalhamento e da profundidade óptica. . . . . . . . . . . . . . . . . . .

3.1 Frequência mensal de ocorrência de nuvens cirrus de julho de 2011 a junho de 2012 (linha azul) com o erro estatístico associado (preto). As precipitações acumulada (verde claro) e climatológica (verde escuro), mostradas no eixo à direita, foram obtidas do conjunto de dados TRMM 3B42 versão 7 , em uma área de $10^{\circ} \mathrm{x} 10^{\circ}$. . . . . . . . . . . . . . . . . . . 
3.2 Painéis à esquerda mostram precipitação média (cores, mm/mês) do TRMM 3B42 versão 7 e campo de vento médio (vetores, $\mathrm{m} / \mathrm{s})$ a $150 \mathrm{hPa}(\approx 14,3 \mathrm{~km})$ da reanálise do ECMWF ERA Interim. Painéis à direita mostram trajetórias de massa de ar de 24 h que chegam ao local no momento e altitude que as camadas de cirrus foram detectadas. Os resultados são mostrados separadamente para os meses seco (JJAS, superior) e chuvoso (JFMA, inferior). As retro-trajetórias foram calculadas usando o modelo HYSPLIT com ventos de resolução de $0,5^{\circ}$ do GDAS/NOAA. A localização do site experimental é indicada em todos os painéis com um círculo.

3.3 O painel (a) mostra os ciclos diários da frequência horária de ocorrência de nuvens cirrus para os períodos anual, chuvoso, de transição e seco. O mesmo é mostrado para SVC, nuvens cirrus finas e opacas durante as estações seca (b) e chuvosa (d). A taxa de precipitação observada média $(\mathrm{mm} / \mathrm{h})$ da versão 7 do TRMM sobre uma área de $2^{\circ} \times 2^{\circ}$ centrada no sítio experimental, para os períodos seco e chuvoso, é dada no painel (c). . . . . . . . .

3.4 Os painéis mostram os histogramas normalizados de (a) base da nuvem cirrus, (b) espessura geométrica da nuvem, (c) topo da nuvem cirrus e (d) profundidade óptica, para o período total (preto), estação chuvosa (JFMA, vermelho) e estação seca (JJAS, azul). Barras de erro indicam a incerteza de estatísticas de contagem. . . . . . . . . . . . . . . . . . . .

3.5 Histogramas bidimensionais da frequência de ocorrência de cirrus com a altitude em função da profundidade óptica durante os meses chuvosos (topo) e secos (abaixo) são mostrados à esquerda. O mesmo é mostrado à direita, mas integrado para profundidades ópticas SVC, cirrus finas e opacas. . . . . . . . . . . . . . . . . . . . . . . . . 46

3.6 Os histogramas normalizados da distância da tropopausa à base e ao topo dos cirrus são mostrados para o período total (preto) e para cada estação (cores). Valores negativos significam que as nuvens estão abaixo da tropopausa. A altitude média da tropopausa foi de $16,2 \pm 0,4 \mathrm{~km}$.

3.7 Histogramas normalizados da razão lidar, já corrigidos para espalhamento múltiplo, para as diferentes estações do ano (topo) e para diferentes tipos de cirrus (inferior) são mostrados. Barras de erro indicam a incerteza de estatísticas de contagem.. . . . . . . . . . . . . 50

3.8 A dependência da razão lidar em função da temperatura no topo da nuvem é mostrada para as estações chuvosa (azul) e seca (vermelha). Os marcadores dão a média e desvio padrão da média. As linhas contínuas e tracejadas fornecem a mediana e o intervalo interquartil. A temperatura é dividida em intervalos de $2,5^{\circ} \mathrm{C}$. . . . . . . . . . . . . . . . . . . . . 51

4.1 Histograma normalizado da temperatura do topo das nuvens cirrus, para a estação chuvosa (wet) e seca (Dry). . . . . . . . . . . . . . . . . . . . . . . . . . 55 
4.2 Exemplo da aplicação do modelo libRadtran a um perfil vertical de nuvem cirrus. a) Coeficiente de extinção da nuvem cirrus derivado pelo lidar (azul) e coeficiente utilizado como entrada para o libRadtran (preto). Os asteriscos mostram a base e o topo da nuvem. b) resultado para as irradiâncias no espectro de onda curta. c) irradiâncias no espectro se onda longa. d) resultado da forçante radiativa instantânea. e) Perfil vertical da taxa de aquecimento radiativo. . . . . . . . . . . . . . . . . . . . . . . 58

4.3 Exemplo de um dia de medidas com do lidar, com o resultado da profundidade óptica, forçante radiativa no topo da atmosfera e ângulo solar zenital.. . . . . . . . . . . . . . 62

4.4 Forçante radiativa instantânea, no topo e na superfície, quando a fonte de radiação é SW, LW e NET, calculada para cada um dos perfis verticais de 5 minutos de média temporal com a presença de nuvem cirrus (overcast). O código de cores representa ou a altitude da camada de nuvem mais alta no perfil ou o ângulo solar zenital local no instante de ocorrência da nuvem. . . . . . . . . . . . . . . . . . . . . 64

4.5 Comparação entre os resultados para a forçante radiativa instantânea calculados pelo libRadtran e pelo modelo de Corti e Peter. . . . . . . . . . . . . . . . . . . . . . . 66

4.6 Média horária da forçante radiativa overcast no topo da atmosfera (TOA) e na superfície (BOA). As barras de erros representam o intervalo interquartil da distribuição horária.

4.7 Frequência relativa de ocorrência das categorias de nuvens cirrus e sua contribuição para a forçante radiativa overcast no topo e na base da atmosfera. . . . . . . . . . . . . . .

4.8 (Esquerda): perfil da taxa de aquecimento radiativo para a atmosfera sem a presença de nuvens cirrus (clear sky), média do perfil quado as nuvens cirrus estão presentes (Cirrus overcast) e média ponderada pela frequência de ocorrência entre Clear sky e Cirrus overcast, representando o perfil da taxa de aquecimento radiativo da atmosfera. (Centro e direita): Contribuição das nuvens cirrus para o perfil da taxa de aquecimento radiativo da atmosfera, considerando o caso All sky e cirrus overcast. . . . . . . . . . . . . . . . . . . . .

4.9 Taxa de aquecimento radiativo, calculado sem incluir o perfil de nuvem (linha pontilhada em vermelho), média considerando somente a parte do perfil dentro de nuvens (azul) e para o ar fora da nuvem (em vermelho), que inclui a parte do perfil fora da nuvem, entre camadas, e também perfis em que não ocorre nuvens cirrus (céu limpo). As barras horizontais representam o intervalo interquartil em relação a distribuição das médias horárias das taxas de aquecimento. A linha em preto é a taxa de aquecimento radiativo total, calculado como a média temporal das taxas em dentro e fora da nuvem ponderadas pelo respectivo perfil de frequência de ocorrência.

4.10 Boxplot $(5,25,50,75$ e 95 percentil) da profundidade óptica total da coluna de nuvens cirrus em função da hora do dia. A linha em azul mostra o valor médio. . . . . . . . . . . . . 76 


\section{LISTA DE TABELAS}

Pág.

3.1 Resumo de alguns estudos recentes sobre nuvem cirrus baseados em pelo menos alguns meses de observações por lidar em solo nos trópicos e latitudes médias. As primeiras colunas mostram o período de estudo e o comprimento de onda do laser (nm) para cada local, para o qual mais de um estudo pode estar disponível. As características dos cirrus são aquelas relatadas pelos diferentes autores, que podem incluir: altura base e topo $(\mathrm{km})$, espessura $(\mathrm{km})$, temperatura base e topo $\left({ }^{\circ} \mathrm{C}\right)$, frequência de ocorrência $(\%)$ e razão lidar $(\mathrm{sr})$. . . . . 32

3.2 Resumo das estatísticas integradas na colunas para o tempo total de observação, bem como para as estações chuvosa, de transição e seca. A frequência de ocorrência é calculada usando uma amostragem condicional para evitar vieses (seção 3.1.3). As propriedades médias das nuvens cirrus e o desvio padrão da amostra (entre parênteses) são mostrados. Os desvios padrão da média foram calculados e utilizados para determinar se as diferenças sazonais (chuvo-seco) dos valores médios são estatisticamente significativas para o nível de confiança de $95 \%$ (indicado como *) usando um teste t de 2 amostras. Propriedades geométricas não são fornecidas porque a maioria dos perfis de nuvem possui mais de uma camada de cirrus. A razão lidar é calculada como uma média da coluna. . . . . . . . . . . . . . . . . . 35

3.3 Resumo das estatísticas das camadas para o tempo total de observação, bem como para as estações chuvosa, de transição e seca. As propriedades médias da nuvem cirrus e o desvio padrão da amostra (entre parênteses) são mostrados. Os desvios padrão da média foram calculados e utilizados para determinar se as diferenças sazonais (chovoso-seco) são estatisticamente significativas para o nível de confiança de $95 \%$ (indicado como *) usando um teste t de 2 amostras. A razão lidar é calculada como uma média da coluna. . . . . . . . . . . 39

4.1 Forçante radiativa das nuvens cirrus na Amazônia. . . . . . . . . . . . . . . . . . . 69

4.2 Forçante radiativa das nuvens cirrus na Amazônia para os cenários hipotéticos que simulam medidas do CALIPSO, MODIS e do lidar em solo porém ignorando o ciclo diurno das nuvens cirrus. Os resultados marcados como "Verdadeiro" são os mesmos da tabela 4.1 calculados pelo modelo de Corti e Peter . . . . . . . . . . . . . . . . . . . . . . . . . . . . 78 



\section{LISTA DE ABREVIATURAS E SIGLAS}

\begin{tabular}{|c|c|c|}
\hline ACONVEX & - & Aerosols, Clouds, cONVection EXperiment \\
\hline ACRIDICON & - & $\begin{array}{l}\text { Aerosol, Cloud, Precipitation, and Radiation Interactions } \\
\text { and Dynamics of CoNvective Cloud Systems }\end{array}$ \\
\hline AERONET & - & AErosol RObotic NETwork \\
\hline AOD & - & Profundidade óptica de aerossóis (do ingles Aerosol Optical Depth) \\
\hline $\mathrm{BOA}$ & - & Superfície (do inglês Bottom Of Atmosphere) \\
\hline CALIOP & - & Cloud-Aerosol Lidar and Infrared Pathfinder Satellite Observations \\
\hline CALIPSO & - & Cloud-Aerosol Lidar with Orthogonal Polarization \\
\hline COD & - & Profundidade óptica de nuvens (do inglês Cloud Optical Depth) \\
\hline $\mathrm{CP}$ & - & Corti e Peter (2009). \\
\hline $\mathrm{CRF}$ & - & Forçante radiativa de nuvens (do inglês Cloud Radiative Forcing) \\
\hline FOV & - & Campo de Visão (do inglês Field of View) \\
\hline GCM & - & General Circulation Model \\
\hline GDAS & - & Global Data Assimilation System \\
\hline HALO & - & High Altitude and Long Range Research Aircraft \\
\hline $\mathrm{HR}$ & - & Taxa de aquecimento (do inglês Heating Rate) \\
\hline HYSPLIT & - & Hybrid Single Particle Lagrangian Integrated Trajectory \\
\hline INP & - & Núcleo de condensação de gelo (do inglês Ice Nuclei Particle) \\
\hline IPCC & - & Intergovernmental Panel on Climate Change \\
\hline IWC & - & Conteúdo de gelo (do inglês Ice Water Content) \\
\hline JFMA & - & Janeiro, Fevereiro, Março e Abril \\
\hline JJAS & - & Junho, Julho, Agosto e Setembro \\
\hline $\mathrm{LR}$ & - & Razão lidar (do ingles Lidar Ratio) \\
\hline LT & - & Hora local (do ingles Local Time) \\
\hline LW & - & Onda Longa (do ingês Longwave) \\
\hline MODIS & - & Moderate Resolution Imaging Spectroradiometer \\
\hline mol & - & Moléculas, Molecular \\
\hline MS & - & Espalhamento Múltiplo (do inglês Multiple Scattering) \\
\hline NET & - & $\begin{array}{l}\text { Líquido, referindo ao saldo total de radiação, } \\
\text { descendente menos ascendente }\end{array}$ \\
\hline NOAA & - & National Oceanic and Atmospheric Administration \\
\hline par & - & Particulas, Particular, por Partículas \\
\hline PMT & - & Tubo fotomultiplicador (do inglês Photomultiplier Tube) \\
\hline RCS & - & Sinal Corrigido pela Distância (do inglês Range Corrected Signal) \\
\hline RMSE & - & Raiz do erro quadrático médio (do inglês Root Mean Square Error) \\
\hline $\mathrm{S} / \mathrm{N}$ & - & Razão sinal-ruído (do ingles signal do noise ratio) \\
\hline SS & - & Espalhamento Simples (do ingles Single Scattering) \\
\hline std & - & Padrão (do ingles Standard) \\
\hline SVC & - & Cirrus subvisual ou cirrus subvisível \\
\hline SW & - & Onda curta (do inglês Shortwave) \\
\hline
\end{tabular}


SZA - Ângulo Zenital Solar (do inglês Solar Zenith Angle)

TOA - Topo da atmosfera (do inglês Top Of Atmosphere)

TR - Transferência Radiativa

TRMM - Tropical Rainfall Measuring Mission

TTL - Camada da Tropopausa Tropical (do inglês Tropical Tropopause Layer)

UTC - Tempo Universal Coordenado (do inglês Universal Time Coordinated)

UV - Ultravioleta

ZCIT - Zona de Convergência Intertropical 


\section{LISTA DE SÍMBOLOS}

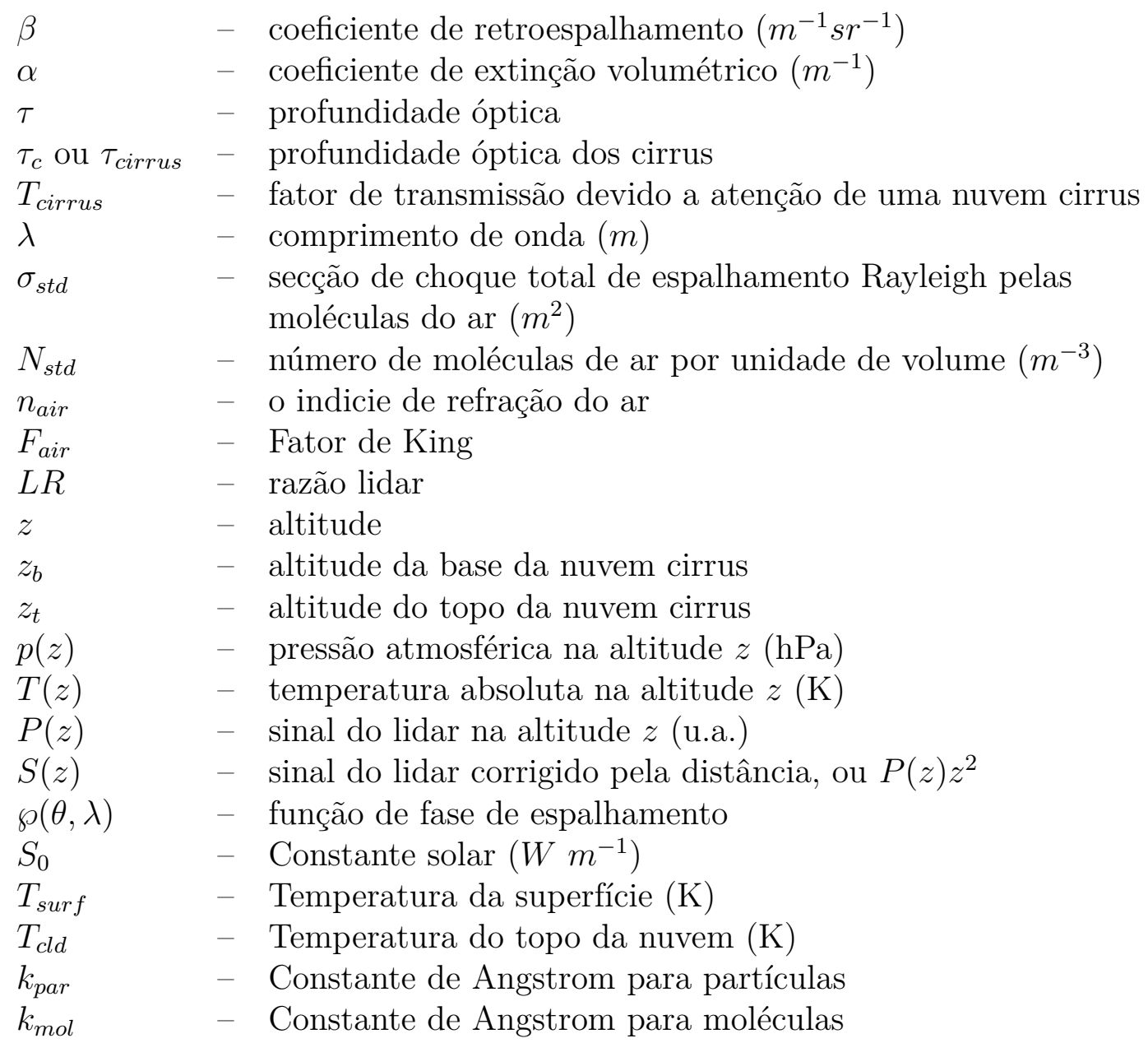





\section{SUMÁRIO}

Pág.

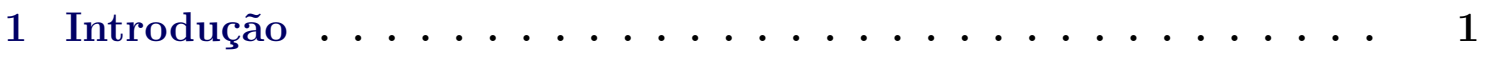

2 Instrumentação, Dados Experimentais e Metodologia $\quad$. . . . . 7

2.1 Sítio Experimental . . . . . . . . . . . . . . . . . . . . . 7

2.2 Sensoriamento remoto com lidar . . . . . . . . . . . . . . . . . 8

2.2.1 Lidar Elástico ou Rayleigh-Mie . . . . . . . . . . . . . . . . . . . . . . 10

2.2 .2 Lidar Raman . . . . . . . . . . . . . . . . . . . . . . 11

2.3 Propriedade dos cirrus por medidas do lidar . . . . . . . . . . . . . . 12

2.3.1 Coeficiente de retroespalhamento e extinção molecular . . . . . . . . . 12

2.3.2 Coeficiente de Retroespalhamento e Extinção de Partículas . . . . . . . 13

2.3.2.1 Método Klett-Fernald . . . . . . . . . . . . . . . . . . . . . . . . 13

2.3.2.2 Método Raman . . . . . . . . . . . . . . . . . . . . . 14

2.3.2.3 Método da Transmitância . . . . . . . . . . . . . . . 15

2.3.3 Correção de Espalhamento Múltiplo em Medidas de lidar . . . . . . . . 17

2.3.4 Avaliação dos Algoritmos de Detecção de Nuvens Cirrus . . . . . . . . 20

3 Nuvens Cirrus na Amazônia . . . . . . . . . . . . . . . 31

3.1 Instrumentação . . . . . . . . . . . . . . . . . . . . . 31

3.1 .1 Conjuntos de dados . . . . . . . . . . . . . . . . . . 31

3.1.2 Algoritmo de detecção de nuvens Cirrus. . . . . . . . . . . . . . . . . . 32

3.1.3 Frequência de Ocorrência e Problemas de Amostragem . . . . . . . . . 33

3.1.4 Profundidade óptica, coeficiente de retroespalhamento e razão lidar das nuvens cirrus . . . . . . . . . . . . . . . . . . . . . 34

3.2 Resultados e discussão . . . . . . . . . . . . . . . . . . . 37

3.2.1 Frequência da ocorrência de nuvens cirrus. . . . . . . . . . . . . . . . . 37

3.2.2 Propriedades geométricas, ópticas e microfísicas de nuvens cirrus . . . 42

4 Forçante Radiativa das Nuvens Cirrus . . . . . . . . . . 53

4.1 Nuvens cirrus e cálculo da forçante radiativa . . . . . . . . . . . . . 53

4.1.1 Medida dos cirrus com o lidar . . . . . . . . . . . . . . . . . 53

4.1.2 Cálculo da CRF: definição e descrição do modelos . . . . . . . . . . . . 55

4.1.3 Transferência radiativa com o libRadtran . . . . . . . . . . . . . 57

4.1.4 Transferência radiativa com Corti e Peter (2009) . . . . . . . . . . . 60 
4.1.5 Aplicação dos modelos de TR . . . . . . . . . . . . . . . . . . 61

4.2 Resultados da CRF na Amazônia . . . . . . . . . . . . . . . . . . 62

4.2.1 Forçante radiativa instantânea vs profundidade óptica . . . . . . . . . 62

4.2 .2 Ciclo diurno da forçante radiativa . . . . . . . . . . . . . . 66

4.2.3 Forçante radiativa vs Classificação dos Cirrus . . . . . . . . . . . . . . 69

4.2.4 Perfil da taxa de aquecimento radiativo . . . . . . . . . . . . . 70

4.3 Análise exploratória . . . . . . . . . . . . . . . . . . 74

4.3.1 Estimativa do viés da determinação do CRF por instrumentos em satélites polares. . . . . . . . . . . . . . . . . 74

5 Conclusões Gerais . . . . . . . . . . . . . . 79

REFERÊNCIAS BIBLIOGRÁFICAS . . . . . . . . . . 85

APENDICE A - ATIVIDADES E CURSOS EXTRA-

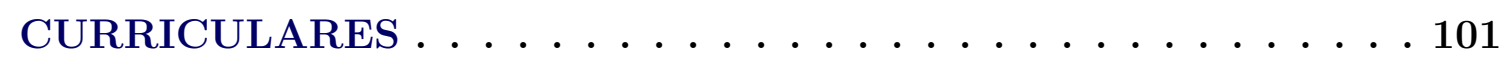

APÊNDICE B - APRESENTACOES EM EVENTOS CIENTIFI$\mathrm{COS} \ldots \ldots \ldots \ldots \ldots$

APÊNDICE C - TRABALHOS PUBLICADOS OU SUBMETIDOS 109 


\section{Introdução}

As nuvens cobrem, em média, cerca de $50 \%$ da superfície da Terra (MACE et al., 2007) sendo cirrus isoladamente responsáveis por cobrir 16,7 \% (SASSEN et al., 2008), com maiores frações ocorrendo nos trópicos (SASSEN et al., 2009). Assim, nuvens cirrus são importantes para compreender o clima atual e prever o clima futuro (WYLIE et al., 2005; STUBENRAUCH et al., 2006; NAZARYAN et al., 2008). Vários estudos enfatizam a importância do papel que as nuvens cirrus desempenham no balanço de radiação da Terra (LIOU, 1986; LYNCH, 2002; YANG et al., 2010a). A interação da radiação com as nuvens cirrus depende fortemente de suas propriedades ópticas, macro e microfísicas, em especial sua distribuição vertical na atmosfera, sua temperatura e profundidade óptica (LIOU, 1986; CORTI; PETER, 2009; KIENAST-SJÖGREN et al., 2016). Seus efeitos são ainda mais importantes considerando que nuvens cirrus podem cobrir grandes áreas, sendo o tipo de nuvem mais abundante na atmosfera, especialmente em regiões tropicais onde tem maior frequência de ocorrência. Portanto, entender suas propriedades é fundamental para determinar seu impacto no albedo planetário e no efeito estufa (BARJA; ANTUNA, 2011; BOUCHER et al., 2013). Além disso, nuvens cirrus tropicais podem influenciar a distribuição vertical do aquecimento radiativo na tropopausa tropical (e.g, Yang et al. (2010b), Lin et al. (2013)) e foi demonstrado que uma representação precisa da estrutura vertical das nuvens cirrus resultam em melhores estimativas da interação destas nuvens com a radiação (KHVOROSTYANOV; SASSEN, 2002; HOGAN; KEW, 2005; BARJA; ANTUNA, 2011). Pesquisas recentes também mostram que um aumento do vapor de água estratosférico está ligado principalmente à ocorrência de nuvens cirrus na camada da tropopausa tropical (TTL) (RANDEL; JENSEN, 2013). Finalmente, as medidas das propriedades das nuvens cirrus em diferentes localizações geográficas são de extrema importância, permitindo potencialmente melhorias nas parametrizações dos modelos numéricos e, assim, reduzindo as incertezas nos estudos climáticos.

\section{Efeito Radiativo}

O resultado da interação das nuvens cirrus com a radiação pode ser bem distinto ao que ocorre com os outros tipos de nuvens. Sendo nuvens opticamente finas e ocorrendo nas camadas mais elevadas da troposfera (com temperaturas muito baixas), as nuvens cirrus refletem uma pequena parte da radiação solar (radiação de onda curta - SW) de volta para o espaço causando um efeito de esfriamento. Ao mesmo tempo, absorvem a radiação térmica da superfície/atmosfera (radiação de onda longa - LW) e reemitem uma fração desta radiação causando um efeito de aquecimento. A figura 


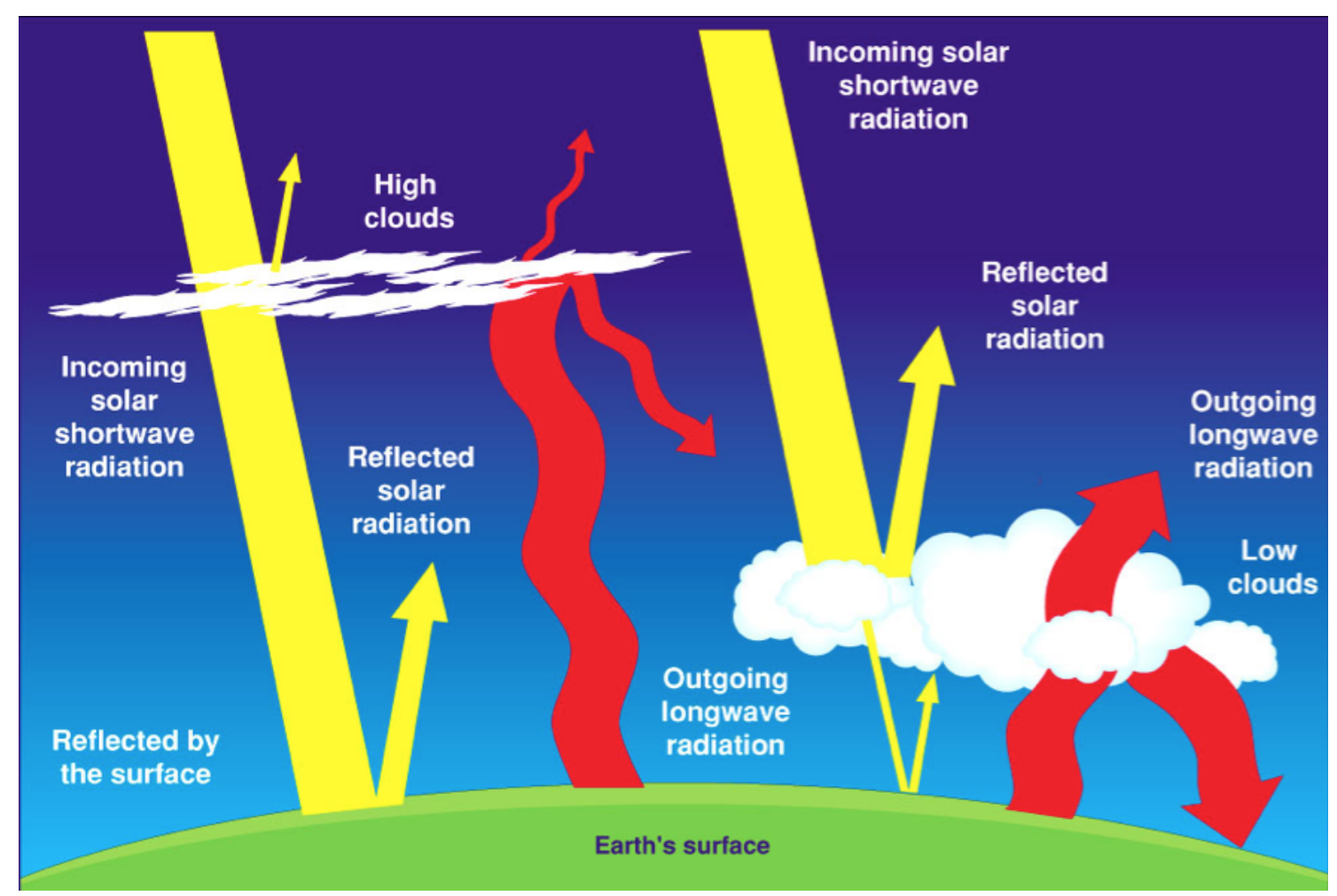

Figura 1.1 - Diferente do que ocorre em nuvens baixas e que possuem grande albedo, nuvens cirrus são mais translucidas e deixam passar grande parte da radiação solar, ao mesmo tempo em que impedem que parte da radiação emitida pela terra se perca para o espaço (Figura retirada de http://mynasadata.larc.nasa.gov/oyw/scool-featured-lesson-classificationof-clouds/).

1.1 mostra uma representação dessa interação com a radiação. O saldo final é que, em geral, nuvens cirrus causam um efeito de aquecimento no topo da atmosfera (e esfriamento em superfície), comportamento único entre todos os tipos de nuvens (CHEN et al., 2000; CAMPBELL et al., 2016). Através de medidas realizadas por satélites, Chen et al. (2000) estimou o efeito radiativo das nuvens cirrus, média global no topo da atmosfera, em 1,3 W $\mathrm{m}^{-2}$, valor muito menor que o estimado por um GCM como sendo 5,7 W $\mathrm{m}^{-2}$ (GASPARINI; LOHMANN, 2016). Kienast-Sjögren et al. (2016), utilizando medidas de perfis verticais de nuvens cirrus realizadas com lidar em solo em 3 sítios na Europa $\left(51^{\circ} \mathrm{N}, 6{ }^{\circ} \mathrm{E} ; 47^{\circ} \mathrm{N}, 9^{\circ} \mathrm{E} ; 47^{\circ} \mathrm{N}, 8^{\circ} \mathrm{E}\right)$, estimou um efeito radiativo overcast (considerando somente dados com a presença de nuvens) de $6,2,10,6$ e 11,0 $\mathrm{W} \mathrm{m}^{-2}$, respectivamente. Isto corresponde a um efeito radiativo de 0,9, 1,0 e 1,6 W $\mathrm{m}^{-2}$ considerando All sky (isto é, normalizando pela frequência de ocorrência). Este efeito radiativo é da mesma ordem de grandeza da forçante radiativa antrópica devido ao aumento do $\mathrm{CO}_{2}$ na atmosfera e, portanto, é uma questão 
científica importante entender como as nuvens cirrus alteram o balanço de radiação, e também como alterações antrópicas podem alterar este papel.

De fato, desde as primeiras constatações de seu efeito de aquecimento que se discute a possibilidade de manipulação artificial (geoengenharia) dessas nuvens a fim de mitigar os efeitos do aquecimento global, tema que tem ganhado grande atenção nos últimos anos. Mitchell e Finnegan (2009) propuseram uma estratégia de alterar a produção natural dos cristais de gelo nas nuvens cirrus pela introdução artificial de núcleos de condensação de gelo (INP) muito eficientes, prevenindo assim a formação de gelo por congelamento homogêneo e produzindo nuvens com cristais de gelo maiores, menos numerosos e com maior sedimentação/sublimação. O resultado seriam nuvens cirrus menos frias (menor altitude), com menor profundidade óptica e menor tempo de vida, o que reduziria a intensidade do seu efeito de aquecimento, sem modificar drasticamente o balanço de radiação de onda curta. Segundo Lohmann e Gasparini (2017) isso é visto como uma vantagem sobre outros métodos de geoengenharia que buscam especificamente a redução da radiação solar que chega na superfície e podem ter mais efeitos adversos no sistema climático (ex. mudanças na precipitação).

O uso de semeadura de cirrus em geoengenharia, entretanto, parece distante de ser viável. Apesar de Mitchell e Finnegan (2009) e Storelvmo et al. (2013) confirmarem um potencial de aproximadamente 2 a $3 W \mathrm{~m}^{-2}$ de redução na forçante radiativa de nuvens cirrus (suficiente para conter o aquecimento pela duplicação da concentração de $\mathrm{CO}_{2}$ ) e Gasparini et al. (2017) indicar que o aumento da velocidade de sedimentação é de fato um bom indicador para a redução da forçante de cirrus, Storelvmo e Herger (2014) mostraram que o resultado de semeadura de cirrus pode ser muito dependente da concentração de INP's aplicados, da localização geográfica, horário de aplicação e, principalmente, fração natural de formação de gelo por nucleação homogênea/heterogênea nas nuvens. Dependendo desta fração, a semeadura pode até gerar o resultado oposto ao desejado causando um aumento no efeito de aquecimento dessas nuvens para o caso em que o mecanismo natural de nucleação predominante é heterogênea, que parece ser o caso para a grande maioria de nuvens cirrus observadas na natureza (CZICZO et al., 2013). Gasparini e Lohmann (2016) simulou utilizando o modelo ECHAM-HAM o cenário de semeadura global homogênea de cirrus, mas não obteve um efeito de esfriamento significativo. Eles observaram um aumento na cobertura das nuvens e uma diminuição no número e tamanho dos cristais de gelo, atribuindo a essa diminuição no tamanho o principal fator limitante do potencial das técnicas de semeação. De fato, como apontado na recente monografia da AMS sobre 
a fase de gelo em nuvens (MCFARQUHAR et al., 2017), os mecanismos de formação dos cristais de gelo e o papel do congelamento homogêneo e heterogêneo ainda é pouco entendido, sendo desafiadora as observações in-situ desses fenômenos.

\section{Monitoramento}

Segundo o capítulo 7 do relatório do IPCC de 2013 (BOUCHER et al., 2013), medidas globais de nuvens cirrus são imprescindíveis para a caracterização de suas propriedades ópticas, macro e microfísicas, e para entender os seus possíveis feedbacks em um clima futuro mais quente. Espera-se um aumento na fração de cobertura dessas nuvens em direção a latitudes maiores seguindo a expansão da célula de Hadley, com nuvens cirrus ocorrendo em altitudes maiores e em regiões com menor radiação solar, aumentando ainda mais seus efeitos de aquecimento (BOUCHER et al., 2013). Sistemas lidar baseados em solo são ferramentas indispensáveis para o monitoramento de nuvens cirrus, particularmente aquelas com baixa profundidade ótica, que são indetectáveis por radares de nuvens (COMSTOCK et al., 2002) ou por instrumentos passivos (por exemplo,(ACKERMAN et al., 2008)). Por esta razão, vários estudos com lidar baseados em solo relataram as características das nuvens cirrus ao redor do mundo durante a última década. Existem alguns estudos de longo prazo relatando climatologias em latitudes médias (por exemplo,Sassen e Campbell (2001), Goldfarb et al. (2011), Giannakaki et al. (2007), Hoareau et al. (2013), Kienast-Sjögren et al. (2016)) e regiões tropicais (por exemplo, Comstock et al. (2002), Cadet (2003), Barja e Antuna-Marrero (2006), Seifert et al. (2007), Thorsen et al. (2011), Pandit et al. (2015)). Há também algumas publicações com resultados de curto prazo sobre as características das nuvens cirrus durante as campanhas de medição em latitudes médias (por exemplo, Immler e Schrems (2002)) e nos trópicos (Immler e Schrems (2002), Pace et al. (2003) e referências). Além disso, medidas com lidar baseadas em satélite têm sido usadas para investigar a distribuição global das características das nuvens cirrus (por exemplo, Nazaryan et al. (2008), Sassen et al. (2008), Sassen et al. (2009), Wang e Dessler (2012), Jiang et al. (2015)). As características geométricas das nuvens cirrus tropicais e subtropicais têm valores similares e ocorrem em altitudes mais elevadas do que nas latitudes médias. No entanto, as frequências de ocorrência dos tipos de nuvens cirrus diferem significativamente entre locais diferentes.

Apesar desta vasta literatura, publicações relatando medidas de nuvens cirrus sobre florestas tropicais, como na Amazônia, são escassos. Apenas alguns estudos globais com instrumentos de satélite incluem essas regiões, porém, por serem baseados em 
satélites de órbita polar, não fornecem informações sobre o ciclo diurno. Há também alguns estudos focados em convecção profunda na Amazônia que relatam nuvens cirrus (GOES-IR: Machado (2002), Hong et al. (2005); In-situ: Wendisch et al. (2016)), mas nenhuma medida lidar foi usada. Baars et al. (2012) concentraram-se em observações de aerossóis com um lidar em solo e, por isso, relataram apenas um caso de nuvens cirrus, observado entre $12 \mathrm{~km}$ e $16 \mathrm{~km}$ de altura em 11 de setembro de 2008, durante um período de medição de 11 meses. Barbosa et al. (2014) descrevem uma semana de medições de nuvens cirrus realizadas de 30 de agosto a 6 de setembro de 2011 durante uma campanha intensiva para calibração do canal de vapor de água do lidar que também é usado neste estudo. Nuvens cirrus durante esse período estavam presentes em $60 \%$ das medições. As alturas médias da base e do topo das nuvens foram de 11,5 km e 13,4 km, respectivamente, e a média da altura de máximo retroespalhamento ocorreu a 12,8 km. Na maioria das vezes, duas camadas de nuvens cirrus estavam presentes.

Para avançar nosso conhecimento sobre a distribuição vertical de aerossóis e nuvens na Amazônia, o Laboratório de Física da Atmosfera operou o sítio experimental e o sistema lidar descritos por Barbosa et al. (2014), de julho de 2011 a julho de 2018. Este sítio experimental fez parte dos experimentos recentes Goamazon 2014/5 (MARTIN et al., 2016) e CHUVA (MACHADO et al., 2014), e este sistema lidar tem dado importantes contribuições (ANTUÑA-MARRERO et al., 2017; GUERRERORASCADO et al., 2016; BARBOSA H.M.J., 2014) para a Rede Latino-Americana de Lidar (www.lalinet.org). Foi neste contexto que se desenvolveu estre trabalho, que tem como objetivos principais a caracterização das nuvens cirrus sobre a região da Amazônia central e o estudo de seus efeitos no balanço de radiação. Para alcançar esses objetivos, utilizamos os dados do primeiro ano de medidas do lidar Raman UV (de julho de 2011 a junho de 2012) para investigar os ciclos sazonais e diários das propriedades geométricas e ópticas. Para isso, foi desenvolvido um algoritmo automatizado para a deteç̧ão das nuvens cirrus presentes no perfil vertical do lidar, medido com alta resolução temporal (5 min) e vertical $(7,5 \mathrm{~m})$, e determinação da frequência de ocorrência, altitude de base e topo, profundidade óptica e razão lidar. A partir das características geométricas e ópticas medidas no UV, utilizamos parametrizações para estimar o tamanho dos cristais de gelo e a dependência espectral das propriedades ópticas destes cristais. Assim, utilizando o LibRadtran (EMDE et al., 2016) e o modelo de Corti e Peter (CORTI; PETER, 2009), estimamos os efeitos radiativos das nuvens cirrus através do cálculo da sua forçante radiativa e do perfil da taxa de aquecimento da atmosfera. 
A metodologia utilizada para inversão dos dados do lidar é descrita no capítulo 2 . Esta tese e as publicações científicas derivadas dela são a primeira descrição do ciclo diurno das nuvens cirrus sobre uma floresta tropical, cujos resultados são apresentados no capítulo 3. Os resultados do estudo dos efeitos radiativos das nuvens cirrus são apresentados no capítulo 4. As conclusões e considerações finais são feitas no capítulo 5. Os apêndices A-C listam algumas atividades realizadas durante o doutorado (cursos extra-curriculares, visitas científicas, colaborações em outros projetos), apresentações em eventos científicos e trapalhos publicados ou submetidos. 


\section{Instrumentação, Dados Experimentais e Metodologia}

Sensoriamento remoto é a única maneira viável para uma caracterização extensiva e com alta resolução temporal e vertical de nuvens cirrus. Neste contexto, os sistemas de radar laser (lidar) são as melhores ferramentas disponíveis para realizar medidas de nuvens com profundidades ópticas tão baixas como as que possuem as nuvens cirrus. Neste capítulo, começamos descrevendo o sítio experimental onde as medidas foram realizadas e fazendo um resumo da técnica lidar. Apresentamos então os algoritmos utilizados para a obtenção das propriedades macro e microfísica das nuvens cirrus através dessas medidas, bem como simulações para avaliar sua acurácia e precisão. Por fim, apresentamos como são tratados os efeitos de espalhamento múltiplo nas medidas com sistemas lidar na presença de nuvens.

\subsection{Sítio Experimental}

O sítio experimental do projeto ACONVEX (Aerosols, Clouds, cONVection EXperiment) ou T0e (nomenclatura do experimento GoAmazon2014/15, Martin et al. (2016)) está localizado ao norte de Manaus-AM, a 2,89 ${ }^{\circ} \mathrm{S}$ e $59,97{ }^{\circ} \mathrm{W}$, na parte central da floresta Amazônica, como mostrado na imagem de satélite da figura 2.1. Observações atmosféricas neste local começaram em 2011 com o objetivo de medir a umidade atmosférica, nuvens e aerossóis, bem como processos que levam à precipitação convectiva (BARBOSA et al., 2014).

Como na maioria dos sítios continentais tropicais, o ciclo diurno de precipitação é forte com um pico no final da tarde (ADAMS et al., 2013). A definição precisa das estações climatológicas varia entre os autores (por exemplo, Machado et al. (2004), Arraut et al. (2012), Tanaka et al. (2014)), no entanto, a convecção profunda é uma característica da região durante todo o ano, inclusive durante a estação seca. A convecção é mais ativa durante a estação chuvosa, quando a zona de convergência intertropical (ZCIT) influencia a região. À medida que a ZCIT se desloca para o norte durante os meses da estação seca, a atividade convectiva diminui. Para a região e o período de estudo, consideramos estação chuvosa (jan-abr), seca (jun-set) e de transição (mar, out-dez).

O sistema lidar utilizado neste trabalho utiliza um laser ultravioleta (UV) de comprimento de onda $355 \mathrm{~nm}$, medindo a luz retroespalhada elasticamente (355 nm), bem como a luz retroespalhada inelasticamente, pelo efeito Raman, pelas moléculas de nitrogênio $(387 \mathrm{~nm})$ e de vapor de água $(408 \mathrm{~nm})$. As medidas são realizadas simultaneamente nos modos analógico e de contagem de fótons, cuja combinação 
permite maior intervalo dinâmico. O sistema é inclinado em $5^{\circ}$ a partir do zênite para evitar a reflexão especular de cristais de gelo orientados horizontalmente (por exemplo, Westbrook et al. (2010)). É operado automaticamente 7 dias por semana, sendo fechado apenas entre 11h e 14h, horário local (LT é -4 UTC) para evitar que o sol cruze o campo de visão e danifique os sensores. Informações detalhadas sobre o sistema lidar e sua caracterização são dadas por Barbosa et al. (2014). Para recuperar os perfis do coeficiente de retroespalhamento e extinção de partículas das nuvens cirrus através do sinal do lidar, os perfis de temperatura e pressão foram obtidos de radiossondagens lançadas às 0 e 12 UTC do Aeroporto de Ponta Pelada, localizado a $28,5 \mathrm{~km}$ ao sul $\left(3,14^{\circ} \mathrm{S}, 59,98^{\circ} \mathrm{W}\right)$ do sítio experimental.

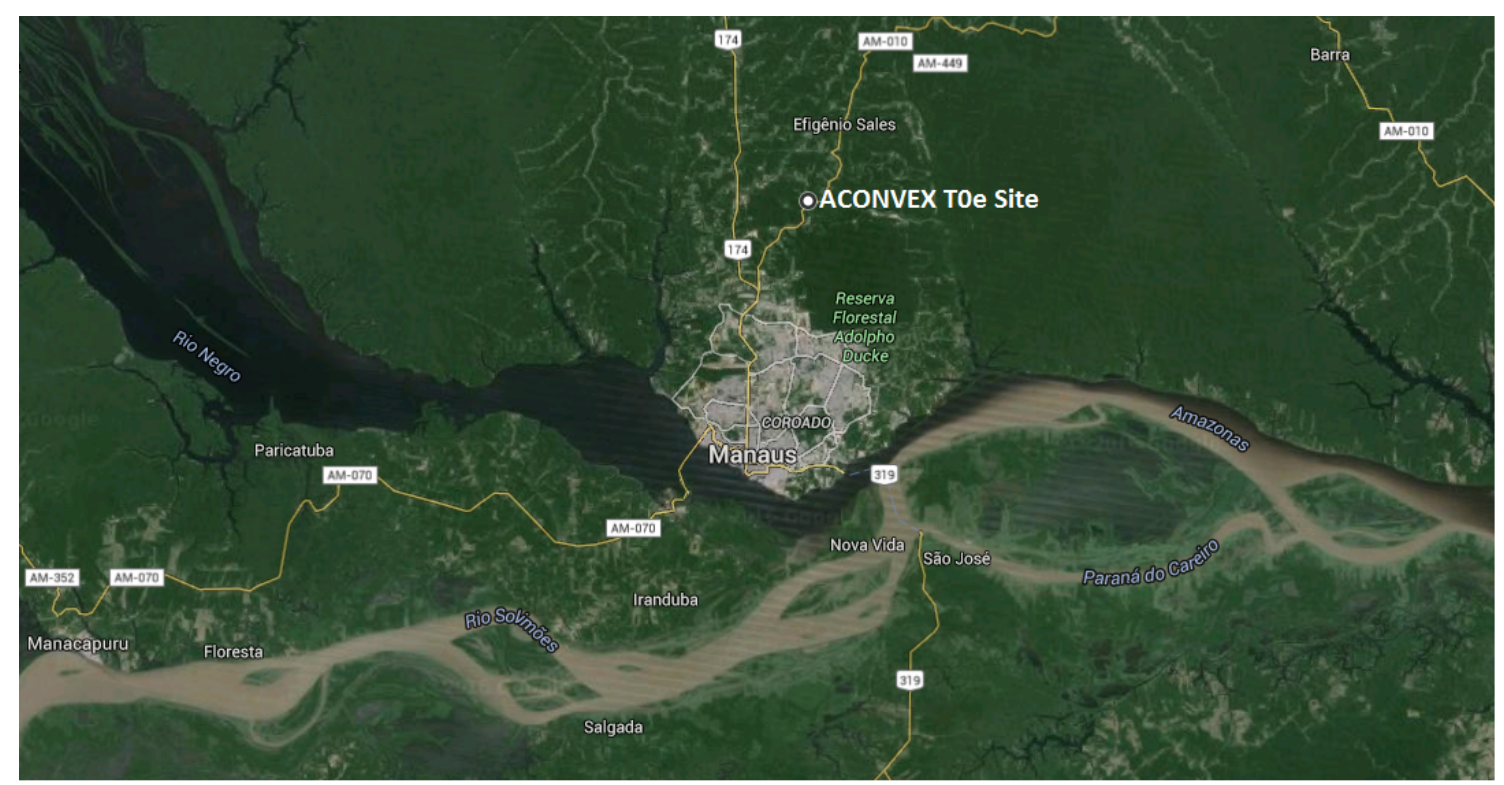

Figura 2.1 - Mapa por satélite (Google Earth) mostrando a localização do lidar (ACONVEX T0e, $2.89^{\circ} \mathrm{S}$ $59.97^{\circ} \mathrm{W}$ ), $30 \mathrm{~km}$ vento acima (norte) do centro de Manaus-AM, Brasil.

\subsection{Sensoriamento remoto com lidar}

As observações atmosféricas utilizando sistemas lidar desempenham um papel muito importante no estudo de aerossóis e nuvens. Capaz de realizar medições com alta resolução temporal e vertical, o lidar permite o estudo detalhado da evolução temporal das características macro e microfísicas de aerossóis e nuvens, desde ciclos diurnos a ciclos sazonais, com um limite de detecção suficientemente pequeno para estudar características que vão desde pequenas estruturas, tais como turbulência ou finas camadas de aerossóis, até múltiplas camadas de nuvens cirrus tropicais, que podem ter entre 1-8 km de espessura e estarem localizados a até $18 \mathrm{~km}$ de altitude 
(WANDINGER, 1998a; WANDINGER, 2005).

LIDAR, acrônimo para LIght Detection And Ranging (WANDINGER, 2005), é um sistema de sensoriamento remoto ativo baseado em laser. Um pulso de luz laser é emitido na atmosfera onde interage com moléculas e partículas. À medida que o pulso de radiação eletromagnética se propaga na atmosfera, parte da energia será atenuada devido ao espalhamento e/ou à absorção. Parte da luz que é retroespalhada (ou seja, espalhada com um ângulo de $180^{\circ}$ em relação à direção de propagação) é coletada por um telescópio e medida por fotomultiplicadores (PMT) com alta resolução temporal. Como a velocidade da luz no ar é conhecida, ao medir a intensidade deste sinal em função do tempo, estamos fazendo uma medida da quantidade de material espalhador em função da distância. A distância, z, entre o lidar e o volume espalhador é calculada como $z=c t / 2$, onde $c$ é a velocidade da luz, $t$ é o tempo decorrido entre a emissão do pulso de luz e a detecção do sinal pelo telescópio e o fator 2 contabiliza o tempo que o pulso leva para ir e voltar. A figura 2.2 mostra um exemplo de medida com o lidar e a detecção de nuvens cirrus.

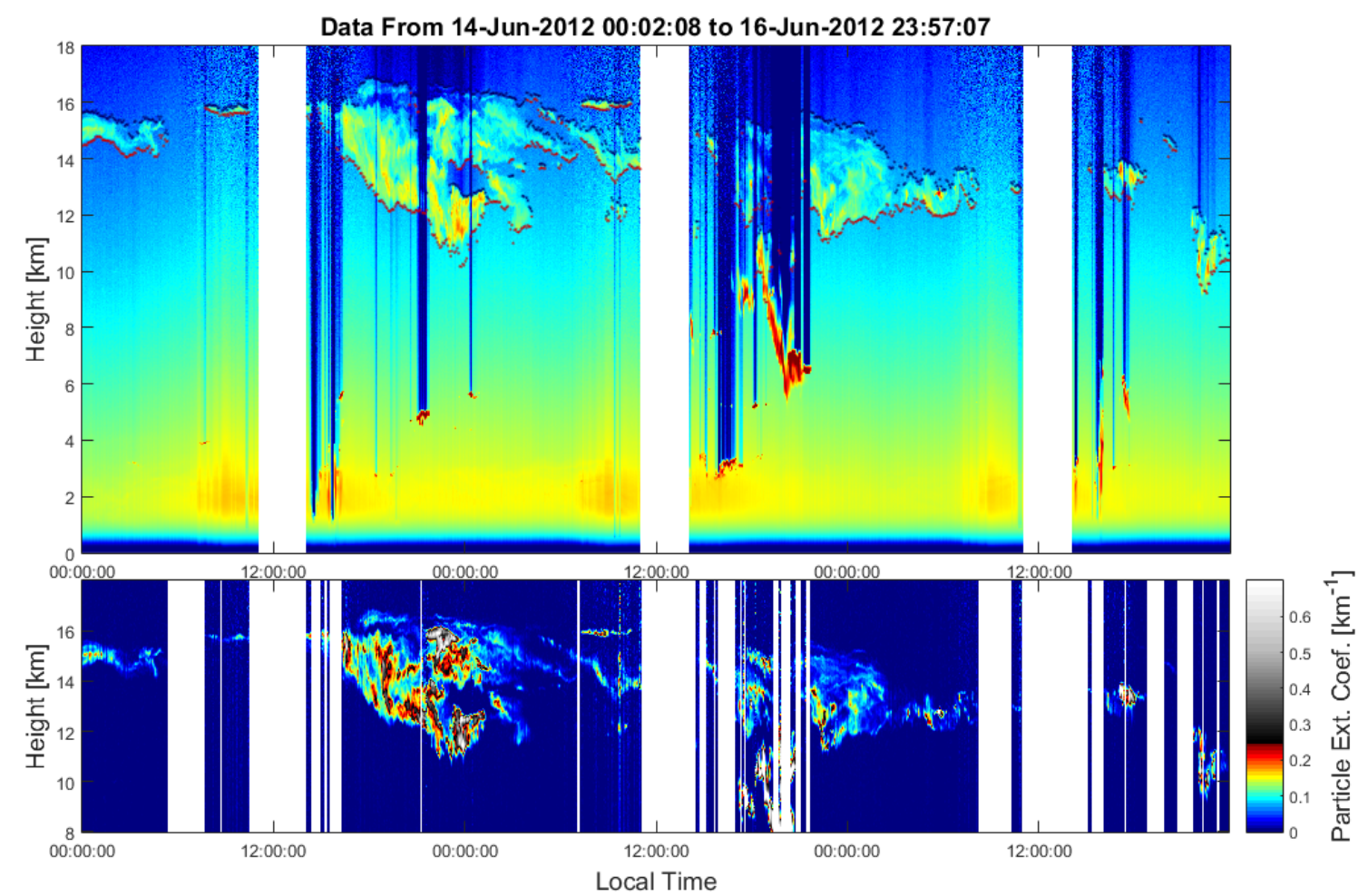

Figura 2.2 - Exemplo de medidas com o sistema lidar do LFA-IFUSP e a detecção de nuvens cirrus. Painel superior: logaritmo do sinal (elástico) do lidar corrigido pela distância, com média temporal de 5 min. Os pontos vermelhos e pretos mostram a base e o topo da nuvem para cada perfil vertical, dados pela máscara de nuvens. Painel inferior: Coeficiente de extinção por partículas calculado com o método descrito na seção 2.3 . 


\subsubsection{Lidar Elástico ou Rayleigh-Mie}

O sistema lidar mais simples é aquele que detecta apenas os fótons retroespalhados em interações elásticas. Neste caso, a equação que descreve a potência recebida no mesmo comprimento de onda $\lambda=\lambda_{0}$ da luz emitida pelo laser, também chamada de equação lidar Rayleigh-Mie, tem a forma

$$
P\left(\lambda_{0}, z\right)=P_{0} \frac{c \Delta t}{2} A_{t e l} \epsilon_{e f}\left(\lambda_{0}\right) \frac{O(z)}{z^{2}} \beta\left(\lambda_{0}, z\right) \exp \left[-2 \int_{0}^{z} \alpha\left(\lambda_{0}, \zeta\right) d \zeta\right]
$$

onde a potência inicial do pulso $P_{0}$ e seu comprimento efetivo $c \Delta t / 2$ determinam a intensidade inicial do feixe e $A_{t e l}$ é a área do telescópio. Para simplificar a notação, todos os termos independentes de $z$ serão escritos como $K\left(\lambda_{0}\right)=P_{0}(c \Delta t / 2) A_{t e l} \epsilon_{e f}\left(\lambda_{0}\right)$. O fator $z^{-2}$ dá conta da dispersão sofrida pela luz retroespalhada. A função de superposição ( overlap em inglês), $O(z)$, descreve a superposição entre o volume iluminado pelo pulso de luz laser e o campo de visão (FOV, do inglês field of view) do telescópio e pode assumir valores entre $0 \leq O(z) \leq 1$. Este termo depende de fatores como a divergência do laser, do FOV do telescópio, do alinhamento do sistema, etc. Para sistemas biaxiais, onde o eixo de emissão do laser e o FOV do telescópio são diferentes, uma superposição completa $(O(z)=1)$ pode ocorrer a partir de algumas centenas de metros até alguns quilômetros. Para sistemas coaxiais, é possível ter superposição completa desde altura $z=0$, mas tipicamente o foco do telescópio limita as medidas mais próximas. A exponencial é o termo de transmissão e é resultado da lei de Lambert-Beer-Bouguer para a transmissão do pulso do laser (para o lidar elástico, $\lambda_{0}=$ cte). O fator 2 vem do fato da luz laser ser atenuada da mesma maneira no caminho de ida e de volta até o volume espalhador localizado à distância $z$. Os coeficientes de retroespalhamento $(\beta)$ e de extinção volumétrica $(\alpha)$ são constituídos pela soma das contribuições de moléculas e de partículas (gotas, cristais de gelo, aerosol)

$$
\beta(z)=\beta_{\text {mol }}(z)+\beta_{\text {par }}(z)
$$

$\mathrm{e}$

$$
\alpha(z)=\alpha_{m o l}(z)+\alpha_{p a r}(z)
$$

onde os índices mol e par significam moléculas e partículas, respectivamente. O coeficiente de extinção pode, eventualmente, ser dividido nas componentes de absorção e de espalhamento. O espalhamento elástico do pulso do laser pelas moléculas, ou espalhamento Rayleigh, é bem documentado na literatura (ex. McCartney (1979)) e os coeficientes $\alpha_{m o l}(z)$ e $\beta_{\text {mol }}(z)$ podem ser determinado através de perfis de tem- 
peratura e pressão obtidos de modelos ou de radiossondagens (BUCHOLTZ, 1995).

Para soluções da equação do lidar que veremos a seguir, é conveniente definir agora a relação entre os coeficientes de extinção e retroespalhamento, de moléculas e de partículas, também conhecido como razão lidar ( $L R$ - do inglês Lidar Ratio) como

$$
L R_{m o l}(\lambda, z)=\frac{\alpha_{m o l}(\lambda, z)}{\beta_{m o l}(\lambda, z)}
$$

$\mathrm{e}$

$$
\operatorname{LR}_{\text {par }}(\lambda, z)=\frac{\alpha_{\text {par }}(\lambda, z)}{\beta_{\text {par }}(\lambda, z)}
$$

É também importante definir a profundidade óptica da nuvem cirrus, $\tau_{c}$, que é obtido a partir de

$$
\tau_{c}(\lambda)=\int_{z_{b}}^{z_{t}} \alpha_{\text {par }}\left(\lambda, z^{\prime}\right) d z^{\prime}
$$

onde $z_{b}$ e $z_{t}$ são as altitudes da base e do topo da nuvem, respectivamente. A questão chave em se obter os coeficientes de retroespalhamento e extinção das partículas atmosféricas através da medida do sinal elástico do lidar é como obter estas duas quantidades a partir de uma única equação. Uma maneira de fazer isso é através do chamado método de Klett-Fernald (KLETT, 1985; FERNALD, 1984), onde se assume um valor constante com a altitude para a razão lidar de partículas $L R_{\text {par }}$, eliminandose assim uma das incógnitas. A solução da equação do lidar elástico será apresentada mais adiante, na seção 2.3.2.1.

\subsubsection{Lidar Raman}

O pulso do laser também pode sofrer espalhamento inelástico pelas moléculas atmosféricas devido ao espalhamento Raman, onde o comprimento de onda da luz retroespalhada $\left(\lambda_{R}\right)$ é diferente do comprimento de onda do laser $\left(\lambda_{0}\right)$. Essa mudança no comprimento de onda é devido ao efeito Raman e é específico para cada um dos diferentes componentes moleculares da atmosfera, fato que diferencia o tipo de gás espalhador (ex: nitrogênio e vapor de água). O sistema lidar capaz de fazer essas medidas é chamado de lidar Raman, e sua equação é escrita como

$$
P\left(\lambda_{R}, z\right)=K\left(\lambda_{R}\right) \frac{O(z)}{z^{2}} \beta\left(\lambda_{R}, z\right) \exp \left[-\int_{0}^{z} \alpha\left(\lambda_{0}, \zeta\right)+\alpha\left(\lambda_{R}, \zeta\right) d \zeta\right]
$$

São duas as principais diferenças entre esta e a equação do lidar elástico. Primeiro, o coeficiente de retroespalhamento, que depende da probabilidade de ocorrer o es- 
palhamento Raman, depende dos dois comprimentos de onda. Segundo, o termo de transmissão é calculado no caminho de ida até o volume espalhador com o coeficiente de extinção para o comprimento de onda do laser, $\alpha\left(\lambda_{0}, z\right)$, e com $\alpha\left(\lambda_{R}, z\right)$ para o caminho percorrido pela luz retroespalhada. A função de superposição para as equações do lidar elástico e Raman pode ser considerada igual para um lidar com sistema óptico bem alinhado. Como um sistema lidar Raman detecta o sinal de retorno nos dois comprimentos de onda, tem-se duas informações e, portanto, é possível obter, de maneira independente, o retroespalhamento e a extinção, e medir a LR das partículas. A solução conjunta das equações 2.1 e 2.7 é conhecida como método Raman e foi descrita pela primeira vez por Ansmann et al. (1992). A solução da equação do lidar Raman será apresentada mais adiante, na seção 2.3.2.2.

\subsection{Propriedade dos cirrus por medidas do lidar}

\subsubsection{Coeficiente de retroespalhamento e extinção molecular}

A estimativa do espalhamento da luz laser pelos componentes moleculares atmosféricos precisa ser determinado com acurácia, pois são a base para se obter informações importantes através das medidas do lidar. Como explicamos acima, o espalhamento Rayleigh, como é chamado, é bem documentado na literatura (ex. McCartney (1979)) e pode ser determinado através de perfis de temperatura e pressão obtidos de modelos ou medidas de radiossondagens. Bucholtz (1995) descreve a secção de choque total de espalhamento Rayleigh pelas moléculas do ar:

$$
\sigma_{\text {std }}(\lambda)=\frac{24 \pi^{3}\left(n_{\text {air }}^{2}-1\right)^{2}}{\lambda^{4} N_{\text {std }}^{2}\left(n_{\text {air }}^{2}+2\right)^{2}} F_{\text {air }}
$$

onde $N_{s t d}$ é o número de moléculas de ar por unidade de volume e $n_{a i r}$ é o índice de refração do ar que, por sua vez, é dado por Peck e Reeder (1972)

$$
\left(n_{\text {air }}-1\right)=10^{-8}\left[\frac{5791817}{238,0185-\lambda^{-2}}+\frac{167909}{57,362-\lambda^{-2}}\right]\left[1+0,54\left(X_{C O_{2}}-0,0003\right)\right]
$$

para $\lambda$ dado em $\mu m$ e $\lambda>0,23 \mu m$. $X_{\mathrm{CO}_{2}}$ é a concentração específica de $\mathrm{CO}_{2}$ na atmosfera, considerado como 375 ppmv para o período do estudo. O termo $F_{\text {air }}$ é chamado de Fator de King do ar e leva em conta a anisotropia dos principais componentes moleculares atmosféricos ponderado pelas suas concentrações, podendo ser calcular por (BODHAINE et al., 1999; BATES, 1984)

$$
F_{\text {air }}=\frac{78,084 F_{N_{2}}+20,946 F_{O_{2}}+0,934 F_{A r}+0,0375 F_{C O_{2}}}{78,084+20,946+0,934+0,0375}
$$


Onde $F_{N_{2}}, F_{O_{2}}, F_{A r}$ e $F_{C O_{2}}$, são, respectivamente, os fatores de king para os gases nitrogênio, oxigênio, argônio e gás carbônico $\left(X_{\mathrm{CO}_{2}}=375 \mathrm{ppmv}\right)$. Estes fatores são fornecidos por (BATES, 1984) e podem ser escritos como

$$
\begin{aligned}
F_{N_{2}} & =1,034+3,17 \times 10^{-4} \frac{1}{\lambda^{2}} \\
F_{O_{2}} & =1,096+1,385 \times 10^{-3} \frac{1}{\lambda^{2}}+1,448 \times 10^{-4} \frac{1}{\lambda^{4}} \\
F_{A r} & =1,00 \\
F_{C O_{2}} & =1,15
\end{aligned}
$$

com $\lambda$ dado em $\mu m$. Por fim, o coeficiente de extinção volumétrico devido as moléculas pode ser calculado em qualquer altitude z, como:

$$
\alpha_{m o l}(\lambda, z)=N_{s t d} \sigma_{s t d}\left(\lambda, X_{C O_{2}}\right) \frac{p(z) / T(z)}{p_{s t d} / T_{s t d}}
$$

em que $p(z)$ e $T(z)$ são, respectivamente, os perfis verticais de pressão e temperatura. Os índices std representam os valores destas grandezas no nível padrão de temperatura e pressão. Assim, o coeficiente de retroespalhamento molecular pode ser calculado (BUCHOLTZ, 1995) a partir do coeficiente de extinção e da função de fase $(\wp)$, como (BUCHOLTZ, 1995)

$$
\beta_{m o l}(\lambda, z)=\frac{\alpha_{m o l}(\lambda, z)}{4 \pi} \wp(\pi, \lambda)=\alpha_{m o l}(\lambda, z) \frac{3}{8 \pi} \frac{2}{2+\rho_{n}}
$$

onde $\rho_{\text {air }}=\left(6 F_{\text {air }}-6\right) /\left(3+7 F_{\text {air }}\right)$ é o fator de depolarização. Para $\lambda=354,68 \mathrm{~nm}$ (espalhamento elástico), $p_{\text {std }}=1013,25 \mathrm{hPa}, T_{\text {std }}=288,15 \mathrm{~K}, \mathrm{~N}_{\text {std }}=2,54690 \times$ $10^{19} \mathrm{~cm}^{-3}$ e $X_{\mathrm{CO}_{2}}=375 \mathrm{ppmv}$, temos $F_{\text {air }}=1,0529$ e $\rho_{\text {air }}=0,0306$.

\subsubsection{Coeficiente de Retroespalhamento e Extinção de Partículas}

\subsubsection{Método Klett-Fernald}

Como explicamos anteriormente, um lidar elástico mede apenas uma grandeza, $P(z)$, mas a equação (2.1) envolve duas grandezas desconhecidas: $\beta_{\text {par }}$ e $\alpha_{\text {par }}$. Assim, só é possível resolver a equação assumindo uma relação entre estas duas grandezas, de forma a eliminar uma delas do problema. O método mais conhecido é o de KlettFernald (KLETT, 1985; FERNALD, 1984), onde se assume um valor constante com a altitude para a razão lidar de partículas, $L R_{p a r}=\alpha_{p a r} / \beta_{\text {par }}$. A solução para o 
coeficiente de retroespalhamento pode ser escrito como:

$$
\begin{aligned}
\beta(z) & =S(z) T\left(z, z_{0}\right)\left[\frac{S\left(z_{0}\right)}{\beta_{m}\left(z_{0}\right)}-2 L R_{\text {par }} \int_{z_{0}}^{z} S\left(z^{\prime}\right) T\left(z^{\prime}, z_{0}\right) d z^{\prime}\right]^{-1} \\
T\left(z, z_{0}\right) & =\exp \left[-2\left(L R_{\text {par }}-L R_{\text {mol }}\right) \int_{z_{0}}^{z} \beta_{m o l}\left(z^{\prime}\right) d z^{\prime}\right]
\end{aligned}
$$

Onde $S(z)=P\left(\lambda_{0}, z\right) z^{2}$ é o sinal corrigido pela distância e $z_{0}$ é o ponto de referência onde temos a condição de contorno $\beta\left(z_{0}\right)_{p a r}<<\beta\left(z_{0}\right)_{\text {mol }}$. Valores típicos de $L R_{\text {par }}$ para nuvens cirrus podem ser encontrados na literatura e são reflexo do tipo de partículas que fazem parte da composição da nuvem cirrus. Isto significa, portanto, que é importante medir o $L R$ das nuvens cirrus. Contudo, como vemos pela solução acima, o método de Klett-Fernald para o lidar elástico só permite obter o valor do coeficiente de retroespalhamento de partículas, ficando a extinção determinada por $\alpha=L R \beta$, onde o $L R$ foi arbitrariamente escolhido. Há pelo menos duas maneiras tradicionais para estimar a extinção e a razão lidar: através da medida de um lidar Raman e através do método da transmitância, ambos apresentados abaixo.

\subsubsection{Método Raman}

Com a adição da medida da luz retroespalhada pelo efeito Raman, podemos obter os coeficientes de extinção e retroespalhamento independentemente, sem precisar assumir um valor à priori para a razão lidar. Isso pode ser feito através do método Raman (ANSMANN et al., 1992). O coeficiente de extinção pode ser escrito como

$$
\alpha_{\text {par }}\left(\lambda_{0}, z\right)=\frac{\frac{d}{d z}\left\{\ln \left[\frac{N_{R}(z) O(z)}{S_{R}(z)}\right]\right\}-\alpha_{m o l}\left(\lambda_{0}, z\right)\left[1+\left(\lambda_{0} / \lambda_{R}\right)^{k_{m o l}}\right]}{1+\left(\lambda_{0} / \lambda_{R}\right)^{k_{p a r}}}
$$

onde $S_{R}=P\left(\lambda_{R}, z\right) z^{2}$ é o sinal Raman corrigido pela distância e $N_{R}(z)$ é o número por unidade de volume da molécula responsável pelo espalhamento Raman. Aqui, o espalhamento por partículas foi considerado sendo proporcional a $\lambda^{-k_{p a r}}$, com valor de exponente de angstrom $k_{\text {par }} \approx 0$ para o caso de cristais de gelo das nuvens cirrus (ANSMANN et al., 1992). O coeficiente de retroespalhamento pode ser calculado por:

$$
\begin{aligned}
\beta_{\text {par }}\left(\lambda_{0}, z\right)= & -\beta_{\text {mol }}\left(\lambda_{0}, z\right)+\beta\left(\lambda_{0}, z_{0}\right) \frac{S(z) / S_{R}(z)}{S_{m}\left(z_{0}\right) / S_{m, R}\left(z_{0}\right)} \frac{N_{R}(z)}{N_{R}\left(z_{0}\right)} \\
& \times \exp \left\{\int_{z_{0}}^{z}\left[\alpha\left(\lambda_{0}, z^{\prime}\right)-\alpha\left(\lambda_{R}, z^{\prime}\right)\right] d z^{\prime}\right\}
\end{aligned}
$$

Estas soluções, usando o método Raman, tipicamente só podem ser aplicadas durante a noite devido ao grande ruído de fundo no sinal Raman durante o dia, o que 
impede uma medida precisa e acurada deste sinal. Como, neste trabalho, queremos medir o ciclo diurno das propriedades das nuvens cirrus, este método não é o mais apropriado, sendo utilizado neste trabalho somente para comparação com os outros métodos (como feito na figura 2.4). A partir destas soluções para o coeficiente de extinção e retroespalhamento, é possível determinar a razão lidar para partículas em função da altitude usando a equação 2.5.

\subsubsection{Método da Transmitância}

O segundo método para a determinação da LR é o chamado método da transmitância. Ele é baseado no fato de que a profundidade óptica da nuvem poder ser obtida de uma medida direta da atenuação do sinal elástico do lidar causada pelas camadas de nuvens cirrus, sem a necessidade de se obter previamente o coeficiente de extinção para partículas. A partir da equação do lidar para espalhamento elástico (eq. 2.1), a razão entre o sinal corrigido pela distância no topo e na base da nuvem é dado por

$$
\frac{S\left(z_{t}\right)}{S\left(z_{b}\right)}=\frac{\beta\left(z_{t}\right)}{\beta\left(z_{b}\right)} \exp \left[-2 \int_{z_{b}}^{z_{t}} \alpha_{p a r}\left(z^{\prime}\right) d z^{\prime}\right] \exp \left[-2 \int_{z_{b}}^{z_{t}} \alpha_{m o l}\left(z^{\prime}\right) d z^{\prime}\right],
$$

Devido à grande altitude das nuvens cirrus, podemos considerar que a quantidade de aerossóis é muito pequena na camada atmosférica logo abaixo da base e acima do topo da nuvem cirrus (BAARS et al., 2012), ou seja, para $z<z_{b}$ e $z>z_{t}$ temos que $\alpha_{\text {par }}(z) \approx 0$ e $\beta_{\text {par }}(z) \approx 0$. Assim, o fator de transmissão da equação do lidar devido à nuvem cirrus $\left(T_{\text {cirrus }}\right)$ é dada por

$$
\begin{aligned}
T_{\text {cirrus }} & =\exp \left[-2 \int_{z_{b}}^{z_{t}} \alpha_{\text {par }}\left(z^{\prime}\right) d z^{\prime}\right]= \\
& =\frac{S\left(z_{t}\right)}{S\left(z_{b}\right)} \frac{\beta_{\text {mol }}\left(z_{b}\right)}{\beta_{\text {mol }}\left(z_{t}\right)} \exp \left[2 \int_{z_{b}}^{z_{t}} \alpha_{m o l}\left(z^{\prime}\right) d z^{\prime}\right] .
\end{aligned}
$$

Portanto, a profundidade óptica da nuvem cirrus $\left(\tau_{\text {cirrus }}\right)$ pode ser obtida por

$$
\tau_{\text {cirrus }}=\int_{z_{b}}^{z_{t}} \alpha_{\text {par }}\left(z^{\prime}\right) d z^{\prime}=-\frac{1}{2} \ln \left(T_{\text {cirrus }}\right) .
$$

A qualidade da determinação da profundidade óptica por este método depende, principalmente, da qualidade do sinal do lidar, da determinação do coeficiente de extinção e de retroespalhamento moleculares, e da determinação dos limites geométricos da nuvem cirrus. Dado que o método é baseado na razão entre o sinal do lidar abaixo e acima da nuvem, uma superestimação de $z_{b}$ ou subestimação de $z_{t}$ pode resultar em um grande erro na determinação da profundidade óptica da nuvem 
cirrus. Por outro lado, utilizando um valor mais baixo do que a altura verdadeira da base ou um valor mais elevado do que o valor verdadeiro da altura do topo, em outras palavras, $z_{b}^{\prime}=z_{b}-\delta z$ e $z_{t}^{\prime}=z_{t}+\Delta z \operatorname{com} \delta z, \Delta z>0$, não há alteração do valor da profundidade óptica. Se tivermos uma camada de ar limpo acima e abaixo da nuvem, então

$$
\int_{z_{b}-\delta z}^{z_{t}+\Delta z} \alpha_{p a r}\left(z^{\prime}\right) d z^{\prime}=\int_{z_{b}}^{z_{t}} \alpha_{\text {par }}\left(z^{\prime}\right) d z^{\prime}=\tau_{\text {cirrus }}
$$

pois $\alpha_{\text {par }}^{\text {cirus }}=0, \forall z<z_{b}$ e $z>z_{t}$. Quando o sinal é completamente atenuado pela nuvens cirrus, ou seja, quando o fator de transmissão é igual a zero $\left(T_{\text {cirrus }}=0\right)$, é impossível obter a verdadeira altura do topo da nuvem e a verdadeira profundidade óptica. Em tais casos, os valores de altura do topo e da profundidade óptica são chamados de aparentes, $z_{t}^{\text {appar }}$ e $\tau_{\text {cirrus }}^{\text {appar }}$, representando limites inferiores para essas quantidades. A figura 2.3 mostra o exemplo da aplicação deste método. Vale ressaltar que a equação (2.24) pode ser utilizada para determinar a COD dos cirrus durante o dia ou a noite, uma vantagem em relação ao método Raman; e também não depende de uma escolha da LR, uma vantagem em relação ao método Klett.
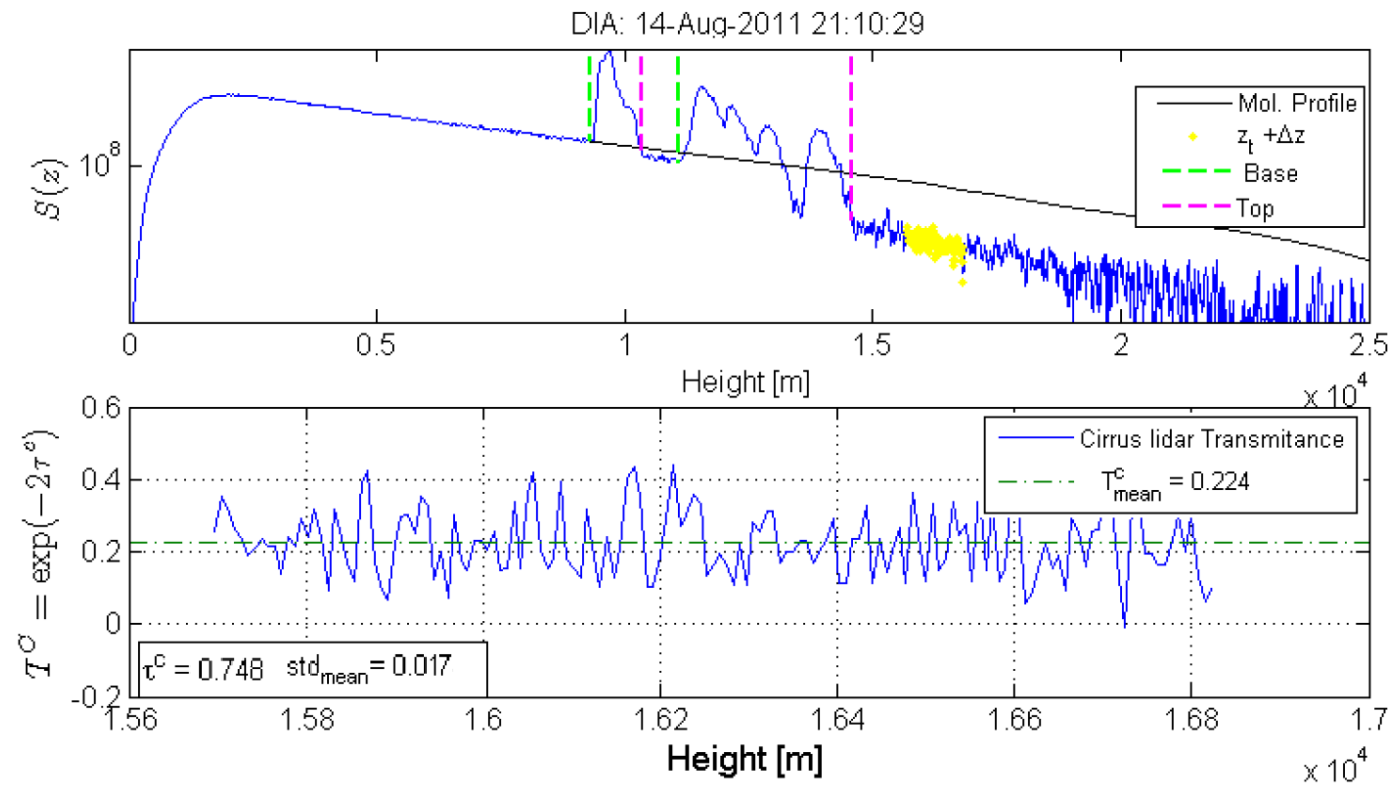

Figura 2.3 - Exemplo de uma nuvem cirrus detectada com o algoritmo automatizado. (painel superior): $\mathrm{S}(\mathrm{z})$ com as alturas de base e de topo (linhas tracejadas verdes e magentas), o S(z) molecular ajustado abaixo da base da nuvem (linha preta), e a região acima da nuvem utilizado para calcular o fator de transmissão. (painel inferior): O fator de transmissão da equação do lidar para essa nuvem, com o valor médio e a profundidade óptica $\tau_{c}$ obtido com o método de transmitância descrito acima. 
Para obter informação sobre a razão lidar, podemos combinar a profundidade óptica do cirrus obtida acima (eq. 2.24), com a solução do método de Klett como sugerido por Chen et al. (2002). Isto é feito da seguinte maneira. Para cada nuvem medida, aplicamos o método de Klett várias vezes, alterando o valor assumido para a $L R$, obtendo portanto vários $\beta^{\text {Klett }}(L R)$ e $\alpha^{\text {Klett }}(L R)$. Para cada um dos $\alpha^{\text {Klett }}(L R)$,

obtemos o valor de $C O D$ correspondente, $\tau_{\text {cirrus }}^{\text {Klett }}$, que comparamos com os valores da profundidade óptica obtida pelo método da transmitância (eq. 2.24), ou seja,

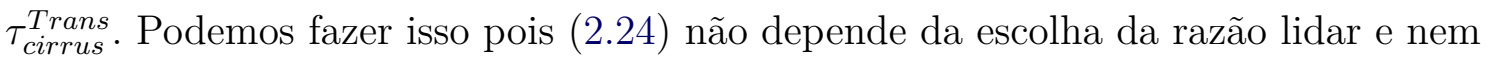
da quantidade de luz retroespalhada de dentro da camada de nuvem, sendo uma medida independente daquela obtida pelo método de Klett. O valor de razão lidar é aquele que minimizar o resíduo:

$$
Q(L R)=\left(\tau_{\text {cirrus }}^{\text {Klett }}(L R)-\tau_{\text {cirrus }}^{\text {Trans }}\right)^{2}
$$

A figura 2.4 à esquerda mostra o perfil do coeficiente de retroespalhamento obtido pelo método Raman (em vermelho) e obtido pelo método Klett para 3 valores diferentes de razão lidar (10, 18 e 30 sr). À direita temos a profundidade óptica da nuvem cirrus em função da altitude calculada para os 3 valores de razão lidar, com a linha vertical em azul representando o valor da profundidade óptica obtida pelo método da transmitância. Podemos ver que o perfil com a razão lidar $L R=18$ sr é o que gera um sinal de retroespalhamento razoável abaixo da nuvem, onde esperamos obter o valor zero, e que corresponde a profundidade óptica mais próxima do valor obtido pelo método da transmitância. Comparando com o perfil de retroespalhamento obtido pelo método Raman (em vermelho), que não depende da escolha da razão lidar, encontramos concordância entre os perfis abaixo da nuvem e até $12 \mathrm{~km}$. Acima disso, os perfis são similares, porém com diferentes estruturas em algumas partes da nuvem, reflexo do uso de um valor constante de razão lidar para a nuvem como um todo. Essas diferenças podem ser devido a diferentes camadas na nuvem onde predominam diferentes tipos, tamanhos e orientações dos cristais de gelo, que gera uma razão lidar não constante com a altitude.

\subsubsection{Correção de Espalhamento Múltiplo em Medidas de lidar}

Embora os sistemas lidar atmosféricos forneçam medições com alta precisão e alta sensibilidade (baixo limite de detecção), a maioria dos algoritmos para calcular parâmetros relevantes (por exemplo, $\beta, \alpha, L R$ e $\tau$ ) são construídos com a hipótese de espalhamento único (SS de single scattering), ou seja, que os fótons detectados e 

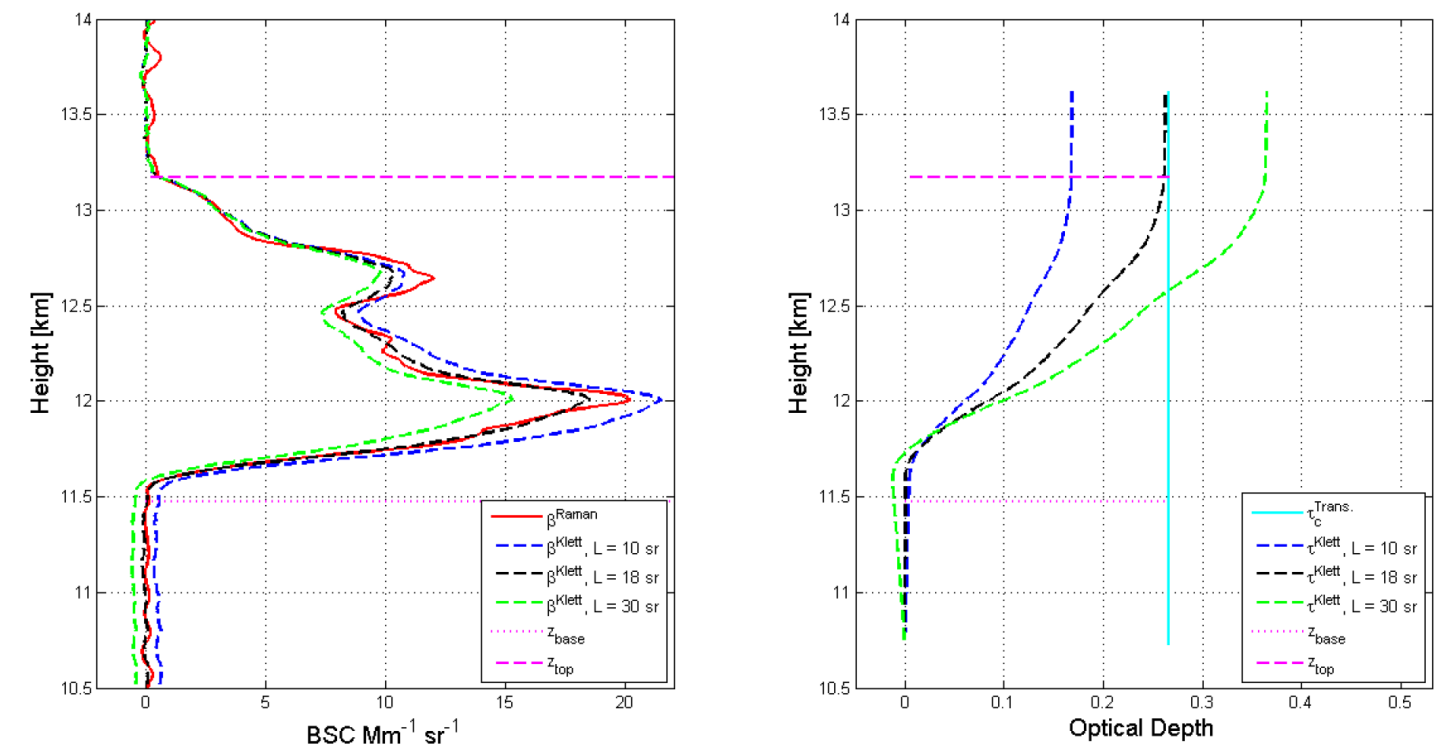

Figura 2.4 - (Esquerda): Perfil vertical do coeficiente de retroespalhamento para uma nuvem cirrus derivado pelos métodos Raman e de Klett para 3 valores diferentes de razão lidar. (Direita): Profundidade óptica da nuvem cirrus em função da altitude calculado para os 3 valores de razão lidar. A linha vertical em verde representa o valor da profundidade óptica obtido pelo método da transmitância.

que constituem o sinal do lidar são o resultado de um único espalhamento de $180^{\circ}$.

No entanto, é bem conhecido que as medições com lidar podem ser altamente influenciadas por efeitos de espalhamento múltiplo (MS de multiple scattering), onde uma fração substancial dos fótons espalhados na direção frontal permanece próxima do campo de visão do telescópio receptor, onde estarão sujeitos a eventos de espalhamento subsequentes e uma fração deles acaba sendo detectado pelo sistema lidar (WANDINGER, 1998a). A figura 2.5 mostra um exemplo de uma simulação de uma medida de nuvens cirrus utilizando um lidar com e sem efeitos de MS. A quantidade de fótons detectados que vêm de dispersão múltipla depende principalmente da amplitude do FOV, do volume coberto por ele e da largura e intensidade do pico de difração do espalhamento do pulso de laser pelos cristais de gelo da nuvem. Portanto, os efeitos do espalhamento múltiplo são particularmente intensos nas medições de nuvens, que são meios opticamente espessos e possuem partículas grandes em relação ao comprimento de onda do laser. Isso gera um pico de difração estreito que permanece dentro do FOV (REICHARDT; REICHARDT, 2006). Como sinal que sofreu MS demora mais para ser coletado, ele aparenta vir de uma altitude maior, assim, afeta a região do sinal que deveria ser molecular, medido pelo lidar muito 
acima do topo ( $\tilde{1} 0 \mathrm{~km})$ da nuvem (REICHARDT; REICHARDT, 2006).
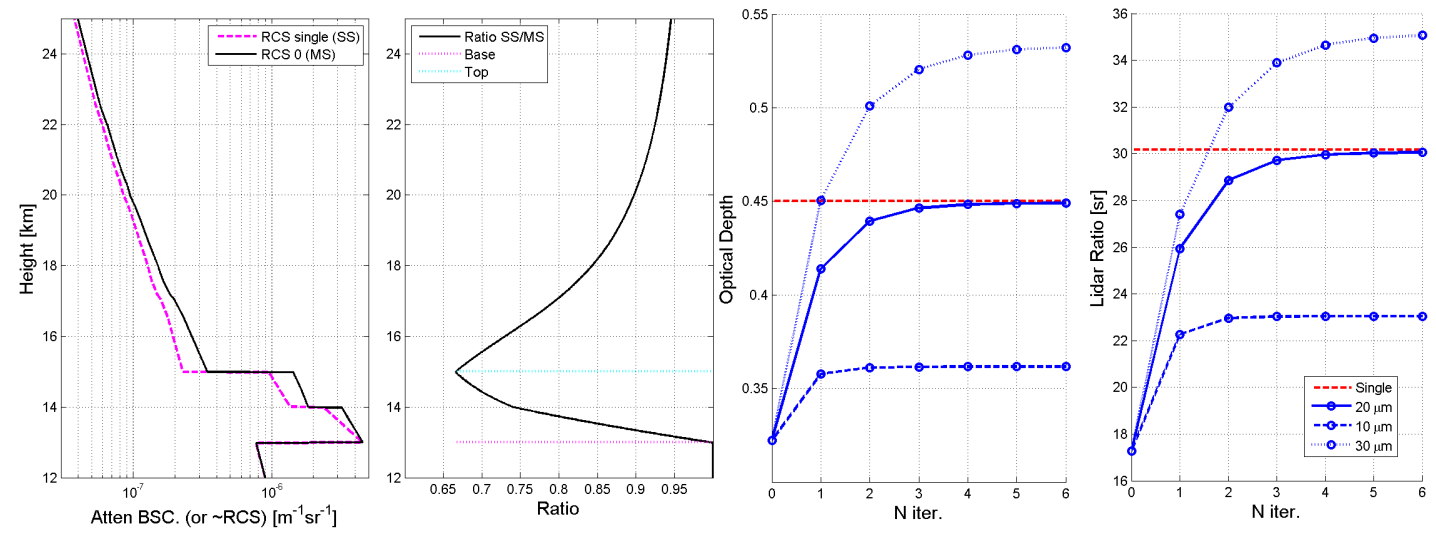

Figura 2.5 - (esquerda) Sinal lidar simulado com e sem os efeitos de espalhamento múltiplo. (centro esquerda) Razão entre sinais com espalhamento único e múltiplo (SS/MS). Convergência da profundidade óptica recuperada (centro direita) e da razão lidar (direita) quando corrigida pelo método iterativo. A curva cheia são os resultados calculados com o valor correto do raio efetivo do cristal de gelo simulado $(20 \mu m)$ e as pontilhadas quando calculadas com \pm $10 \mu \mathrm{m}$.

Ignorar os efeitos do espalhamento múltiplo na recuperação das propriedades das nuvens leva a uma considerável subestimação do coeficiente de extinção e da razão lidar. Felizmente, temos à disposição modelos precisos (HOGAN, 2006; ELORANTA, 1998) que nos permitem calcular a intensidade de fótons multiplamente espalhados por nuvens em sinais de lidar.

As distorções não lineares no sinal molecular, que podem ser maiores que $10 \%$, mesmo em alturas de $10 \mathrm{~km}$ acima do topo da nuvem (veja a figura 2.5), demonstram que somente com uma correção MS para todo o perfil lidar (não apenas dentro da nuvem) é possível derivar as propriedades ópticas através das técnicas elásticas, Raman ou transmitância. Isso pode ser feito usando o modelo de Hogan (HOGAN, 2006) que é rápido o suficiente para ser usado em uma solução iterativa. A figura 2.6 mostra o passo a passo da correção que aplicamos neste trabalho. Inicialmente, utilizamos como entrada do modelo uma estimativa do perfil de extinção recuperado sem qualquer correção (iteração 0), e assim calculamos uma primeira aproximação da relação SS/MS que é usada para corrigir o perfil do lidar. Após a primeira correção, o novo perfil de extinção é usado para melhorar a estimativa do fator de correção, e assim por diante nas seguintes iterações (iteração 1, 2, ...). Para estimar a relação SS/MS, entretanto, é preciso conhecer a distribuição de tamanho dos cristais de gelo 
dentro da nuvem.

A figura 2.5 à direita mostra os valores calculados do COD e LR em cada uma das iterações derivadas do sinal MS simulado. Podemos ver que o método iterativo corrige com precisão os valores da profundidade óptica e da razão lidar após algumas iterações $(\approx 3)$, convergindo para valores muito próximos dos valores reais simulados. Vemos também que a correção depende muito do valor do raio efetivo escolhido, com a correção sendo tão boa quanto a acurácia deste raio efetivo. Assim, para aplicações reais, é necessário ter uma boa parametrização do raio efetivo dos cristais de gelo, ou o resultado pode gerar mais erros do que o caso não corrigido. Neste trabalho, foram utilizado os resultados de (KRÄMER et al., 2016), uma look-up table de $R_{e f f}$ em função da temperatura, que contem medidas in-situ de cirrus tropicais, inclusive com dados da Amazônia, do experimento ACRIDICON-CHUVA (WENDISCH et al., 2016).

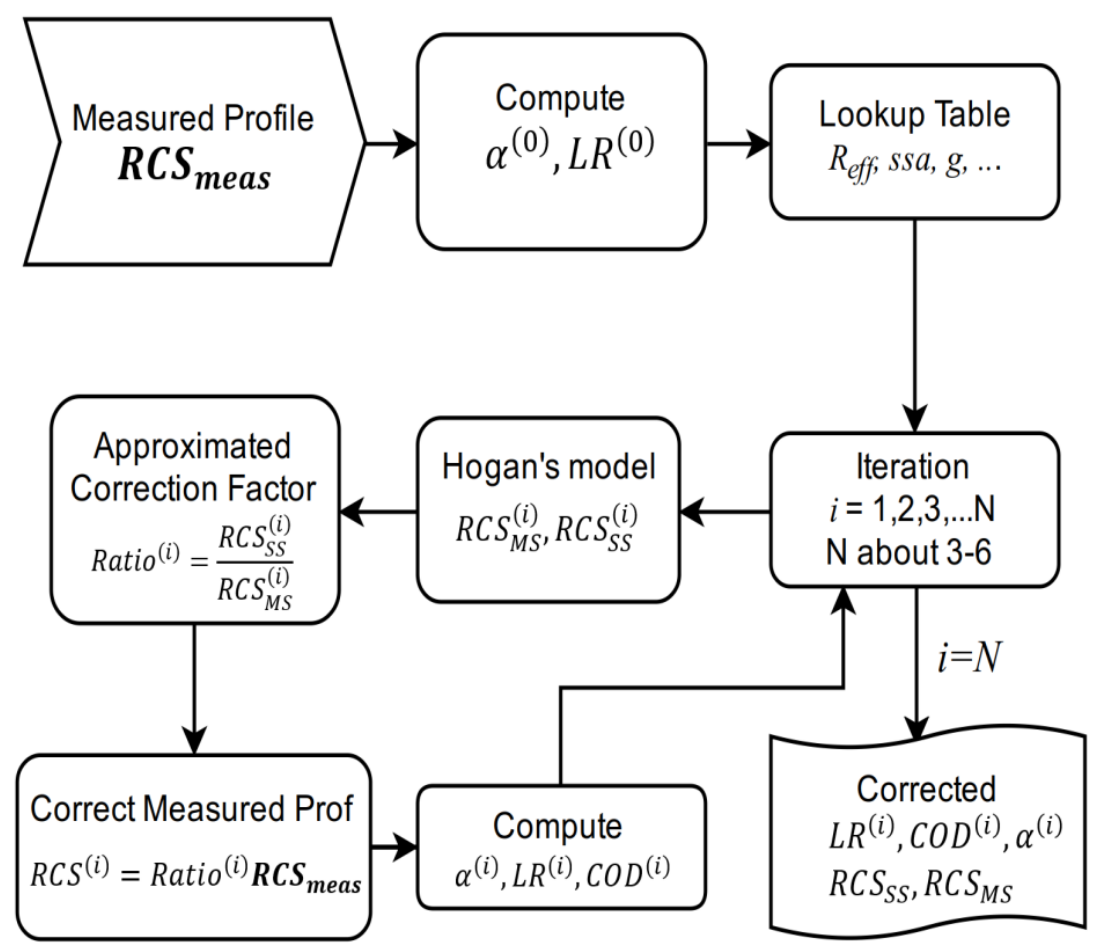

Figura 2.6 - Fluxograma do método de correção dos efeitos de espalhamento múltiplo.

\subsubsection{Avaliação dos Algoritmos de Detecção de Nuvens Cirrus}

É importante conhecer as incertezas nos valores obtidos da profundidade óptica e da razão lidar, particularmente usando o método da transmitância (CHEN et al., 2002), 
que é muito sensível à razão sinal-ruído (S/N como em Signal-to-Noise) para nuvens com baixa profundidade óptica. Para estimar o efeito do ruído aleatório do sinal lidar nos nossos resultados e quantificar os erros para diferentes profundidades ópticas (COD), nós realizamos simulações numéricas dos perfis do lidar, com a presença de nuvens cirrus. $\mathrm{O}$ valor de razão lidar fixo de $20 \mathrm{sr}$. A base da nuvem foi fixada a 12 $\mathrm{km}$ de altitude e oito valores de espessura geométrica foram simuladas: 15, 30, 45, 90, 150, 450, 1200, e 4500 m. Para o perfil do coeficiente de extinção da nuvem, dois valores foram simulados: 0.02 e $0.1 \mathrm{~km}^{-1}$, com isso o COD variou entre $3 \times 10^{-4} \mathrm{e}$ 0.45. O ruído aleatório do sinal medido no regime de photon-count (PC) foi simulado seguindo uma distribuição de Poisson de forma que obteve-se razão sinal-ruído de 50, 10, 5 e 3 em cada um dos bins (correspondente a $7.5 \mathrm{~m}$ de resolução espacial) logo abaixo da base da nuvem simulada. Para cada combinação do COD e da razão S/N, 100 simulações foram feitas.
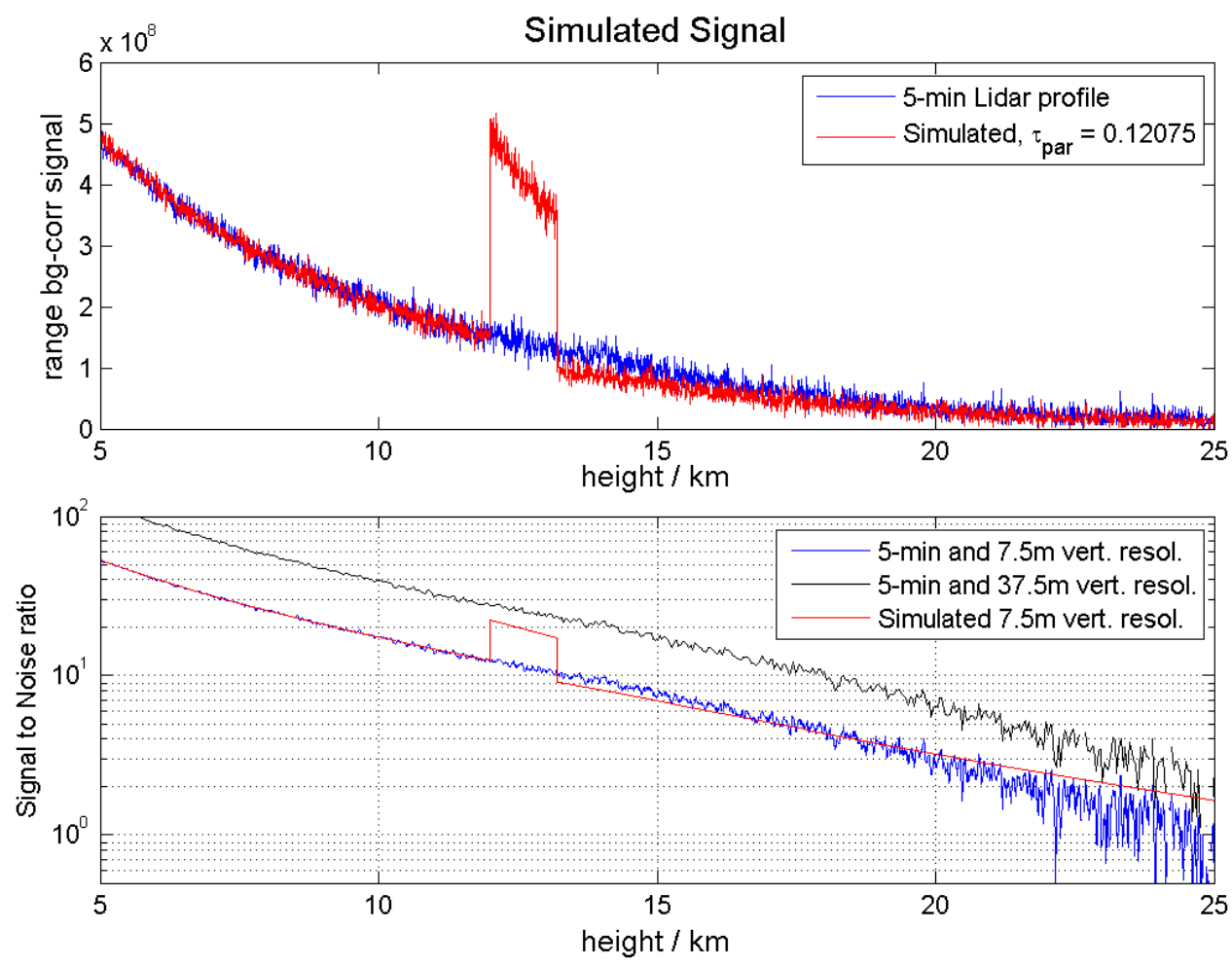

Figura 2.7 - Exemplos de sinais corrigidos pelo background e pela distância (topo) e a correspondente relação $\mathrm{S} / \mathrm{N}$ (abaixo). A curva azul é um perfil de lidar medido com média temporal de 5 min e resolução vertical de $7,5 \mathrm{~m}$, enquanto a curva vermelha é um perfil simulado com uma relação $\mathrm{S} / \mathrm{N}$ semelhante na base da nuvem cirrus simulada com profundidade óptica de 0,12 . A curva preta é o mesmo perfil medido, mas com um média vertical de 5 bins $(37,5$ $\mathrm{m})$ e, portanto, uma relação $\mathrm{S} / \mathrm{N}$ mais elevada. 
Os perfis simulados foram processados com o mesmo algoritmo usado nos perfis atmosféricos reais. Desta forma, pode-se avaliar a incerteza no valor do COD e no LR como uma função da razão $\mathrm{S} / \mathrm{N}$, usando o cálculo do valor médio, do desvio padrão e do desvio padrão do valor médio sobre os 100 casos. O desvio padrão dará informações de como o ruído aleatório do sinal pode afetar as derivações do COD e do LR, enquanto que a média e o desvio padrão da média mostrarão se os valores recuperados convergem para os valores esperados após muitas observações.

A Figura 2.7 mostra um exemplo de um perfil com média de 5 min e resolução vertical original de 7,5 m, medido em algum dia em julho de 2011. O sistema mostra um bom desempenho. A razão $\mathrm{S} / \mathrm{N}$ típica para o retroespalhamento molecular a $12 \mathrm{~km}$ de altitude, para esta resolução temporal e espacial, varia de 6 a 20, dependendo da presença de nuvens baixas e da radiação solar de fundo durante o dia (Background). Esta relação S/N pode ser melhorada, por exemplo, reduzindo a resolução vertical, como mostrado no painel inferior (curva preta).

\section{Incertezas no cálculo da profundidade óptica}

Para o cálculo da profundidade óptica com o método de transmitância, é necessário ajustar a parte molecular do sinal abaixo e acima da nuvem. Considerar uma grande região para esses ajustes, no nosso caso de 1 a $10 \mathrm{~km}$, ajuda a reduzir o efeito do ruído. A diferença entre os dois ajustes dá a transmitância do cirrus e a profundidade óptica é metade do logaritmo natural desse valor. A figura 2.8 mostra a média do COD e o desvio padrão desse valor médio, para as 100 simulações. Estes resultados mostram que a magnitude do erro médio absoluto (diferença entre COD médio e o valor verdadeiro simulado) é independente do COD verdadeiro. A raiz do erro quadrático médio (RMSE) é $2,5 \times 10^{-3}$, para $\mathrm{S} / \mathrm{N}=3$, e apenas $2,3 \times 10^{-4}$, para $\mathrm{S} / \mathrm{N}=50$. Isso é para os valores médios em 100 simulações, enquanto que para perfis únicos de 5-min o erro é quase 10 vezes maior. O erro relativo é menor para valores de COD grandes. Este erro é inferior a $20 \%$ para COD $>0,005$ e $\mathrm{S} / \mathrm{N}=3$ e inferior a 6 $\%$ para $\mathrm{COD}>4,5 \times 10^{-4}$ (valor mínimo) e $\mathrm{S} / \mathrm{N}=50$ (maior valor). Observamos que mesmo para uma relação $\mathrm{S} / \mathrm{N}$ muito baixa e um COD pequeno, o método utilizado neste trabalho (seção 2.3) ainda encontra um valor médio compatível com o COD verdadeiro.

A profundidade óptica da nuvem também pode ser calculada integrando o coeficiente de extinção obtido com o método de Klett, no entanto é necessário um LR a priori. Usamos esse método em dois casos. Primeiro, quando há mais de uma camada de nuvem. Nesta situação, o método de transmitância dá a profundidade óptica total da 
nuvem, que é usado para obter um LR médio para todas as camadas combinadas. O perfil de extinção do método de Klett (com esse LR médio) é então usado para dividir a profundidade óptica total em contribuições de cada camada de nuvem cirrus. O segundo caso é quando o método interativo descrito na seção 2.3.2.3 não converge, isto é, quando não consegue encontrar um valor de LR razoável que faça com que a inversão de Klett dê a mesma profundidade óptica que o método da transmitância. Isso acontece para uma fração dos nossos perfis com nuvens que têm profundidade óptica muito baixa (geralmente COD $<0,01$, com discutido na seção seguinte), pois o valor absoluto do COD para nuvens muito finas tem pouca sensibilidade ao valor do LR. Estes perfis são geralmente aqueles perto das bordas das nuvens. Nestes casos, a profundidade óptica da nuvem é obtida com o método de Klett, assumindo uma LR igual ao valor médio obtido de todos os outros perfis (ou seja, aqueles em que podemos determinar o LR, para a nuvem em questão).
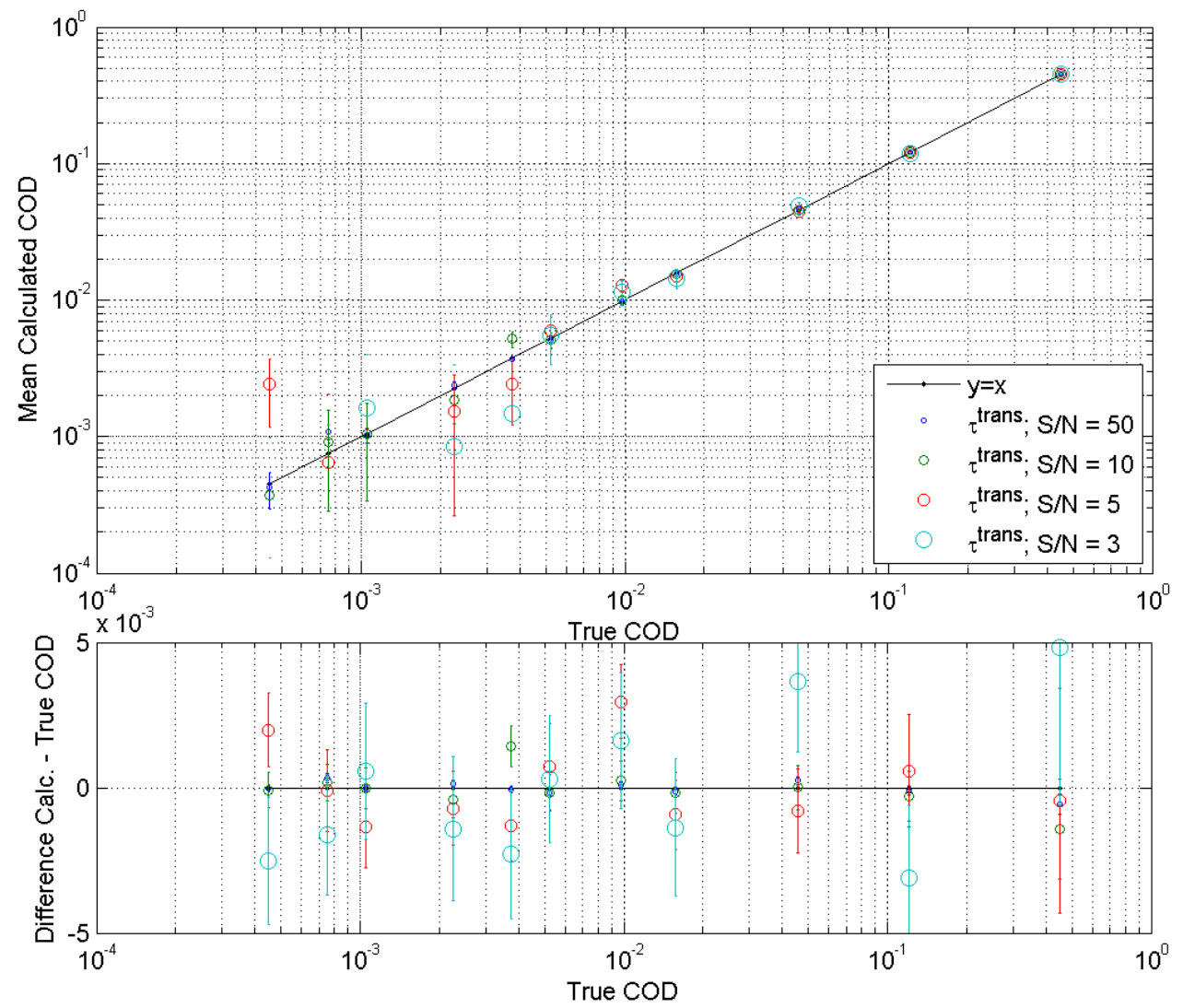

Figura 2.8 - COD calculado pelo método da transmitância em função do COD real para diferentes razões $\mathrm{S} / \mathrm{N}$. As barras de erro são o desvio padrão dos valores médios. As diferenças absolutas (painel inferior) são todas compatíveis com zero (isto é, o COD médio calculado é compatível com o COD verdadeiro). 
A figura 2.9 mostra o COD obtido por este método no melhor cenário, isto é, ao impor o LR verdadeiro (20 sr). Podemos ver que o método de Klett é muito menos sensível à relação $\mathrm{S} / \mathrm{N}$. O RMSE é $2,8 \times 10^{-4}$ para $\mathrm{S} / \mathrm{N}=3$, e $5,5 \times 10^{-5}$ para $\mathrm{S} / \mathrm{N}=50$, ambos muito menores do que os erros médios obtidos com o método de transmitância, mas também mais próximos uns dos outros. Da mesma forma que no método da transmitância, o método de Klett também encontra um valor médio compatível com o COD verdadeiro, mesmo para razões S/N muito baixas e CODs pequenos.
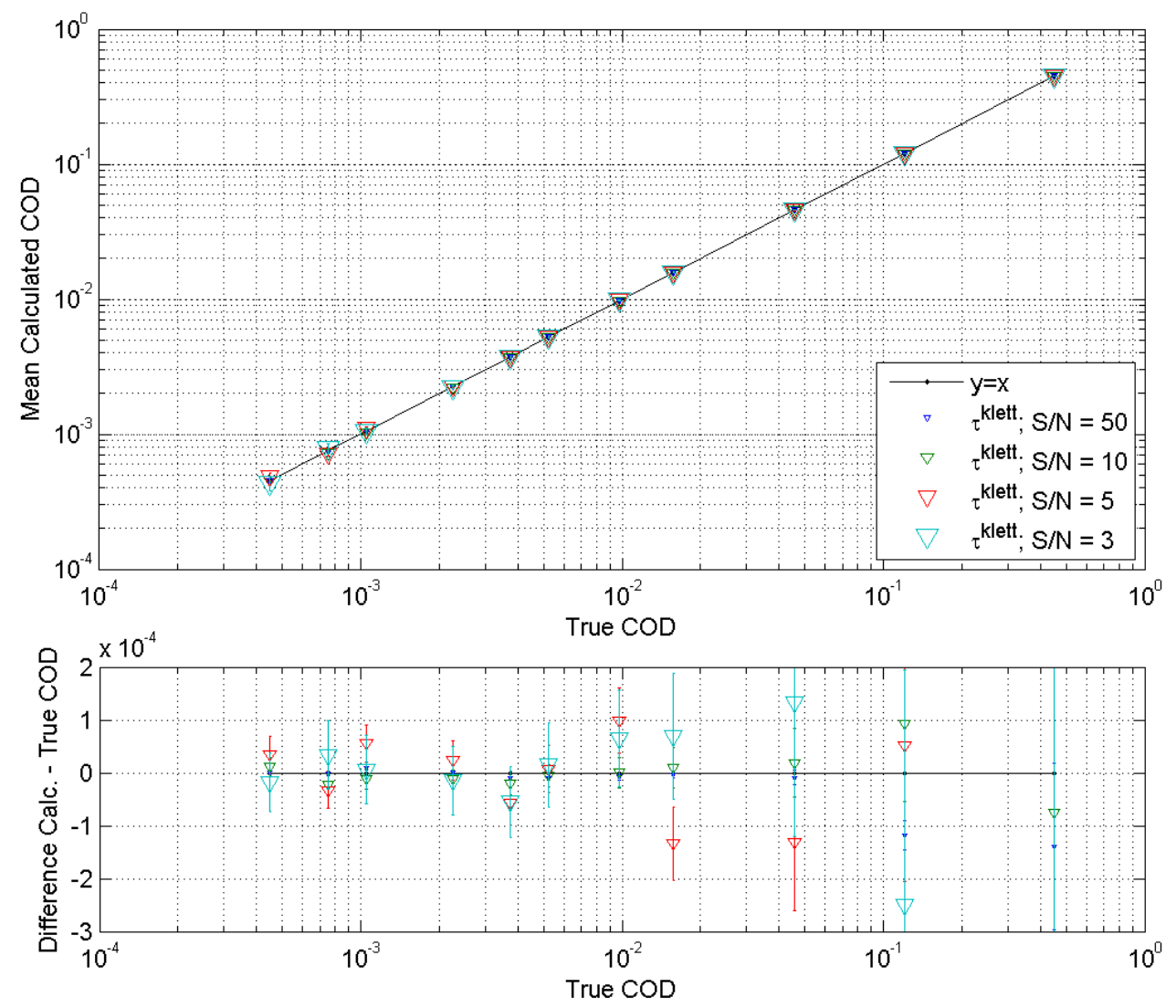

Figura 2.9 - COD calculado pelo método de Klett, assumindo o verdadeiro LR $=20 \mathrm{sr}$, em função do COD real para diferentes razões $\mathrm{S} / \mathrm{N}$. As barras de erro são o desvio padrão dos valores médios. As diferenças absolutas (painel inferior) são todas compatíveis com zero (isto é, o COD médio calculado é compatível com o COD verdadeiro).

Deve-se notar, no entanto, que uma estimativa errada sobre o LR iria causar um viés nos valores de CODs obtidos com o método Klett. Para quantificar esse efeito, aplicamos o método de Klett assumindo um valor de LR $50 \%$ maior e menor que o valor verdadeiro (ou seja, 10 e $30 \mathrm{sr}$ ) e $\mathrm{S} / \mathrm{N}$ de 50 (para que o ruído possa ser desconsiderado). O resultado é mostrado na Figura 2.10 juntamente com o resultado 


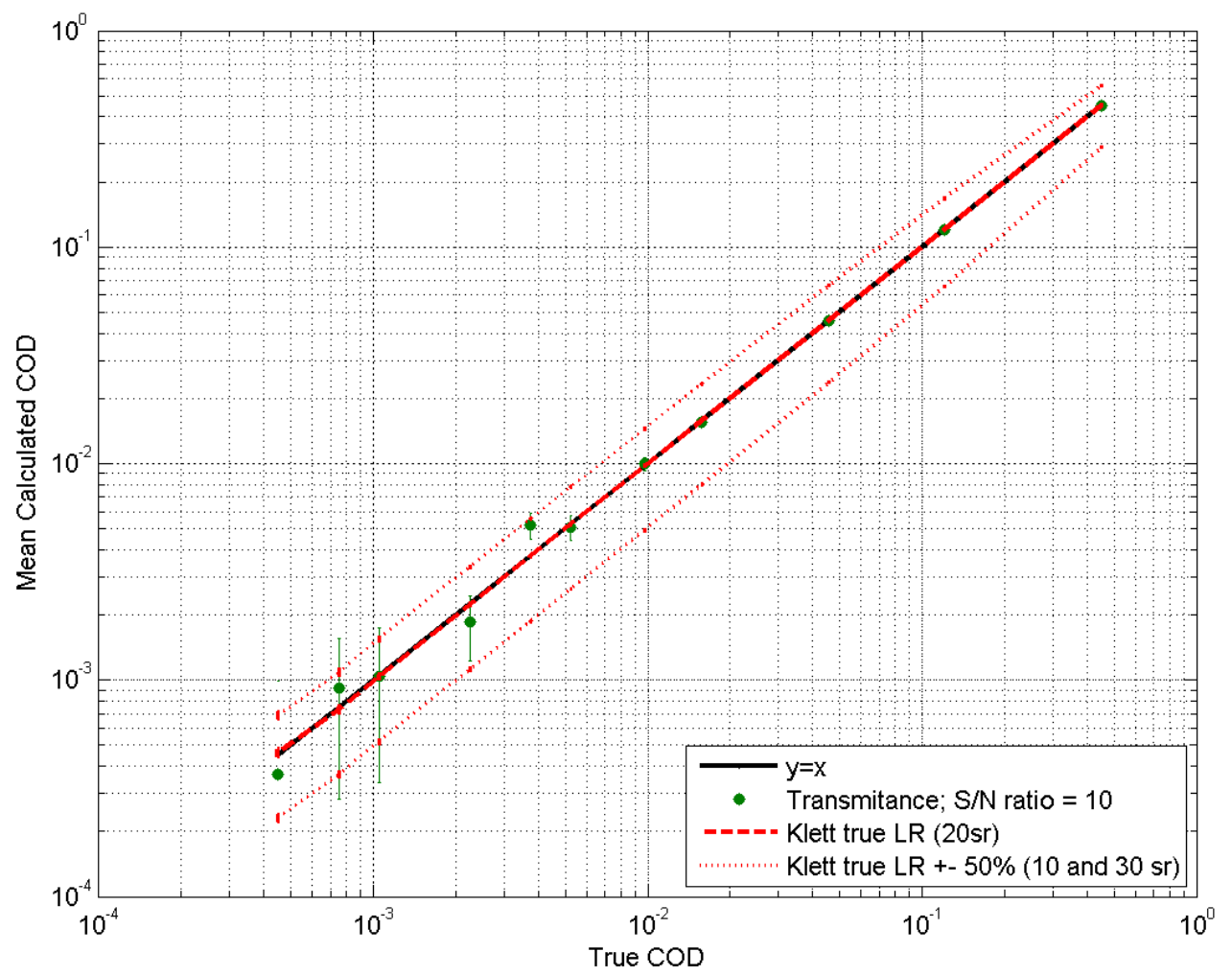

Figura 2.10 - COD calculada pelo método de Klett, para LR = 10, 20 (verdadeiro) e 30 sr, é mostrada como um função do COD verdadeiro para $\mathrm{S} / \mathrm{N}=50$. Pontos em verde são o método de transmissão para $\mathrm{S} / \mathrm{N}=10$. As barras de erro são o desvio padrão dos valores médios.

para o método de transmissão com razão $\mathrm{S} / \mathrm{N}$ de 10 . Fica evidente que o COD obtido pelo método de Klett é apenas tão bom quanto a estimativa do LR.

A Figura 2.11 mostra os erros relativos para ambos os métodos. Isso é definido como $R M S E / C O D_{\text {True }}$. Como esperado, quanto menor a relação $\mathrm{S} / \mathrm{N}$, maior o erro. No pior caso, isto é, $\mathrm{S} / \mathrm{N}=3$, o erro relativo do resultado calculado em um único perfil de 5-min utilizando o método de transmissão é inferior a $20 \%$ apenas para $C O D>0,1$. Para $\mathrm{S} / \mathrm{N}=10$, este limite é $C O D>0,025$. Este erro, no entanto, é aleatório e flutua em torno de zero como mostrado anteriormente. Com a média de mais de 100 perfis (painel direito, Figura 2.11), os erros relativos diminuem por um fator de 10. Nestas circunstâncias, com muitos perfis, ou se o S/N é alto, ou se o COD não é muito pequeno, é vantajoso utilizar o método de transmitância porque não depende de um LR a priori. Em nosso estudo, analisamos cerca de 37k perfis de 5 -min em um ano de medidas, onde $21 \mathrm{k}$ teve $\mathrm{S} / \mathrm{N}>3$ a $12 \mathrm{~km}$ e em $14 \mathrm{k}$ destes encontramos uma nuvem cirrus.

Incertezas no cálculo da razão lidar 

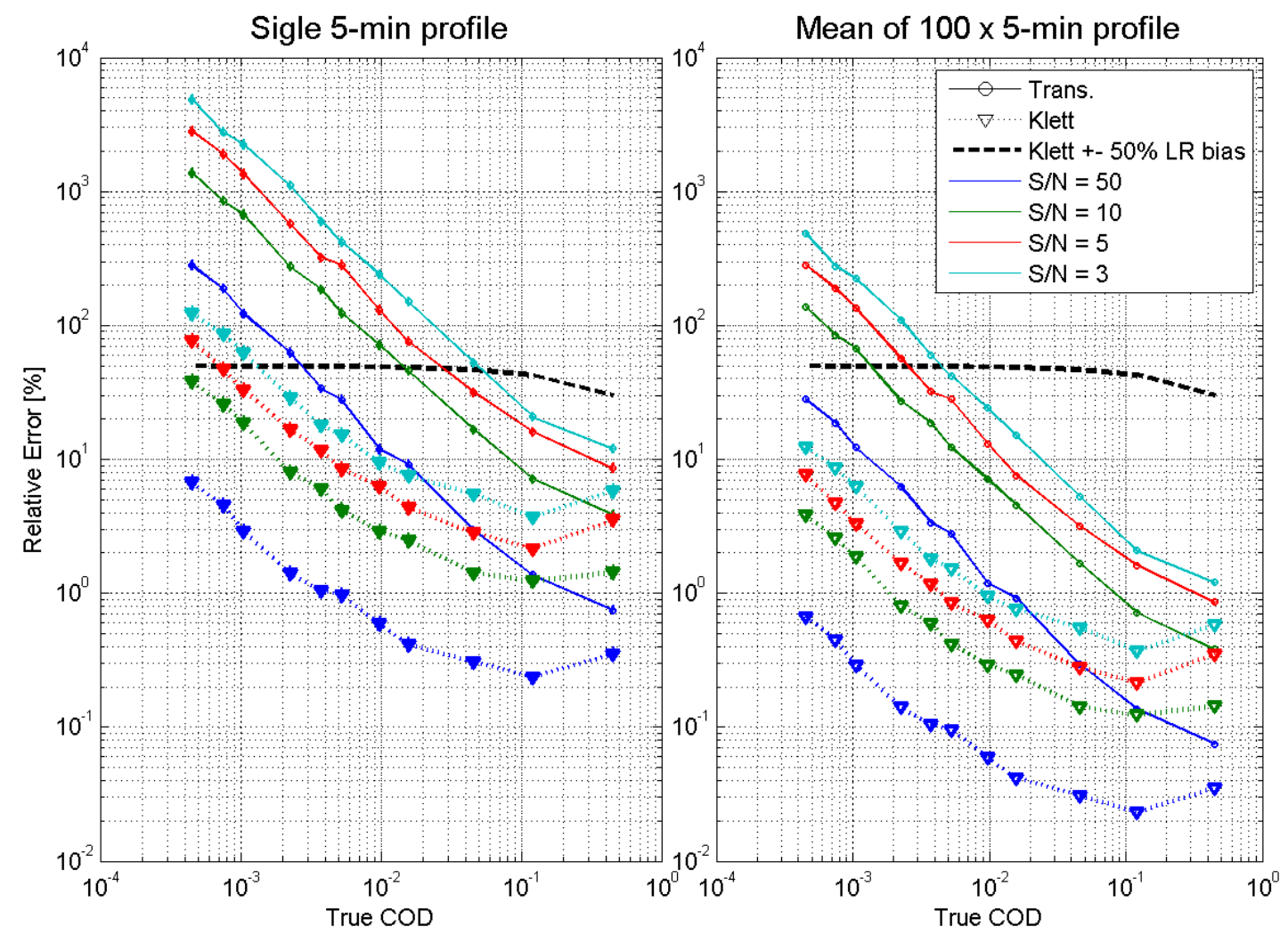

Figura 2.11 - São mostrados os erros relativos (em \%) na determinação do COD para ambos os métodos em função do COD verdadeiro para as diferentes relações sinal/ruído.

Como explicado acima, o LR é estimado por um procedimento de minimização no qual o LR pode variar de 2 a 50 sr. O LR ótimo é o que faz com que a profundidade óptica da nuvem a partir do algoritmo de Klett seja igual à do método de transmitância. Tipicamente, somos capazes de estimar o LR para nuvens com $C O D>0,01$, que são cerca de $91 \%$ das nossas observações. Abaixo desse limiar, o COD não é muito sensível a mudanças no LR e o método não converge. É por isso que estimamos o COD, nestes casos, com o método de Klett e um LR fixo.

A figura 2.12 mostra os resultados do LR estimada para os mesmos perfis simulados anteriormente, mas apenas para os casos em que o algoritmo do LR convergiu. Quando o S/N é baixo ou quando o COD é pequeno, há uma tendência de superestimar o LR (todos os desvios são positivos). No entanto, todos os valores recuperados são ainda compatíveis com o valor verdadeiro (teste $t<3$ ) e o desvio máximo é apenas 4,7 sr. Além disso, o erro do LR calculado para perfis individuais (desvio padrão, isto é, 10 vezes as barras de erro na figura 2.12) diminui com o aumento do COD. Para $\mathrm{S} / \mathrm{N}$ de 5 , vale $12 \mathrm{sr}$ para $\mathrm{COD}=0,02$ e 3 sr para $\mathrm{COD}=0,45$. O erro 

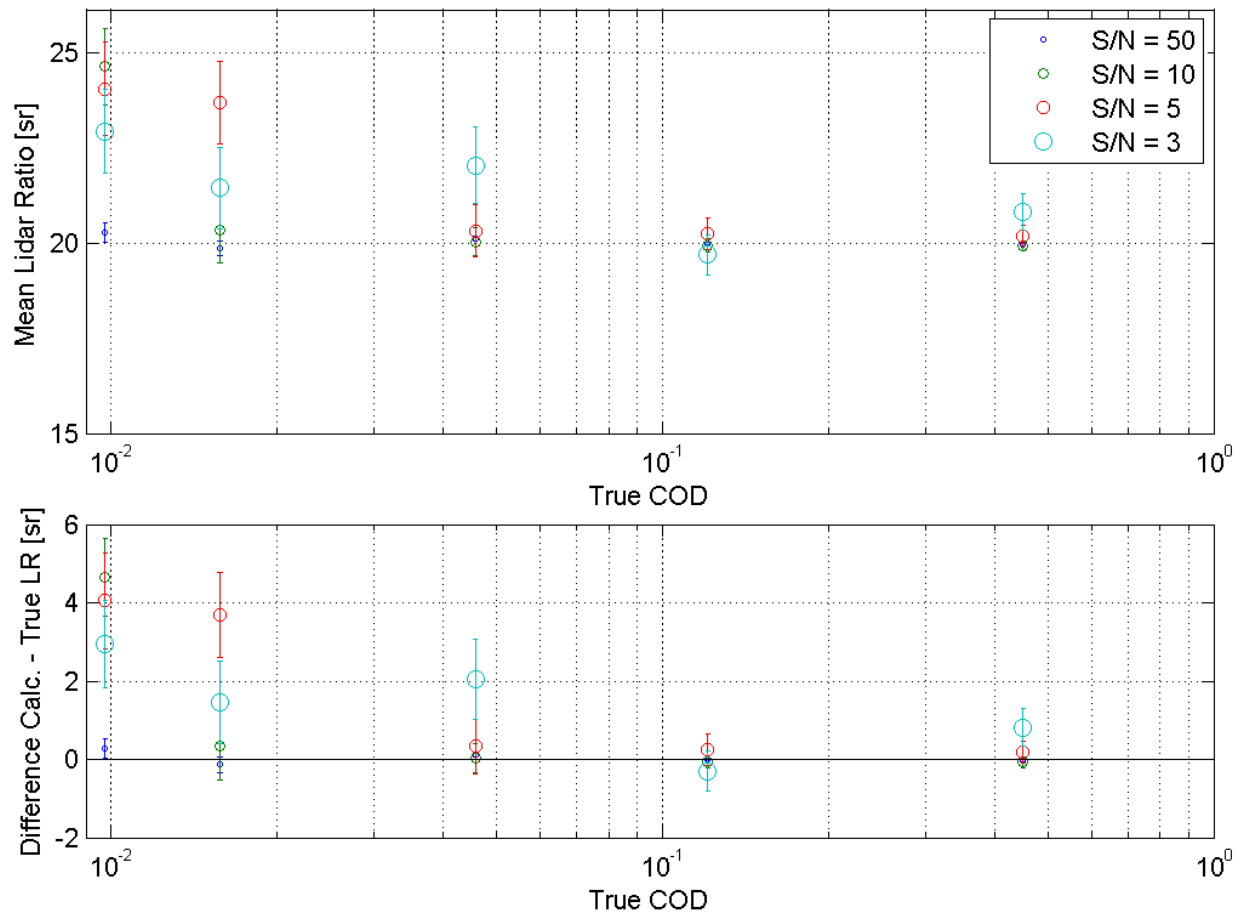

Figura 2.12 - LR calculado a partir da combinação dos métodos de transmitância e Klett, em função do COD verdadeiro para diferentes relações S/N. As barras de erro são o desvio padrão dos valores médios. As diferenças absolutas (painel inferior) são todas compatíveis com zero (isto é, a média do LR calculada é compatível com o LR verdadeiro).

também diminui com o aumento da relação S/N. Isto é mostrado nos histogramas na figura 2.13, para $\mathrm{COD}>0,02$ e $\mathrm{S} / \mathrm{N}$ de 5 e 10 . O erro foi reduzido de 5 para 2,5 sr, respectivamente. Para estes casos com COD um pouco maior, é claro que não há viés na média recuperada do LR.

\section{Incertezas na detecção das nuvens}

De maneira similar ao que foi feito na seção anterior, utilizamos simulações para avaliar o desempenho do algoritmo de detecção de nuvens cirrus. Para isso, foram simuladas nuvens com base a $16 \mathrm{~km}$ de altitude e lidar ratio de $20 \mathrm{sr}$, com espessuras de $15,30,45,60,75,85,100,150,250,325,450,1000,2000$ e 3500m para perfis com razão sinal-ruído variando de 10 a 1 . Como um dos parâmetros importantes para a detecção é a presença de um pico de retroespalhamento no sinal, para cada uma das espessuras e razão sinal ruído, foram simuladas nuvens com um coeficiente de retroespalhamento que variava de $1 \mathrm{Mm}^{-1} \mathrm{sr}^{-1}$ até $5 \mathrm{Mm}^{-1} \mathrm{sr}^{-1}$. Para cada combinação de espessura, coeficiente de retroespalhamento e razão S/N, 40 simulações foram feitas para calcularmos a eficiência do algoritmo de detecção. 

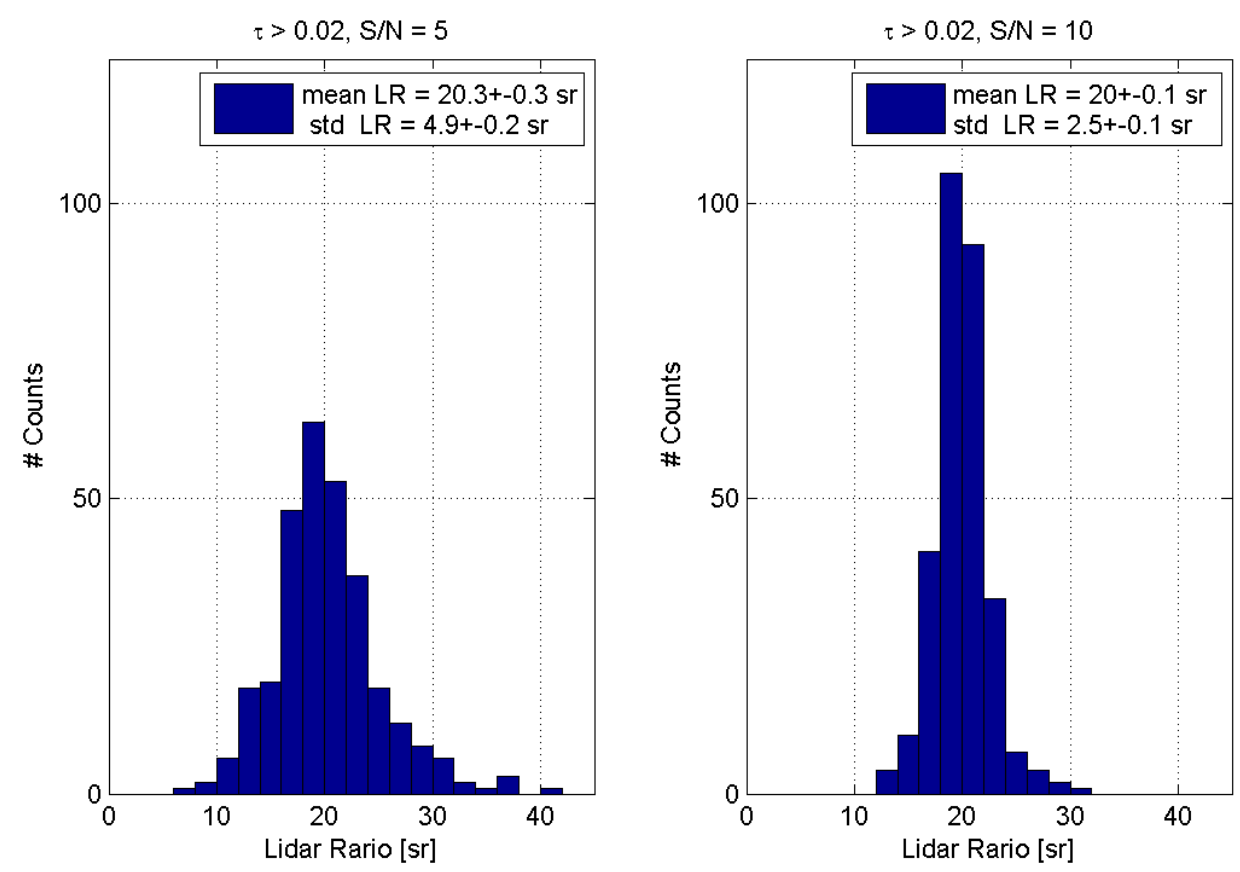

Figura 2.13 - Os histogramas de LR calculados a partir da combinação dos métodos de transmitância e Klett para $\mathrm{S} / \mathrm{N}=5$ (esquerda) e $\mathrm{S} / \mathrm{N}=10$ (direita) são mostrados apenas para COD> 0.02 .

Podemos ver na figura 2.14 que mesmo com sinais muito fracos (com razão sinal ruído baixo) é possível detectar as nuvens cirrus muito finas opticamente, desde que elas possuam um coeficiente de retroespalhamento grande $\left(\beta_{\text {par }}>2-3 \mathrm{Mm}^{-1} \mathrm{sr}^{-1}\right)$, pois este gera um pico grande no sinal do lidar que é fácil de ser diferenciado do sinal molecular. Para nuvens que não possuem $\beta_{\text {par }}$ muito grande (menor que $\approx 2$ $M m^{-1} s r^{-1}$ ), ainda é possível detectar nuvens com sinais não muito fortes desde que essas nuvens possuam uma espessura geométrica não muito pequena (tipicamente $>$ $300 \mathrm{~m}$ ) e consequentemente, um COD não muito pequeno (tipicamente $>0,01$ ). De maneira geral, $100 \%$ das nuvens cirrus simuladas com COD $>0,005, \operatorname{com} \beta_{\text {par }}>$ $1 \mathrm{Mm}^{-1} s r^{-1}$ e razão sinal-ruído na base da nuvem $>1$ foram detectadas. Para um $\mathrm{S} / \mathrm{N}=3$ na base, o COD mínimo em que foram detectadas todas as nuvens foi próximo a 0,001 . 

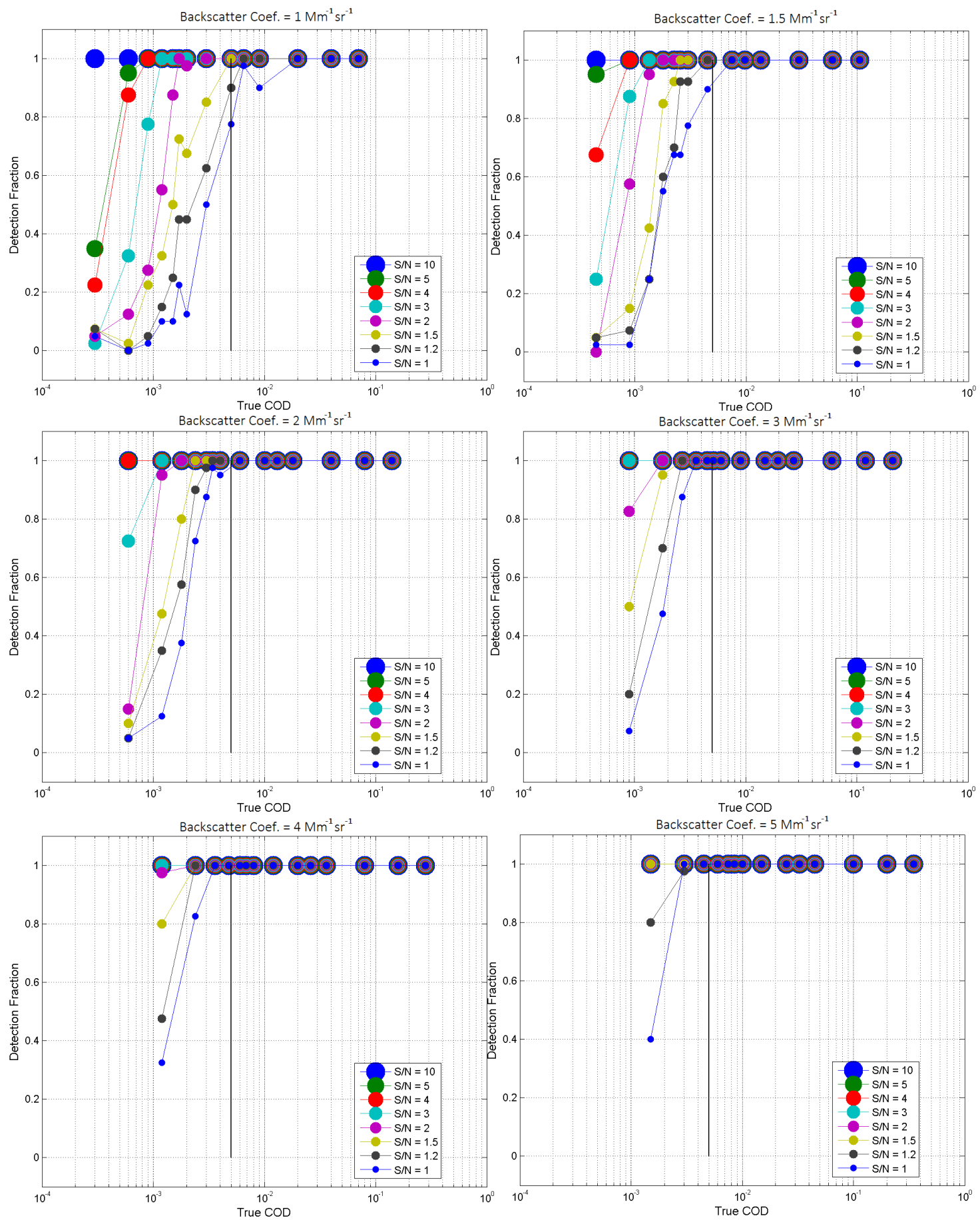

Figura 2.14 - Fração de nuvens detectadas em função da razão sinal ruído logo abaixo da base, do coeficiente de retroespalhamento e da profundidade óptica. 



\section{Nuvens Cirrus na Amazônia}

Neste capítulo nós derivamos a primeira estatística abrangente das propriedades macro e microfísicas das nuvens cirrus na Amazônia. A detecção das camadas de nuvens a partir do sinal do lidar, o cálculo da espessura óptica, e a correção de múltiplo espalhamento foram aplicadas de acordo com a metodologia desenvolvida no capítulo anterior. São apresentados os resultados das medidas da altitude de base e topo, espessura geométrica, profundidade óptica, razão lidar e sua relação com a temperatura. A análise cobre o período de um ano de dados (entre jul-2011 a jun2012). Estes resultados foram publicados em Gouveia et al. (2017) e foram a base para a determinação da forçante radiativa das nuvens cirrus na Amazônia, que serão apresentadas no próximo capítulo.

\subsection{Instrumentação}

\subsubsection{Conjuntos de dados}

O conjunto de dados utilizado no presente estudo compreende as medidas registradas entre julho de 2011 e junho de 2012, com perfis verticais do lidar com média temporal de 5 minutos (média de 3.000 pulsos do laser que opera a $10 \mathrm{~Hz}$ ). Um total de 36.597 perfis foram analisados correspondendo aproximadamente a 1/3 do número máximo possível de perfis durante 1 ano. Informação sobre a circulação atmosférica foi obtida a partir de dados da reanálise ERA Interim (DEE et al., 2011) do European Center for Medium-Range Weather Forecast (ECMWF) com resolução espacial de 0,75 e resolução temporal de $6 \mathrm{~h}$. As altitudes da tropopausa foram calculadas usando perfis de temperatura do ERA Interim interpolados para o tempo de medição de cada observação. Seguimos a definição da Organização Meteorológica Mundial (IMV, 1967), ou seja, "the lowest level at which the lapse rate decreases to $2{ }^{\circ} \mathrm{C} \mathrm{km}^{-1}$ or less, provided that the average lapse rate between this level and all higher levels within 2 $\mathrm{km}$ does not exceed $2{ }^{\circ} \mathrm{C} \mathrm{km}^{-1} "$. Assumimos ainda que o lapse rate varia linearmente com a pressão (MCCALLA, 1981), e a altitude exata em que $\Gamma=2{ }^{\circ} \mathrm{C} \mathrm{km}^{-1}$ (ou seja, a tropopausa) foi encontrada pela interpolação linear entre os níveis de pressão disponíveis. A precipitação foi obtida a partir do produto 3B42 versão 7 do TRMM (Tropical Rainfall Measuring Mission - Huffman et al. (2007)) com 0,25 e $3 \mathrm{~h}$ de resolução espacial e temporal, respectivamente. Retro trajetórias foram calculadas usando o modelo HYSPLIT (STEIN et al., 2015) forçado pelos campos meteorológicos do Global Data Assimilation System (GDAS) da National Oceanic and Atmospheric Administration (NOAA) dos EUA, disponível em resolução de 0,5 grau. 
Tabela 3.1 - Resumo de alguns estudos recentes sobre nuvem cirrus baseados em pelo menos alguns meses de observações por lidar em solo nos trópicos e latitudes médias. As primeiras colunas mostram o período de estudo e o comprimento de onda do laser (nm) para cada local, para o qual mais de um estudo pode estar disponível. As características dos cirrus são aquelas relatadas pelos diferentes autores, que podem incluir: altura base e topo $(\mathrm{km})$, espessura $(\mathrm{km})$, temperatura base e topo $\left({ }^{\circ} \mathrm{C}\right)$, frequência de ocorrência $(\%)$ e razão lidar $(\mathrm{sr})$.

\begin{tabular}{|c|c|c|c|c|c|c|c|c|c|c|c|c|}
\hline \multirow{3}{*}{$\begin{array}{l}\text { Measurement } \\
\text { site }\end{array}$} & \multirow{3}{*}{ Location } & \multirow{3}{*}{$\begin{array}{l}\text { Period of } \\
\text { study }\end{array}$} & \multirow{3}{*}{$\begin{array}{r}\text { Wavelength } \\
(\mathrm{nm})\end{array}$} & \multicolumn{8}{|c|}{ Average values } & \\
\hline & & & & \multicolumn{3}{|c|}{ Height (km) } & \multicolumn{2}{|c|}{ Temp. $\left({ }^{\circ} \mathrm{C}\right)$} & \multicolumn{2}{|c|}{ Frequency (\%) } & \multirow[t]{2}{*}{ LR (sr) } & \\
\hline & & & & Base & Top & Thick. & Base & Top & SVC & Thin & & \\
\hline $\begin{array}{l}\text { Salt Lake City, } \\
\text { Utah, USA }\end{array}$ & $\begin{array}{l}40.8^{\circ} \mathrm{N} \\
111.8^{\circ} \mathrm{W}\end{array}$ & $\begin{array}{l}1986 \text { to } \\
1996\end{array}$ & 694 & 8.8 & 11.2 & 1.8 & -34.4 & -53.9 & 50 & - & & Sassen and Campbell (2001) \\
\hline $\begin{array}{l}\text { Haute } \\
\text { Provence, } \\
\text { France }\end{array}$ & $\begin{array}{l}43.9^{\circ} \mathrm{N} \\
5.7^{\circ} \mathrm{E}\end{array}$ & $\begin{array}{l}1997 \text { to } \\
2007\end{array}$ & $532 / 1064$ & 9.3 & 10.7 & 1.4 & & & 38 & & 18.2 & $\begin{array}{l}\text { Goldfarb et al. (2001) } \\
\text { Hoareau et al. (2013) }\end{array}$ \\
\hline $\begin{array}{l}\text { Thessaloniki, } \\
\text { Greece }\end{array}$ & $\begin{array}{l}40.6^{\circ} \mathrm{N} \\
22.9^{\circ} \mathrm{E}\end{array}$ & $\begin{array}{l}2000 \text { to } \\
2006\end{array}$ & $355 / 532$ & 8.6 & 11.7 & 2.7 & -38 & -65 & & 57 & 30 & Giannakaki et al. (2007) \\
\hline $\begin{array}{l}\text { Seoul, } \\
\text { South Korea }\end{array}$ & $\begin{array}{l}37^{\circ} \mathrm{N} \\
127^{\circ} \mathrm{E}\end{array}$ & $\begin{array}{l}2006 \text { to } \\
2009\end{array}$ & $532 / 1064$ & 8.8 & 10.6 & & & & & & 20 & Kim et al. (2014) \\
\hline $\begin{array}{l}\text { Buenos Aires, } \\
\text { Argentina }\end{array}$ & $\begin{array}{l}34.6^{\circ} \mathrm{S} \\
58.5^{\circ} \mathrm{W}\end{array}$ & $\begin{array}{l}2001 \text { to } \\
2005\end{array}$ & 532 & 9.6 & 11.8 & 2.4 & & -64.5 & & & & Lakkis et al. (2009) \\
\hline Réunion & $\begin{array}{l}21^{\circ} \mathrm{S} \\
55^{\circ} \mathrm{E}\end{array}$ & $\begin{array}{l}1996 \text { to } \\
2001\end{array}$ & 532 & 11 & 14 & & & & 65 & & 18.3 & Cadet et al. (2003) \\
\hline $\begin{array}{l}\text { Camagüey, } \\
\text { Cuba }\end{array}$ & $\begin{array}{l}21.4^{\circ} \mathrm{N} \\
77.9^{\circ} \mathrm{W}\end{array}$ & $\begin{array}{l}1993 \text { to } \\
1998\end{array}$ & 532 & 11.6 & 13.8 & & & & 25 & & 10 & Antuña and Barja (2006) \\
\hline $\begin{array}{l}\text { Gadanki, } \\
\text { India }\end{array}$ & $\begin{array}{l}13.5^{\circ} \mathrm{N} \\
79.2^{\circ} \mathrm{E}\end{array}$ & $\begin{array}{l}1998 \text { to } \\
2013\end{array}$ & 532 & 13.0 & 15.3 & 2.3 & & -65 & 52 & 36 & 25 & Pandit et al. (2015) \\
\hline $\begin{array}{l}\text { Hulule, } \\
\text { Maldives }\end{array}$ & $\begin{array}{l}4.1^{\circ} \mathrm{N} \\
73.3^{\circ} \mathrm{E}\end{array}$ & $\begin{array}{l}1999 \\
2000\end{array}$ & 532 & 11.9 & 13.7 & 1.8 & -50 & -65 & 15 & 49 & 32 & Seifert et al. (2007) \\
\hline $\begin{array}{l}\text { Mahé, } \\
\text { Seychelles }\end{array}$ & $\begin{array}{l}4.4^{\circ} \mathrm{S} \\
55.3^{\circ} \mathrm{E}\end{array}$ & $\begin{array}{l}\text { Feb-Mar } \\
1999\end{array}$ & 532 & & & $0.2-2.0$ & & & & & 19 & Pace et al. (2003) \\
\hline Nauru & $\begin{array}{l}0.5^{\circ} \mathrm{S} \\
166.9^{\circ} \mathrm{E}\end{array}$ & $\begin{array}{l}\text { Apr-Nov } \\
1999\end{array}$ & 532 & $\sim 14$ & $\sim 16$ & & & & & & & Comstock et al. (2002) \\
\hline
\end{tabular}

\subsubsection{Algoritmo de detecção de nuvens Cirrus.}

Utilizamos o algoritmo automático desenvolvido por Gouveia (2014a), baseado na metodologia proposta por Barja e Aroche (2001), para a detecção da base, topo, e as alturas de máximo retroespalhamento das nuvens. O algoritmo é explicado em detalhes em Gouveia (2014b) e Barbosa et al. (2014) e discutido na seção 2.3.4, sendo aqui apenas descrito brevemente. Basicamente, ele assume uma intensidade monotonicamente decrescente do sinal do lidar com altitude em uma atmosfera limpa (sem nuvens) e procura por mudanças abruptas no sinal que tenham significância estatística. As mudanças abruptas são marcadas como possíveis bases de nuvens. Examinando o ruído do sinal, cada base de nuvem verdadeira é discriminada (consideramos falso positivo mudanças no sinal dentro de um intervalo de 3 std do valor médio). O topo da nuvem é determinado observando-se em que altitude o sinal retorna ao valor que tinha na base, com inclinação compatível com o sinal típico da atmosfera limpa. Quando mais de uma camada de nuvem está presente no mesmo 
perfil e as camadas são separadas por mais de $500 \mathrm{~m}$ de atmosfera limpa, elas são consideradas como nuvens individuais no mesmo perfil vertical. Barbosa et al. (2014) também fornecem informações sobre a discriminação de falsos positivos e a distinção entre aerossóis e camadas de nuvens finas. Depois de obter as alturas da base, topo e de máximo retroespalhamento, as temperaturas correspondentes a esses níveis da nuvem são obtidas a partir da radiossondagem mais próxima. Uma nuvem alta detectada é classificada como sendo uma nuvem cirrus se a temperatura do topo da nuvem for menor que $-37^{\circ} \mathrm{C}$ (SASSEN; COMSTOCK, 2001; CAMPBELL et al., 2015), garantindo que a nuvem é formada por cristais de gelo. Essas temperaturas são tipicamente encontradas a cerca de 10,5 km de altitude sobre a Amazônia.

\subsubsection{Frequência de Ocorrência e Problemas de Amostragem}

De forma simplificada, a frequência de ocorrência seria apenas a razão entre o número de perfis com nuvens cirrus e o número total de perfis. No entanto, embora se possa ter certeza de quando uma nuvem cirrus foi detectada em um determinado perfil, não há certeza de sua presença quando o perfil tem uma baixa razão sinal/ruído ou quando não há medição disponível. A amostragem de nuvens cirrus com um instrumento de perfilamento a partir do solo pode ser problemática, particularmente para o cálculo da frequência temporal de ocorrência, devido ao obscurecimento por nuvens mais baixas ou pela (in)disponibilidade de medidas, que podem introduzir vieses de amostragem (THORSEN et al., 2011).

Para evitar esses vieses, utilizamos uma abordagem semelhante à amostragem condicional proposta por Thorsen et al. (2011) e Protat et al. (2014). Primeiro, reconhecemos que a presença de nuvens cirrus é independente da presença de nuvens de água líquida que ocorrem em níveis mais baixos e que podem atenuar totalmente o feixe de laser, restringindo o tempo de medição. Assim, a melhor estimativa da verdadeira frequência de ocorrência das nuvens cirrus é a razão entre o número de perfis com cirrus e o número de perfis em que as nuvens cirrus poderiam ter sido detectadas, excluindo-se os perfis em que o sinal foi bloqueado por nuvens baixas ou em que a razão sinal-ruído, independente do motivo, seja baixa.

Esses perfis são identificados da seguinte maneira. O ruído em cada bin do sinal referente a medida de retroespalhamento do céu claro segue uma distribuição de Poisson e é avaliado como a raiz quadrada do sinal. A relação sinal/ruído (S/N) é definida como a intensidade do sinal dividido pelo ruído, semelhante a Heese et al. (2010). Os perfis são selecionados se um $\mathrm{S} / \mathrm{N}$ de céu claro com valor maior que 1,0 for encontrado a $16 \mathrm{~km}$, para uma resolução vertical de 7,5 m. Note que este não é o 
$\mathrm{S} / \mathrm{N}$ da nuvem cirrus, que seria o (sinal dentro do cirrus - sinal molecular) / ruído e que normalmente varia de 6 a 36. Este limiar foi obtido a partir de uma avaliação de desempenho do algoritmo de detecção (seção 2.3.4). Usando simulações, variamos a espessura da nuvem (15 m a 4,5 km), o coeficiente de retroespalhamento da nuvem (1 a $10 \mathrm{Mm}^{-1} \mathrm{sr}^{-1}$ ) e o $\mathrm{S} / \mathrm{N}(1$ a 50 ). Verificamos que nosso algoritmo detecta $99 \%$ das nuvens cirrus com COD >0,005. Em outras palavras, dadas as profundidades ópticas típicas das nuvens cirrus, o limiar usado implica em um S/R alta o suficiente para possibilitar a identificação do topo verdadeiro da nuvem cirrus e também para aplicar o método de transmissão para o cálculo da profundidade óptica desta nuvem.

A partir da análise dos perfis disponíveis, 16.025 satisfizeram esses critérios (ver tabela 3.2). Julho, agosto e setembro, os meses mais secos, mostram a maior fração de perfis com boa $\mathrm{S} / \mathrm{R}$, enquanto os meses mais úmidos têm a menor fração dos perfis do lidar com boa S/R. Para evitar a introdução de vieses dos diferentes tamanhos de amostra em meses diferentes, a frequência de ocorrência para o ano é calculada como a frequência média de ocorrência para cada estação. A frequência de cada estação, por sua vez, é calculada a partir da frequência de cada mês. Finalmente, a frequência para cada mês é calculada pela média dos ciclos diurnos médios (ou seja, média das médias horárias), feito assim porque há mais perfis com boa $\mathrm{S} / \mathrm{R}$ durante a noite em comparação com o dia.

\subsubsection{Profundidade óptica, coeficiente de retroespalhamento e razão li- dar das nuvens cirrus}

A profundidade óptica das nuvens cirrus, $\tau^{\text {cirrus }}$, podem ser obtidas utilizado-se o método da transmitância (YOUNG, 1995), Comparando-se a intensidade do sinal na base e no topo da nuvem cirrus, é possível calcular quase diretamente a atenuação que o feixe do laser sofreu ao atravessar as camadas de nuvens cirrus (como descrito na seção 2.2). A precisão deste cálculo depende principalmente da $\mathrm{S} / \mathrm{R}$ na altitude da nuvem cirrus. No entanto, quando o sinal do lidar é completamente atenuado pela nuvem cirrus (isto é, o fator de transmissão se aproxima de zero), é impossível obter os valores reais da altitude do topo e da profundidade óptica do cirrus. As altitudes e profundidades ópticas, nesses casos chamadas de aparentes, são necessariamente subestimadas e não foram incluídas em nossa análise (ver Tabela 3.2). Os coeficientes de retroespalhamento das nuvens cirrus foram determinados pelo método de Fernald-Klett-Sasano (FERNALD, 1984; KLETT, 1985; SASANO; NAKANE, 1984) (ver seção 2.2)) para cada perfil vertical de 5 minutos com nuvem e satisfazendo as condições discutidas na seção anterior $(\mathrm{S} / \mathrm{N}>1 \mathrm{em} 16 \mathrm{~km})$. Para recuperar o perfil do 
Tabela 3.2 - Resumo das estatísticas integradas na colunas para o tempo total de observação, bem como para as estações chuvosa, de transição e seca. A frequência de ocorrência é calculada usando uma amostragem condicional para evitar vieses (seção 3.1.3). As propriedades médias das nuvens cirrus e o desvio padrão da amostra (entre parênteses) são mostrados. Os desvios padrão da média foram calculados e utilizados para determinar se as diferenças sazonais (chuvo-seco) dos valores médios são estatisticamente significativas para o nível de confiança de $95 \%$ (indicado como *) usando um teste t de 2 amostras. Propriedades geométricas não são fornecidas porque a maioria dos perfis de nuvem possui mais de uma camada de cirrus. A razão lidar é calculada como uma média da coluna.

\begin{tabular}{|c|c|c|c|c|}
\hline & Total & Wet & Transition & Dry \\
\hline Observation time $(\%)^{\mathrm{a}}$ & 37.4 & 41.5 & 21.9 & 48.9 \\
\hline No. prof. measured ${ }^{b}$ & 36844 & 13828 & 7423 & 15593 \\
\hline No. prof. used in analysis ${ }^{c}$ & 16025 & 3458 & 2099 & 10468 \\
\hline No. prof. discarded for apparent top ${ }^{d}$ & 476 & 223 & 148 & 105 \\
\hline Frequency of occurrence $(\%)^{*}$ & 73.8 & 88.1 & 74.2 & 59.2 \\
\hline No. prof. w/cirrus & 11252 & 3145 & 1706 & 6397 \\
\hline Frequency of occurrence, opaque $(\%)^{*}$ & 22.6 & 31.3 & 24.6 & 11.8 \\
\hline No. prof. w/cirrus, Opaque & 3327 & 1316 & 610 & 1401 \\
\hline Frequency of occurrence, thin $(\%)^{*}$ & 32.8 & 37.9 & 36.5 & 23.9 \\
\hline No. prof. w/cirrus, thin & 4577 & 1224 & 798 & 2555 \\
\hline Frequency of occurrence, SVC $(\%)^{*}$ & 18.3 & 18.7 & 13.0 & 23.3 \\
\hline No. prof. w/cirrus, SVC & 3322 & 603 & 296 & 2423 \\
\hline Cloud optical depth* & $0.35(0.55)$ & $0.47(0.65)$ & $0.40(0.57)$ & $0.25(0.45)$ \\
\hline Max. backscatter altitude $(\mathrm{km})^{*}$ & $13.4(2.0)$ & $13.4(2.2)$ & $13.3(2.2)$ & $13.6(1.7)$ \\
\hline Temperature max. back. alt. $\left({ }^{\circ} \mathrm{C}\right)^{*}$ & $-60(15)$ & $-60(16)$ & $-59(17)$ & $-62(13)$ \\
\hline Lidar ratio $(\mathrm{sr})^{* \mathrm{e}}$ & $23.6(8.1)$ & $22.8(8.0)$ & $22.8(7.8)$ & $24.6(7.7)$ \\
\hline No. of cirrus layers per cloud prof. & $1.41(0.63)$ & $1.62(0.77)$ & $1.61(0.67)$ & $1.25(0.48)$ \\
\hline
\end{tabular}

${ }^{a}$ Fraction of observation time to total possible time $\left(21 \mathrm{~h} \mathrm{day}^{-1}\right) .{ }^{\mathrm{b}}$ Total number of profiles measured - i.e., not screened for low clouds or precipitation. ${ }^{\mathrm{c}}$ Refers to the number of 5 min profiles with high enough SNR (Sect. 2.4). ${ }^{\mathrm{d}}$ Number of profiles with apparent cirrus top, considering only good profiles. ${ }^{\mathrm{e}}$ All layers in the same profile share the same average lidar ratio (LR).

coeficiente de extinção da nuvem cirrus, o método de Klett requer um valor predeterminado para a razão lidar (LR) média da camada, que é a razão entre os coeficientes de extinção e de retroespalhamento. Em seguida, integrando o coeficiente de extinção da base ao topo da nuvem, também é possível obter a profundidade óptica da nuvem de cirros $\left(\tau_{\text {Klett }}^{\text {cirrus }}\right)$, que dependerá da LR utilizada inicialmente. Seguindo o proposto por Chen et al. (2002), estimamos o valor de LR para cada perfil de nuvem iterando sobre uma faixa de valores de LR e comparando os valores de $\tau_{\text {Klett }}^{\text {cirus }}$ com o valor independente da profundidade óptica da nuvem cirrus obtida a partir do método de transmitância descrito acima $\left(\tau^{\text {cirrus }}\right)$. A razão lidar média da nuvem cirrus é a única que minimiza o resíduo: $Q(L R)=\left(\tau_{\text {Klett }}^{\text {cirrus }}-\tau^{\text {cirrus }}\right)^{2}$. Nós optamos 
por usar a abordagem de Chen et al. (2002) em vez do método Raman (ANSMANN et al., 1992) porque nosso instrumento só pode detectar o retroespalhamento Raman durante a noite, já que o espalhamento Raman é muito fraco comparado ao espalhamento elástico. Além disso, os resultados do método Raman são muito ruidosos mesmo durante a noite e, para a configuração de nosso estudo (análise 24/7 dos perfis de $5 \mathrm{~min}$ ), uma estimativa mais precisa da razão lidar média da camada das nuvens cirrus pode ser obtida com o método de Chen et al. (2002).

O método de Klett assume um único espalhamento, mas eventualmente os fótons detectados pelo lidar podem ter sido espalhados várias vezes por outras partículas antes de chegar ao telescópio. Esse efeito, denominado espalhamento múltiplo, aumenta a transmitância aparente do laser e diminui os valores correspondentes do coeficiente de extinção. A inversão de sinais não corrigidos poderia influenciar a medida do coeficiente de extinção e, consequentemente, da profundidade óptica (COD) e razão lidar (LR), gerando erros tipicamente de 5 a $30 \%$ (THORSEN; FU, 2015). Isto é particularmente importante nos comprimentos de onda UV, para os quais ocorre um espalhamento frontal muito mais forte e, portanto, maiores quantidades de espalhamento múltiplo em comparação com os comprimentos de onda visível ou infravermelho. Por essa razão, nos abstivemos de aplicar fórmulas de correção empíricas (por exemplo, como a eq. 10 em Chen et al. (2002)) e, em vez disso, realizamos um tratamento completo de espalhamento múltiplo seguindo o modelo de Hogan (2008). A correção é encontrada de forma iterativa, semelhante a Seifert et al. (2007) e Kienast-Sjögren et al. (2016), como descrito na seção 2.3.3. O modelo de espalhamento múltiplo é inicializado com o perfil de extinção não corrigido e a saída do modelo é usada para corrigir o perfil de extinção, iterativamente, até convergir. No nosso caso, assumimos que o raio efetivo dos cristais de gelo das nuvens cirrus variam com a temperatura de acordo com uma climatologia feita a partir das medições in-situ com dados de cirrus tropicais (KRÄMER et al., 2016), que inclui a recente campanha de campo do projeto ACRIDICON com a aeronave alemã HALO na região amazônica (WENDISCH et al., 2016). O tratamento completo corrige a LR recuperada em cerca de $40 \%$, de $16.8 \pm 5.8 \mathrm{sr}$ (não corrigido) para $23.6 \pm 8.2 \mathrm{sr}$, enquanto a abordagem de Chen só iria corrigi-lo para o valor de $20.2 \pm 7.0 \mathrm{sr}$. Nas seções seguintes, todas as propriedades ópticas das nuvens cirrus (razão lidar, coeficiente de extinção e profundidade óptica) derivadas neste trabalho foram corrigidas para espalhamento múltiplo. 


\subsection{Resultados e discussão}

\subsubsection{Frequência da ocorrência de nuvens cirrus.}

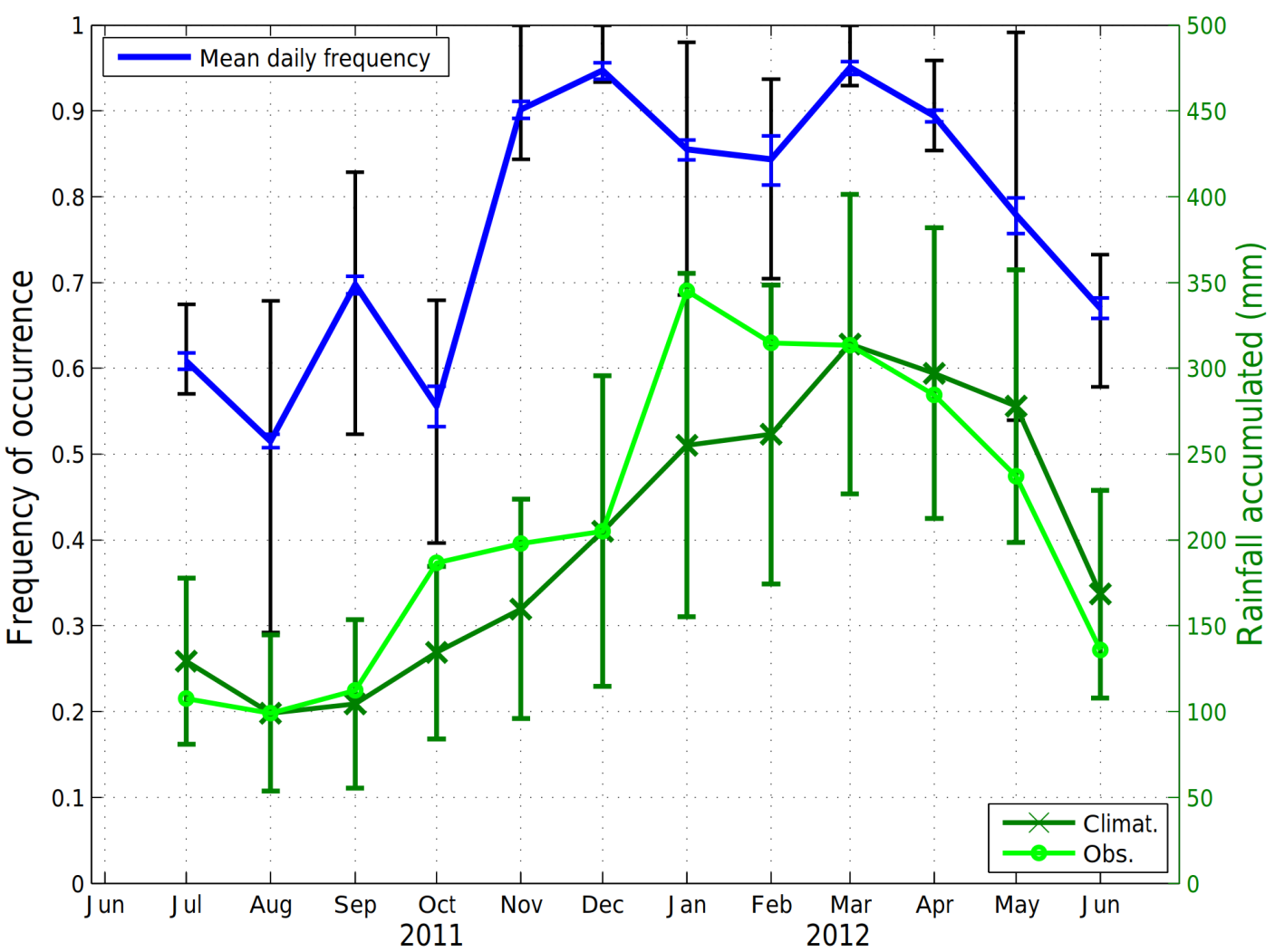

Figura 3.1 - Frequência mensal de ocorrência de nuvens cirrus de julho de 2011 a junho de 2012 (linha azul) com o erro estatístico associado (preto). As precipitações acumulada (verde claro) e climatológica (verde escuro), mostradas no eixo à direita, foram obtidas do conjunto de dados TRMM 3 B42 versão 7 , em uma área de $10^{\circ} \times 10^{\circ}$.

Um total de 11.252 perfis de lidar foram registrados com a presença de nuvens cirrus, resultando em uma frequência de ocorrência temporal média de nuvens cirrus de 73,8 $\%$ de julho de 2011 a junho de 2012. A Figura 3.1 mostra a frequência de ocorrência mensal de nuvens cirrus e o erro estatístico associado. Há um ciclo sazonal bem definido, que segue o da precipitação (ver mesmo gráfico), com valores máximos de novembro a abril, chegando a 88,1 \% durante a estação chuvosa, e um valor mínimo em agosto na estação seca (59,2 \%), mas com frequências não inferiores a 50 \% (ver Tabela 3.2). Além disso, a frequência média mensal da nuvem cirrus segue o mesmo ciclo sazonal da precipitação acumulada, que responde às mudanças sazonais da 
ZCIT, sendo maior de janeiro a abril, e menor de junho a setembro (MACHADO, 2002; MACHADO et al., 2014). As frequências médias das nuvens cirrus durante os meses chuvosos são maiores (com significância estatística) do que nos meses secos (observe o pequeno desvio padrão da média apesar da alta variabilidade). Esse resultado e a falta, na região, de outros possíveis mecanismos de formação propostos na literatura (SASSEN et al., 2002) sugerem que a convecção profunda é o principal mecanismo de formação das nuvens cirrus na Amazônia central. Nuvens convectivas profundas geram nuvens cirrus quando os ventos na troposfera superior removem os cristais de gelo do topo da grande coluna convectiva, gerando nuvens de bigorna (tradução livre de Anvil Cloud). Nuvens de bigorna permanecem mesmo depois que a nuvem convectiva profunda se dissipa e pode persistir de 0,5 a 3,0 dias (SEIFERT et al., 2007).
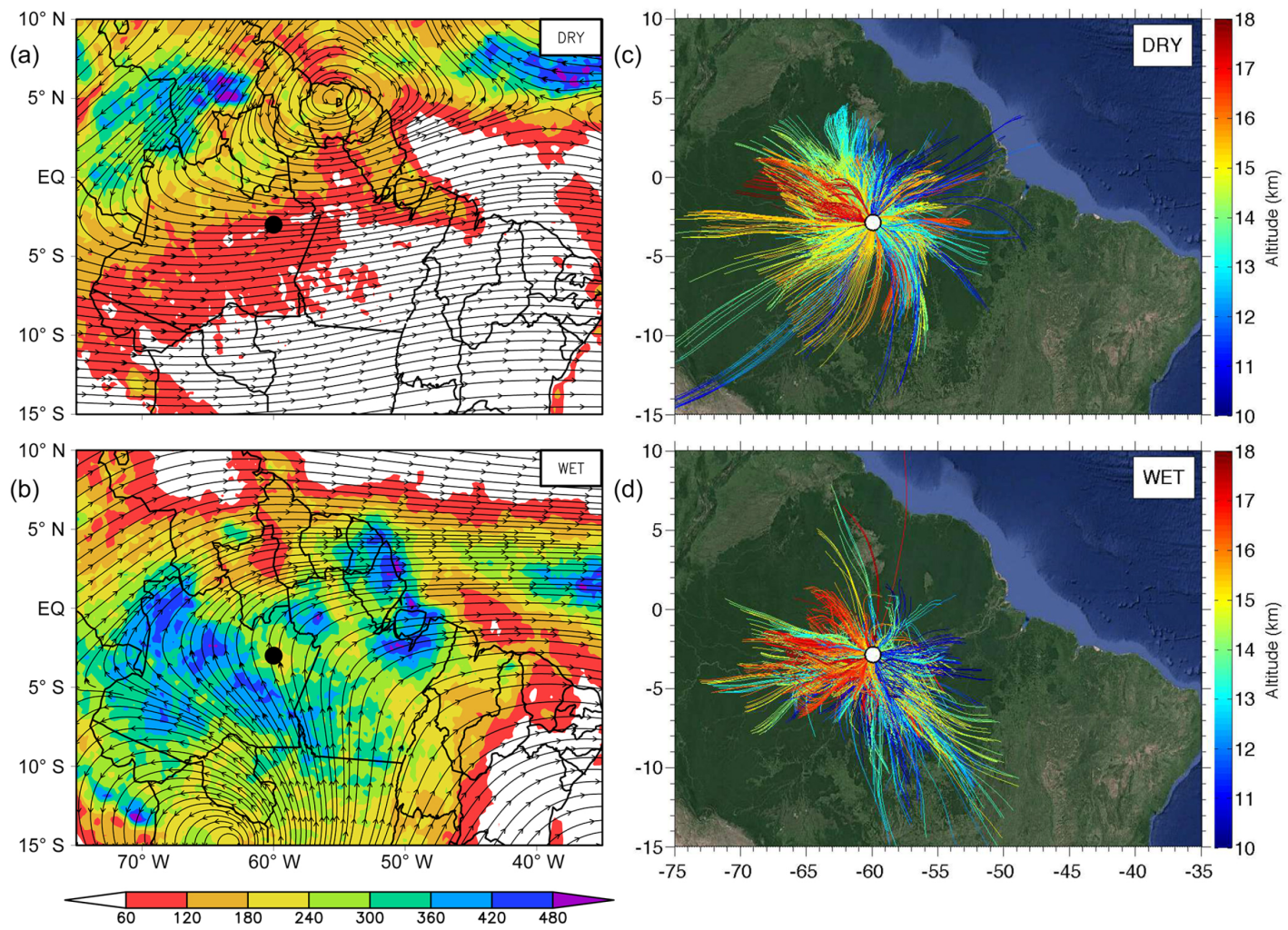

Figura 3.2 - Painéis à esquerda mostram precipitação média (cores, mm/mês) do TRMM 3B42 versão 7 e campo de vento médio (vetores, $\mathrm{m} / \mathrm{s})$ a $150 \mathrm{hPa}(\approx 14,3 \mathrm{~km})$ da reanálise do ECMWF ERA Interim. Painéis à direita mostram trajetórias de massa de ar de $24 \mathrm{~h}$ que chegam ao local no momento e altitude que as camadas de cirrus foram detectadas. Os resultados são mostrados separadamente para os meses seco (JJAS, superior) e chuvoso (JFMA, inferior). As retro-trajetórias foram calculadas usando o modelo HYSPLIT com ventos de resolução de $0,5^{\circ}$ do GDAS/NOAA. A localização do site experimental é indicada em todos os painéis com um círculo. 
Tabela 3.3 - Resumo das estatísticas das camadas para o tempo total de observação, bem como para as estações chuvosa, de transição e seca. As propriedades médias da nuvem cirrus e o desvio padrão da amostra (entre parênteses) são mostrados. Os desvios padrão da média foram calculados e utilizados para determinar se as diferenças sazonais (chovoso-seco) são estatisticamente significativas para o nível de confiança de $95 \%$ (indicado como *) usando um teste t de 2 amostras. A razão lidar é calculada como uma média da coluna.

\begin{tabular}{|c|c|c|c|c|}
\hline & Total & Wet & Transition & Dry \\
\hline \multicolumn{5}{|l|}{ All layers } \\
\hline No. of cirrus layers & 15824 & 5096 & 2739 & 7989 \\
\hline Base altitude $(\mathrm{km})^{*}$ & $12.9(2.2)$ & $12.8(2.4)$ & $12.6(2.3)$ & $13.0(1.9)$ \\
\hline Top altitude (km) & $14.3(1.9)$ & $14.3(2.0)$ & $14.1(2.0)$ & $14.3(1.6)$ \\
\hline Thickness $(\mathrm{km})^{*}$ & $1.4(1.1)$ & $1.5(1.2)$ & $1.5(1.1)$ & $1.3(1.0)$ \\
\hline Cloud optical depth* & $0.25(0.46)$ & $0.30(0.52)$ & $0.26(0.47)$ & $0.20(0.40)$ \\
\hline Max. backscatter altitude $(\mathrm{km})$ & $13.6(2.0)$ & $13.7(2.3)$ & $13.5(2.2)$ & $13.6(1.8)$ \\
\hline Lidar ratio $(\mathrm{sr})^{*}$ & $23.3(8.0)$ & $22.6(8.1)$ & $22.8(7.9)$ & $24.4(7.9)$ \\
\hline Relative freq. opaque cirrus (\%)* & 20.5 & 25.2 & 21.0 & 17.4 \\
\hline Relative freq. thin cirrus (\%) & 37.8 & 37.0 & 43.2 & 36.5 \\
\hline Relative freq. SVC $(\%)^{*}$ & 41.6 & 37.8 & 35.8 & 46.0 \\
\hline Base above the tropopause $(\%)^{*}$ & 5.9 & 6.9 & 5.5 & 5.3 \\
\hline Top above the tropopause $(\%)^{*}$ & 15.7 & 18.7 & 16.1 & 12.9 \\
\hline \multicolumn{5}{|l|}{ Opaque layers } \\
\hline No. of opaque layers & 3251 & 1283 & 574 & 1394 \\
\hline Base altitude $(\mathrm{km})^{*}$ & $10.7(1.5)$ & $10.6(1.6)$ & $10.4(1.5)$ & $10.8(1.2)$ \\
\hline Top altitude (km) & $13.4(1.6)$ & $13.5(1.7)$ & $13.1(1.6)$ & $13.6(1.4)$ \\
\hline Thickness $(\mathrm{km})^{*}$ & $2.76(1.02)$ & $2.84(1.07)$ & $2.65(1.04)$ & $2.73(0.94)$ \\
\hline Cloud optical depth* & $0.93(0.64)$ & $1.00(0.66)$ & $0.90(0.66)$ & $0.86(0.59)$ \\
\hline Max. backscatter altitude (km) & $12.0(1.7)$ & $12.1(1.9)$ & $11.6(1.7)$ & $12.1(1.5)$ \\
\hline Lidar ratio $(\mathrm{sr})^{*}$ & $25.7(6.3)$ & $26.0(6.7)$ & $25.8(6.6)$ & $25.3(5.7)$ \\
\hline \multicolumn{5}{|l|}{ Thin layers } \\
\hline No. of thin layers & 5985 & 1888 & 1183 & 2914 \\
\hline Base altitude $(\mathrm{km})^{*}$ & $12.9(1.7)$ & $13.1(1.9)$ & $12.9(1.8)$ & $12.8(1.4)$ \\
\hline Top altitude $(\mathrm{km})^{*}$ & $14.4(1.7)$ & $14.6(2.0)$ & $14.4(1.8)$ & $14.3(1.4)$ \\
\hline Thickness $(\mathrm{km})^{*}$ & $1.46(0.78)$ & $1.42(0.82)$ & $1.49(0.78)$ & $1.47(0.74)$ \\
\hline Cloud optical depth & $0.12(0.07)$ & $0.12(0.07)$ & $0.12(0.07)$ & $0.11(0.07)$ \\
\hline Max. backscatter altitude $(\mathrm{km})^{*}$ & $13.7(1.7)$ & $13.9(1.9)$ & $13.7(1.9)$ & $13.5(1.5)$ \\
\hline Lidar ratio $(\mathrm{sr})^{*}$ & $22.8(7.9)$ & $21.8(7.7)$ & $21.6(7.4)$ & $24.3(8.1)$ \\
\hline \multicolumn{5}{|l|}{ SVC layers } \\
\hline No. of SVC layers & 6581 & 1924 & 980 & 3677 \\
\hline Base altitude $(\mathrm{km})^{*}$ & $14.4(1.9)$ & $14.7(2.1)$ & $14.4(2.1)$ & $14.2(1.6)$ \\
\hline Top altitude $(\mathrm{km})^{*}$ & $14.9(1.9)$ & $15.2(2.1)$ & $15.0(2.1)$ & $14.7(1.6)$ \\
\hline Thickness (km) & $0.51(0.37)$ & $0.50(0.38)$ & $0.53(0.38)$ & $0.51(0.36)$ \\
\hline Cloud optical depth & $0.011(0.008)$ & $0.011(0.008)$ & $0.012(0.009)$ & $0.011(0.008)$ \\
\hline Max. backscatter altitude $(\mathrm{km})^{*}$ & $14.6(1.9)$ & $14.9(2.1)$ & $14.7(2.1)$ & $14.4(1.6)$ \\
\hline Lidar ratio $(\mathrm{sr})^{*}$ & $21.6(8.4)$ & $19.9(7.6)$ & $21.5(8.1)$ & $23.5(9.0)$ \\
\hline
\end{tabular}


Para investigar ainda mais o papel da convecção profunda como principal mecanismo de formação local, estudamos a circulação de altos níveis e a distribuição espacial da precipitação. O campo de vento médio em $150 \mathrm{hPa}$, aproximadamente a altitude média do topo das nuvens cirrus (14,3 km, ver Tabela 3.3), e a precipitação acumulada são mostrados na Figura 3.2. O período do estudo foi dividido em período chuvoso (janeiro, fevereiro, março e abril), seco (junho, julho, agosto e setembro) e transição (maio, outubro, novembro e dezembro), com base na precipitação acumulada. Durante os meses chuvosos, a monção sul-americana é prevalente, e a quantidade de chuva associada varia de 8 a $14 \mathrm{~mm} \mathrm{dia}^{-1}$, com totais mensais de cerca de $300 \mathrm{~mm}$. Ventos em $150 \mathrm{hPa}$ sopram de Sul-Sudeste a cerca de $6 \mathrm{~m} \mathrm{~s}^{-1}$. Durante o período seco, a atividade convectiva desloca-se para o norte em direção à Colômbia e Venezuela e o escoamento em $150 \mathrm{hPa}$ é de oeste, também a cerca de $6 \mathrm{~m} \mathrm{~s}^{-1}$, permitindo que as nuvens cirrus sejam transportadas por $520 \mathrm{~km}$ ou $4,5^{\circ}$ por dia. Como estudos anteriores relataram que os cirrus tropicais poderiam ser transportados por milhares de quilômetros (FORTUIN et al., 2007), foram calculadas retro trajetórias de 24 horas para investigar a possível origem das nuvens observadas. Estas trajetórias são mostrados nos painéis à direita da figura 3.2. Uma trajetória foi calculada para cada camada de cirrus detectada, com a altura de chegada ajustada para a altura do topo da camada da nuvem cirrus. A maioria das trajetórias são direcionadas para as regiões de máxima precipitação acumulada (painel esquerdo), que estão muito mais próximas do local durante a estação chuvosa $\left(\approx 5^{\circ}\right)$ do que seca $\left(\approx 10^{\circ}\right)$. Isto dá mais evidências de que as nuvens cirrus observadas na Amazônia central são provavelmente resultado da grande atividade convectiva da região, sendo formadas diretamente da bigorna remanescente da torre convectiva ou formada insitu (KRÄMER et al., 2016) pela grande quantidade de vapor de água transportada para os altos níveis pela convecção profunda.

As retro trajetórias revelam ainda que a circulação em grandes altitudes é bastante variável. De fato, muitas trajetórias não seguem o padrão de vento médio e parecem apontar na direção oposta à precipitação, particularmente durante a estação seca. Deve-se notar, no entanto, que a Amazônia central ainda recebe cerca de $100 \mathrm{~mm}$ por mês de precipitação na estação seca (cores avermelhadas ao redor do sítio experimental, Figura 3.2) e a maior parte vem de sistemas convectivos de mesoescala (MACHADO et al., 2004; BURLEYSON et al., 2016). Assim, durante a estação seca, há uma mistura de cirrus transportados de longas distâncias e produzidos localmente, em contraste com a estação chuvosa quando há sempre ocorrência de convecção profunda nas proximidades. 

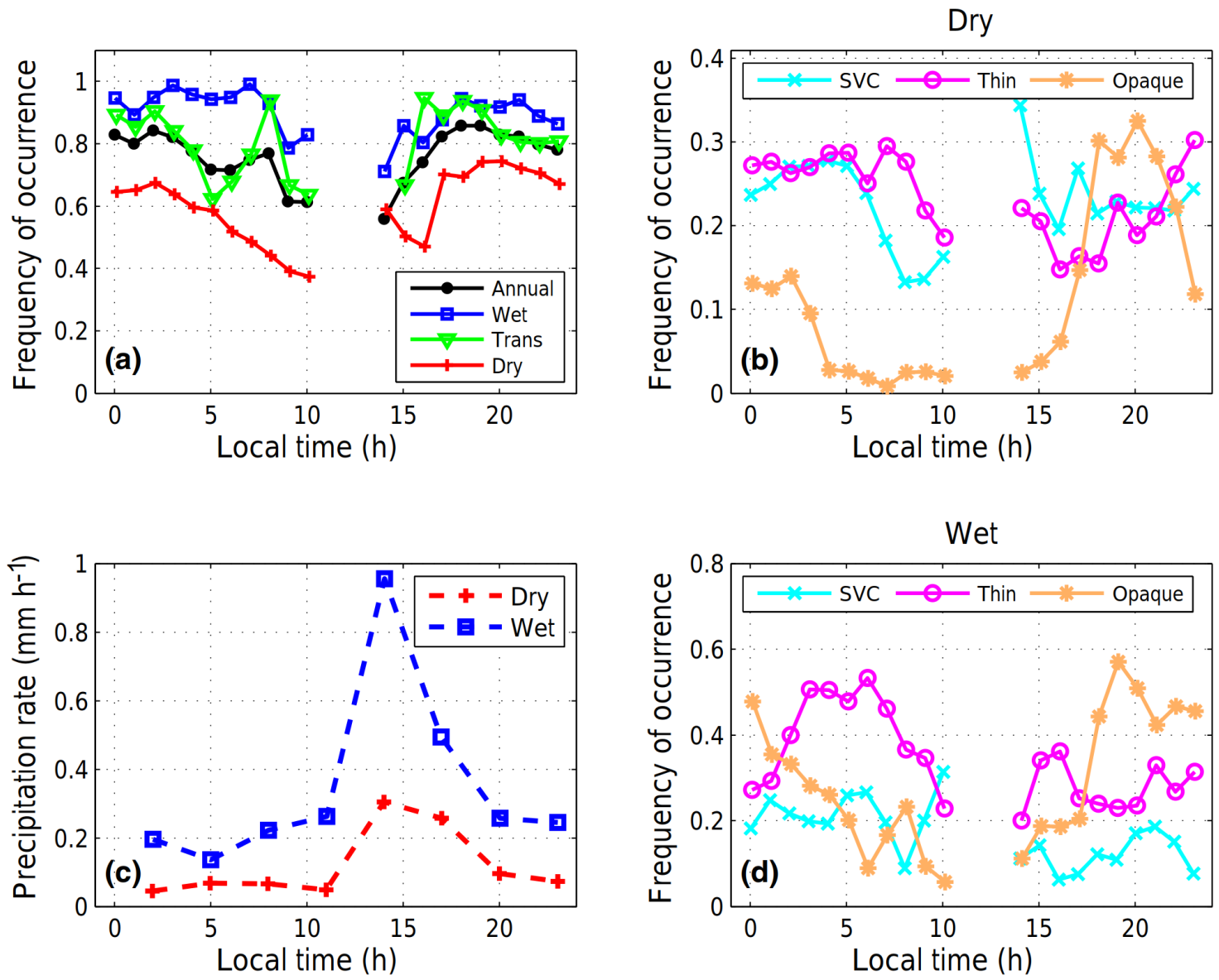

Figura 3.3 - O painel (a) mostra os ciclos diários da frequência horária de ocorrência de nuvens cirrus para os períodos anual, chuvoso, de transição e seco. O mesmo é mostrado para SVC, nuvens cirrus finas e opacas durante as estações seca (b) e chuvosa (d). A taxa de precipitação observada média $(\mathrm{mm} / \mathrm{h})$ da versão 7 do TRMM sobre uma área de $2^{\circ} \times 2^{\circ}$ centrada no sítio experimental, para os períodos seco e chuvoso, é dada no painel (c).

O ciclo diurno da frequência das nuvens cirrus, mostrado na figura 3.3, também tem uma relação próxima com o ciclo convectivo. A frequência de ocorrência, para o período total de observação ou em qualquer estação, exibe um mínimo entre 10 e 14h, hora local (LT). Os valores máximos são encontrados entre 17h e 18h LT, no final da tarde, quando os valores são ligeiramente superiores àqueles do período matutino. Essa variação diurna segue o ciclo diurno da convecção documentado na literatura (MACHADO, 2002; SILVA et al., 2011; ADAMS et al., 2013), como também mostrado na figura 3.3, onde está indicado o ciclo diurno médio de precipitação na área de $2^{\circ} \times 2^{\circ}$ centrada no sítio experimental. A precipitação máxima ocorre entre $13 \mathrm{~h}$ e $18 \mathrm{~h}$ LT, durante as estações seca e chuvosa, o que coincide com o aumento na frequência de cirrus. Na figura 3.3, uma menor amplitude na frequência do cirrus durante a estação chuvosa em relação aos meses da estação seca é vista. Isso pode 
ser explicado analisando-se as taxas máximas de precipitação e a circulação de altos níveis (veja a figura 3.2). Quando a frequência de convecção profunda é maior (3 vezes mais na estação úmida) e mais próxima do local $\left(\approx 5^{\circ}\right.$ na chuvosa e $\approx 10^{\circ}$ na seca), as nuvens cirrus, que tem tempo de vida longo, presumivelmente ficam mais uniformemente distribuído durante o dia.

Para verificar se a menor cobertura de nuvens cirrus observada por volta do meio-dia não estava relacionada a uma diminuição na razão sinal-ruído (S/R) das medidas e, portanto, a uma diminuição na eficiência de detecção, analisamos a frequência de ocorrência de diferentes tipos de nuvens cirrus, seguindo Sassen e Cho (1992), classificando-as em nuvens cirrus opacas (COD >0,3), finas $(0,3>\mathrm{COD}>0,03)$ e sub-visuais ( SVC, COD $<0,03$ ). Sua variação diurna também é mostrada na figura 3.3. A frequência de ocorrência de nuvens cirrus opacas têm a maior amplitude, tanto na estação seca quanto na chuvosa. Durante a estação seca (chuvosa), a frequência aumenta de menos de $5 \%$ (20\%) para cerca de $30 \%$ (50\%) nas horas seguintes ao máximo de precipitação, de $15 \mathrm{~h}$ à $19 \mathrm{~h}$ LT. A segunda maior variação diurna corresponde à frequência de ocorrência de nuvens cirrus finas, que diminuem após o nascer do sol de $30 \%$ (50 \%) para $20 \%$ (30 \%) durante a estação seca (chuvosa), e aumentam novamente durante a noite, quando nuvens cirrus opacas estão se dissipando. Os SVC, cuja detecção pode ser influenciada por um S/R mais baixo, não mostra um claro ciclo diurno. Assim, o ciclo diurno da frequência de ocorrência de nuvens cirrus na Amazônia central é provavelmente um resultado dos ciclos diurnos dos cirrus opacos e finos, que têm um COD suficientemente alto para não serem negligenciados pelo algoritmo de detecção.

\subsubsection{Propriedades geométricas, ópticas e microfísicas de nuvens cirrus}

A Tabela 3.2 mostra as estatísticas de coluna integrada das propriedades das nuvens, isto é, propriedades que representam a média da coluna vertical da atmosfera para cada perfil medido. A profundidade óptica integrada na coluna, isto é, a soma do COD de todas as camadas de nuvens cirrus no perfil vertical, varia de 0,25 $\pm 0,45$ na estação seca até $0,47 \pm 0,65$ na estação chuvosa. A frequência de ocorrência de perfis verticais com COD integrada que se caracteriza como opaca, fina e SVC é de $11,8 \%$ (31,3\%), 23,9\% (37,9\%) e 23,3\% (18,3\%) na estação seca (chuvosa), respectivamente. A altitude de máximo retroespalhamento não mostra um ciclo sazonal e é, em média, $13,4 \pm 2,0 \mathrm{~km}$ ( ou $-60 \pm 15{ }^{\circ} \mathrm{C}$ ). O número médio de camadas individuais simultâneas em cada perfil nublado é 1,4 (1,25 durante a seca e 1,62 durante a estação chuvosa) e, portanto, as propriedades geométricas, no sentido 
de uma coluna integrada, não são discutidas.

Como as nuvens cirrus em diferentes altitudes pode ter diferentes origens ou propriedades microfísicas, é mais importante analisar as estatísticas baseadas em cada camada detectada, como mostrado na Tabela 3.3. O valor médio para a altitude da base das camadas de nuvens é 12,9 $\pm 2,2 \mathrm{~km}$, para a altitude do topo, 14,3 \pm $1,9 \mathrm{~km}$, e para a espessura geométrica, 1,4 $\pm 1,1 \mathrm{~km}$. $\mathrm{O}$ valor médio da altitude de máximo retroespalhamento é de $13,6 \pm 2,0 \mathrm{~km}$. As diferenças entre os valores médios das propriedades geométricas nas estações seca e chuvosa não são estatisticamente significantes, exceto para a espessura, que varia de $1,3 \mathrm{~km}$ para $1,5 \mathrm{~km}$, respectivamente. Esses valores são semelhantes aos relatados por Seifert et al. (2007) para as Maldivas (4,1 $\left.{ }^{\circ} \mathrm{N}, 73,3^{\circ} \mathrm{E}\right): 11,9 \pm 1,6 \mathrm{~km}$ (base), $13,7 \pm 1,4 \mathrm{~km}$ (topo), $1,8 \pm 1,0 \mathrm{~km}$ (espessura), 12,8 $\pm 1,4 \mathrm{~km}$ (máx. retroespalhamento) e $-58 \pm 11{ }^{\circ} \mathrm{C}$ (temperatura no máximo de retroespalhamento). Publicações de regiões subtropicais também mostram valores semelhantes. Cadet (2003) reporta para Ilha da Reunião $\left(21^{\circ} \mathrm{S}, 55^{\circ} \mathrm{E}\right)$ nuvens cirrus com altitude da base e do topo de $11 \mathrm{~km}$ e $14 \mathrm{~km}$, respectivamente. Barja e Antuna-Marrero (2006) relatam em um sítio experimental subtropical (Camagüey, Cuba, $21.4^{\circ} \mathrm{N}, 77.9^{\circ} \mathrm{W}$ ) a altitude da base e do topo das nuvens cirrus como sendo 11,63 km e 13,77 km, respectivamente. Por outro lado, Sassen e Campbell (2001) apresentam valores médios de 8,79 km para a base e 11,2 $\mathrm{km}$ para o topo de nuvens cirrus medidas em latitudes, que é menor que o caso para cirrus tropicais, e uma espessura geométrica média de 1,81 km. Para comparação, algumas características das nuvens cirrus relatadas em várias regiões do mundo são apresentadas na Tabela 3.1.

As características geométricas das nuvens cirrus detectadas foram examinadas através de histogramas normalizados. A figura 3.4 mostra os resultados para a altitude de base e topo, espessura e profundidade óptica das diferentes camadas de nuvem. Os histogramas para os meses da estação úmida e seca revelam diferenças. A distribuição da altitude da base da nuvem (figura 3.4a) é maior durante a estação chuvosa. Existem relativamente mais camadas de cirrus com base abaixo de $12 \mathrm{~km}$ e acima de $16,5 \mathrm{~km}$ durante a estação chuvosa do que durante a estação seca. Particularmente, há um pico centrado em 16,5 km durante os meses chuvosos que não existe durante os meses da estação seca. A distribuição da espessura geométrica (figura 3.4b) mostra mais camadas de cirrus com mais de $2 \mathrm{~km}$ de espessura (e menos nuvens mais finas do que isso) na estação chuvosa. O histograma normalizado de COD (figura 3.4d) mostra relativamente mais camadas de cirrus com COD > 0,1 na estação chuvosa e mais com $\mathrm{COD}<0,1$ na estação seca. As maiores diferenças, no entanto, são 

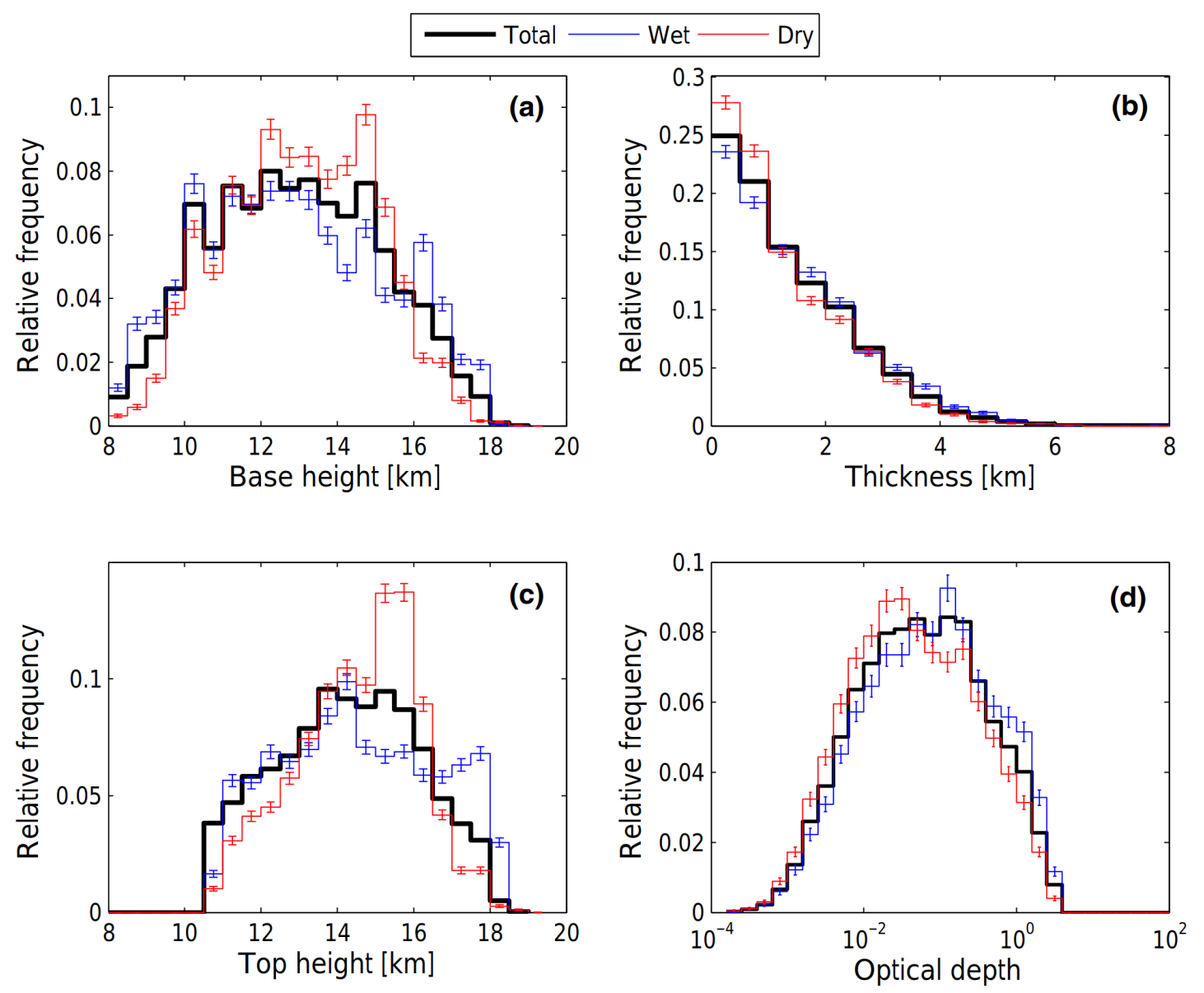

Figura 3.4 - Os painéis mostram os histogramas normalizados de (a) base da nuvem cirrus, (b) espessura geométrica da nuvem, (c) topo da nuvem cirrus e (d) profundidade óptica, para o período total (preto), estação chuvosa (JFMA, vermelho) e estação seca (JJAS, azul). Barras de erro indicam a incerteza de estatísticas de contagem.

vistas na distribuição de altitude do topo das nuvens cirrus (figura 3.4c). Ele mostra dois picos nos meses chuvosos, um centrado em 14,25 km e o segundo em 17,75 km. Por outro lado, para meses secos, há apenas um pico centrado em 15,75 km. Essas diferenças sugerem diferentes tipos de cirrus com diferentes origens.

Comstock et al. (2002) propuseram dois tipos diferentes de nuvens cirrus em um sítio com condições oceânicas na Ilha Nauru no Pacífico tropical ocidental: um tipo (cirrus finos laminares) com altitudes de base das nuvens acima de $15 \mathrm{~km}$ e o outro (cirrus geometricamente mais grossas e com mais estruturas internas) com altitudes de base abaixo de $15 \mathrm{~km}$, com características diferentes. Liu e Zipser (2005) usaram o conjunto de dados TRMM Precipitation Radar (PR) para rastrear a convecção profunda e a precipitação em toda a zona tropical, incluindo oceanos e continentes. 
Os autores mostraram que apenas 1,38 \% (0,1\%) dos sistemas convectivos tropicais, e consequentemente as nuvens cirrus geradas pela bigorna, alcançaram $14 \mathrm{~km}$ (16,8 $\mathrm{km})$ de altitude.

Considerando esses resultados, uma possível interpretação seria que o pico mais alto na distribuição do topo das nuvens nos meses chuvosos se origina da convecção que penetra acima da tropopausa, localizada em cerca de 15,9-16,5 km, enquanto o pico mais baixo é o teto da maioria das convecções tropicais. O pico único observado durante os meses secos, por sua vez, é originário de nuvens cirrus transportadas por grandes distâncias. Nuvens geradas por sistemas convectivos podem persistir na atmosfera de horas a dias se forem lentamente levantadas (ACKERMAN et al., 1988; SEIFERT et al., 2007). Nuvens que ascendem e são transportadas horizontalmente por longas distâncias são, em geral, opticamente e geometricamente mais finas e encontradas em altas altitudes na troposfera. Isso também explica por que as espessuras geométricas e a profundidade óptica são menores durante os meses da estação seca.

Para investigar se as camadas de cirrus mais altas eram de fato geometricamente e opticamente mais finas, uma análise mais profunda da distribuição vertical foi realizada. A figura 3.5 mostra histogramas bidimensionais da profundidade óptica das nuvens e da distribuição vertical da frequência de ocorrência das nuvens cirrus nos meses da estação chuvosa (em cima) e nos meses da estação seca (em baixo). Os painéis da direita mostram a distribuição vertical da frequência de ocorrência para as três categorias de cirrus. Durante os meses chuvosos, há mais dispersão (maior amplitude de COD para uma altitude fixa e vice-versa) do que nos meses secos, o que especulamos pode estar associado à variabilidade bem documentada na intensidade da convecção profunda na Amazônia. (MACHADO, 2002; ADAMS et al., 2009; ADAMS et al., 2013; ADAMS et al., 2015). De fato, é somente durante a estação chuvosa que uma fração significativa dos cirrus é encontrada acima de $16 \mathrm{~km}$ de altitude, e eles têm um COD variando de 0,001 a 0,02. Além disso, enquanto a distribuição de cirrus opacos é máxima a $12 \mathrm{~km}$ de altura em ambas as estações, cirrus finos e SVC mostram uma distribuição bimodal apenas na estação chuvosa, com os máximos mais altos acima de $14 \mathrm{~km}$ e $16 \mathrm{~km}$, respectivamente. Isso está presumivelmente associado à convecção de overshooting discutida acima, que ocorre principalmente durante a estação chuvosa (LIU; ZIPSER, 2005). Além disso, a introdução de gelo diretamente na camada da tropopausa tropical (TTL) é um dos principais mecanismos de formação de cirrus TTL; o outro é a formação in situ por supersaturação promovida pela elevação em mesoescala (CZICZO et al., 2013), que pode ocorrer acima dos sistemas convectivos tropicais (GARRETT et al., 2004), uma característica muito comum do 


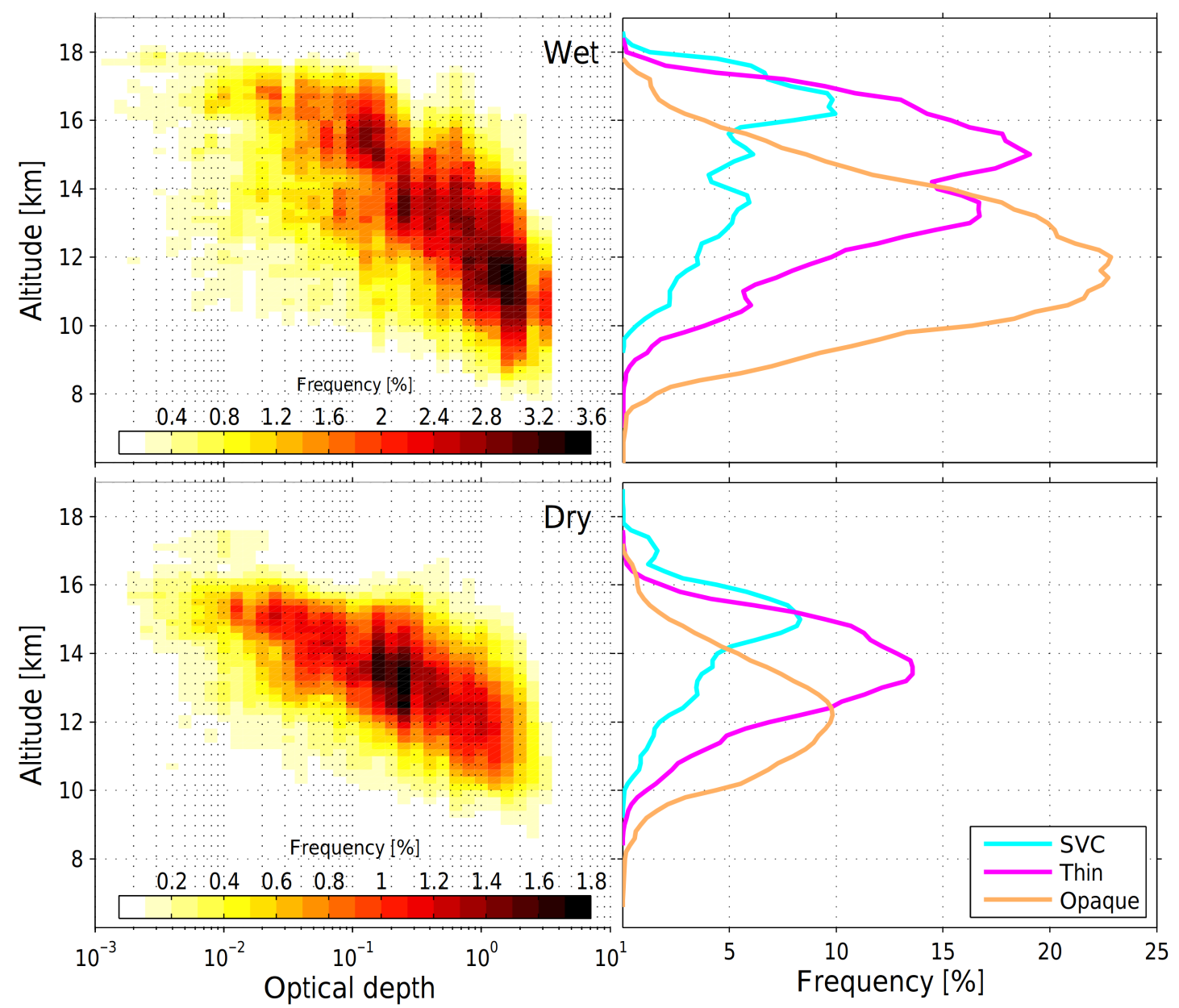

Figura 3.5 - Histogramas bidimensionais da frequência de ocorrência de cirrus com a altitude em função da profundidade óptica durante os meses chuvosos (topo) e secos (abaixo) são mostrados à esquerda. O mesmo é mostrado à direita, mas integrado para profundidades ópticas SVC, cirrus finas e opacas.

ciclo hidrológico da Amazônia.

Para investigar o papel da inversão no topo da tropopausa no desenvolvimento vertical das nuvens cirrus, sua altitude foi calculada a partir de dados do ERA Interim para os mesmos instantes de tempo das observações de cada perfil das nuvens cirrus. As altitudes médias da tropopausa durante os períodos chuvoso, transição e seco foram 16,5 $\pm 0,2 \mathrm{~km}, 16,3 \pm 0,3$ e 15,9 \pm 0,4, respectivamente. Portanto, uma fração não desprezível dos cirrus observados durante as estações chuvosa e seca (figura 3.5) ocorreram provavelmente acima da tropopausa. A figura 3.6 mostra a distribuição da distância da base e do topo da nuvem cirrus até a tropopausa. Cerca de $7 \%$ (19 \%) das nuvens cirrus detectadas têm sua altitude da base (topo) 

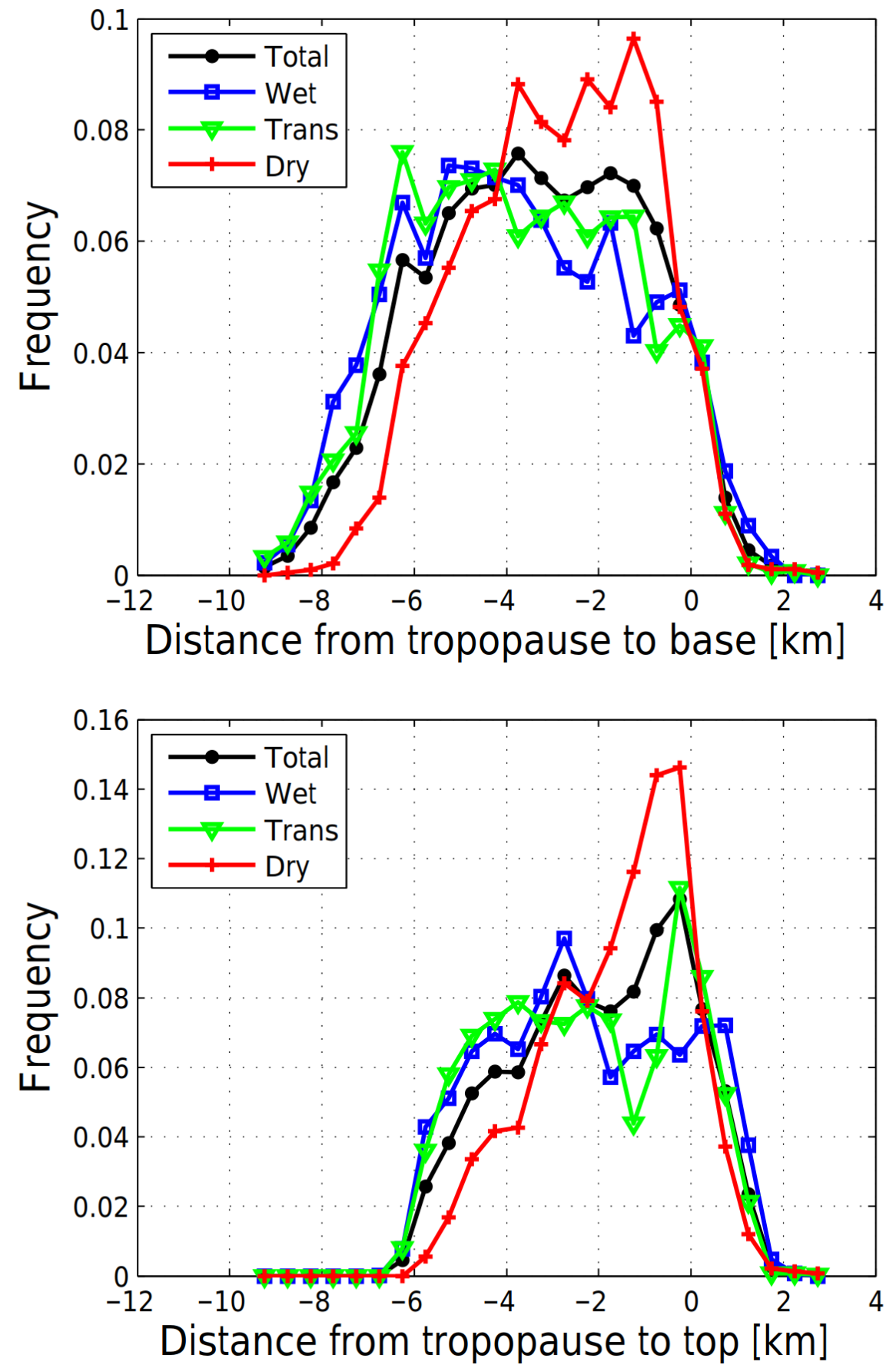

Figura 3.6 - Os histogramas normalizados da distância da tropopausa à base e ao topo dos cirrus são mostrados para o período total (preto) e para cada estação (cores). Valores negativos significam que as nuvens estão abaixo da tropopausa. A altitude média da tropopausa foi de $16,2 \pm 0,4 \mathrm{~km}$. 
da nuvem acima da tropopausa durante a estação chuvosa e 5\% (13\%) durante a estação seca. A maioria dos topos de nuvens cirrus são encontrados logo abaixo da inversão térmica da tropopausa, exceto durante a estação chuvosa quando eles estão uniformemente distribuídos de $-2 \mathrm{~km}$ a $+0,5 \mathrm{~km}$, o que está associado à variabilidade na intensidade da convecção profunda, como discutido acima. Durante a estação seca, por outro lado, o overshooting da convecção profunda ocorre principalmente ao norte do equador (figura 2 de Liu e Zipser (2005)). Esses cirrus que se formam ao redor da tropopausa não podem ser mais levantados acima da inversão térmica e, portanto, duram menos de um dia (JENSEN et al., 1996). Portanto, eles não podem ser transportados por distâncias muito longas, o que corrobora com o pico único próximo a $15 \mathrm{~km}$ na distribuição da altitude do topo de nuvens, que está logo abaixo da tropopausa.

Seguindo a classificação das nuvens cirrus de Sassen e Cho (1992) para as camadas individuais de nuvens, temos que 41,6 \% das nuvens cirrus medidas em nosso sítio experimental são subvisíveis $(\tau<0,03), 37,8 \%$ são cirrus finos $(0,03<\tau<0,3)$ e 20,5 \% são cirrus opacos $(\tau>0,3)$. A Tabela 3.3 mostra esses valores para cada estação. As nuvens SVC têm uma maior (menor) fração durante os meses secos (chuvosos). Nuvens opacas têm a maior (menor) fração durante os meses chuvosos (secos), o que é esperado, pois há uma predominância de nuvens cirrus recém-geradas por convecção profunda.

Essa grande fração de nuvens cirrus opticamente finas e subvisíveis na Amazônia representa um desafio para as medidas de sensoriamento remoto passivo do espaço, como o MODIS. Como mencionado por Ackerman et al. (2010), nuvens cirrus finas são difíceis de detectar devido ao contraste insuficiente com a radiância da superfície. O MODIS detecta apenas cirrus com profundidade óptica tipicamente superior a 0,2 (ACKERMAN et al., 2008). Portanto, a máscara de nuvens do MODIS não inclui $71 \%$ das nuvens cirrus sobre a Amazônia e, da mesma forma, sua estimativa da profundidade óptica do aerossol pode estar contaminada com esses cirrus finos. Medições de profundidade óptica de aerossóis (AOD) da AERONET também podem ser contaminadas com nuvens cirrus finas. Chew et al. (2011), por exemplo, estimaram que a fração de medições contaminadas de AOD da AERONET em Cingapura $\left(1,5^{\circ} \mathrm{N}\right.$, $\left.103,7^{\circ} \mathrm{E}\right)$ é de 0,034 a 0,060. A determinação da contaminação real dos produtos de aerossol do MODIS e AERONET para a Amazônia devido as nuvens cirrus finas será o assunto de um estudo futuro.

Os diferentes tipos de nuvens cirrus medidos na Amazônia central, com diferentes 
mecanismos de formação, profundidades ópticas e faixas de altitude, devem ser compostos por cristais de gelo de diferentes formatos. Uma maneira de obter informações sobre os hábitos dos cristais de gelo é calcular a razão lidar (SASSEN et al., 1989). Como explicado na seção 3.1, podemos estimar o valor médio da razão lidar para as camadas de nuvens cirrus detectadas em cada perfil usando uma abordagem interativa em vez de calcular explicitamente a extinção do pelo espalhamento Raman, o qual seria possível apenas durante a noite. Os valores médios de LR são apresentados na Tabela 3.3 para todos os cirrus e para cada categoria. Obteve-se um valor médio de 23,9 $\pm 8,0$ (std) sr para todo o período e a variação é inferior a 1,5 sr para as diferentes estações do ano (ou seja, não apresenta um ciclo sazonal). Para cirrus opacos, finos e SVC as médias foram 25,7 $\pm 6,3 \mathrm{sr}, 22,8 \pm 7,9$ sr e 21,6 \pm 8,4 sr, respectivamente. Pace et al. (2003) encontraram um valor médio da razão lidar de 19,6 sr para o sítio tropical de Mahé, Seychelles. Seifert et al. (2007), também para regiões tropicais, relatam valores próximos a 32 sr. PLATT e DILEY (1984) relataram o valor de 18,2 sr com um erro de $20 \%$. Para as outras latitudes, os exemplos são apresentados na tabela 3.1. Observamos, no entanto, que a razão lidar pode variar muito dependendo da altitude e composição das nuvens cirrus (GOLDFARB et al., 2011), mas também da correção para espalhamento múltiplo (PLATT, 1981; HOGAN, 2008). Este último depende do raio efetivo dos cristais de gelo, e a incerteza associada pode variar de 20 a $60 \%$ (WANDINGER, 1998b).

Embora a média do LR para todas as estações e categorias de cirrus seja semelhante, sua distribuição estatística ainda pode revelar diferenças. A figura 3.7 mostra os histogramas da razão lidar corrigidos para o espalhamento múltiplo para as diferentes estações do ano (painel superior) e para as diferentes categorias (painel inferior). Para todas as estações, a razão lidar mais frequentes estão entre 18 sr e 28 sr. Existem diferenças notáveis apenas para diferentes categorias de cirrus. A distribuição dos cirrus opacos tem um pico em $25 \mathrm{sr}$, enquanto os cirrus finos tem seu pico em cerca de 21 sr, e os cirrus SVC em cerca de 15 sr, com um pico secundário em 44 sr.

Como se espera que as propriedades microfísicas do cirrus dependam da altitude (por exemplo, Goldfarb et al. (2011)), examinamos a dependência da razão lidar com a temperatura do topo da nuvem cirrus (figura 3.8). Os gráficos mostram a média, a mediana e a distância interquartil. Um ligeiro aumento nos valores da razão lidar de $20 \mathrm{sr}$ para $28 \mathrm{sr}$ para uma diminuição na temperatura de -40 a $-55^{\circ} \mathrm{C}$ pode ser notado durante o período seco. Durante o período chuvoso, os valores da razão lidar estão entre 18 sr e 28 sr em todos os intervalos de temperatura, sem uma tendência evidente. Seifert et al. (2007) e Pace et al. (2003) mostram a mesma dependência 

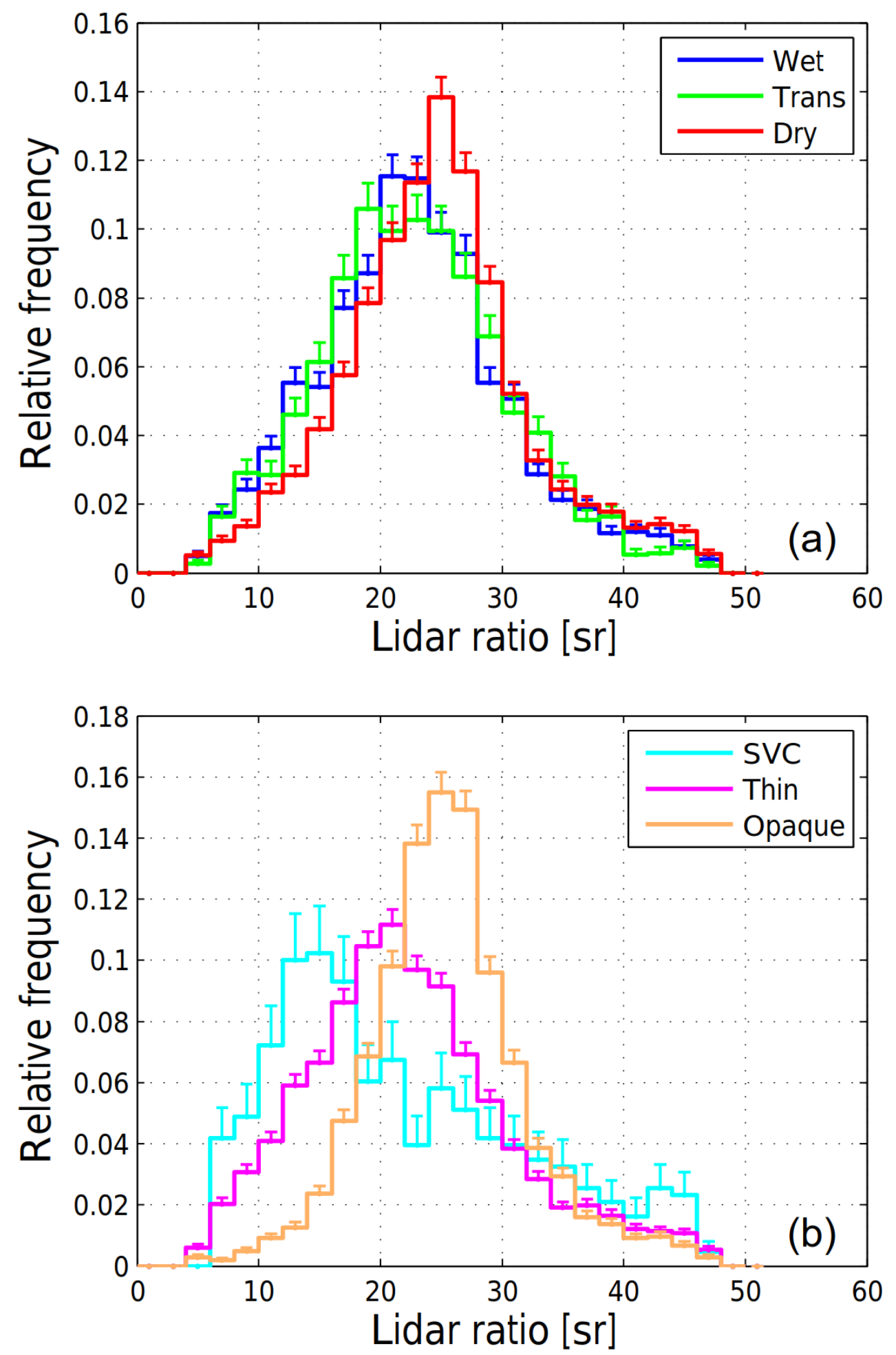

Figura 3.7 - Histogramas normalizados da razão lidar, já corrigidos para espalhamento múltiplo, para as diferentes estações do ano (topo) e para diferentes tipos de cirrus (inferior) são mostrados. Barras de erro indicam a incerteza de estatísticas de contagem.. 
de temperatura da razão lidar, mas com diferentes valores médios da razão lidar. Esse comportamento é uma indicação de uma pequena variação nas características microfísicas das nuvens observadas.

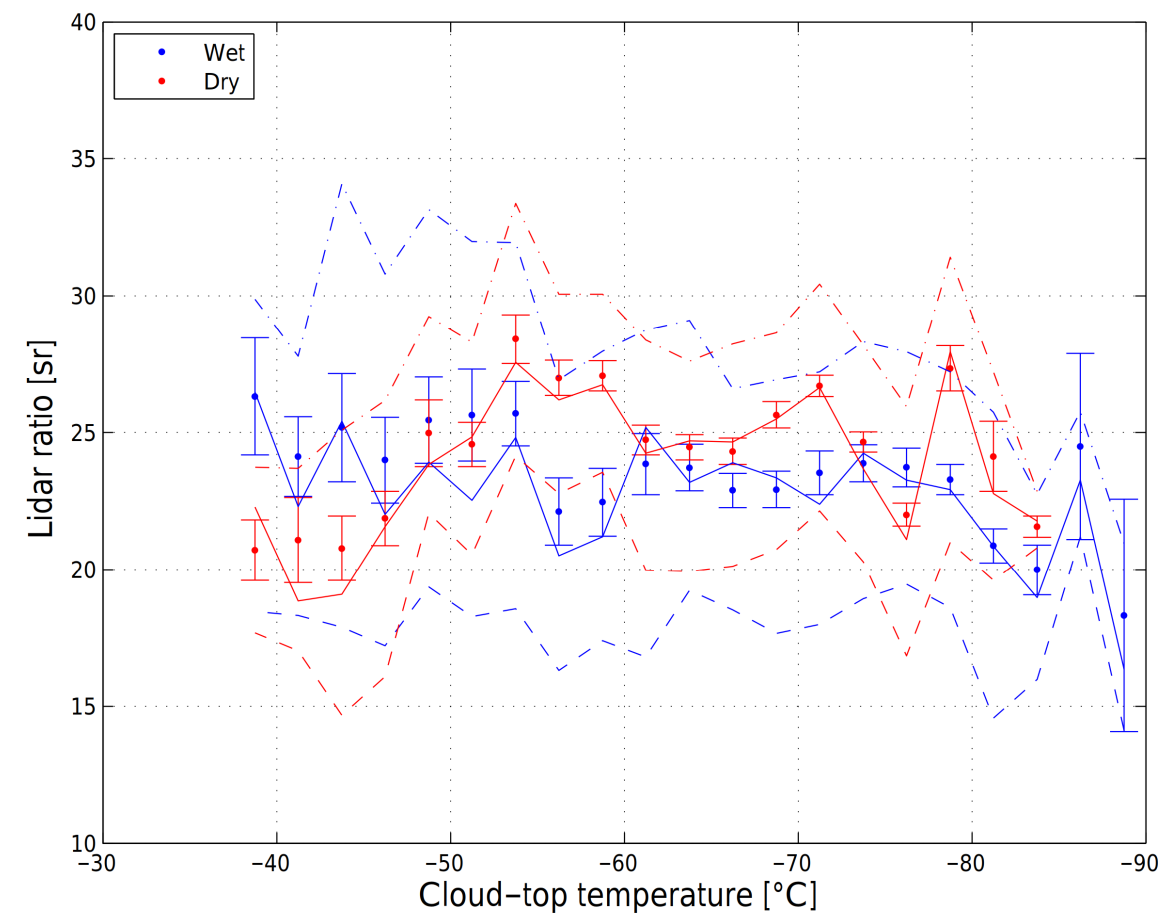

Figura 3.8 - A dependência da razão lidar em função da temperatura no topo da nuvem é mostrada para as estações chuvosa (azul) e seca (vermelha). Os marcadores dão a média e desvio padrão da média. As linhas contínuas e tracejadas fornecem a mediana e o intervalo interquartil. A temperatura é dividida em intervalos de $2,5^{\circ} \mathrm{C}$. 



\section{Forçante Radiativa das Nuvens Cirrus}

Neste capítulo, utilizamos dois modelos de transferência radiativa para estimar, a partir das medidas das propriedades dos cirrus discutidas no capítulo anterior, a forçante radiativa destas nuvens sobre a região central da floresta amazônica com grande resolução temporal e vertical. Na seção 4.1, revisamos os resultados das propriedades ópticas e geométricas das nuvens cirrus medidas na Amazônia, assim como descrevemos a metodologia para a aplicação dos modelos de transferência radiativa e o cálculo da forçante de nuvens cirrus. Na seção 4.2, mostramos os resultados da forçante radiativa instantânea em função do COD, temperatura, SZA e hora do dia, assim como a forçante radiativa anual e o perfil médio da taxa de aquecimento. Os resultados são comparados com trabalhos publicados na literatura para latitudes médias, já que não há trabalhos semelhantes para latitudes tropicais. Na seção 4.3, exploramos os efeitos de não se representar apropriadamente o ciclo diurno, como no caso das estimativas por satélites, no cálculo da forçante radiativa,

\subsection{Nuvens cirrus e cálculo da forçante radiativa}

\subsubsection{Medida dos cirrus com o lidar}

Gouveia et al. (2017) publicou os resultados apresentados no capítulo 3 das medidas de longa duração de propriedades ópticas e geométricas das nuvens cirrus sobre a região central da Amazônia (2.89 S 59.97 W), obtidas a partir de um ano de medidas contínuas (julho de 2011 a junho de 2012) por um lidar em solo (BARBOSA et al., 2014). Este sistema lidar, emite luz UV em $355 \mathrm{~nm}$. A medida do retroespalhamento elástico foi utilizada para calcular, durante o dia e a noite, a profundidade óptica e o perfil vertical do coeficiente de extinção das nuvens cirrus com alta resolução vertical $(7,5 \mathrm{~m})$ e temporal (5 min), utilizando uma combinação dos métodos da transmitância e Klett (ver seção 2.3.2). O sistema operou automaticamente 7 dias por semana, parando somente entre 11 am e 14 pm (LT) para evitar dano à óptica pela incidência direta da luz solar. Informação adicional sobre os perfis de temperatura e pressão foram obtidas de radiossondagens lançadas 2 vezes por dia (00Z e $12 Z$ ) de um aeroporto próximo ( $\approx 28 \mathrm{~km}$ ao sul).

Uma característica marcante da região amazônica é seu intenso ciclo hidrológico, com alta umidade específica e com intensa convecção durante todo o ano. Isso combinado ao ciclo anual da Zona de Convergência Intertropical que passa sobre a região (ADAMS et al., 2013; MACHADO, 2002), produzem uma complexa estrutura vertical de múltiplas camadas de nuvens cirrus. Algumas são provenientes diretamente da 
bigorna das nuvens de convecção profunda e algumas tem origem in-situ favorecida pelo constante fluxo de vapor para os altos níveis da tropopausa (KRÄMER et al., 2016). O resultado é uma ampla distribuição vertical das nuvens cirrus, que ocorrem com altitudes de bases tão baixas quanto $8 \mathrm{~km}$ e com altitudes do topo frequentemente acima da tropopausa. Em média, os topos estão em em $16.5 \pm 0.2 \mathrm{~km}$ na temporada chuvosa e $15.9 \pm 0.4 \mathrm{~km}$ na temporada seca (GOUVEIA et al., 2017). Estas medidas mostraram uma alta frequência de ocorrência anual de 73,8 \%, variando de 59,2 \% na temporada seca (junho a setembro) até 88,1 \% na temporada chuvosa (janeiro a abril). Se considerarmos como uma camada individual de nuvem cirrus aquelas que estão separadas por pelo menos $500 \mathrm{~m}$ de ar limpo, o número médio de camadas de cirrus no perfil vertical foi de 1,41 (stdev =0,63), 1,62 (77) e 1,25 (0.48) para o período total, chuvoso e seco, respectivamente. A altitude média da base da camada foi de 12,9 $\pm 2,2 \mathrm{~km}, 14,3 \pm 1,9 \mathrm{~km}$ para a altitude do topo e $1,4 \pm 1,1 \mathrm{~km}$ de espessura média.

A temperatura da camada de nuvem é um parâmetro crítico para a determinação da quantidade de radiação térmica emitida pela nuvem, especialmente aquela emitida pela nuvem para o topo da atmosfera e que acaba deixando o sistema climático. A figura 4.1 mostra o histograma normalizado da temperatura do topo da camada das nuvens cirrus durante a temporada chuvosa e seca. Com tão ampla distribuição vertical, as nuvens cirrus podem atingir temperaturas muito baixas, que é uma característica comum a nuvens cirrus tropicais (CAMPBELL et al., 2015). A distribuição de temperaturas para ambas as estações possui uma clara moda principal, que ocorre em torno de $200 \mathrm{~K}$ na estação seca e um pouco mais frio na estação úmida, em torno de $193 \mathrm{~K}$, modas estas que estão relacionadas à temperatura da tropopausa. Uma moda secundária, mais evidente na estação chuvosa, aparece em torno de $208 \mathrm{~K}$ ( $14 \mathrm{~km}$ ), provavelmente relacionada ao desentranhamento da convecção profunda, que tem teto em torno de $14-14.5 \mathrm{~km}$ para regiões tropicais (LIU; ZIPSER, 2005). O histograma também mostra uma descontinuidade em $238 \mathrm{~K}\left(-37^{\circ} \mathrm{C}\right)$, mas esta é causada pelo critério de seleção utilizado para discriminar uma camada de nuvem como sendo cirrus e garantir que a camada é completamente composta por cristais de gelo.

Tendo temperaturas tão baixas, uma alta frequência de ocorrência e uma grande extensão vertical, as nuvens cirrus na Amazônia, que ocupam um grande volume da parte superior da troposfera, tem grande potencial de perturbação do balanço radiativo. O enorme contraste de temperatura com a superfície quente da floresta $\left(26,8{ }^{\circ} \mathrm{C}\right.$ em média,FISCH et al. (1998)) se traduz numa quantidade muito menor 


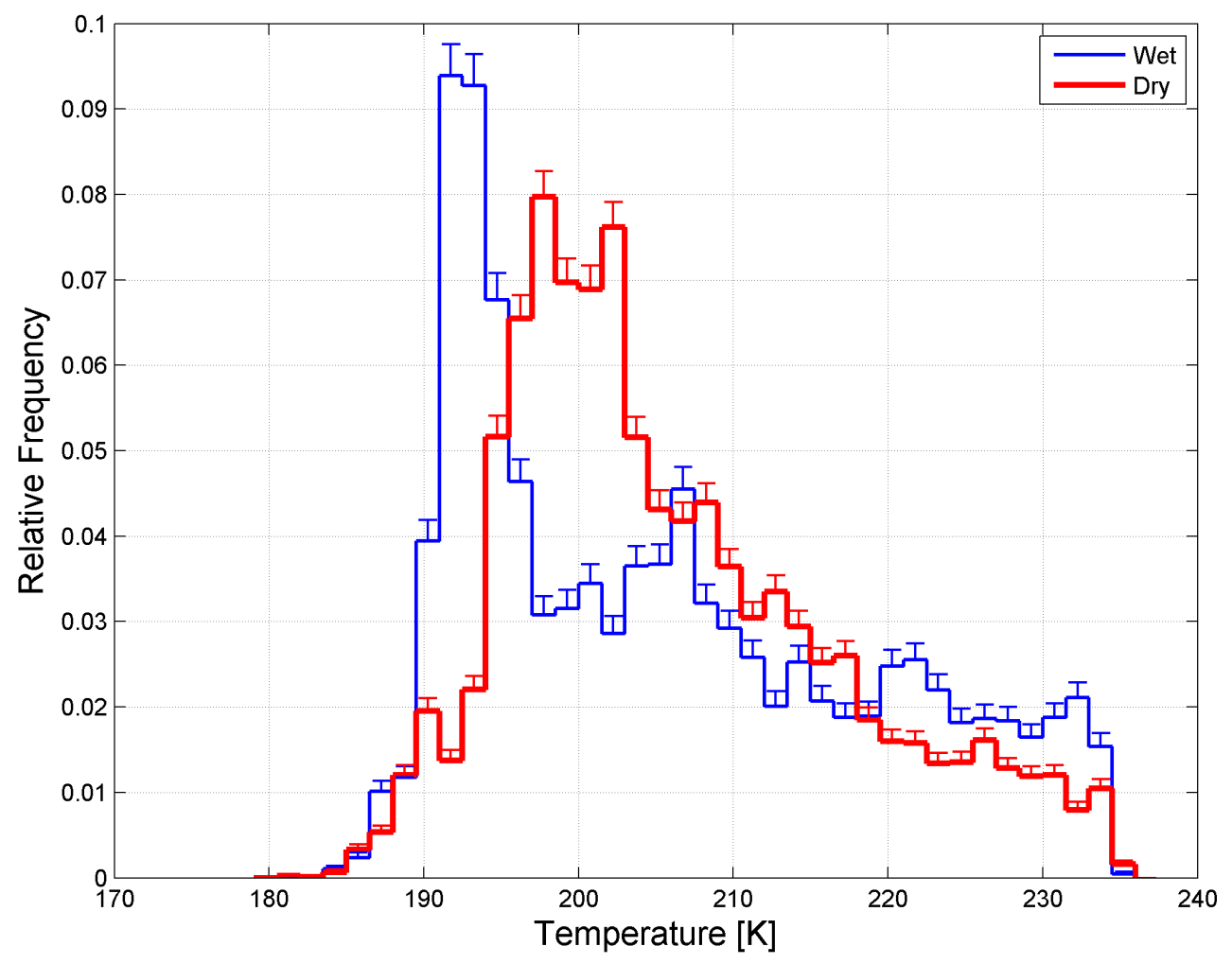

Figura 4.1 - Histograma normalizado da temperatura do topo das nuvens cirrus, para a estação chuvosa (wet) e seca (Dry).

de radiação térmica emitida pela nuvem para o topo da atmosfera (CORTI; PETER, 2009). Por isso, dedicamos este capítulo para avaliar a forçante radiativa das nuvens cirrus na Amazônia. Faremos isto considerando os perfis verticais de nuvens cirrus medidos (extinção e COD) como entrada para cálculos detalhados de transferência radiativa, de forma que a real estrutura das nuvens fosse levada em conta. Segundo Barja (2002) isto é necessário para que a forçante radiativa seja estimada com acurácia.

\subsubsection{Cálculo da CRF: definição e descrição do modelos}

O papel das nuvens cirrus no balanço radiativo será avaliado em termos de sua forçante radiativa, CRF (CORTI; PETER, 2009), definida como a diferença no fluxo radiativo na atmosfera causada pela presença da nuvem cirrus em relação ao calculado com céu limpo, podendo ser expresso como:

$$
C R F_{S W}(z)=\Delta F_{S W}^{\text {cloud }}(z)-\Delta F_{S W}^{\text {clear }}(z)
$$




$$
\begin{gathered}
C R F_{L W}(z)=\Delta F_{L W}^{\text {cloud }}(z)-\Delta F_{L W}^{\text {clear }}(z) \\
C R F_{N E T}(z)=C R F_{S W}(z)+C R F_{L W}(z)
\end{gathered}
$$

Onde $\Delta F=F_{\text {down }}-F_{\text {up }}$, é a diferença entre o fluxo radiativo descendente $\left(F_{\text {down }}\right)$ e ascendente $\left(F_{u p}\right)$. Os fluxos $F\left(\mathrm{em} W \mathrm{~m}^{-2}\right)$ são calculados separadamente quando a fonte de radiação é solar (SW) e quando a fonte é térmica (LW). Da forma que é definido, o sinal da CRF em uma dada altitude será positivo quando as nuvens cirrus causarem um efeito de aquecimento, e negativo quando causarem um efeito de resfriamento. Os termos $F^{\text {cloud }}$ e $F^{\text {clear }}$ são calculados pelo código de transferência radiativa considerando os mesmos parâmetros de entrada, sendo a única diferença a inclusão do perfil vertical das nuvens cirrus. Os fluxos radiativos, que são definidos para qualquer nível de altitude da atmosfera, são avaliados no topo da atmosfera (TOA, do inglês Top Of Atmosphere) e superfície (BOA, do inglês Bottom Of Atmosphere). Os cálculos foram realizados para cada um dos perfis verticais (5-min) de nuvem cirrus medidos pelo lidar, de forma que a forçante radiativa represente o real perfil de nuvens cirrus medido durante todo o ano.

É importante apontar aqui que o termo forçante radiativa pode ter outras definições. Por exemplo, o relatório do IPCC de 2007 define a forçante radiativa e em relação a níveis pré-industriais e com ação global, incluindo os ajustes decorrentes no sistema climático. Da maneira que definimos nesta tese, a CRF calculada para cada perfil vertical da atmosfera pode ser entendida como uma "forçante radiativa instantânea", sem incluir ajustes no perfil termodinâmico da atmosfera e com ação local. Essa forçante instantânea então pode ser posteriormente promediada para se obter a forçante radiativa sazonal e anual.

Em complemento ao cálculo da $\mathrm{CRF}$, o efeito radiativo das nuvens cirrus também será avaliado a partir do perfil vertical da taxa de aquecimento da atmosfera pela absorção da radiação (ou taxa de aquecimento radiativo), que, analogamente ao definido para o CRF, é calculado como:

$$
\Delta H R(z)_{N E T}=H R_{N E T}^{\text {cloud }}(z)-H R_{N E T}^{\text {clear }}(z)
$$

Os cálculos de transferência radiativa de onda longa e de onda curta em diferentes condições de nebulosidade sobre a floresta foram realizados utilizando dois códigos de transferência radiativa: O libRadtran (EMDE et al., 2016) e o modelo de Corti e Peter (CORTI; PETER, 2009). 


\subsubsection{Transferência radiativa com o libRadtran}

O libRadtran (v 2.0.1) é um pacote de software bem conhecido e bem documentado, desenvolvido e mantido principalmente pela Instituto Meteorológico de Munique. Ele é uma poderosa e versátil ferramenta para o cálculo de transferência radiativa. Inclui uma biblioteca de propriedades ópticas e microfísicas para nuvens e aerossóis, assim como parametrizações para o espalhamento e absorção molecular pelos gases da atmosfera, que possibilita uma simulação detalhada da transferência radiativa. Neste trabalho, os fluxos radiativos são calculados utilizando o DISORT solver (STAMNES et al., 1988), que é o padrão do libRadtran. Utilizou-se o perfil molecular da atmosfera tropical padrão (Anderson, 1986) incluído no pacote do software, com a absorção da radiação pelos gases dada pela parametrização de Fu (FU; LIOU, 1992; FU; LIOU, 1993) que é apropriada para o cálculo de irradiâncias solares e térmicas integradas (EMDE et al., 2016). O ângulo solar zenital foi calculado automaticamente pelo libRadtran a partir da latitude, longitude e data para cada um dos perfis medidos. O albedo de superfície para a floresta tropical amazônica utilizado neste estudo foi de 0.12 como determinado por Sena et al. (2013). Da mesma forma que em Gouveia et al. (2017), o raio efetivo dos cristais de gelo foi obtido como uma função da temperatura de acordo com Krämer et al. (2016), que fez uma climatologia a partir de medidas de avião em regiões tropicais. Esta climatologia inclui dados do recente experimento ACRIDICON (WENDISCH et al., 2016), que realizou medidas sobre a região da Amazônia central, muito próximo ao site experimental. Exceto pelo perfil do coeficiente de extinção de partículas das nuvens cirrus e sua correspondente profundidade óptica total, as propriedades microfísicas e ópticas das nuvens de gelo foram obtidas pela mais nova parametrização "baum V3.6" para um "general habit mixture" (BAUM et al., 2014).

O perfil do coeficiente de extinção das nuvens cirrus e sua profundidade óptica, que são os parâmetros medidos mais importantes para a avaliação da forçante radiativa, são obtidos diretamente pelas medidas do lidar e introduzidos como parâmetros de entrada nos cálculos de transferência radiativa. Para alcançar um resultado o mais acurado possível, o perfil do coeficiente de extinção é mantido com alta resolução vertical (camadas de $200 \mathrm{~m}$ ) para melhor representar a verdadeira estrutura vertical da nuvem cirrus, repetindo isso para todos os perfis individuais de 5 min medidos.

A figura 4.2 mostra um exemplo do cálculo de transferência radiativa utilizando o libRadtran para um perfil de nuvem cirrus com múltiplas camadas e com uma estrutura vertical interessante. O painel (a) mostra o perfil vertical de $5 \mathrm{~min}$ do 
coeficiente de extinção determinado dos dados do lidar com a resolução vertical original (azul). Indicamos em preto o perfil vertical utilizado como entrada para o libRadtran, que foi obtido pela divisão do perfil do coeficiente de extinção em camadas homogêneas de $200 \mathrm{~m}$ de espessura, indo desde a base da camada mais baixa da nuvem até o topo da camada mais alta (* vermelho e magenta na figura). Vemos que com $200 m$ de resolução vertical conseguimos representar adequadamente a complexa estrutura vertical que a nuvem cirrus normalmente tem, retratando bem suas características como: as regiões próximas ao topo, que é a partir de onde a nuvem é formada e contem muitos cristais de gelo bem pequenos; passando pelo centro do perfil, onde, como reportado para a região amazônica, frequentemente apresentam camadas de ar limpo entre camadas de cirrus; e indo até as partes mais baixas das camadas de nuvens onde os cristais de gelo, que estão caindo, podem crescer até tamanhos muito grandes.
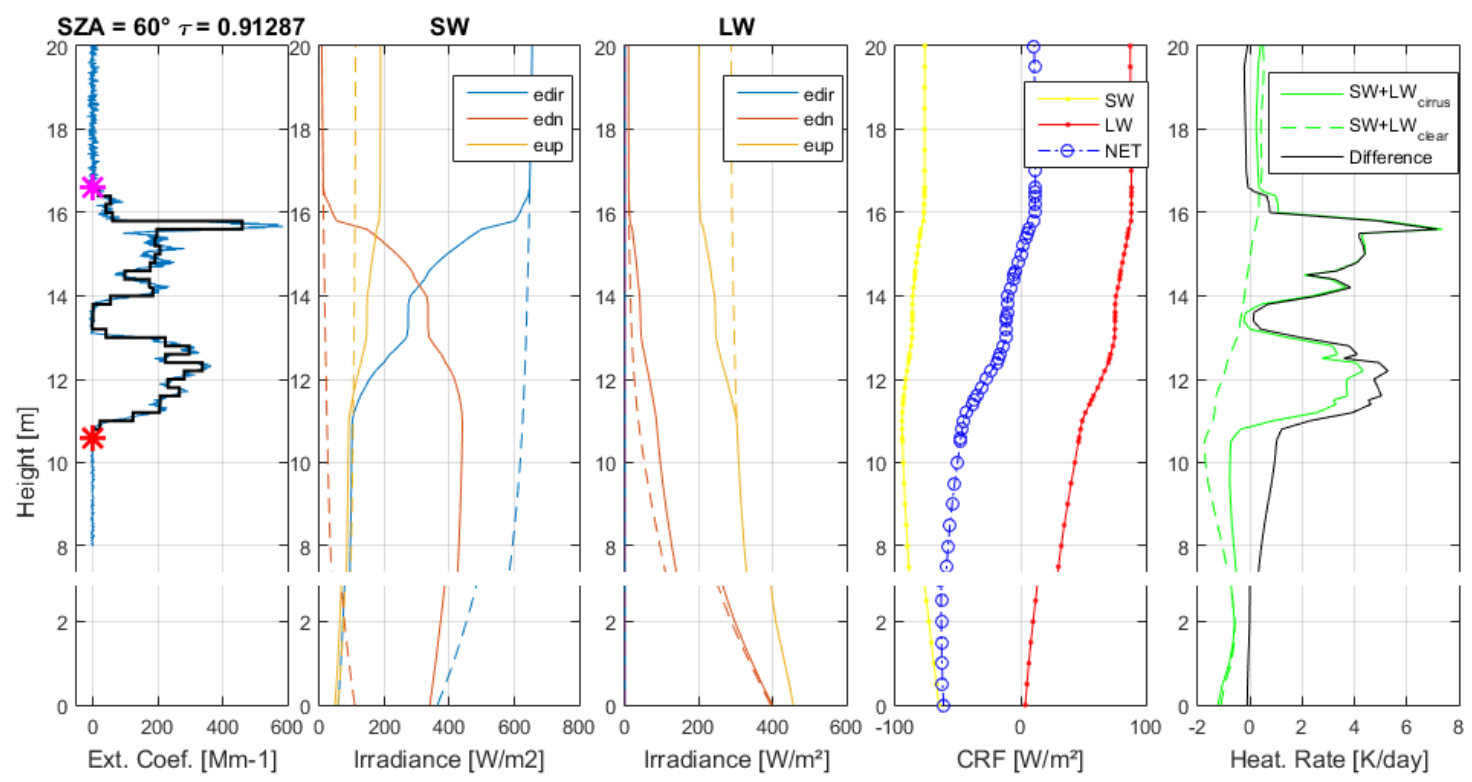

Figura 4.2 - Exemplo da aplicação do modelo libRadtran a um perfil vertical de nuvem cirrus. a) Coeficiente de extinção da nuvem cirrus derivado pelo lidar (azul) e coeficiente utilizado como entrada para o libRadtran (preto). Os asteriscos mostram a base e o topo da nuvem. b) resultado para as irradiâncias no espectro de onda curta. c) irradiâncias no espectro se onda longa. d) resultado da forçante radiativa instantânea. e) Perfil vertical da taxa de aquecimento radiativo.

Com os parâmetros acima mencionados, o modelo de transferência radiativa é aplicado duas vezes para cada nuvem medida. A primeira é feita incluindo o perfil vertical da nuvem cirrus (situação nublado) e uma segunda vez com os mesmos pa- 
râmetros, exceto pelo coeficiente de extinção e pela profundidade óptica da nuvem, que são substituídos com valores iguais a zero (situação céu limpo). Como explicado anteriormente, os dois cálculos são necessários para encontrar a forçante radiativa. Escolhemos como saída dos cálculos de transferência radiativa do libRadtran as irradiâncias direta (edir), difusa descendente (edn) e a difusa ascendente (eup), todos em $W m^{-2}$, além do perfil da taxa de aquecimento $\left(K d i a^{-1}\right)$.

Os painéis (b) e (c) mostram os cálculos, para a faixa solar (SW) e térmica (LW), respectivamente, sendo a linha contínua o caso nublado e a linha tracejada o caso de céu limpo. Nós podemos ver claramente o reflexo da estrutura da nuvem cirrus nos perfis das irradiâncias. De fato, os fluxos radiativos têm uma dependência complexa com a estrutura vertical da nuvem cirrus principalmente porque, sendo nuvens de gelo que em sua grande maioria são pouco densas, são em geral translúcidas no SW (profundidade óptica pequena) e agem como um corpo cinza no LW. Para o SW, podemos ver que a nuvem cirrus reduz a quantidade de radiação direta que chegaria na superfície, porém uma grande fração de radiação difusa é gerada para baixo e acaba chegando na superfície. Consequentemente, somente uma fração pequena da radiação solar é espalhada de volta para o espaço (para o topo da atmosfera). Para a radiação de onda longa, a distribuição vertical da nuvem cirrus é ainda mais importante. A quantidade de radiação térmica terrestre absorvida pela nuvem cirrus, assim como a radiação térmica emitida para cima e para baixo, são altamente relacionadas com a estrutura interna da nuvem cirrus. Definitivamente elas não são determinadas somente pela temperatura da base e do topo, como seria o caso em um corpo negro ou para uma nuvem muito densa opticamente (como nuvens de água). Particularmente, para as nuvens cirrus na Amazônia, que ocorrem muito altas na atmosfera, a quantidade de radiação térmica emitida para o espaço é muito pequena. Essas características combinadas resultam em uma significativa alteração do balanço de LW.

Com os fluxos ascendentes e descendentes, para os casos nublado e de céu limpo, nós podemos então calcular a forçante radiativa instantânea, isto é, a forçante calculada para um único perfil de 5 min. A figura $4.2 \mathrm{~d}$ mostra o perfil da forçante radiativa instantânea para a onda curta, onda longa e total para o mesmo exemplo. Por último, em (e), temos os perfis das taxas de aquecimento total calculadas para a atmosfera limpa e com a presença da nuvem cirrus. A diferença entre eles representa o efeito absoluto na taxa de aquecimento gerada pela nuvem cirrus. Podemos ver que o perfil da taxa de aquecimento reflete claramente a estrutura da nuvem cirrus, chegado a valores de $\sim 7 \mathrm{~K} \mathrm{~d}^{-1}$ dentro da nuvem, mas com efeitos que se estendem para níveis 
muito abaixo e acima da nuvem.

\subsubsection{Transferência radiativa com Corti e Peter (2009)}

O segundo modelo de transferência radiativa utilizado neste trabalho é o modelo de Corti e Peter (CORTI; PETER, 2009), que é muito mais simplificado porém ainda acurado. Ele permite o cálculo da forçante radiativa no espectro de onda curta e onda longa no topo da atmosfera tomando apenas 6 valores de grandezas físicas como entrada, sendo: as propriedades da superfície dadas pelo albedo $(\alpha)$ e temperatura $\left(T_{\text {srf }}\right)$, a constante solar $\left(S_{0}\right)$ e o ângulo solar zenital $(S Z A)$ como propriedades solares, e a profundidade óptica $(C O D)$ e temperatura do topo da nuvem $\left(T_{c l d}\right)$ como propriedades da nuvem. Esse modelo é baseado na simplificação da equação de transferência radiativa para o caso de uma única camada de nuvem. O resultado é uma expressão para o CRF com poucos parâmetros livres, que foram estimados utilizando o modelo mais complexo de FU-Liou (FU; LIOU, 1992; FU; LIOU, 1993) para uma grande variedade de condições atmosféricas. Estas características fazem com que o modelo de CP seja particularmente adequado para aplicações em medidas de Lidar, pois este é capaz de fornecer diretamente os parâmetros de entrada: a profundidade óptica e a altitude do topo da nuvem (prontamente relacionada a temperatura do topo). Exemplos recentes da aplicação do modelo de CP à medidas de Lidar incluem uma climatologia de nuvens cirrus em 3 estações na Europa (KIENASTSJÖGREN et al., 2016) e o estudo do impacto radiativo de nuvens finas em altitudes médias sobre os trópicos, a partir de medidas do CALIOP (BOURGEOIS et al., 2016). Uma versão online do código está disponível em: http://www.iac.ethz.ch/url/crf.

Neste trabalho, aplicamos o modelo de CP à mesma base de dados de nuvens cirrus, utilizando os mesmos $\alpha, T_{\text {suf }}, C O D, S Z A, S_{0}$, e $T_{\text {cld }}$ utilizados no libRadtan, sendo $T_{c l d}$ a temperatura do topo da camada mais alta do perfil de cirrus. Para o exemplo da figura 4.2, o modelo resulta em uma forçante radiativa instantânea no topo da atmosfera de $-75,9$, 95,9 e 20,0 $\mathrm{W} \mathrm{m}^{-2}$ para o SW, LW e NET, respectivamente, enquanto que os respectivos resultados pelo libRadtran foram de $-75,6$, 85,3 e 9,6 $\mathrm{W} \mathrm{m}^{-2}$. A vantagem na utilização do modelo de CP é que sua simplicidade destaca as variáveis mais importantes na determinação da intensidade da forçante radiativa. Alem disso é um código que roda com quase nenhum esforço computacional, o que permite uma avaliação rápida da sensibilidade da forçante radiativa a cada parâmetro de entrada. Por fim, o modelo de CP oferece uma referência independente e simples. A principal desvantagem do modelo de CP é que ele não leva em conta a estrutura vertical das camadas de nuvens cirrus, fato que sozinho é capaz de criar um 
viés nos resultados (BARJA; ANTUNA, 2011). A acurácia do modelo de CP foi avaliada por seus autores como sendo melhor que $20 \%$, porém uma recente publicação (LOLLI et al., 2017) aponta que sobre determinadas circunstâncias a acurácia pode ser pior em comparação com um modelo mais complexo e por isso presumido mais acurado. De qualquer maneira, nós apresentamos na figura 4.5 uma comparação entre os resultados da forçante radiativa instantânea calculada pelos dois modelos para cada um dos perfis de nuvem cirrus, além do resultado da CRF anual para ambos os modelos na seção 4.2.2.

\subsubsection{Aplicação dos modelos de TR}

Com a metodologia discutida até aqui, fomos capazes de produzir uma série temporal de um ano das propriedades ópticas, geométricas e da forçante radiativa para as nuvens cirrus na Amazônia. A figura 4.3 mostra alguns parâmetros de um dia de medidas, que demonstram algumas características chave dessa série temporal. Por várias horas, do começo do dia até o início da tarde, o céu é coberto por nuvens cirrus subvisuais $(\mathrm{COD} \leqslant 0.03)$ e finas $(0.03>\mathrm{COD} \leqslant 0.3)$, que evoluem para nuvens cirrus muito mais espessas $(\mathrm{COD}>0.3)$ próximas ao fim do dia. A intensidade da forçante radiativa instantânea no topo da atmosfera segue um padrão correlacionado ao COD, incluindo um período de forçante radiativa igual a zero em torno das $6 \mathrm{~h}$ quando não se tem cobertura de nuvem. Como mencionado na seção anterior e em Gouveia et al. (2017), nenhum dado está disponível das 11h às 14h, sendo o efeito causado por isso discutido com mais detalhes na seção 4.2.2.

Nas seções seguintes, a relação da forçante radiativa instantânea com características das nuvens como profundidade óptica e temperatura do topo, assim como a relação com o ângulo solar zenital, será discutida. Estatísticas da forçante radiativa anual e sazonal serão determinadas, separando em ciclos diurnos relativos a contribuição de cada tipo de nuvem (subvisual, fina e opaca). A intensidade da interação da radiação com as nuvens cirrus resulta tanto de suas características macro e microfísicas, quanto da sua relativa abundância na atmosfera. Para ajudar a separar as duas contribuições, os resultados serão apresentados em condições de céu nublado (ou overcast) e subsequentemente ponderados pela sua frequência de ocorrência absoluta (condição de All sky), como feito em Kienast-Sjögren et al. (2016) e Chen et al. (2000). Isso ajudará a comparar as propriedades radiativas das nuvens cirrus detectadas na Amazônia com aquelas encontradas em latitude médias, que serão mais discutidas na seção 4.2 . 


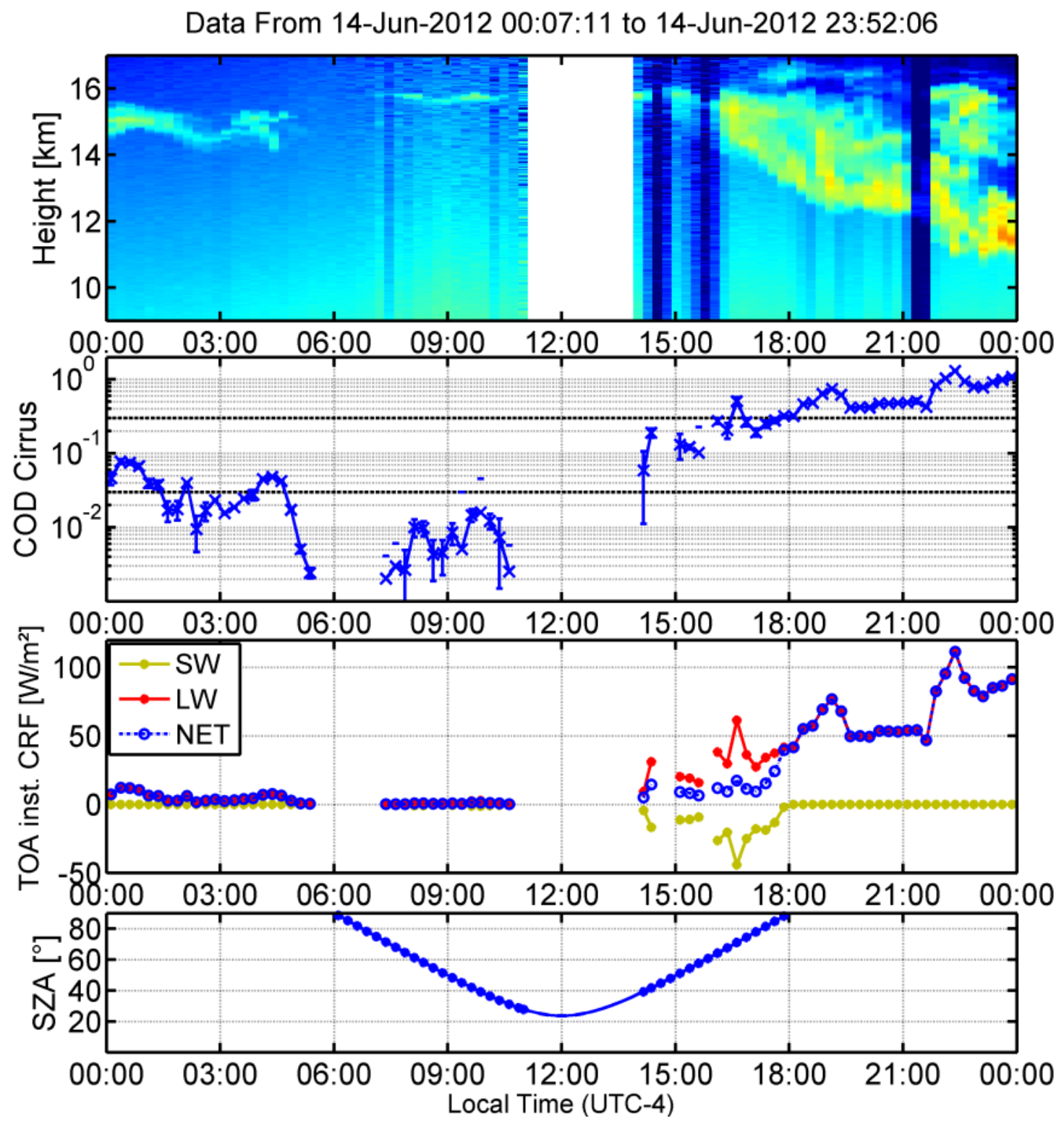

Figura 4.3 - Exemplo de um dia de medidas com do lidar, com o resultado da profundidade óptica, forçante radiativa no topo da atmosfera e ângulo solar zenital..

\subsection{Resultados da CRF na Amazônia}

\subsubsection{Forçante radiativa instantânea vs profundidade óptica}

A figura 4.4 mostra o resultado da forçante radiativa instantânea das nuvens cirrus (overcast) para a radiação SW, LW e NET, calculados utilizando o libRadtran para cada um dos perfis verticais das nuvens com 5 min de média temporal. As forçantes foram calculadas no topo da atmosfera e na superfície, e são mostradas como função da profundidade óptica total das nuvens cirrus integrada na coluna (i.e. somando 
o COD de todas as camadas de nuvens cirrus presentes em cada perfil vertical). O esquema de cores indica o valor do ângulo solar zenital (SZA) para os casos de SW e a altitude do topo da camada de nuvem mais alta do perfil para os casos de LW. Em todos os casos é possível ver uma forte dependência da forçante radiativa com o COD, porém com diferentes dispersões relacionadas principalmente ao ângulo solar zenital, altitude/temperatura e a distribuição vertical das nuvens.

Quando a fonte de radiação é solar (SW), que possui forçante diferente de zero somente para o período diurno, a forçante instantânea pode ser tão baixa quanto $-180 W m^{-2}$, com um efeito de esfriamento um pouco menos intenso no BOA em relação ao TOA. É possível ver que para um dado ângulo solar zenital (principalmente para $\mathrm{SZA} \lesssim 75^{\circ}$ ) a forçante instantânea é bem determinada para um dado COD. Mesmo considerando um grande intervalo de SZA, como entre $15^{\circ}$ e $75^{\circ}$, a dispersão da forçante instantânea em torno do COD não é grande e vem principalmente da variação do ângulo solar zenital, resultado que reflete o fato da estrutura vertical e espessura geométrica das nuvens cirrus não terem tanta influência relativa na forçante para esses casos. Este comportamento, entretanto, não se repete para os períodos próximos ao nascer e pôr do sol, quando o ângulo solar zenital é grande $\left(>75^{\circ}\right)$. Para um SZA tão alto, o caminho óptico da radiação de onda curta cresce rapidamente, o que causa um aumento na atenuação da radiação direta e gera uma maior fração de radiação difusa. Esse efeito é mais pronunciado no BOA, especialmente para $\mathrm{COD}<0,5$, onde podemos ver uma maior quantidade de casos em que a intensidade do efeito de esfriamento é reduzida para estes SZA altos. É importante destacar que usamos a aproximação plano-paralela nos nossos cálculos. Contudo, ângulos tão inclinados seriam melhor resolvidos com geometria completamente esférica, o que exigiria o cálculo de transferência radiativa em 3D com método de Monte Carlo. .

Para a radiação de onda longa (LW), a distribuição vertical das nuvens e sua profundidade óptica têm um papel crítico na intensidade da forçante radiativa. Como pode ser visto na figura 4.4, a forçante radiativa de onda longa das nuvens cirrus tem uma forte dependência com a sua profundidade óptica, mas, ainda assim, fortemente regulada pela temperatura (altitude) da camada de nuvem cirrus. Esse comportamento é bem diferente do que ocorre com nuvens de água e de fase mista, que em geral são opticamente espessas e tem um comportamento similar à de um corpo negro quando interagem com a radiação de onda longa. Para essas nuvens similares a um corpo negro, a forçante radiativa pode ser determinada basicamente pela temperatura da base e do topo da nuvem. 

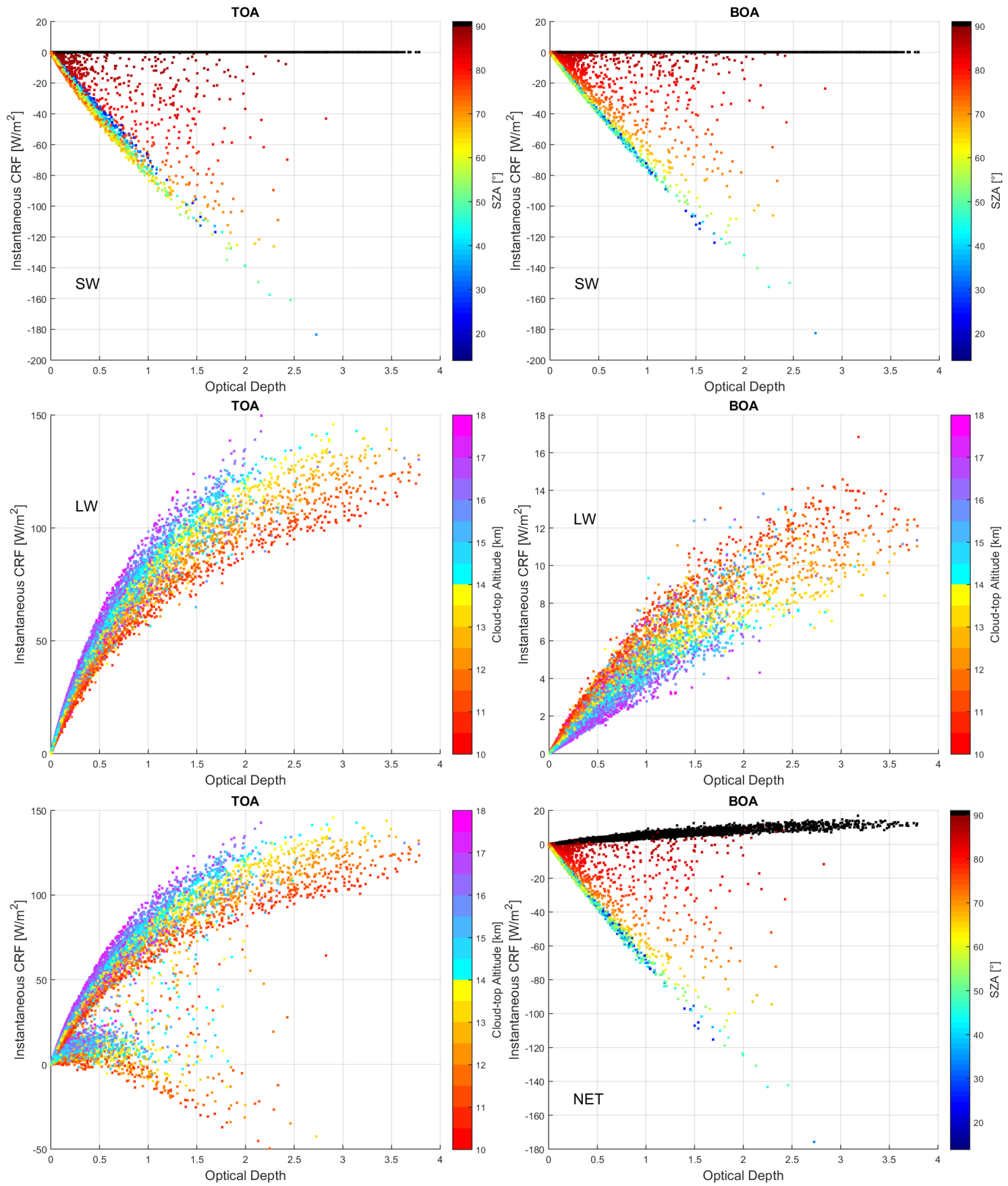

Figura 4.4 - Forçante radiativa instantânea, no topo e na superfície, quando a fonte de radiação é SW, LW e NET, calculada para cada um dos perfis verticais de 5 minutos de média temporal com a presença de nuvem cirrus (overcast). O código de cores representa ou a altitude da camada de nuvem mais alta no perfil ou o ângulo solar zenital local no instante de ocorrência da nuvem. 
Diferente do que ocorre no espectro solar, a forçante radiativa de onda longa é sempre positiva (efeito de aquecimento) e com intensidade muito diferente no TOA e BOA. Do nosso conjunto de dados, vemos que a $\mathrm{CRF}_{L W}^{T O A}$ instantânea pode chegar a valores de até $150 \mathrm{~W} \mathrm{~m}^{-2}$ e com mais intensidade para as nuvens com os topos mais altos (temperaturas mais baixas). Também é possível observar claramente a diminuição do incremento na forçante radiativa com o aumento da profundidade óptica, que assintoticamente se tornariam praticamente independentes da profundidade óptica para nuvens com COD $\gtrsim 10$ (CORTI; PETER, 2009). Na superfície, a forçante radiativa de onda longa é cerca de um décimo que no topo da atmosfera, com intensidade não maiores que $18 W^{-2}$. Em ambos, TOA e BOA, podemos observar, pelo esquema de cores, uma forte correlação entre a altitude do topo e a forçante radiativa de onda longa para uma dada profundidade óptica, apesar da dispersão causada pela inomogeneidade do perfil vertical das camadas de nuvens cirrus.

Por fim, os dois painéis inferiores da figura 4.4 mostram o resultado para a forçante radiativa instantânea líquida (NET) no TOA e no BOA, que é a soma das forçantes radiativas nos espectros de onda curta e onda longa. Nos dois casos, dá para identificar imediatamente os valores para a forçante instantânea no período noturno, onde a forçante NET só tem contribuição da componente de onda longa. Para a $\mathrm{CRF}_{N E T}$ instantânea diurna, temos a competição entre o efeito de esfriamento no espectro solar (forçante negativa) e o aquecimento no infravermelho (forçante positiva). No topo da atmosfera, a intensidade das forçantes de SW e LW são próximas e a maioria dos perfis de nuvem produzem forçantes positivas, com exceção de alguns casos de nuvens mais baixas (e, portanto, menos frias) ou com profundidade óptica maiores. Para o BOA, entretanto, a forçante de LW é muito menor que a de SW, resultando em uma forçante instantânea líquida negativa, com exceção apenas para o período noturno ou com ângulo solar zenital muito elevado.

Para o segundo modelo de transferência radiativa utilizado neste trabalho (modelo $\mathrm{CP}$ ), os efeitos da inomogeneidade das nuvens cirrus não são levados em conta nos cálculos da CRF, pois nesse modelo a nuvem é considerada como uma camada homogênea de $1 \mathrm{~km}$ de espessura. Na figura 4.5 é apresentada uma comparação entre os resultados da forçante radiativa instantânea no TOA quando calculados com o libRadtran (detalhado) com o modelo de CP (simplificado). Vemos que, apesar de ambos os modelos utilizarem a aproximação plano-paralela, há diferenças da dependência das forçantes com o SZA, especialmente para SZA $>70^{\circ}$. Em geral, a forçante radiativa instantânea no TOA calculada pelo modelo CP apresenta intensidade um 

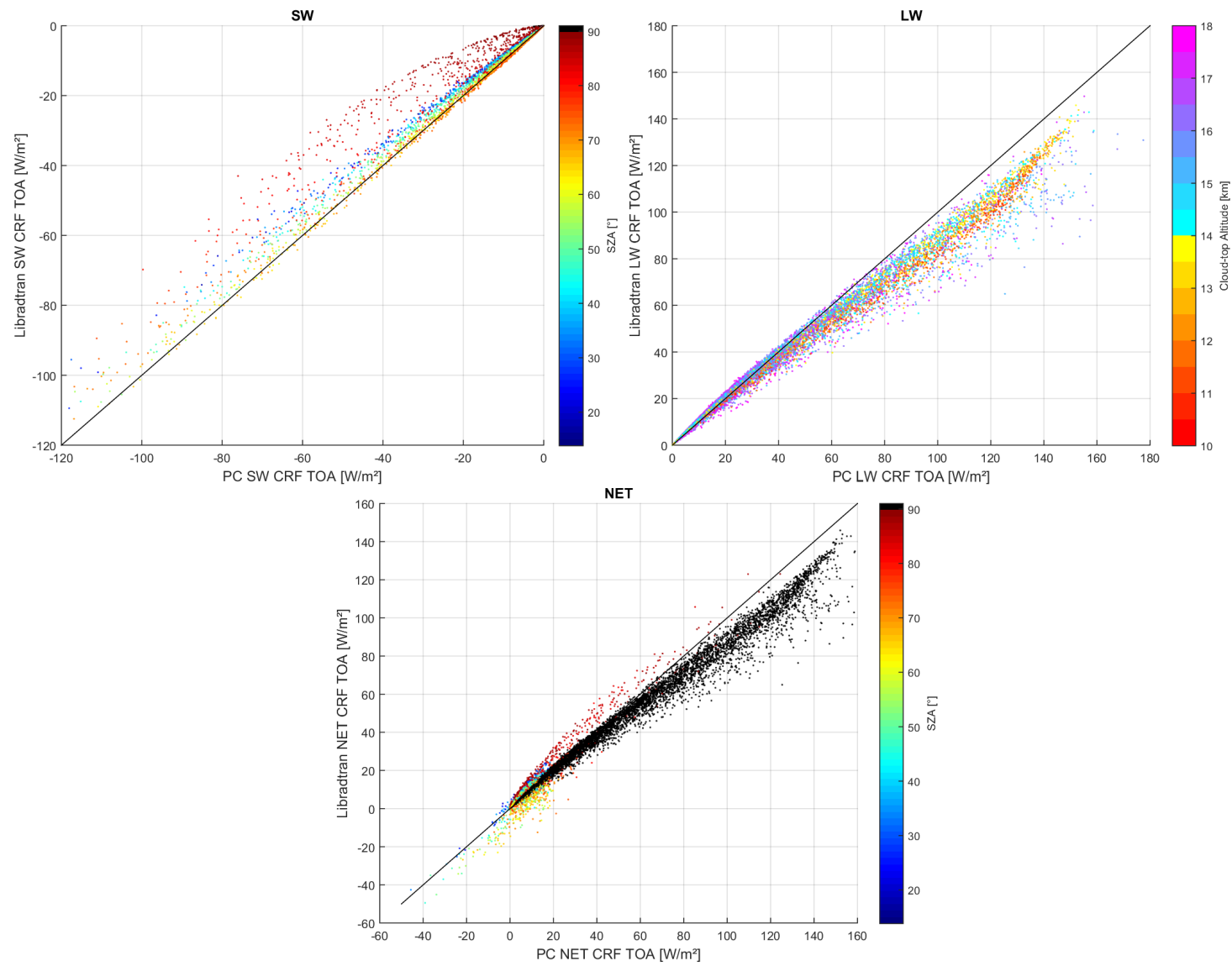

Figura 4.5 - Comparação entre os resultados para a forçante radiativa instantânea calculados pelo libRadtran e pelo modelo de Corti e Peter.

pouco maior que o calculado utilizando o libRadtran. Entretanto, os valores médios da forçante anual para ambos os modelos são compatíveis entre si, sendo esses resultados mais discutidos nas seções seguintes.

\subsubsection{Ciclo diurno da forçante radiativa}

Com os resultados da seção 3.2.1 do capítulo anterior, ficou clara a importância de estudar o ciclo diurno das nuvens cirrus na Amazônia, que apresentou uma variação da profundidade óptica bem determinada e que correlaciona bem com o ciclo diurno de precipitação. Com a forte dependência que o efeito radiativo das nuvens cirrus têm com o COD, é esperado que o reflexo desse ciclo diurno apareça também na forçante radiativa. Desta forma, calculamos a forçante radiativa no TOA e BOA ao longo do dia, que são apresentadas na figura 4.6. As curvas mostram o valor médio horário da forçante radiativa overcast no SW, LW e NET, com as barras representando o intervalo interquartil ( $25 \%$ e $75 \%$ ) da distribuição da forçante radiativa instantânea 
naquela hora do dia. Podemos ver imediatamente os efeitos do ciclo diurno do COD na forçante radiativa, tanto no TOA quanto no BOA. No espectro de LW, o efeito na forçante é claro e causado majoritariamente pelo ciclo diurno da profundidade óptica, com um aumento no efeito de aquecimento a partir das 14h, com valor médio máximo em torno das $18 \mathrm{~h}$ e que diminui a partir dai. No espectro de SW, o ângulo solar zenital e a profundidade óptica são capazes de gerar uma variação grande da forçante radiativa com a hora do dia. Antes das $7 \mathrm{~h}$ e depois das 16h, o SZA se aproxima de $90^{\circ}$ e a irradiância solar direta, que interage com a camada de nuvem cirrus, é drasticamente reduzida, o que reduz a forçante radiativa das nuvens cirrus mesmo com o aumento da profundidade óptica a partir das 14h. Porem, é possível ver claramente a assimetria na forçante radiativa em torno do meio-dia causado pelo ciclo diurno da profundidade óptica, com uma maior intensidade da forçante no fim da tarde.
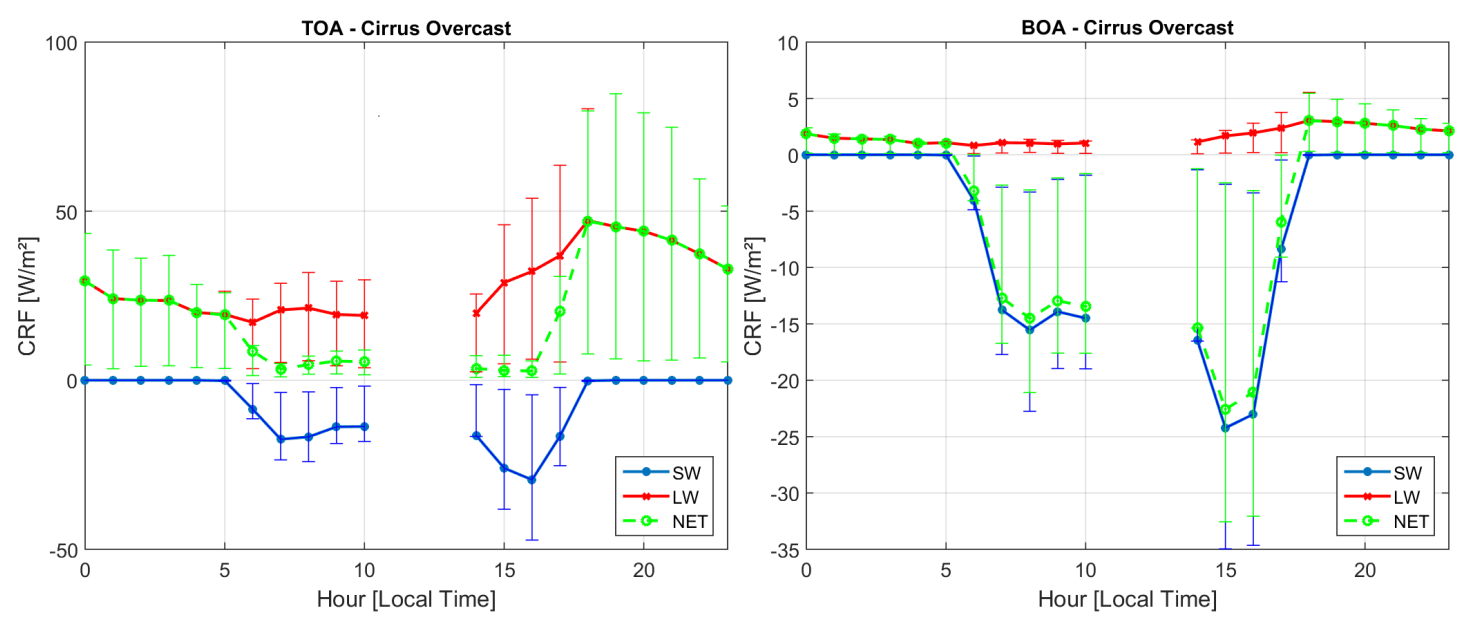

Figura 4.6 - Média horária da forçante radiativa overcast no topo da atmosfera (TOA) e na superfície (BOA). As barras de erros representam o intervalo interquartil da distribuição horária.

Esse tipo de ciclo diurno não é esperado em latitudes médias porque a formação de nuvens cirrus nessas latitudes ocorre principalmente pela chegada de frentes, e não tem relação com ciclo de precipitação e convecção profunda, como é o caso da Amazônia. Kienast-Sjögren et al. (2016) reforça esse comportamento em sua climatologia de cirrus sobre a Europa na medida em que fixou, para todos os seus cálculos de transferência radiativa, a constante solar em $684 W \mathrm{~m}^{-2}$ e o ângulo solar zenital em $60^{\circ}$, que resulta em um fluxo solar incidente de $342 \mathrm{~W} \mathrm{~m}^{-2}$ e que corresponde aproximadamente à condição de irradiância solar média global (com zero irradiância durante a noite), como sugerido pela versão online do modelo CP 
e outros estudos (ex. Liou (1986)). O resultado prático disso é que para qualquer cálculo da forçante radiativa instantânea de uma nuvem cirrus o valor encontrado representaria a média diurna e anual da forçante radiativa, independente da hora que a nuvem foi detectada. Um efeito dessa abordagem é que, mesmo que as nuvens cirrus não apresente ciclo diurno, esse método poderia introduzir um viés (difícil) na forçante radiativa caso as nuvens cirrus apresente um ciclo anual, que é o que acontece em todo planeta.

Desta forma, para contabilizar corretamente os efeitos radiativos do ciclo diurno das nuvens cirrus na Amazônia, a forçante radiativa anual overcast deve ser calculada como a média do ciclo diurno da forçante radiativa da figura 4.6 e a forçante radiativa anual all sky (ou simplesmente forçante radiativa das nuvens cirrus) deve ser calculada pela média do ciclo diurno da forçante radiativa ponderada pelo ciclo diurno da frequência de ocorrência. Fazendo esse procedimento, e considerando uma interpolação linear para o período entre 11h e 13h em que não temos medidas, os resultados da forçante radiativa de nuvens cirrus na Amazônia são apresentados na tabela 4.1. Vemos que a forçante radiativa (NET) das nuvens cirrus é positiva no topo da atmosfera e negativa na superfície, correspondendo a 19,1(4) e -5,9(3) $\mathrm{W} \mathrm{m}^{-2}$, respectivamente, com valores overcast muito próximos aos valores all sky (devido a alta frequência de ocorrência). Os resultados obtidos com o modelo de Corti e Peter (CP) foram notavelmente muito próximos aos do libRadtran, com diferença percentual de 13,1 \%, 8,6 \% e 6,6\% para a forçante no SW, LW e NET, respectivamente. Esse resultado é surpreendentemente bom, dada a simplicidade do modelo frente a natureza de multicamadas das nuvens cirrus na Amazônia e a metodologia aplicada neste trabalho, em que consideramos apenas a temperatura da camada mais alta do perfil. Outro aspecto interessante foi que a maior diferença apareceu no espectro de onda curta, onde, apesar de ambos os modelos utilizarem a aproximação plano-paralelo da atmosfera, mostra grandes diferenças no valor da forçante radiativa instantânea em função do SZA.

Kienast-Sjögren et al. (2016) utilizou o modelo de CP em sua climatologia de nuvens cirrus na Europa, medida com 3 sistemas lidar (similares ao utilizado neste trabalho) em 3 sítios experimentais distintos (Jungfraujoch, Zürich e Jülich). As nuvens cirrus na Europa possuem uma forçante radiativa overcast não muito diferente das nuvens cirrus na amazônia $\left(6,2,10,6\right.$ e $11 \mathrm{~W} \mathrm{~m}^{-2}$ para os 3 sítios), sendo estes valores um pouco menor principalmente por ocorrerem em altitudes mais baixas. Apesar disso e do menor contraste entre a temperatura da nuvem e da superfície, a forçante radiativa All sky dessas nuvens é muito menor que na Amazônia, estimada em 0.9, 
Tabela 4.1 - Forçante radiativa das nuvens cirrus na Amazônia.

\begin{tabular}{|c|c|c|c|c|}
\hline & & $\mathrm{CRF}_{\mathrm{SW}}\left[\mathrm{W} / \mathrm{m}^{2}\right]$ & $\mathrm{CRF}_{\mathrm{LW}}\left[\mathrm{W} / \mathrm{m}^{2}\right]$ & $\mathrm{CRF}_{\mathrm{NET}}\left[\mathrm{W} / \mathrm{m}^{2}\right]$ \\
\hline \multicolumn{5}{|l|}{ Overcast } \\
\hline \multirow{2}{*}{ libRadtran } & $\mathrm{BOA}$ & $-7,5 \pm 0.6$ & $1,63 \pm 0,04$ & $-5,9 \pm 0,3$ \\
\hline & TOA & $-8,5 \pm 0.7$ & $27,6 \pm 0,5$ & $19,1 \pm 0,4$ \\
\hline Corti and Peter & TOA & $-9,6 \pm 0,7$ & $30,0 \pm 0,6$ & $20,4 \pm 0,4$ \\
\hline \multicolumn{5}{|l|}{ All sky } \\
\hline \multirow{2}{*}{ libRadtran } & $\mathrm{BOA}$ & $-5,0 \pm 0,4$ & $1,25 \pm 0,04$ & $-3,7 \pm 0,2$ \\
\hline & TOA & $-5,7 \pm 0,5$ & $21,0 \pm 0,6$ & $15,3 \pm 0,4$ \\
\hline Corti and Peter & TOA & $-6,5 \pm 0,5$ & $22,9 \pm 0,6$ & $16,4 \pm 0,5$ \\
\hline
\end{tabular}

1.0 e $1.7 \mathrm{~W} \mathrm{~m}^{-2}$. Isso se deve porque a frequência de ocorrência absoluta das nuvens cirrus na Europa é muito menor que na Amazônia ou em regiões tropicais em geral.

\subsubsection{Forçante radiativa vs Classificação dos Cirrus}

Apesar da forçante radiativa instantânea poder assumir valores altos, como mostrado na seção 4.2.1, a maioria das nuvens cirrus medidas na Amazônia são opticamente finas $(\tau<0,3)$, correspondendo a cerca de $75 \%$ das nuvens cirrus detectadas. Essas nuvens mais finas, que estão na faixa de profundidades ópticas em que a sua detecção representa um desafio, ainda podem interagir fortemente com a radiação, correspondendo a um grande intervalo de valores da forçante radiativa. Assim, para avaliar o impacto relativo que essas nuvens mais finas têm na forçante total de nuvens cirrus, utilizamos a definição de Sassen et al. (2008) para categorizar o perfil de nuvens cirrus em subvisuais $\left(\tau_{\text {column }}<0,03\right)$, finas $\left(0,03<\tau_{\text {column }}<0,3\right)$ e opacas $\left(\tau_{\text {column }}\right.$ $>0,3)$, e calculamos sua correspondente contribuição para a forçante radiativa. A figura 4.7 mostra a frequência relativa de cada categoria de nuvens cirrus e sua correspondente contribuição para a $C R F_{N E T \text { (overcast) }}$ no TOA e BOA. Podemos ver que apesar das nuvens cirrus subvisuais representarem aproximadamente $1 / 3$ de todas as nuvens, elas contribuem com uma fração da forçante radiativa anual (overcast) de apenas $1,8 \%\left(0,36 \mathrm{~W} \mathrm{~m}^{-2}\right)$ e $2,4 \%\left(-0,10 \mathrm{~W} \mathrm{~m}^{-2}\right)$ no TOA e BOA, respectivamente, variando de $1,4 \%$ e 1,6 \% (TOA e BOA) na estação de transição, a até $3,7 \%$ e $6,0 \%$ (TOA e BOA) na estação seca. Em contraste, as nuvens opacas, que representam também algo em torno de $1 / 3$ da frequência relativa das nuvens cirrus, são responsáveis por $72.5 \%\left(14.09 \mathrm{~W} \mathrm{~m}^{-2}\right)$ e $62.8 \%\left(-2.52 \mathrm{~W} \mathrm{~m}^{-2}\right)$ da forçante 
radiativa (overcast) no TOA e BOA.
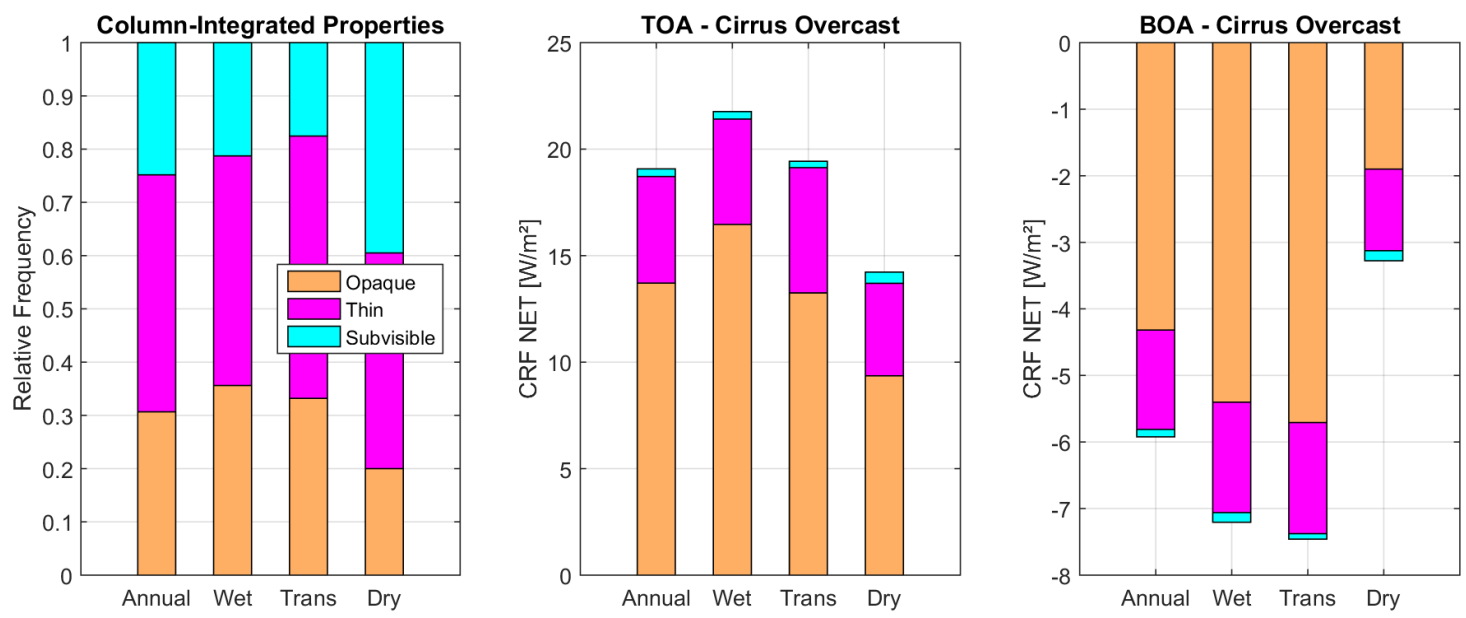

Figura 4.7 - Frequência relativa de ocorrência das categorias de nuvens cirrus e sua contribuição para a forçante radiativa overcast no topo e na base da atmosfera.

Mesmo que a contribuição relativa das nuvens subvisuais na forçante radiativa total pareça pequena, em termos absolutos (All sky) ainda é muito significativa. Como mencionado acima, a forçante radiativa anual de nuvens cirrus no TOA sobre a Europa foi estimada em $0,9,1,0$ e $1,7 \mathrm{~W} \mathrm{~m}^{-2}$ para os 3 diferentes sites experimentais do estudo (KIENAST-SJÖGREN et al., 2016), que é muito próximo da forçante radiativa de $0,26 \mathrm{~W} \mathrm{~m}^{-2}$ das nuvens subvisuais e dos $3,7 \mathrm{~W} \mathrm{~m}^{-2}$ das nuvens finas. Essa alta frequência de ocorrência e alto valor da forçante radiativa faz com que possíveis efeitos que alterem a formação, tempo de vida e outras propriedades físicas dessas nuvens possam resultar em um impacto significativo no balaço radiativo do planeta. Um passo complementar na avaliação dos efeitos climáticos dessas nuvens mais finas poderia ser feito através da avaliação da performance dos produtos de satélites na detecção e determinação das propriedades físicas dessas nuvens na região da Amazônia. A avaliação poderia ser feita pela comparação entre medidas concomitantes com o lidar em solo. Alem disso, determinar o grau de contaminação causada por essas nuvens mais finas em medidas de instrumentos passivos baseados em solo, como os fotômetros da rede Aeronet.

\subsubsection{Perfil da taxa de aquecimento radiativo}

As nuvens cirrus não somente diminuem a quantidade de radiação que chega na superfície ou que é emitida pelo sistema climático para o espaço, mas também par- 
ticipam ativamente de processos radiativos que tem influência na dinâmica e no equilíbrio térmico da troposfera e baixa estratosfera, sendo atribuído a essas nuvens um papel importante na circulação entre a troposfera e a estratosfera, e na manutenção da tropopausa tropical (LIOU, 1986; CORTI et al., 2005; CORTI et al., 2006). Utilizamos o libRadtran para calcular o perfil da taxa de aquecimento radiativo para a atmosfera com e sem a presença das nuvens cirrus e assim calcular seu efeito radiativo.

O painel a esquerda na figura 4.8 mostra o perfil da taxa de aquecimento radiativo médio (em $K d i a^{-1}$ ) que a atmosfera teria sem a presença de nuvens (Clear sky, $\left.H R_{\text {clear }}\right)$, o perfil médio do $H R$ considerando somente os perfis com a presença de nuvens cirrus (overcast, $H R_{\text {cloudy }}$ ) e o perfil médio da taxa de aquecimento radiativo total (All Sky), que é a média entre $H R_{\text {clear }}$ e $H R_{\text {cloudy }}$ ponderada pela frequência de ocorrência de nuvens cirrus e a frequência complementar de céu limpo. Para uma atmosfera limpa, temos uma taxa de aquecimento negativa (ou taxa de esfriamento)

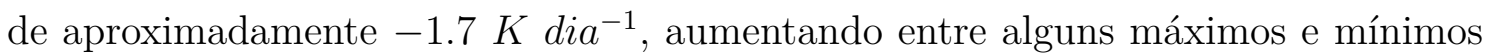
locais até um máximo de $-1 K d_{d i a^{-1}}$ entre 4 e $5 \mathrm{~km}$ devido principalmente à estrutura de vapor de água nessas altitudes. A taxa de aquecimento então decresce para um valor de $\approx-2 K d_{i a^{-1}}$ em uma altitude de $10 \mathrm{~km}$, onde a partir dai cresce, principalmente pelo perfil de ozônio, até fazer a transição entre esfriamento e aquecimento em $\approx 15 \mathrm{~km}$ e chegar a $0.5 \mathrm{~K} \mathrm{dia}^{-1} \mathrm{em} 17 \mathrm{~km}$, que é aproximadamente a altitude onde ocorre a temperatura mínima média da camada da tropopausa tropical (e define a cold point tropopause).

Quando consideramos a média da taxa de aquecimento radiativo instantâneo para os perfis com a presença de nuvens cirrus (curva verde) vemos que a taxa de esfriamento da atmosfera limpa é significativamente suprimido, principalmente nas regiões próximas às altitudes onde ocorrem as nuvens cirrus. Podemos ver ainda que a transição entre resfriamento e aquecimento acontece em uma altitude bem mais baixa, em torno de $13 \mathrm{~km}$. Devido a grande frequência de ocorrência das nuvens cirrus na Amazônia, o perfil médio da taxa de aquecimento radiativo com e sem a presença de nuvens cirrus é muito próximo ao perfil considerando somente cirrus, o que demonstra que os efeitos dessas nuvens no equilíbrio radiativo é quase permanente no perfil termodinâmico da floresta e não só episódico.

É importante mencionar que o perfil médio da taxa de aquecimento radiativo para o céu limpo (clear sky da figura 4.8) não é independente dos efeitos das nuvens cirrus que ocorrem na amazônia. Em outras palavras, este perfil não representa a 

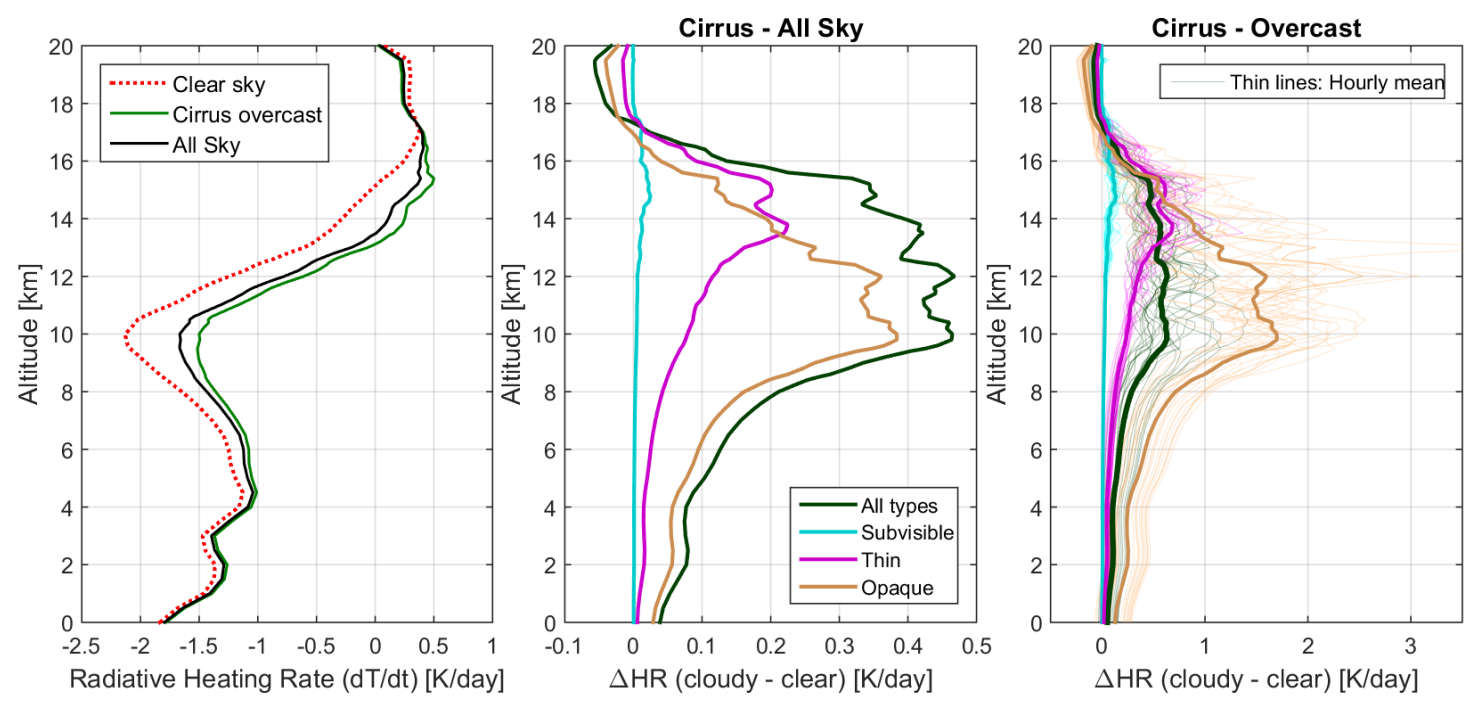

Figura 4.8 - (Esquerda): perfil da taxa de aquecimento radiativo para a atmosfera sem a presença de nuvens cirrus (clear sky), média do perfil quado as nuvens cirrus estão presentes (Cirrus overcast) e média ponderada pela frequência de ocorrência entre Clear sky e Cirrus overcast, representando o perfil da taxa de aquecimento radiativo da atmosfera. (Centro e direita): Contribuição das nuvens cirrus para o perfil da taxa de aquecimento radiativo da atmosfera, considerando o caso All sky e cirrus overcast.

taxa de aquecimento que seria observado caso as nuvens cirrus não "existissem" na Amazônia. Da mesma forma, o perfil $H R_{\text {cloudy }}$ não representa o efeito isolado da nuvem presente naquele instante na atmosfera. Isso ocorre porque, como mencionado acima, essa taxa de aquecimento é calculado utilizando perfis médios de temperatura e concentração de gases presentes na atmosfera e que são o resultado do equilíbrio de todos os componentes do sistema climático. Desta forma, para tentar isolar os efeitos que as nuvens cirrus causam no perfil da taxa de aquecimento, calculamos o $\Delta H R$ (equação 4.4) que é a diferença entre o perfil da taxa de aquecimento simulado com e sem incluir o perfil da nuvem cirrus medido, como descrito na seção 4.1.2, e os resultados estão apresentados no painel central e à direita da figura 4.8. Vemos que, em média, as nuvens cirrus aumentam o perfil de aquecimento até uma altitude de aproximadamente $17 \mathrm{~km}$, a partir de onde reduzem a taxa de aquecimento pois impedem que a radiação térmica emitida pela superfície aqueça estes níveis superiores. Como esperado, as nuvens cirrus mais opticamente espessas possuem maior intensidade de aquecimento, com as nuvens cirrus opacas apresentando valor médio máximo em torno de $1.5 \mathrm{~K} \mathrm{dia}^{-1}$ (overcast) e ocorrendo mais baixo na atmosfera. Depois, as nuvens finas tem máximo em torno de $14 \mathrm{~km}$, e com o perfil da taxa de aquecimento das cirrus subvisuais muito perto da tropopausa, com temperaturas muito mais frias (com emissão térmica baixa), porém com profundidade óptica 
muito pequena para gerar um efeito próximo ao das nuvens finas e opacas.

Apesar de parecer pequeno, o incremento na taxa de aquecimento gerado por nuvens finas e subvisíveis, frequentemente observadas dentro da camada da tropopausa (TTL, de Tropical Tropopause Layer) e que podem cobrir grandes áreas por muito tempo, podem ter um papel importante na manutenção da TTL. Isto é sugerido por simulações do equilíbrio térmico da atmosfera quando nuvens cirrus de diferentes profundidades ópticas estão presentes (LIOU; GEBIHART, 1982). Os autores concluíram que uma nuvem com profundidade óptica entre 0,2 e 0,4 à $10 \mathrm{~km}$ de altitude poderia gerar um perfil de temperatura que se equilibraria e com aproximadamente +10 K em relação à temperatura de equilíbrio para a atmosfera sem a presença de nuvens cirrus, aumentando também a espessura da camada da tropopausa, porém sem muitos efeitos no perfil acima de $20 \mathrm{~km}$. Entretanto, para nuvens cirrus mais espessas, a temperatura de equilíbrio ficava entre -3 e $+1 \mathrm{~K}$ (dependendo da altitude dos cirrus) em relação ao perfil de equilíbrio sem nuvens.

Até aqui vimos, separadamente, o efeito que as nuvens cirrus causam no perfil da taxa de aquecimento da troposfera como um todo. Os perfis médios mostrados na figura 4.8, mesmo mostrando separadamente os efeitos por tipos de nuvens, escondem algumas características interessantes sobre os efeitos nas vizinhanças das nuvens cirrus e que podem ter efeitos importantes na dinâmica da circulação atmosférica na parte superior da troposfera. Assim, a exemplo do que foi feito por Corti et al. (2005) e Corti et al. (2006), calculamos separadamente os perfis da taxa de aquecimento para o ar dentro das nuvens (in Clouds - HR $R_{\text {inClouds }}$ ) e para o ar fora da nuvem (Cloud free air - $H R_{\text {Cloud free air }}$ ). O $H R_{\text {inClouds }}$ é calculado fazendo-se a média das partes do perfil da taxa de aquecimento em que o coeficiente de extinção da nuvem cirrus é diferente de zero (entre a base e topo das camadas de nuvem

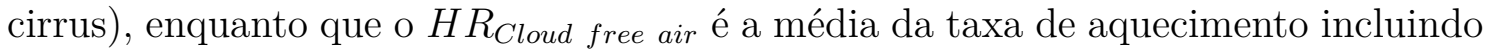
todas ar partes onde não se tem partículas da nuvem, o que inclui as partes do perfil fora da nuvem, entre camadas, e também os perfis onde não se tinha nenhuma nuvem presente (clear sky).

A figura 4.9 mostra os perfis médios da taxa de aquecimento dentro das nuvens (em azul), e do ar sem nuvens (Cloud free air, em vermelho). As barras horizontais representam os intervalos interquartis das médias horárias das correspondentes taxas de aquecimento. A curva pontilhada em vermelho (clear sky) é a média da taxa de aquecimento calculada sem incluir nenhuma nuvem (como feito na figura anterior) e em preto (all sky) é a taxa de aquecimento obtida pela média entre os 
perfis $H R_{\text {Cloud free air }}$ e $H R_{\text {inClouds }}$ ponderada pelo correspondente perfil vertical da frequência de ocorrência. Podemos ver um comportamento bem distinto da taxa de aquecimento dentro das camadas de nuvens. Esse perfil vertical da taxa de aquecimento no formato de " $S$ ", principalmente abaixo de $13 \mathrm{~km}$, é característico da interação com radiação de onda longa (tendo em vista que no SW só se tem aquecimento). Para as nuvens mais espessas, a radiação térmica emitida pela superfície é absorvida muito próximo da base da nuvem, que apresenta um aumento grande da taxa que aquecimento (como entre 7 e $10 \mathrm{~km}$ ). Próximo ao topo, essas mesmas nuvens emitem radiação para o topo da atmosfera e assim a taxa de aquecimento fica negativa. Entretanto, as nuvens mais altas emitem muito menos radiação pois possuem temperaturas bem mais baixas. Assim, o efeito combinado de absorção da radiação térmica emitida pela superfície e baixa emissão de nuvem faz com que a taxa de aquecimento nessas nuvens mais altas seja, em média, positiva. Vale ainda notar que o perfil de aquecimento dentro da nuvem mostrado aqui é uma média. Para algumas nuvens mais espessas, a taxa de aquecimento instantânea dentro da nuvem pode chegar a valores muito mais altos, como no exemplo da figura 4.2 do começo do capítulo.

\subsection{Análise exploratória}

\subsubsection{Estimativa do viés da determinação do CRF por instrumentos em satélites polares.}

Medidas de satélites polares, como os feitos pelos instrumentos abordo dos satélites da constelação A-Train (https://atrain.nasa.gov/intro.php), são imprescindíveis para a caracterização global do efeito radiativo das nuvens cirrus. Um desses instrumentos é o CALIOP, um sistema lidar a bordo do satélite CALIPSO e que foi utilizado extensivamente na caracterização global de nuvens cirrus (ex., Nazaryan et al. (2008)). Por ser um sistema lidar, o CALIOP também é capaz de dar informação sobre a estrutura vertical do coeficiente de extinção das nuvens e também é capaz de detectar nuvens cirrus muito finas, como em nossas medidas com lidar em solo. Além do CALIOP, o sensor MODIS, a bordo dos satélites AQUA e TERRA, mede radiâncias solares refletidas pela Terra e são extensivamente utilizados para estimar a fração de cobertura de nuvens cirrus, conteúdo de gelo, e raio das partículas, além de utilizado para avaliar os efeitos radiativos das nuvens globalmente.

Apesar da diferente resolução espacial das medidas dos satélites e delas somente se repetirem sobre a mesma região em um período de aproximadamente 15 dias, uma importante limitação dessas medidas é a impossibilidade de acompanhar a evolução 


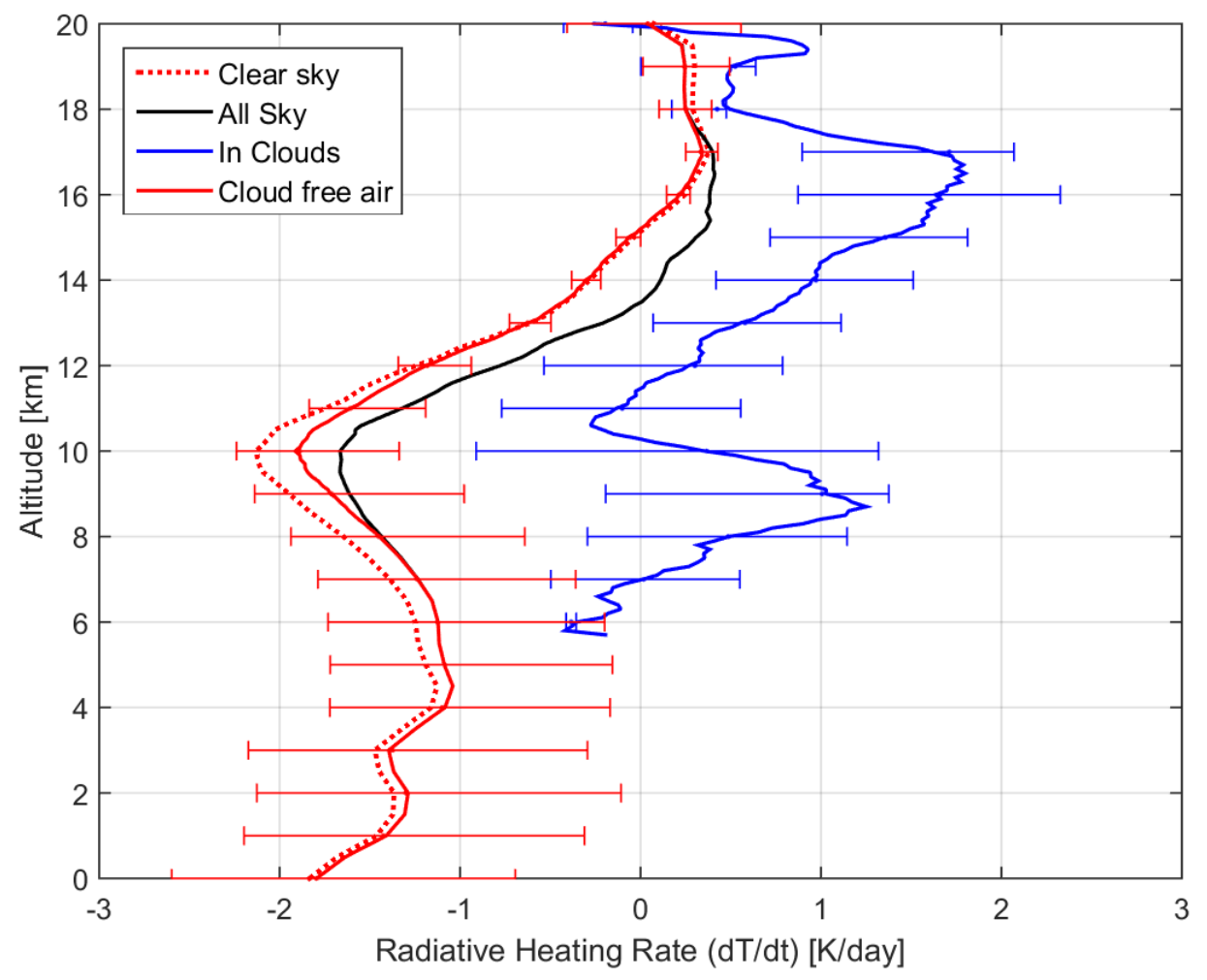

Figura 4.9 - Taxa de aquecimento radiativo, calculado sem incluir o perfil de nuvem (linha pontilhada em vermelho), média considerando somente a parte do perfil dentro de nuvens (azul) e para o ar fora da nuvem (em vermelho), que inclui a parte do perfil fora da nuvem, entre camadas, e também perfis em que não ocorre nuvens cirrus (céu limpo). As barras horizontais representam o intervalo interquartil em relação a distribuição das médias horárias das taxas de aquecimento. A linha em preto é a taxa de aquecimento radiativo total, calculado como a média temporal das taxas em dentro e fora da nuvem ponderadas pelo respectivo perfil de frequência de ocorrência.

temporal das nuvens. Por serem satélites polares, cruzam a região amazônica em poucos horários do dia. O CALIOP, por exemplo, realiza medidas mais próximo ao sítio experimental no início da tarde (aprox. entre 13:30 e 14:30 LT) e na madrugada (entre 1:00 e 2:00 LT). Para o MODIS, as propriedades das nuvens são medidas no fim da manha (entre 10h e 11h LT) e no início da tarde, (aprox. entre 13:00 e 14:30). Essa limitação de horários de observação pode gerar um viés nos resultados das propriedades das nuvens cirrus medidas na Amazônia, que, como visto, apresentam um ciclo diurno bem determinado (ver figura 4.10).

Com isto mente, fizemos um exercício para estimar a magnitude desse viés no valor da forçante radiativa de nuvens cirrus quando derivada das medidas do CALIOP e do 


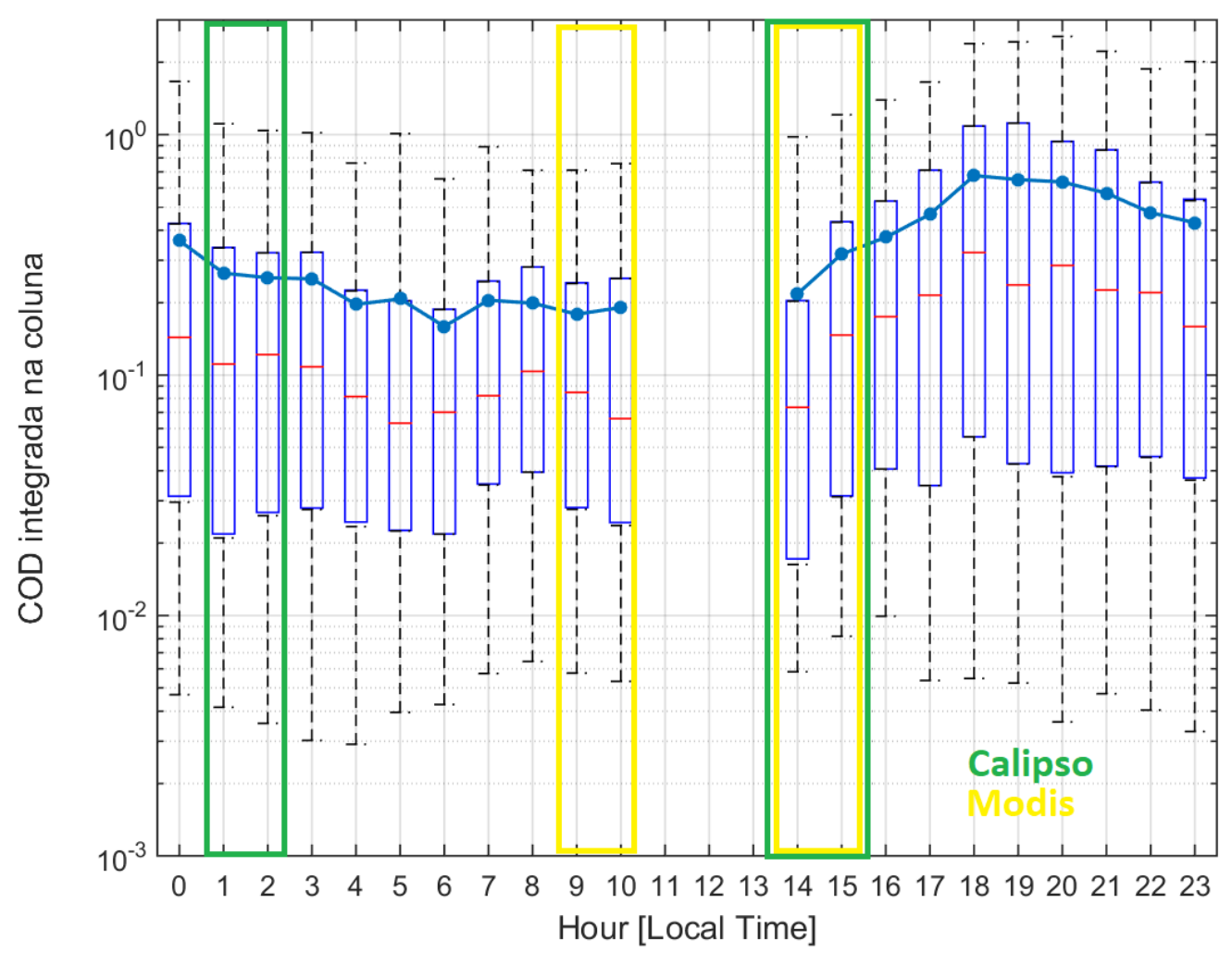

Figura 4.10 - Boxplot (5, 25, 50, 75 e 95 percentil) da profundidade óptica total da coluna de nuvens cirrus em função da hora do dia. A linha em azul mostra o valor médio.

MODIS. Para isso, utilizamos recortes temporais dos nossos resultados das propriedades ópticas e geométricas das nuvens cirrus para emular quais seriam os resultados dessas medidas caso tivessem sido realizadas por esses satélites (assumindo que não há diferenças nos limites de detecção entre o nosso lidar e os instrumentos dos satélites). Na figura 4.9, temos o boxplot da profundidade óptica das nuvens cirrus em função da hora do dia e as janelas temporais utilizadas para emular as medidas do CALIPSO e do MODIS. Para essas simulações, definimos, então, os seguintes cenários:

- Cenário 1 - CALIPSO: Recorte dos dados tomados de 1:00 às 14:59 e de 14:00 às 15:59.

- Cenário 2 - MODIS: Recorte dos dados tomados de 9:00 às 10:59 e de 14:00 às $15: 59$.

Para o cálculo da forçante radiativa, utilizamos o modelo CP que é mais rápido de 
ser aplicado. Para calcular o valor da forçante de forma que represente o resultado para a média anual a partir de um subconjunto com poucas horas no dia, calculamos, para cada perfil de nuvem, a média da forçante radiativa para $24 \mathrm{~h}$ de variação do ângulo solar zenital (condição média diária de radiação). Dessa forma, estaríamos considerando que as nuvens medidas nesses pequenos recortes no tempo seriam as mesmas em qualquer hora do dia e ainda preservamos os ciclos sazonais dessas nuvens. Além desses dois cenários, um terceiro cenário foi obtido determinando qual seria a forçante radiativa para toda nossa base de dados ignorando o ciclo diurno das nuvens cirrus. Isso foi feito pelo cálculo da forçante utilizando o modelo CP, porém com as condições de radiação médias diárias de radiação descrito acima (e não como feito por Erika et al, discutido na seção 4.2.2).

A tabela 4.2 compila os resultados para a forçante radiativa nos 3 cenários descritos acima, além do resultado real para referência. Começamos a análise pelo cenário 3, onde toda a base de dados é utilizada, porém o ciclo diurno é ignorado. Vemos que, como esperado, não existe nenhuma diferença na $C R F_{L W}$ para o caso de referência (verdadeiro). Isso é esperado pois a forçante de onda longa não depende da hora do dia, sempre causando um efeito de aquecimento. Este resultado não é o mesmo para o SW. Como podemos ver, a $C R F_{S W}$ no cenário 3 é mais negativa se comparada ao caso verdadeiro, sendo assim porque, neste cenário, as nuvens mais espessas que ocorrem durante o fim da tarde e à noite também contribuem para a forçante média diurna. Como saldo, para o cenário 3 , há uma diminuição na $C R F_{N E T}$ de $3 \mathrm{~W} \mathrm{~m}^{-2}$.

Para ambos os cenários 1 e 2 , a $C R F_{L W}$ é substancialmente menor em relação ao caso verdadeiro. Isso ocorre porque os horários medidos pelo CALIPSO e MODIS não incluem aqueles horários em que ocorre um grande aumento na profundida óptica das nuvens cirrus. Como vimos, isso ocorre no fim da tarde e começo da noite, com máximo $\approx 18 \mathrm{~h}$ (ver figura 4.9 ). Para a forçante de onda curta, o resultado não difere muito do caso verdadeiro, mas os cenários 1 e 2 tem resultados diferentes. Para o caso do CALIPSO (cenário 1), a forçante de onda curta é um pouco mais negativa, pois os dados do CALIPSO incluírem uma parte do ciclo diurno em que o COD já começa a aumentar durante a tarde, ou ainda não chegou próximo ao mínimo durante a madrugada. Para o MODIS, a forçante de onda curta é menos intensa, pois os horários de medidas estão próximos ao mínimo que ocorre ao meio-dia. Como balanço geral, a forçante radiativa líquida $\left(C R F_{N E T}\right)$, para os cenários 1 e 2 , são significativamente menores que o caso verdadeiro. Com o cenário do CALIPSO subestimando em $32 \%$ a forçante no topo da atmosfera, enquanto que no cenário do MODIS se subestimaria em cerca de $49 \%$. 
Tabela 4.2 - Forçante radiativa das nuvens cirrus na Amazônia para os cenários hipotéticos que simulam medidas do CALIPSO, MODIS e do lidar em solo porém ignorando o ciclo diurno das nuvens cirrus. Os resultados marcados como "Verdadeiro" são os mesmos da tabela 4.1 calculados pelo modelo de Corti e Peter

\begin{tabular}{ccrrr}
\hline \multicolumn{1}{c}{ Modelo: Corti and Peter } & & $\mathrm{CRF}_{\mathrm{SW}}\left[\mathrm{W} / \mathrm{m}^{2}\right]$ & $\mathrm{CRF}_{\mathrm{LW}}\left[\mathrm{W} / \mathrm{m}^{2}\right]$ & $\mathrm{CRF}_{\mathrm{NET}}\left[\mathrm{W} / \mathrm{m}^{2}\right]$ \\
\hline Overcast & & & & \\
\hline Verdadeiro & TOA & $-9,6 \pm 0,7$ & $30,0 \pm 0,6$ & $20,4 \pm 0,4$ \\
\hline Cenário 1: CALIPSO & TOA & $-10.6 \pm 0.7$ & $25,9 \pm 1,4$ & $15,3 \pm 0,8$ \\
\hline Cenário 2: MODIS & TOA & $-9.3 \pm 0.7$ & $22,7 \pm 1,5$ & $13,4 \pm 0,8$ \\
\hline Cenário 3: ignorando ciclo diurno & TOA & $-12.7 \pm 0.3$ & $30,0 \pm 0,6$ & $17,3 \pm 0,3$ \\
\hline All sky & & & & \\
\hline & TOA & $-6,5 \pm 0,5$ & $22,9 \pm 0,6$ & $16,4 \pm 0,5$ \\
\hline Verdadeiro & TOA & $-7,7 \pm 0,5$ & $18,8 \pm 1,1$ & $11,1 \pm 0,6$ \\
\hline Cenário 1: CALIPSO & TOA & $-5,8 \pm 0,5$ & $14,1 \pm 1,0$ & $8,3 \pm 0,5$ \\
\hline Cenário 2: MODIS & TOA & $-9,7 \pm 0,3$ & $22,9 \pm 0.6$ & $13,2 \pm 0,4$ \\
\hline Cenário 3: ignorando ciclo diurno & & & &
\end{tabular}

Apesar dos valores tão altos encontrados para o viés nestes cenários, é importante lembrar que esses resultados foram encontrados sobre condições específicas descritas nesta seção e que não são necessariamente representativos de estudos publicados na literatura. Estes cenários serviram aqui somente como uma primeira investigação da magnitude desse possível viés, sem o rigor adequado que esse assunto demanda. Entretanto, pelo grande valor do viés encontrado, seria importante uma investigação mais detalhada. Especialmente porque dados do CALIPSO e MODIS são utilizados na literatura para o cálculo da forçante radiativa de nuvens cirrus nas regiões tropicais, onde se pode esperar um ciclo diurno intenso como o que encontramos na Amazônia. 


\section{Conclusões Gerais}

As nuvens cirrus cobrem uma grande fração de latitudes tropicais e desempenham um papel importante no balanço de radiação da Terra. Suas propriedades ópticas, altitude, cobertura vertical e horizontal controlam sua forçante radiativa e, portanto, medidas detalhadas de nuvens cirrus em diferentes locais geográficos são de extrema importância. Estudos relatando propriedades de nuvens cirrus sobre florestas tropicais como a Amazônia, no entanto, são escassos. Foi neste contexto que se inseriu este trabalho.

Uma extensiva base de dados medidos pelo sistema lidar UV do laboratório de Física Atmosférica entre julho de 2011 e junho de 2012 foi utilizada para a caracterização do ciclo anual das nuvens cirrus, que nos permitiu a derivação com alta resolução temporal e vertical das propriedades macro e microfísicas necessárias para avaliar o papel dessas nuvens no sistema climático. Além dos dados do Lidar, perfis de temperatura, pressão e umidade foram obtidos de radiossondagens próximas e informação adicional de reanálise foram utilizadas nesta caracterização (precipitação e velocidade do vento).

Simulações detalhadas dos perfis de retroespalhamento foram realizadas para a avaliação do desempenho dos algoritmos utilizados e da acurácia e precisão dos resultados obtidos. As simulações mostraram que a profundidade óptica das nuvens cirrus pode ser obtida sem erros sistemáticos, sofrendo somente a influência da flutuação estatística que tende a zero para um grande número de medidas, como é o caso da nossa base de dados. Vimos que, em geral, o erro aleatório na profundidade óptica (COD) determinado pelo método da Transmitância para um perfil único de 5 min medido com o nosso instrumento (pulso do laser com comprimento de onda de 355 nm) está tipicamente entre 0,006 e 0,014 para os valores típicos de razão sinal ruído $(S / R)$, que, por se tratar apenas de ruído aleatório, decresce com a raiz quadrada do número de perfis medidos (foram mais de 11 mil perfis com nuvens cirrus na base de dados analisado). O método de Klett para o cálculo da profundidade óptica é muito mais preciso, com um décimo do erro aleatório quando é aplicado nos mesmos perfis de $5 \mathrm{~min}$, porém é sujeito a erro sistemático devido a escolha de um valor à priori, que pode estar equivocado, para a razão lidar (razão entre os coeficientes de extinção e retroespalhamento - $L R$ ). Assim se torna vantajoso combinar o método da Transmitância com o método de Klett para calcularmos o melhor valor de razão lidar para as nuvens cirrus. Pelas simulações, vimos que a utilização de perfis de nuvens cirrus com COD > 0,01 é suficiente para uma medida confiável do LR. 
Também foram realizadas simulações para avaliar o limite de detecção de nuvens cirrus pelo sistema lidar como uma função da qualidade do sinal de retroespalhamento (determinada pela razão sinal ruído), pela profundidade óptica e pelo coeficiente de retroespalhamento $\left(\beta_{\text {par }}\right)$. Vimos que mesmo com sinais muito fracos (com razão sinal ruído baixo) é possível a detecção de nuvens cirrus muito finas opticamente, desde que elas possuam um coeficiente de retroespalhamento grande, pois este gera um pico intenso no sinal do lidar que é fácil de ser diferenciado do sinal molecular. Para nuvens que não possuem valores altos de $\beta_{\text {par }}$ e com sinais não muito fortes (baixo S/R), ainda é possível realizar a detecção desde que essas nuvens possuam uma espessura geométrica não muito pequena (e, consequentemente, um COD não muito pequeno). De maneira geral, $100 \%$ das nuvens cirrus simuladas com COD > $0,005, \beta_{\text {par }}>1 \mathrm{Mm}^{-1} \mathrm{sr}^{-1}$ e razão sinal ruído na base da nuvem $>1$ foram detectadas. Para nuvens com $\mathrm{S} / \mathrm{N}=3$ na base, o COD mínimo em que foram detectadas todas as nuvens foi próximo a 0,001 .

Os cristais de gelo das nuvens cirrus são grandes, $R_{\text {eff }} \approx 10-100 \mu \mathrm{m}$, em comparação com o comprimento de onda do pulso do laser (355 nm) e produzem um grande espalhamento na direção frontal (pico de difração). Esse fato, combinado com a pequena abertura angular típica do campo de visão do telescópio dos sistemas lidar, resultam em um importante efeito de múltiplo espalhamento que pode causar grande distorção no sinal medido pelo lidar. Durante a análise dos dados, foi constatado que esse efeito era significante e que a correção simplificada que era aplicada anteriormente (e ainda muito aplicada na literatura) não era suficiente para dar uma correção acurada, o que demandou um esforço significativo para a correção desses efeitos. Assim, com a ajuda de colaboradores do Leibniz Institute for Tropospheric Research, em Leipzig, Alemanha, desenvolvemos um método que corrige simultaneamente, de forma iterativa, as distorções no COD e no LR, utilizando o bem conhecido modelo de Hogan (HOGAN, 2006) para a simulação de múltiplo espalhamento neste trabalho. Esse método desenvolvido para a correção de efeitos de MS foi apresentado no 28th International Laser Radar Conference em 2017 (GOUVEIA et al., 2018). Essa metodologia para correção dos dados será futuramente expandida para casos gerais e submetida para publicação.

O conjunto de dados com um ano de medições com lidar em solo coletados entre julho de 2011 e junho de 2012 foi usado para investigar as propriedades geométricas e ópticas das nuvens cirrus na Amazônia central, cujos resultados foram publicados na revista Atmos. Chem. and Phys. (GOUVEIA et al., 2017). Um algoritmo foi desenvolvido para analisar esse conjunto de dados, com alta resolução vertical e tem- 
poral, e para encontrar automaticamente as nuvens, calcular o retroespalhamento de partículas, obter a profundidade óptica e a razão lidar. A frequência de ocorrência de nuvens cirrus durante o período de observação foi de 73,8 \%, valor superior ao relatado anteriormente na literatura para outras regiões tropicais. A frequência de cirrus atingiu 88,1 \% nos meses chuvosos (janeiro, fevereiro, março e abril), mas diminuiu para 59,2 \% nos meses secos (junho, julho, agosto e setembro). Análises da circulação de altos níveis e da precipitação durante os meses chuvosos indicam que a convecção profunda próxima ao sítio experimental provavelmente é a principal fonte desses cirrus. Durante o período seco, houve uma mistura de nuvens produzidas localmente e transportadas. Além disso, descobrimos que o ciclo diurno da frequência de ocorrência de cirros opacos e finos mostra um mínimo em torno de $12 \mathrm{~h}$ e um máximo em torno de 18h, seguindo o ciclo diurno da precipitação para ambas as estações.

As características geométricas, ópticas e microfísicas das nuvens cirros medidas no presente estudo foram consistentes com outros relatos de regiões tropicais. Os valores médios foram 12,9 \pm 2,2 $\mathrm{km}$ (base), 14,3 $\pm 1,9 \mathrm{~km}$ (topo), 1,4 $\pm 1,1 \mathrm{~km}$ (espessura) e $0,25 \pm 0,46$ (profundidade óptica). Nuvens cirrus foram encontradas em temperaturas abaixo de $-90{ }^{\circ} \mathrm{C}$, e $6 \%(16 \%)$ dos cirros observados tiveram sua base (topo) acima do nível da tropopausa ou dentro da camada da tropopausa tropical.

Ao analisar simultaneamente a altitude das nuvens e a COD, verificou-se que as nuvens cirrus observadas durante os meses da estação seca são opticamente mais finas e mais baixas em altitude do que aquelas observadas durante o período chuvoso. Durante os meses da estação chuvosa, há uma faixa mais ampla de COD para uma altitude fixa e vice-versa, que está associada à variabilidade na intensidade da convecção profunda na Amazônia. A distribuição vertical da frequência de ocorrência das nuvens detectadas mostra uma distribuição bimodal para os cirrus finos e subvisíveis durante a estação chuvosa, que provavelmente se origina do overshooting da convecção profunda e da formação in-situ próximo à tropopausa.

Pela primeira vez, a razão lidar das nuvens cirrus foi obtida para a região amazônica. A razão lidar média, corrigida para o efeito de espalhamento múltiplo, foi de 23,6 \pm 8,1 sr, de acordo com outros relatos das regiões tropicais. A distribuição estatística das razões lidar medidas durante as diferentes estações é a mesma, e elas também não variam com a temperatura (altitude) das nuvens, indicando que elas são bem misturadas verticalmente. Observou-se, no entanto, que as distribuições da razão lidar para diferentes categorias de cirrus são bastante diferentes. Eles tendem para 
razão lidar mais baixas para COD menor. De todas as nuvens cirrus observadas, 41,6 $\%$ foram classificadas como subvisíveis (COD $<0,03), 37,8 \%$ como finas $(0,03<$ COD $<0,3)$ e $20,5 \%$ como opacas (COD $>0,3)$. Durante os meses secos, as nuvens cirros subvisíveis atingiram uma frequência máxima de ocorrência de $46 \%$, enquanto os cirros opacos tiveram seu máximo durante os meses da estação chuvosa (25,2 \%). Esses valores são característicos para a região em estudo e um pouco diferentes de outras regiões tropicais. Assim, a Amazônia central tem uma alta frequência de nuvens cirrus em geral e uma grande fração de nuvens cirrus subvisíveis. Portanto, a profundidade óptica do aerossol determinada nesta região, por exemplo por fotômetros solares e sensores baseados em satélite, podem estar contaminados pela presença dessas nuvens finas. Trabalhos futuros devem ser realizados para avaliar a extensão dessa contaminação na Amazônia.

Utilizamos o conjunto de propriedades ópticas e geométricas das nuvens cirrus, derivadas a partir deste um ano de medições com lidar em solo, para estimar o efeito radiativo das nuvens cirrus na região da Amazônia. Os efeitos radiativos dessas nuvens foram estimados em termos de sua forçante radiativa (CRF) e do perfil da taxa de aquecimento radiativo. Para isso, utilizamos o modelo libRadtran para o cálculo detalhado da transferência radiativa na atmosfera mantendo a informação detalhada da estrutura vertical da nuvem cirrus, com alta resolução vertical e temporal. Adicionalmente, utilizamos o modelo simplificado de Corti e Peter, que forneceu um cálculo simples, porém acurado, da forçante radiativa no topo da atmosfera. Estes resultados serviram de validação para o cálculo mais detalhado e também possibilitaram uma análise exploratória de alguns cenários para a CRF.

Com uma frequência de ocorrência tão elevada, e ocorrendo com temperaturas muito baixas (grande altitude) sobre uma floresta intocada e de albedo de superfície baixo $(\alpha=0,12)$, as nuvens cirrus na Amazônia causam um efeito de aquecimento no topo da atmosfera (TOA) e um efeito de esfriamento na superfície (BOA), com forçante radiativa no TOA e BOA de $15,5 \pm 0,4 W m^{-2}$ e $-3,7 \pm 0,2 W^{-2}$, respectivamente, muito mais intenso do que o estimado para 3 sítios experimentais na Europa $(0,9$, 1,0 e 1,7 W $m^{-2}$ no TOA) (KIENAST-SJÖGREN et al., 2016).

A forçante radiativa instantânea mostrou uma dependência aproximadamente linear com a profundidade óptica total das camadas de nuvens cirrus no perfil $\tau_{\text {Coluna }}$ para o espectro de onda curta, com uma dependência mais complexa quando o ângulo solar zenital (SZA) era maior que aproximadamente $75^{\circ}$. No espectro de onda longa, uma forte dependência com a $\left(\tau_{\text {Coluna }}\right)$ também foi observada, porém bastante mo- 
dulada pela temperatura das nuvens cirrus. De maneira geral, as nuvens cirrus com profundidade óptica maiores apresentam maior CRF líquido, com valores instantâneos atingindo máximos (mínimos) de $140(-65) W m^{-2}$ para o período noturno (diurno) no TOA. Juntos, os perfis verticais com $\tau_{\text {Coluna }}>0,3$ foram responsáveis por cerca de $72 \%$ (62\%) da forçante radiativa líquida no TOA (BOA), o que significa que uma importante fração do CRF é gerada por cirrus opticamente mais finos $\left(\tau_{\text {Coluna }}<0,3\right)$, que são mais difíceis de serem detectados por radares e instrumentos passivos a bordo de satélites.

O ciclo diurno observado para a profundidade óptica das nuvens cirrus se refletiu na forçante radiativa horária média, que apresentou um ciclo diurno visível tanto no espectro de onda longa quando no de onda curta. Esse ciclo resultou em um CRF líquido médio no TOA (BOA) que variou em função da hora do dia entre 1,7 (-23) $W m^{-2}$ à tarde, evoluindo até $47(3,1) W m^{-2}$ durante a noite. Um ciclo diurno intenso como esse não pode ser medido por satélites polares como os do A-Train, os quais cruzam o equador em horários fixos, por isso suas medidas podem apresentar um importante viés. Com isso em mente, fizemos um experimento simplificado para ter uma primeira estimativa exploratória do possível viés que as medidas do CALIPSO e do MODIS poderiam gerar se utilizados na determinação da forçante radiativa dos cirrus na Amazônia. O resultado mostrou que o valor da forçante radiativa líquida calculada pelas medidas do CALIPSO poderia ser subestimada em $32 \%$, enquanto que pelo MODIS seria cerca de $49 \%$. Apesar dos valores tão altos encontrados para o viés, lembramos que esses resultados foram encontrados sobre condições específicas descritas neste trabalho, servindo aqui somente como uma primeira investigação deste viés.

Vimos que as nuvens cirrus suprimem significativamente o esfriamento radiativo da atmosfera, gerando, em média, um aquecimento de aproximadamente 0,5 $\mathrm{K} \mathrm{dia} \mathrm{di}^{-1}$ entre 8 e 16 km, aquecendo menos próximo à superfície e causando um pequeno esfriamento acima de $17 \mathrm{~km}$. Se considerar somente o aquecimento que ocorre dentro da nuvem cirrus, a taxa de aquecimento instantâneo pode alcançar valores muito altos, chegando a extremos entre 10 e $20 \mathrm{~K} \mathrm{dia}^{-1}$, mas que em geral fica com uma taxa de aquecimento entre -1 e $2 \mathrm{~K} d i a^{-1}$. Na média, a taxa de aquecimento varia de uma maneira bem particular com a altitude onde ocorrem as nuvens cirrus, variando em torno de $1 \mathrm{~K} \mathrm{dia}^{-1}$. Acredita-se que esse perfil de aquecimento gerado pelas nuvens cirrus tenha um papel importante na circulação alta troposfera/baixa estratosfera, gerando um fluxo ascendente médio de massa de ar entre 15 e $2 \mathrm{~kg} \mathrm{~m}^{-2} \mathrm{dia}^{-1}$ para altitudes entre 13 e $16,5 \mathrm{~km}$ promovida somente pelo aquecimento radiativo do ar 
dentro das camadas de nuvem cirrus, realimentando a manutenção da camada da tropopausa tropical. 


\section{REFERÊNCIAS BIBLIOGRÁFICAS}

ACKERMAN, S.; STRABALA, K.; MENZEL, P.; FREY, R.; MOELLER, C.; GUMLEY, L. Discriminating clear-sky from cloud with modis algorithm theoretical basis document $(\bmod 35$. In: MODIS Cloud Mask Team, Cooperative Institute for Meteorological Satellite Studies, University of Wisconsin. [S.l.: s.n.], 2010. 48

ACKERMAN, S. A.; HOLZ, R. E.; FREY, R.; ELORANTA, E. W.; MADDUX, B. C.; MCGILL, M. Cloud detection with MODIS. Part II: Validation. Journal of Atmospheric and Oceanic Technology, v. 25, n. 7, p. 1073-1086, 2008. ISSN 07390572. 4, 48

ACKERMAN, T. P.; LIOU, K.-N.; VALERO, F. P.; PFISTER, L. Heating rates in tropical anvils. J. Atmos. Sci., v. 45, p. 1606-1623, 1988. 45

ADAMS, D. K.; FERNANDES, R. M. S.; HOLUB, K. L.; GUTMAN, S. I.; BARBOSA, H. M. J.; MACHADO, L. A. T.; CALHEIROS, A. J. P.; BENNETT, R. A.; KURSINSKI, E. R.; SAPUCCI, L. F.; DEMETS, C.; CHAGAS, G. F. B.; AREllano, A.; FILIZOLA, N.; ROCHA, A. A. A.; SILVA, R. A.; ASSUNCAO, L. M. F.; CIRINO, G. G.; PAUliqueVIS, T.; PORTElA, B. T. T.; SA, A.; SOUSA, J. M. de; TANAKA, L. M. S. The amazon dense gnss meteorological network: A new approach for examining water vapor and deep convection interactions in the tropics. Bulletin of the American Meteorological Society, v. 96, n. 12 , p. 2151-2165, 2015. Disponível em: <https://doi.org/10.1175/BAMS-D-13-00171.1>. 45

ADAMS, D. K.; GUTMAN, S. I.; HOLUB, K. L.; PEREIRA, D. S. GNSS observations of deep convective time scales in the Amazon. Geophysical Research Letters, v. 40, n. 11, p. 2818-2823, 2013. ISSN 00948276. 7, 41, 45, 53

ADAMS, D. K.; SOUZA, E. P. D.; COSTA, A. A. Convecção úmida na Amazônia: implicações para modelagem numérica. Revista Brasileira de Meteorologia, v. 24 , p. $168-178,2009.45$

Anderson, G. P. AFGL atmospheric constituent profiles (0-120km). [S.l.: s.n.], 1986. 57

ANSMANN, A.; WANDINGER, U.; RIEBESELL, M.; WEITKAMP, C.;

MICHAELIS, W. Independent measurement of extinction and backscatter profiles 
in cirrus clouds by using a combined raman elastic backscatter lidar. Appl. Opt., v. 31, p. $71137131,1992.12,14,36$

ANTUÑA-MARRERO, J. C.; LANDULFO, E.; ESTEVAN, R.; BARJA, B.; ROBOCK, A.; WOLFRAM, E.; RISTORI, P.; CLEMESHA, B.; ZARATTI, F.; FORNO, R.; ARMANDILLO, E.; BASTIDAS, Á. E.; BARAJA, Á. M. de F.; WHITEMAN, D. N.; QUEL, E.; BARBOSA, H. M. J.; LOPES, F.;

MONTILLA-ROSERO, E.; GUERRERO-RASCADO, J. L. Lalinet: The first latin american-born regional atmospheric observational network. Bulletin of the American Meteorological Society, v. 98, n. 6, p. 1255-1275, 2017. Disponível em: <https://doi.org/10.1175/BAMS-D-15-00228.1>. 5

ARRAUT, J. M.; NOBRE, C.; BARBOSA, H. M. J.; OBREGON, G.; MARENGO, J. Aerial rivers and lakes: Looking at large-scale moisture transport and its relation to amazonia and to subtropical rainfall in south america. Journal of Climate, v. 25, n. 2, p. 543-556, 2012. Disponível em:

<https://doi.org/10.1175/2011JCLI4189.1>. 7

BAARS, H.; ANSMANN, A.; ALTHAUSEN, D.; ENGELMANN, R.; HEESE, B.; MUlleR, D.; ARTAXO, P.; PAIXAO, M.; PAUliQUEVIS, T.; SOUZA, R.

Aerosol profiling with lidar in the Amazon basin during the wet and dry season. $\mathbf{J}$. Geophys. Res., v. 117, 2012. 5, 15

BARBOSA, H. M. J.; BARJA, B.; PAUliqueVIS, T.; GOUVEIA, D. a.; ARTAXO, P.; CIRINO, G. G.; SANTOS, R. M. N.; OLIVEIRA, a. B. A permanent Raman lidar station in the Amazon: description, characterization, and first results. Atmospheric Measurement Techniques, v. 7, n. 6, p. 1745-1762, jun 2014. ISSN 1867-8548. Disponível em:

$<$ http://www.atmos-meas-tech.net/7/1745/2014/>. 5, 7, 8, 32, 33, 53

BARBOSA H.M.J., F. L. A. S. D. N. B. B. P. R. D. G. C. J. E. M. G. M. E. L. A. B. E. Q. The first aline measurements and intercomparison exercise on lidar inversion algorithms. Óptica Pura y Aplicada, v. 47, p. 99-108, 2014. 5

BARJA, B. Tropical cirrus clouds measurements at Camagüey, Cuba. In: LIDAR REMOTE SENSING IN ATMOSPHERIC AND EARTH SCIENCES, PART II. 21st International Laser Radar Conference, 2002. p. 673-675. 55

BARJA, B.; ANTUNA, J. C. The effect of optically thin cirrus clouds on solar radiation in camaguey, cuba. Atmospheric Chemistry and Physics, v. 11, 
n. 16, p. 8625-8634, 2011. Disponível em:

<https://www.atmos-chem-phys.net/11/8625/2011/>. 1, 61

BARJA, B.; ANTUNA-MARRERO, J. C. Cirrus clouds optical properties measured with lidar at camaguey, cuba. Optica Pura y Aplicada, v. 39, p. 65, 01 2006. 4, 43

BARJA, B.; AROCHE, R. Cirrus clouds at camaguey, cuba. In: Proceedings of the SPARC 2000. [s.n.], 2001. Disponível em:

$<$ http://www . atmosp.physics. utoronto.ca/SPARC/SPARC2000_new/

PosterSess2/SessionP2_2/Gonzalez/BBarjaGonsalez_Abtr.html>. 32

BATES, D. R. Rayleigh scattering by air. Planet. Space Sci., v. 32, p. 785790 , 1984. 12,13

BAUM, B. A.; YANG, P.; HEYMSFIELD, A. J.; BANSEMER, A.; COLE, B. H.; MERRELLI, A.; SCHMITT, C.; WANG, C. Ice cloud single-scattering property models with the full phase matrix at wavelengths from 0.2 to $100 \mu \mathrm{m}$. Journal of Quantitative Spectroscopy and Radiative Transfer, Elsevier, v. 146, p. 123-139, 2014. ISSN 00224073. Disponível em: <http://dx.doi.org/10.1016/j.jqsrt.2014.02.029>. 57

BODHAINE, B. A.; WOOD, N. B.; DUTTON, E. G.; SLUSSER, J. R. On rayleigh optical depth calculations. J. Atmos. Oce. Tech., v. 16, p. 1854, 1999. 12

BOUCHER, O.; RANDALL, D.; ARTAXO, P.; BRETHERTON, C.; FEINGOLD, G.; FORSTER, P.; KERMINEN, V. M.; KONDO, Y.; LIAO, H.; LOHMANN, U.; RASCH, P.; SATHEESH, S.; SHERWOOD, S.; STEVENS, B.; ZHANG, X.

Clouds and aerosols. In: Climate Change 2013: The Physical Science Basis. Contribution of Working Group I to the Fifth Assessment Report of the Intergovernmental Panel on Climate Change. Cambridge, United Kingdom and New York, NY, USA: Cambridge University Press, 2013. book section 7, p. 571-658. ISBN ISBN 978-1-107-66182-0. Disponível em:

$<$ ww. climatechange2013.org $>$. 1, 4

BOURGEOIS, Q.; EKMAN, A. M. L.; IGEL, M. R.; KREJCI, R. Ubiquity and impact of thin mid-level clouds in the tropics. Nature Communications, Nature Publishing Group, v. 7, p. 12432, 2016. ISSN 2041-1723. Disponível em:

<http://www. nature.com/doifinder/10.1038/ncomms12432>. 60

BUCHOLTZ, A. Rayleigh scattering calculations for the terrestrial atmosphere. Appl. Opt., v. 34, p. 2765 2773, 1995. 11, 12, 13 
BURLEYSON, C. D.; FENG, Z.; HAGOS, S. M.; FAST, J.; MACHADO, L. A. T.; MARTIN, S. T. Spatial variability of the background diurnal cycle of deep convection around the goamazon2014/5 field campaign sites. Journal of Applied Meteorology and Climatology, v. 55, n. 7, p. 1579-1598, 2016. Disponível em: <https://doi.org/10.1175/JAMC-D-15-0229.1>. 40

CADET, B. A sub-tropical cirrus clouds climatology from reunion island $\left(21^{\circ} \mathrm{S}\right.$, $\left.55^{\circ} \mathrm{E}\right)$ lidar data set. Geophys. Res. Lett., v. 30, n. 3, p. 1130, 2003. 4, 43

CAMPBELL, J. R.; LOLLI, S.; LEWIS, J. R.; GU, Y.; WELTON, E. J. Daytime cirrus cloud top-of-the-atmosphere radiative forcing properties at a midlatitude site and their global consequences. Journal of Applied Meteorology and Climatology, v. 55, n. 8, p. 1667-1679, 2016. ISSN 15588432. 2

CAMPBELL, J. R.; VAUGHAN, M. A.; OO, M.; HOLZ, R. E.; LEWIS, J. R.; WELTON, E. J. Distinguishing cirrus cloud presence in autonomous lidar measurements. Atmospheric Measurement Techniques, v. 8, n. 1, p. 435-449, 2015. ISSN 18678548. 33, 54

CHEN, T.; ROSSOW, W. B.; ZHANG, Y. Radiative effects of cloud-type variations. Journal of Climate, v. 13, n. 1, p. 264-286, 2000. ISSN 08948755. 2, 61

CHEN, W.; CHIANG, C.; NEE, J. Lidar ratio and depolarization ratio for cirrus clouds. Appl. Opt., v. 41, n. 30, p. 6470 6476, 2002. 17, 20, 35, 36

CHEW, B. N.; CAMPBELL, J. R.; REID, J. S.; GILES, D. M.; WELTON, E. J.; SALINAS, S. V.; LIEW, S. C. Tropical cirrus cloud contamination in sun photometer data. Atmospheric Environment, v. 45, n. 37, p. 6724 - 6731, 2011. ISSN 1352-2310. Disponível em: <http:

//www.sciencedirect.com/science/article/pii/S1352231011008375>. 48

COMSTOCK, J. M.; ACKERMAN, T.; MACE., G. Ground-based lidar and radar remote sensing of tropical cirrus clouds at Nauru island: Cloud statistics and radiative impacts. J. Geophys. Res., v. 107, n. D23, p. 4714, 2002. 4, 44

CORTI, T.; LUO, B. P.; FU, Q.; VÖMEL, H.; PETER, T. The impact of cirrus clouds on tropical troposphere-to-stratosphere transport. Atmospheric Chemistry and Physics, v. 6, n. 9, p. 2539-2547, 2006. ISSN 16807324. 71, 73 
CORTI, T.; LUO, B. P.; PETER, T.; FU, Q. Mean radiative energy balance and vertical mass fluxes in the equatorial upper troposphere and lower stratosphere. v. 32 , p. $1-5,2005.71,73$

CORTI, T.; PETER, T. and Physics A simple model for cloud radiative forcing. Atmospheric Chemistry and Physics, p. 5751-5758, 2009. 1, 5, 55, 56, 60, 65

CZICZO, D. J.; FROYD, K. D.; HOOSE, C.; JENSEN, E. J.; DIAO, M.; ZONDLO, M. A.; SMITH, J. B.; TWOHY, C. H.; MURPHY, D. M. Clarifying the dominant sources and mechanisms of cirrus cloud formation. Science, American Association for the Advancement of Science, v. 340, n. 6138, p. 1320-1324, 2013. ISSN 0036-8075. Disponível em: <http://science.sciencemag. org/content/340/6138/1320>. 3, 45

DEE, D. P. et al. The ERA-Interim reanalysis: configuration and performance of the data assimilation system. Quart. J. Roy. Meteor. Soc., John Wiley \& Sons, Ltd., v. 137, n. 656, p. 553-597, 2011. 31

ELORANTA, E. W. Practical model for the calculation of multiply scattered lidar returns. Applied Optics, v. 37, n. 12, p. 2464, 1998. ISSN 0003-6935. Disponível em: <https://www . osapublishing.org/abstract. cfm?URI=ao-37-12-2464>. 19

EMDE, C.; BURAS-SCHNELL, R.; KYLLING, A.; MAYER, B.; GASTEIGER, J.; HAMANN, U.; KYLlinG, J.; RICHTER, B.; PAUSE, C.; DOWLING, T.; BUGLIARO, L. The libRadtran software package for radiative transfer calculations (version 2.0.1). Geoscientific Model Development, v. 9, n. 5, p. 1647-1672, 2016. ISSN 19919603. 5, 56, 57

FERNALD, F. G. Analysis of atmospheric lidar observations: some comments. Appl. Opt., v. 23, p. 652 653, 1984. 11, 13, 34

FISCH, G.; MARENGO, J. A.; NOBRE, C. A. Uma revisão geral sobre o clima da Amazônia. Acta Amazonica, v. 28, n. 2, p. 101-101, 1998. ISSN 0044-5967.

Disponível em: <http://www.scielo.br/scielo.php?script= sci \{\} arttext $\{\&\}$ pid=S0044-59671998000200101\{\&\}lng=pt $\{\&\}$ tlng=pt $>.54$

FORTUIN, J. P. F.; BECKER, C. R.; FUJIWARA, M.; IMMLER, F.; KELDER, H. M.; SCHEELE, M. P.; SCHREMS, O.; VERVER, G. H. L. Origin and transport of tropical cirrus clouds observed over paramaribo, suriname $\left(5.8 \hat{\mathrm{A}}^{\circ} \mathrm{n}\right.$, $\left.55.2 \widehat{\mathrm{A}}^{\circ} \mathrm{w}\right)$. Journal of Geophysical Research: Atmospheres, v. 112, n. D9, 
2007. Disponível em: <https:

//agupubs.onlinelibrary.wiley.com/doi/abs/10.1029/2005JD006420>. 40

FU, Q.; LIOU, K. N. On the correlated k-distribution method for radiative transfer in nonhomogeneous atmospheres. Journal of the Atmospheric

Sciences, v. 49, n. 22, p. 2139-2156, 1992. Disponível em:

<https://doi.org/10.1175/1520-0469(1992)049<2139:OTCDMF>2.0.C0;2>. 57,60

Parameterization of the radiative properties of cirrus clouds. Journal of the Atmospheric Sciences, v. 50, n. 13, p. 2008-2025, 1993. Disponível em: <https://doi.org/10.1175/1520-0469(1993)050<2008:POTRPO>2.0.C0;2>. 57,60

GARRETT, T. J.; HEYMSFIELD, A. J.; MCGILL, M. J.; RIDLEY, B. A.; BAUMGARDNER, D. G.; BUI, T. P.; WEBSTER, C. R. Convective generation of cirrus near the tropopause. Journal of Geophysical Research D:

Atmospheres, v. 109, n. 21, p. 1-14, 2004. ISSN 01480227. 45

GASPARINI, B.; LOHMANN, U. Why cirrus cloud seeding cannot substantially cool the planet. Journal of Geophysical Research: Atmospheres, v. 121, n. 9, p. 4877-4893, 2016. ISSN 21698996. 2, 3

GASPARINI, B.; MÜNCH, S.; PONCET, L.; FELDMANN, M.; LOHMANN, U. Is increasing ice crystal sedimentation velocity in geoengineering simulations a good proxy for cirrus cloud seeding? Atmospheric Chemistry and Physics, v. 17 , n. 7 , p. 4871-4885, 2017. ISSN 16807324. 3

GIANNAKAKI, E.; BALIS, D. S.; AMIRIDIS, V.; KAZADZIS, S. Optical and geometrical characteristics of cirrus clouds over a southern european lidar station.

Atmos. Chem. Phys., v. 7, n. 21, p. 5519-5530, 2007. 4

GOLDFARB, L.; KECKHUT, P.; CHANIN, M. L.; HAUCHECORNE, A. Cirrus climatological results from lidar measurements at $\mathrm{OHP}\left(44^{\circ} \mathrm{N}, 6^{\circ} \mathrm{E}\right)$. Geophys. Res. Lett., v. 28, p. 1687-1690, 2011. 4, 49

GOUVEIA, D. Caracterização de nuvens cirrus na região da Amazônia central utilizando um lidar em solo. Dissertação de Mestrado, Instituto de Física, Universidade de São Paulo, São Paulo, 2014. 32

GOUVEIA, D. Characterization of cirrus clouds in central Amazon ( $2.89 \stackrel{\circ}{\mathrm{S}}, 59$ $.97^{\circ} \mathrm{W}$ ): Firsts results from observations in 2011. v. 47, n. 2, p. 109-114, 2014. 32 
GOUVEIA, D.; BAARS, H.; SEIFERT, P.; WANDINGER, U.; BARBOSA, H.; BARJA, B.; ARTAXO, P.; LOPES, F.; LANDULFO, E.; ANSMANN, A.

Application of a multiple scattering model to estimate optical depth, lidar ratio and ice crystal effective radius of cirrus clouds observed with lidar. EPJ Web of Conferences, v. 176, p. 05037, 2018. ISSN 2100-014X. Disponível em:

<https://www.epj-conferences.org/10.1051/epjconf/201817605037>. 80

GOUVEIA, D. A.; BARJA, B.; BARBOSA, H. M.; SEIFERT, P.; BAARS, H.; PAULIQUEVIS, T.; ARTAXO, P. Optical and geometrical properties of cirrus clouds in Amazonia derived from 1 year of ground-based lidar measurements.

Atmospheric Chemistry and Physics, v. 17, n. 5, p. 3619-3636, 2017. ISSN 16807324. 31, 53, 54, 57, 61, 80

GUERRERO-RASCADO, J. L.; LANDULFO, E.; nA, J. C. A.; BARBOSA, H. de M. J.; BARJA, B.; BASTIDAS Álvaro E.; BEDOYA, A. E.; COSTA, R. F. da; ESTEVAN, R.; FORNO, R.; GOUVEIA, D. A.; JIMéNEZ, C.; LARROZA, E. G.; LOPES, F. J. da S.; MONTILLA-ROSERO, E.; MOREIRA, G. de A.; NAKAEMA, W. M.; NISPERUZA, D.; ALEGRIA, D.; MúNERA, M.; OTERO, L.; PAPANDREA, S.; PALLOTA, J. V.; PAWELKO, E.; QUEL, E. J.; RISTORI, P.; RODRIGUES, P. F.; SALVADOR, J.; SáNCHEZ, M. F.; SILVA, A. Latin american lidar network (lalinet) for aerosol research: Diagnosis on network instrumentation. Journal of Atmospheric and Solar-Terrestrial Physics, v. 138-139, p. 112 - 120, 2016. ISSN 1364-6826. Disponível em: <http: //www.sciencedirect.com/science/article/pii/S1364682616300013>. 5

HEESE, B.; FLENTJE, H.; ALTHAUSEN, D.; ANSMANN, A.; FREY, S. Ceilometer lidar comparison: Backscatter coefficient retrieval and signal-to-noise ratio determination. Atmospheric Measurement Techniques, v. 3, n. 6, p. 1763-1770, 2010. ISSN 18671381. 33

HOAREAU, C.; KECKHUT, P.; NOEL, V.; CHEPFER, H.; BARAY, J.-L. A decadal cirrus clouds climatology from ground-based and spaceborne lidars above south of france $\left(43.9^{\circ} \mathrm{N}-5.7^{\circ} \mathrm{E}\right)$. Atmos. Chem. Phys. Discuss., v. 13, p. 6379-6417, 2013. 4

HOGAN, R. J. Fast approximate calculation of multiply scattered lidar returns. Applied Optics, v. 45, n. 23, p. 5984, 2006. ISSN 0003-6935. Disponível em: $<$ http://www.ncbi.nlm.nih.gov/pubmed/16926887\{\%\}5Cnhttps: //www . osapublishing. org/abstract. cfm?URI=ao-45-23-5984>. 19, 80 
Fast Lidar and Radar Multiple-Scattering Models. Part I: Small-Angle Scattering Using the Photon Variance-Covariance Method. Journal of the Atmospheric Sciences, v. 65, n. 12, p. 3621-3635, 2008. ISSN 0022-4928. Disponível em: <http://journals.ametsoc.org/doi/abs/10.1175/2008JAS2642.1>. 36, 49 HOGAN, R. J.; KEW, S. F. A 3d stochastic cloud model for investigating the radiative properties of inhomogeneous cirrus clouds. Quarterly Journal of the Royal Meteorological Society, v. 131, n. 611, p. 2585-2608, 2005. Disponível em:

<https://rmets.onlinelibrary.wiley.com/doi/abs/10.1256/qj.04.144>. 1

HONG, G.; HEYGSTER, G.; MIAO, J.; KUNZI, K. Detection of tropical deep convective clouds from amsu-b water vapor channels measurements. Journal of Geophysical Research: Atmospheres, v. 110, n. D5, 2005. Disponível em: $<$ https:

//agupubs.onlinelibrary.wiley.com/doi/abs/10.1029/2004JD004949>. 5

HUFFMAN, G. J. et al. The TRMM multisatellite precipitation analysis (TMPA): Quasi-global, multiyear, combined-sensor precipitation estimates at fine scales. J. Hydrometeor., v. 8, p. 38-55, 2007. 31

IMMLER, F.; SCHREMS, O. Determination of tropical cirrus properties by simultaneous lidar and radiosonde measurements. Geophysical Research Letters, v. 29, n. 23, p. 5-1-5-4, 2002. Disponível em: <https: //agupubs.onlinelibrary.wiley.com/doi/abs/10.1029/2002GL015076>. 4

IMV. International meteorological vocabulary. wmo, no. 182. tp. 91. geneva (secretariat of the world meteorological organization) 1966. pp. xvi, 276. sw. fr. 40. Quarterly Journal of the Royal Meteorological Society, v. 93, n. 395, p. 148-148, 1967. Disponível em: <https :

//rmets.onlinelibrary.wiley.com/doi/abs/10.1002/qj.49709339524>. 31

JENSEN, E. J.; TOON, O. B.; SELKIRK, H. B.; SPINHIRNE, J. D.; SCHOEBERL, M. R. On the formation and persistence of subvisible cirrus clouds near the tropical tropopause. J. Geophys. Res., v. 101, p. $21361-21376,1996$. 48

JIANG, J. H.; SU, H.; ZHAI, C.; SHEN, T. J.; WU, T.; ZHANG, J.; COLE, J. N. S.; SALZEN, K. von; DONNER, L. J.; SEMAN, C.; GENIO, A. D.; NAZARENKO, L. S.; DUFRESNE, J.-L.; WATANABE, M.; MORCRETTE, C.; 


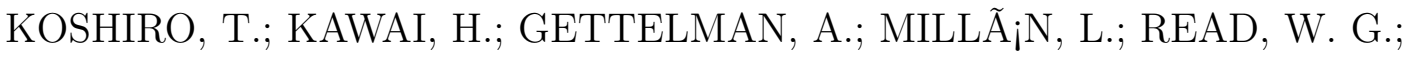
LIVESEY, N. J.; KASAI, Y.; SHIOTANI, M. Evaluating the diurnal cycle of upper-tropospheric ice clouds in climate models using smiles observations.

Journal of the Atmospheric Sciences, v. 72, n. 3, p. 1022-1044, 2015.

Disponível em: <https://doi.org/10.1175/JAS-D-14-0124.1>. 4

KHVOROSTYANOV, V. I.; SASSEN, K. Microphysical processes in cirrus and their impact on radiation a mesoscale modeling perspective. In: CIRRUS. Oxford University Press, 2002. p. 397-432. 1

KIENAST-SJÖGREN, E; ROLF, C.; SEIFERT, P.; KRIEGER, U. K.; LUO, B. P.; KRÄMER, M.; PETER, T. Climatological and radiative properties of midlatitude cirrus clouds derived by automatic evaluation of lidar measurements. Atmospheric Chemistry and Physics, v. 16, n. 12, p. 7605-7621, 2016. ISSN 16807324. 1, 2, 4, 36, 60, 61, 67, 68, 70, 82

KLETT, J. D. Lidar inversion with variable backscatter extinction ratios. Appl. Opt., v. 24, p. 1638 1643, 1985. 11, 13, 34

KRÄMER, M.; ROLF, C.; LUEBKE, A.; AFCHINE, A.; SPELTEN, N.; COSTA, A.; MEYER, J.; ZÖGER, M.; SMITH, J.; HERMAN, R. L.; BUCHHOLZ, B.; EBERT, V.; BAUMGARDNER, D.; BORRMANN, S.; KLINGEBIEL, M.; AVALLONE, L. A microphysics guide to cirrus clouds-Part 1: Cirrus types. Atmospheric Chemistry and Physics, v. 16, n. 5, p. 3463-3483, 2016. ISSN 16807324. 20, 36, 40, 54, 57

LIN, L.; FU, Q.; ZHANG, H.; SU, J.; YANG, Q.; SUN, Z. Upward mass fluxes in tropical upper troposphere and lower stratosphere derived from radiative transfer calculations. Journal of Quantitative Spectroscopy and Radiative Transfer, v. 117, p. 114 - 122, 2013. ISSN 0022-4073. Disponível em: <http: //www.sciencedirect.com/science/article/pii/S0022407312005225>. 1

LIOU, K.-N. Influence of cirrus clouds on weather and climate processes: A global perspective. Mon. Weath. Rev., v. 114, n. 6, p. 1167-1199, 1986. 1, 68, 71

LIOU, K.-N.; GEBIHART, K. L. Numerical experiments on the thermal equilibrium temperature in cirrus cloudy atmospheres. Journal of the Meteorological Society of Japan. Ser. II, v. 60, n. 1, p. 570-582, 1982. 73 LIU, C.; ZIPSER, E. J. Global distribution of convection penetrating the tropical tropopause. J. Geophys. Res., v. 110, p. D23104, 2005. 44, 45, 48, 54 
LOHMANN, U.; GASPARINI, B. A cirrus cloud climate dial? Science, v. 357, n. 6348, p. 248-249, 2017. ISSN 10959203. Disponível em:

<http://www.sciencemag.org/lookup/doi/10.1126/science.aan3325>. 3

LOLLI, S.; CAMPBELL, J. R.; LEWIS, J. R.; GU, Y.; WELTON, E. J. Technical note: Fu-Liou-Gu and Corti-Peter model performance evaluation for radiative retrievals from cirrus clouds. Atmospheric Chemistry and Physics, v. 17, n. 11, p. 7025-7034, 2017. ISSN 16807324. 61

LYNCH, D. K. Cirrus: History and definition. In: CIRRUS. Oxford University Press, 2002. p. 3-10. 1

MACE, G. G.; MARCHAND, R.; ZHANG, Q.; STEPHENS, G. Global hydrometeor occurrence as observed by cloudsat: Initial observations from summer 2006. Geophysical Research Letters, v. 34, n. 9, 2007. Disponível em: <https: //agupubs.onlinelibrary.wiley.com/doi/abs/10.1029/2006GL029017>. 1

MACHADO, L. a. T. Diurnal march of the convection observed during TRMM-WETAMC/LBA. J. Geophys. Res., v. 107, n. D20, p. 8064, 2002. 5, 38, $41,45,53$

MACHADO, L. A. T.; DIAS, M. A. F. S.; MORALES, C.; FISCH, G.; VILA, D.; ALBRECHT, R.; GOODMAN, S. J.; CALHEIROS, A. J. P.; BISCARO, T.; KUMMEROW, C.; COHEN, J.; FITZJARRALD, D.; NASCIMENTO, E. L.; SAKAMOTO, M. S.; CUNNINGHAM, C.; CHABOUREAU, J.-P.; PETERSEN, W. A.; ADAMS, D. K.; BALDINI, L.; ANGELIS, C. F.; SAPUCCI, L. F.; SALIO, P.; BARBOSA, H. M. J.; LANDULFO, E.; SOUZA, R. A. F.; BLAKESLEE, R. J.; BAILEY, J.; FREITAS, S.; LIMA, W. F. A.; TOKAY, A. The chuva project: How does convection vary across brazil? Bulletin of the American Meteorological Society, v. 95, n. 9, p. 1365-1380, 2014. Disponível em: <https://doi.org/10.1175/BAMS-D-13-00084.1>. 5, 38

MACHADO, L. A. T.; LAURENT, H.; DESSAY, N.; MIRANDA, I. Seasonal and diurnal variability of convection over the amazonia: A comparison of different vegetation types and large scale forcing. Theoretical and Applied

Climatology, v. 78, n. 1, p. 61-77, Jun 2004. ISSN 1434-4483. Disponível em: <https://doi.org/10.1007/s00704-004-0044-9>. 7, 40

MARTIN, S. T.; ARTAXO, P.; MACHADO, L. A. T.; MANZI, A. O.; SOUZA, R. A. F.; SCHUMACHER, C.; WANG, J.; ANDREAE, M. O.; BARBOSA, H. M. J.; FAN, J.; FISCH, G.; GOLDSTEIN, A. H.; GUENTHER, A.; JIMENEZ, J. L.; 
PÖSCHL, U.; Silva Dias, M. A.; SMITH, J. N.; WENDISCH, M. Introduction: Observations and Modeling of the Green Ocean Amazon (GoAmazon2014/5). Atmospheric Chemistry and Physics, v. 16, n. 8, p. 4785-4797, 2016. ISSN 16807324. 5, 7

MCCALLA, C. In: __ [s.n.], 1981. (Office note (National Centers for Environmental Prediction (U.S.)) ; 246), cap. Objective Determination of the Tropopause Using WMO Operational Definitions. Professional Paper. Disponível em: <https://repository.library.noaa.gov/view/noaa/11558>. 31

MCCARTNEY, E. J. Optics of the atmosphere: Scattering by molecules and particles. New York: John Wiley, 1979. 10, 12

MCFARQUHAR, G. M.; BAUMGARDNER, D.; HEYMSFIELD, A. J. Background and overview. Meteorological Monographs, v. 58, p. v-ix, 2017. Disponível em: <https://doi .org/10.1175/AMSMONOGRAPHS-D-16-0018.1>. 4

MITCHELL, D. L.; FINNEGAN, W. Modification of cirrus clouds to reduce global warming. Environmental Research Letters, v. 4, n. 4, 2009. ISSN 17489326. 3

NAZARYAN, H.; MCCORMICK, M. P.; MENZEL, W. P. Global characterization of cirrus clouds using CALIPSO data. J. Geophys. Res., v. 113, p. D16211, 2008. $1,4,74$

PACE, G.; CACCIANI, M.; SARRA, A. di; FIOCCO, G.; FUA, D. Lidar observations of equatorial cirrus clouds at Mahé Seychelles. J. Geophys. Res., v. 108(D8), p. 4236, 2003. 4, 49

PANDIT, A. K.; GADHAVI, H. S.; RATNAM, M. V.; RAGHUNATH, K.; RAO, S. V. B.; JAYARAMAN, A. Long-term trend analysis and climatology of tropical cirrus clouds using 16 years of lidar data set over southern india. Atmospheric Chemistry and Physics, v. 15, n. 24, p. 13833-13848, 2015. Disponível em: <https://www.atmos-chem-phys.net/15/13833/2015/>. 4

PECK, E. R.; REEDER, K. Dispersion of air. J. Opt. Soc. Am., v. 62, p. 958-962, 1972. 12

PLATT, C.; DILEY, A. Determination of the cirrus particle single-scattering phase function from lidar and solar radiometric data. Appl. Opt., v. 23, p. 380-386, 1984. 49 
PLATT, C. M. R. Remote sounding of high clouds. iii: Monte carlo calculations of multiple-scattered lidar returns. Journal of the Atmospheric Sciences, v. 38, n. 1, p. 156-167, 1981. Disponível em: <https://doi.org/10.1175/1520-0469(1981)038<0156:RSOHCI>2.0.C0;2>. 49

PROTAT, A.; YOUNG, S. A.; MCFARLANE, S. A.; ECUYER, T. L.; MACE, G. G.; COMSTOCK, J. M.; LONG, C. N.; BERRY, E.; DELANOE, J. Reconciling ground-based and space-based estimates of the frequency of occurrence and radiative effect of clouds around darwin, australia. Journal of Applied Meteorology and Climatology, v. 53, n. 2, p. 456-478, 2014. Disponível em: $<$ https://doi.org/10.1175/JAMC-D-13-072.1>. 33

RANDEL, W. J.; JENSEN, E. J. Physical processes in the tropical tropopause layer and their roles in a changing climate. Nature Geoscience, Nature Publishing Group, a division of Macmillan Publishers Limited. All Rights Reserved. SN -, v. 6, p. 169 EP -, Feb 2013. Review Article. Disponível em: $<$ https://doi.org/10.1038/ngeo1733>. 1

REICHARDT, J.; REICHARDT, S. Determination of cloud effective particle size from the multiple-scattering effect on lidar integration-method temperature measurements. Appl. Opt., OSA, v. 45, n. 12, p. 2796-2804, Apr 2006. Disponível em: <http://ao.osa.org/abstract.cfm?URI=ao-45-12-2796>. 18, 19

SASANO, Y.; NAKANE, H. Significance of the extinction/backscatter ratio and the boundary value term in the solution for the two-component lidar equation.

Appl. Opt., OSA, v. 23, n. 1, p. 11 1-13, Jan 1984. Disponível em: $<$ http://ao.osa.org/abstract.cfm?URI=ao-23-1-111>. 34

SASSEN, K.; CAMPBELL, J. R. A midlatitude cirrus cloud climatology from the facility for atmospheric remote sensing. part i: Macrophysical and synoptic properties. Journal of the Atmospheric Sciences, v. 58, n. 5, p. 481-496, 2001. Disponível em:

<https://doi.org/10.1175/1520-0469(2001)058<0481:AMCCCF>2.0.C0;2>. 4, 43

SASSEN, K.; CHO, B. S. Subvisual-thin cirrus lidar dataset for satellite verification and climatological research. Journal of Applied Meteorology, v. 31, n. 11, p. 1275-1285, 1992. Disponível em: <https://doi.org/10.1175/1520-0450(1992)031<1275:STCLDF>2.0.C0;2>. 42,48 
SASSEN, K.; COMSTOCK, J. M. A midlatitude cirrus cloud climatology from the facility for atmospheric remote sensing. part iii: Radiative properties. Journal of the Atmospheric Sciences, v. 58, n. 15, p. 2113-2127, 2001. Disponível em: $<$ https://doi.org/10.1175/1520-0469(2001)058<2113:AMCCCF>2 .0. C0;2>. 33

SASSEN, K.; GRIN, M.; DOOD, G. C. Optical scattering and microphysical properties of subvisual cirrus clouds and climatic implications. J. Appl. Meteor., v. 28 , p. $91-98,1989.49$

SASSEN, K.; WANG, Z.; KHVOROSTYANOV, V. I.; STEPHENS, G. L.; BENEDETTI, A. Cirrus cloud ice water content radar algorithm evaluation using an explicit cloud microphysical model. J. Appl. Meteor., v. 41, p. 620 - 628, 2002. 38

SASSEN, K.; WANG, Z.; LIU, D. Global distribution of cirrus clouds from CloudSat/Cloud-Aerosol Lidar and Infrared Pathfinder Satellite Observations (CALIPSO) measurements. J. Geophys. Res., v. 113, p. D00A12, 2008. 1, 4, 69

Cirrus clouds and deep convection in the tropics: Insights from CALIPSO and CloudSat. Geophys. Res. Lett., v. 114, n. 3351 - 3354, 2009. 1, 4

SEIFERT, P.; ANSMANN, A.; MüLLER, D.; WANDINGER, U.; ALTHAUSEN, D.; HEYMSFIELD, A. J.; MASSIE, S. T.; SCHMITT, C. Cirrus optical properties observed with lidar, radiosonde and satellite over the tropical indian ocean during the aerosol-polluted northeast and clean maritime southwest monsoon. J.

Geophys. Res., v. 112, p. D17205, 2007. 4, 36, 38, 43, 45, 49

SENA, E. T.; ARTAXO, P.; CORREIA, A. L. Spatial variability of the direct radiative forcing of biomass burning aerosols and the effects of land use change in Amazonia. Atmospheric Chemistry and Physics, v. 13, n. 3, p. 1261-1275, 2013. ISSN 16807316. 57

SILVA, V. B. S.; KOUSKY, V. E.; HIGGINS, R. W. Daily precipitation statistics for south america: An intercomparison between ncep reanalyses and observations. Journal of Hydrometeorology, v. 12, n. 1, p. 101-117, 2011. Disponível em: <https://doi.org/10.1175/2010JHM1303.1>. 41

STAMNES, K.; TSAY, S.-C.; WISCOMBE, W.; JAYAWEERA, K. Numerically stable algorithm for discrete-ordinate-method radiative transfer in multiple scattering and emitting layered media. Appl. Opt., OSA, v. 27, n. 12, p. 
2502-2509, Jun 1988. Disponível em:

$<$ http://ao.osa.org/abstract.cfm?URI=ao-27-12-2502>. 57

STEIN, A. F.; DRAXLER, R. R.; ROLPH, G. D.; STUNDER, B. J. B.; COHEN, M. D.; NGAN, F. Noaa s hysplit atmospheric transport and dispersion modeling system. Bulletin of the American Meteorological Society, v. 96, n. 12, p. 2059-2077, 2015. Disponível em:

<https://doi.org/10.1175/BAMS-D-14-00110.1>. 31

STORELVMO, T.; HERGER, N. Cirrus cloud susceptibility to the injection of ice nuclei in the upper troposphere. Journal of Geophysical Research:

Atmospheres, v. 119, n. 5, p. 2375-2389, 2014. Disponível em: <https:

//agupubs.onlinelibrary.wiley.com/doi/abs/10.1002/2013JD020816>. 3

STORElVMO, T.; KRISTJANSSON, J. E.; MURI, H.; PFEFFER, M.;

BARAHONA, D.; NENES, A. Cirrus cloud seeding has potential to cool climate.

Geophysical Research Letters, v. 40, n. 1, p. 178-182, 2013. Disponível em:

$<$ https:

//agupubs.onlinelibrary.wiley.com/doi/abs/10.1029/2012GL054201>. 3

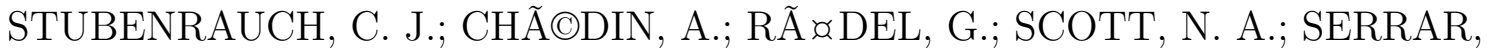
S. Cloud properties and their seasonal and diurnal variability from tovs path-b.

Journal of Climate, v. 19, n. 21, p. 5531-5553, 2006. Disponível em:

<https://doi.org/10.1175/JCLI3929.1>. 1

TANAKA, L. M. d. S.; SATYAMURTY, P.; MACHADO, L. A. T. Diurnal variation of precipitation in central amazon basin. International Journal of Climatology, v. 34, n. 13, p. 3574-3584, 2014. Disponível em: <https://rmets.onlinelibrary.wiley.com/doi/abs/10.1002/joc.3929>. 7

THORSEN, T. J.; FU, Q. Automated retrieval of cloud and aerosol properties from the arm raman lidar. part ii: Extinction. Journal of Atmospheric and Oceanic Technology, v. 32, n. 11, p. 1999-2023, 2015. Disponível em:

<https://doi.org/10.1175/JTECH-D-14-00178.1>. 36

THORSEN, T. J.; FU, Q.; COMSTOCK, J. Comparison of the CALIPSO satellite and ground-based observations of cirrus clouds at the ARM TWP sites. Journal of Geophysical Research Atmospheres, v. 116, n. 21, p. 1-27, 2011. ISSN 01480227. 4, 33

WANDINGER, U. Multiple-scattering influence on extinction- and backscatter-coefficient measurements with raman and high-spectral-resolution 
lidars. Appl. Opt., OSA, v. 37, n. 3, p. 417-427, Jan 1998. Disponível em: $<$ http://ao.osa.org/abstract.cfm?URI=ao-37-3-417>. 9, 18

Multiple-Scattering Influence on Extinction-and Backscatter-Coefficient Measurements with Raman and High-Spectral-Resolution Lidars. Applied optics, v. 37, n. 3, p. 417-27, 1998. ISSN 0003-6935. Disponível em: <http://www.ncbi.nlm.nih.gov/pubmed/18268599>. 49 Introduction to lidar. In: LIDAR RANGE RESOLVED OPTICAL REMOTE SENSING OF THE ATMOSPHERE. Springer, Series in Optical Sciences, 2005. p. 1-18. 9

WANG, T.; DESSLER, A. E. Analysis of cirrus in the tropical tropopause layer from calipso and mls data: A water perspective. Journal of Geophysical Research: Atmospheres, v. 117, n. D4, 2012. Disponível em: <https: //agupubs.onlinelibrary.wiley.com/doi/abs/10.1029/2011JD016442>. 4

WENDISCH, M.; POSCHL, U.; ANDREAE, M. O.; MACHADO, L. A.; ALBRECHT, R.; SCHLAGER, H.; ROSENFELD, D.; MARTIN, S. T.; ABDelmonem, A.; AFCHINE, A.; ARAUjO, A. C.; ARTAXO, P.; AUFMHOFF, H.; BARBOSA, H. M.; BORRMANN, S.; BRAGA, R.; BUCHHOlZ, B.; CECCHINI, M. A.; COSTA, A.; CURTIUS, J.; DOLlnER, M.; DORF, M.; DREILING, V.; EBERT, V.; EHRLICH, A.; EWALD, F.; FISCH, G.; FIX, A.; FRANK, F.; FUTTERER, D.; HECKL, C.; HEIDELBERG, F.; HUNEKE, T.; JAKEL, E.; JARVINEN, E.; JURKAT, T.; KANTER, S.; KASTNER, U.; KENNTNER, M.; KESSELMEIER, J.; KLIMACH, T.; KNECHT, M.; KOHL, R.; KOLLING, T.; KRAMER, M.; KRUGER, M.; KRISNA, T. C.; LAVRIC, J. V.; LONGO, K.; MAHNKE, C.; MANZI, A. O.; MAYER, B.; MERTES, S.; MINIKIN, A.; MOLLEKER, S.; MUNCH, S.; NILLIUS, B.; PFEILSTICKER, K.; POHLKER, C.; ROIGER, A.; ROSE, D.; ROSENOW, D.; SAUER, D.; SCHNAITER, M.; SCHNEIDER, J.; SCHULZ, C.; De Souza, R. A.; SPANU, A.; STOCK, P.; VILA, D.; VOIGT, C.; WALSER, A.; WALTER, D.; WEIGEL, R.; WEINZIERL, B.; WERNER, F.; YAMASOE, M. A.; ZIEREIS, H.; ZINNER, T.; ZOGER, M. Acridicon-chuva campaign: Studying tropical deep convective clouds and precipitation over amazonia using the New German research aircraft HALO. Bulletin of the American Meteorological Society, v. 97, n. 10, p. 1885-1908, 2016. ISSN 00030007. 5, 20, 36, 57

WESTBROOK, C. D.; ILLINGWORTH, A. J.; O'CONNOR, E. J.; HOGAN, R. J. Doppler lidar measurements of oriented planar ice crystals falling from 
supercooled and glaciated layer clouds. Quarterly Journal of the Royal Meteorological Society, v. 136, n. 646, p. 260-276, 2010. 8

WYLIE, D.; JACKSON, D. L.; MENZEL, W. P.; BATES, J. J. Trends in global cloud cover in two decades of HIRS observations. Journal of Climate, v. 18, n. 15, p. 3021-3031, 2005. ISSN 08948755. 1

YANG, P.; HONG, G.; DESSLER, A. E.; OU, S. S. C.; LIOU, K.-N.; MINNIS, P.; HARSHVARDHAN. Contrails and induced cirrus. Bulletin of the American Meteorological Society, v. 91, n. 4, p. 473-478, 2010. Disponível em: <https://doi.org/10.1175/2009BAMS2837.1>. 1

YANG, Q.; FU, Q.; HU, Y. Radiative impacts of clouds in the tropical tropopause layer. Journal of Geophysical Research: Atmospheres, v. 115, n. D4, 2010. Disponível em: <https:

//agupubs.onlinelibrary.wiley.com/doi/abs/10.1029/2009JD012393>. 1

YOUNG, S. A. Analysis of lidar backscatter profiles in optically thin clouds. Appl. Opt., OSA, v. 34, n. 30, p. 7019-7031, Oct 1995. Disponível em: $<$ http://ao.osa.org/abstract.cfm?URI=ao-34-30-7019>. 34 


\section{APÊNDICE A - ATIVIDADES E CURSOS EXTRA-CURRICULARES}

De 12/2016 a 02/2017 eu participei, como pesquisador externo e responsável pela estação lidar de Manaus, no projeto APEL - Assessment of atmospheric optical Properties during biomass burning Events and Long-range transport of desert dust. Este projeto foi coordenado pelo Dr. Eduardo Landulfo (IPEN) e pela Dra. Doina Nicolae (INOE - Bucharest/Romenia), e teve como principal objetivo a transferência de expertise entre a EARLINET (European Aerosol Research LIdar NETwork) e a LALINET (Latin American Lidar Network). O projeto buscou avaliar as atuais capacidades de observação da rede de lidar na América do Sul, em comparação com os padrões e procedimentos EARLINET, a fim de harmonizar os procedimentos operacionais e estabelecer assim o trabalho de base para futuras campanhas de validação (Cal/Val) das missões de satélites atmosféricos da ESA (European Space Agency).

Este projeto teve duas partes. A primeira focou em avaliar as capacidades técnicas das estações da LALINET participantes e promover o treinamento, otimização dos sistemas lidar e implementação dos protocolos de qualidade EARLINET. A segunda parte consistiu em uma campanha de medidas de aerossóis conjunta de entre algumas estações da LALINET e EARLINET.

Em Decorrência dessa parceria entre a LALINET e EARLINET, eu tive a oportunidade de participar de dois cursos de treinamento sobre medidas com sistemas lidar e a utilização da ferramenta automatizada de processamento de dados da EARLINET (SCC - Single Calculus Chain):

a) 2nd LiCalTrain workshop. (Carga horária: 40h), março de 2017. National Institute of R\&D for Optoelectronics, INOE, Romênia.

b) SCC winter school. (Carga horária: 24h), dezembro de 2018. National Research Council, CNR, Potenza, Itália. 



\section{APÊNDICE B - APRESENTACOES EM EVENTOS CIENTIFICOS}

Foram 35 trabalhos apresentados em conferências científicas durante o meu doutorado. Destes, fui primeiro autor de 11 e apresentei 8 nos respectivos eventos.

H. M. J. Barbosa, C. Alves, T. Pauliquevis, D. A. Gouveia, A. V. Santos, A. Calheiros, D. Adams: On the trigger and time-scales of shallow-to-deep convection in Amazonia. In: AGU Fall Meeting 2018, Washington DC, USA, 10-14 December 2018, A11O-0235

A. V. dos Santos, H. M. J. Barbosa, D. A. Gouveia, T. Pauliquevis, E. Landulfo: Investigating the vertical distribution of clouds in Central Amazon from the measurements of a ceilometer during the GoAmazon2014/15 experiment. In: AGU Fall Meeting 2018, Washington DC, USA, 10-14 December 2018, A31P-0270

H. M. J. Barbosa, D. A. Gouveia, H. Kalesse, P. Seifert, B. Barja, M. Monteiro, A. Correia, T. Pauliqueves, A. Ansmann: Optical Properties and Radiative Forcing of Cirrus Clouds in the Central Amazon Forest. In: X Workshop on Lidar Measurements in Latin America, Medellin, Colombia, November 2018

A. V. dos Santos, H. M. J. Barbosa, D. A. Gouveia: Calculating the vertical distribution of aerosol in Central Amazon from the measurements of a ceilometer during GoAmazon IOP1 (Feb-Mar 2014). In: X Workshop on Lidar Measurements in Latin America, Medellin, Colombia, November 2018

A. V. dos Santos, H. M. J. Barbosa and D. A. Gouveia: Vertical distribution of the Manaus pollution plume during goamazon iop1 (feb-mar 2014). In: 26 Simpósio Internacional de Iniciação Científica e Tecnológica da USP, Setembro 2018

A. V. dos Santos, D. A. Gouveia, H. M. J. Barbosa, E. Landulfo: Vertical distribution of clouds in central Amazon from the measurements of a ceilometer. In: SPSAS on Frontiers in Lasers and their Applications, IPEN, SÃ£o Paulo, 16-27 Julho 2018

F. J. S. Lopes, G. A. Moreira, J.L.Guerrero-Rascado, J. A. Silva, D. Gouveia, A. Gomes, L. Belegante, V. Freudenthaler, H. M. J. Barbosa, L. Alados-Arboledas, D. Nicolae, A. Geiss, A. G. Straume, E. Landulfo: Improving the Instrument and Analysis Capabilities of the Sao Paulo LALINET Lidar Station in the Framework of the APEL Project. In: 1st European Lidar Conference ELC2018, Thessaloniki, Greece, 3-5 July 2018. 
J. C. Antuna-Marrero, E. Landulfo, H. M. J. Barbosa, F. Lopes, J. L. Guerrero Rascado, R. Estevan, A. R. Vega, B. Barja, and D. Gouveia: One step further in the objectives of LALINET: preparation for the next major volcanic eruption e validations of the UTLS aerosols measurements from EarthCare and Sage III satellite missions. In: Chapman Conference on Stratospheric aerosol, Tenerife, Spain, 18-23 March 2018

D. A. Gouveia, H. M. J. Barbosa, B. Barja, A. V. dos Santos, E. Landulfo, T. Pauliquevis, P. Artaxo: Research on clouds from LIDAR measurements. In: ATTO Workshop, Manaus, 4-5 October 2017

D. Gouveia, H. Baars, P. Seifert, U. Wandinger, H. M. J. Barbosa, B. Barja, P. Artaxo, F. Lopes, E. Landulfo, A. Ansmann: Application of a multiple scattering model to estimate optical depth, lidar ratio and ice crystal effective radius of cirrus clouds observed with lidar. In. 28th International Radar Laser Conference (IRLC), Bucharest, Romania, June 25-30, 2017

E. Landulfo, F. Lopes, D. Gouveia, A. Bastidas, H. M. J. Barbosa, R. Forno, M. F. Sanchez Barrero, P. Ristori, E. J. Quel, L. Otero: South American Aerosol Tracking - LALINET. In. 28th International Radar Laser Conference (IRLC), Bucharest, Romania, June 25-30, 2017

E. Landulfo, F. Lopes, G. A. Moreira, J. Silva, P. Ristori, E. Quel, J. V. Pallota, M. Herrera, A. Barbero, P. Etala, R. Forno, M. F. Sanchez, R. E. Arredondo, J. C. Antuna-Marrero, A. R. Vega, A. Silva, B. Barja, F. Zamorano, R. P. Legue, J. Hoelzemann, J. H. Fernandez, A. Guedes, E. Montilla, H. M. J. Barbosa, D. Gouveia, A. V. Santos, J. L. Guerrero Rascado, L. A. Arboledas, M. V. Zabala, J. Velez, A. Bastidas, N. Sugimoto, Y. Jin, L. Otero: LALINET status - Station Expansion and Lidar ratio Systematic Measurements. In. 28th International Radar Laser Conference (IRLC), Bucharest, Romania, June 25-30, 2017

D. Gouveia, H. M. J. Barbosa, B. Barja, E. Landulfo: Cirrus clouds observation over the Amazon: Results from 3 lidar systems and radiosondings during the GoAmazon 2014/15 experiment, XVII International Conference on Clouds and Precipitation, Manchester, 25-29 July, 2016.

J. L. Guerrero-Rascado, Landulfo E, Lopes F. J. S., Barbosa H. M. J., Gouveia D. A., Forno R. N., Sanchez M. F., Bastidas A. E., Nisperuza D., Montilla-Rosero E., Silva A., Hoelzemann J. J., Ristori P., Quel E. J., Barja B., and Antuna J. A.: 
Checking the instrumental performance of LALINET: quality assurance during the period 2014-2015, IX Workshop on Lidar Measurements in Latin America, Santos, Brazil, 17-22 July, 2016

B. Barja, H. M. J. Barbosa, D. Gouveia, J. Santana: Cirrus Clouds in the Central Amazon region during GOAMAZON 2014/2015 experiment, IX Workshop on Lidar Measurements in Latin America, Santos, Brazil, 17-22 July, 2016

D. Gouveia, B. Barja, H. M. J. Barbosa, E. Landulfo, P. Almeida, J. Rosas: Study Cases of Cirrus Cloud Radiative Effect in Manaus Region during August - October 2014, IX Workshop on Lidar Measurements in Latin America, Santos, Brazil, 17-22 July, 2016

H. M. J. Barbosa, B. Barja, D. A. Gouveia, E. Landulfo, P. Almeida, B. A. Holanda, T. Pauliquevis, P. Artaxo, S. Martin: Aerosol vertical properties inside the Manaus pollution plume, IX Workshop on Lidar Measurements in Latin America, Santos, Brazil, 17-22 July, 2016

H. M. J. Barbosa, D. Gouveia, B. Barja and P. Artaxo: Ground-based aerosol and cloud profiling in Amazonia during the GoAmazon experiment, 10th Anniversary Yoram Kaufman Memorial Symposium, NASA Goddard Space Flight Center, Greenbelt - USA June 21-23, 2016

B. Barja, H. M. J. Barbosa, D. Gouveia and Jorge Rosas: Study Cases of Cirrus Cloud Radiative Effect in Manaus Region during September - October 2014, Workshop on Aerosol-Cloud-Precipitation interactions in Amazonia during the ACRIDICON-CHUVA Campaign, Ilhabela - SP, Feb 29 - Mar 3, 2016

E. Landulfo, F. J. S. Lopes, G. A. Moreira, M T A Marques, M Osneide, E MontillaRosero, A Silva, C Jimenez, R. N. Forno, M. F. SÃjnchez, O Lazcano, J L Guerrero Rascado, L A Arboledas, E Quel, P. Ristori, L Otero, H. M. J. Barbosa, D. A. Gouveia, B. Barja: ALINE/LALINET NETWORK STATUS. In: The 27th International Laser Radar Conference, New York (USA), July 5-10th, 2015.

D. A. Gouveia, H. M. J. Barbosa, B. Barja, P. Almeida, E. Landulfo: Cirrus clouds observation and instrumental intercomparison from three lidar systems operated during IOP2. In: GoAmazon2014/15 Workshop, Harvard, May 2015

H. M. J. Barbosa, B. Barja, D. A. Gouveia, E. Landulfo, P. Almeida, B. A. Holanda, T. Pauliquevis, P. Artaxo, S. Martin: Disentangling the Manaus pollution 
plume from the biomass burning plume during the second GoAmazon 2014/5 Intensive Operating Period (IOP2). In: VIII Workshop on Lidar Measurement in Latin America, Cayo Coco - Cuba, 6-10 April 2015

D. A. Gouveia, H. M. J. Barbosa, B. Barja: Algorithm for the Determination of the Optical Depth and Lidar Ratio of Cirrus Clouds by Elastic Lidar Measurements. In: VIII Workshop on Lidar Measurement in Latin America, Cayo Coco - Cuba, 6-10 April 2015

D. A. Gouveia, H. M. J. Barbosa, B. Barja, P. Almeida, E. Landulfo: Intercomparison of the Lidar systems operated during GoAmazon 2014/15 experiment. In: VIII Workshop on Lidar Measurement in Latin America, Cayo Coco - Cuba, 6-10 April 2015

B. Barja, H. M. J. Barbosa, D. Gouveia, E. Landulfo and P. Almeida: Characteristics of Cirrus Clouds in the Central Amazon region during the Intensive Observational Period in the dry season 2014 as part of the GOAMAZON experiment. In: VIII Workshop on Lidar Measurement in Latin America, Cayo Coco - Cuba, 6-10 April 2015

Barbosa, H. M. J., T. Pauliquevis, D. K. Adams, P. Artaxo, G. Cirino, B. Barja, A. Correia, H. Gomes, D. A. Gouveia, M. B. Padua, N. M. E. Rosario, R. A. F. Souza, R. M. N. Santos, L. Sapucci, and B. T. Portela: ACONVEX-Aerosols, Clouds, cONvection, Experiment-A new site in central Amazonia for long term monitoring of aerosol-clouds-convection interactions. In: AMS 95th Annual Meeting-Phoenix, Arizona, January 2015

B. Barja, H. M. J. Barbosa, D. A. Gouveia, J. Rosas, and P. Artaxo: Study Cases of Cirrus Cloud Radiative Effect using Lidar Backscatter Data, Radiative Transfer Code and Solar Radiation Measurements in Manaus Region. In: AMS 95th Annual Meeting- Phoenix, Arizona, January 2015

D. A. Gouveia, H. M. J. Barbosa and B. Barja: Comparison of cirrus optical depth from ground-based lidar and radiometer with data from CALIOP and MODIS over Amazon region $\left(2.89^{\circ} \mathrm{S} 59.97^{\circ} \mathrm{W}\right)$. In: AMS 95th Annual Meeting-Phoenix, Arizona, January 2015

T. Pauliquevis, H. M. J. Barbosa, D. Adams, P. Artaxo, G. Cirino, B. Barja, A. Correia, H. Gomes, D. Gouveia, M. Padua, N. Rosario, R. Souza, R. N. dos Santos, L. Sapucci, B. Portela; ACONVEX: A new site in central Amazonia dedicated 
to long-term cloud properpties observations- Description, first results and future perspectives. In: AGU Fall Meeting 2014, San Francisco, December 2014

D. A. Gouveia, H. M. Barbosa and B. Barja: On the Formation and Seasonal Properties of Topical Cirrus Clouds over Amazon Basin (2.89 $\left.{ }^{\circ} \mathrm{S}, 59.97^{\circ} \mathrm{W}\right)$ : Observations from Lidar, Radiosonde and Satellite instruments. In: AGU Fall Meeting 2014, San Francisco, December 2014

D. A. Gouveia; H. M. J. Barbosa; B. Barja; Characterization of Cirrus Clouds in Central Amazon (2.89 $\left.{ }^{\circ} \mathrm{S} 59.97^{\circ} \mathrm{W}\right)$ Using a Ground-Based Lidar System. In: IGAC e iCACGP Conference 2014, Natal-Brazil, September 2014

T. Pauliquevis; H. M. J. Barbosa; D. Kenton Adams; B. Barja; A. J. Peixoto Calheiros; A. L. Correia; H. B. Gomes; D. A. Gouveia; A. Braga Oliveira; M. B. PÃjdua; P. Artaxo; L. F. Sapucci; R M N dos Santos; G. G. Cirino; N. Rosario; R. A. F. Souza; B. T. T. Portela; ACONVEX: A New Site In Central Amazonia Dedicated To Long-Term Cloud Properties Observations-Description, First Results And Future Perspectives. In: IGAC e iCACGP Conference 2014, Natal-Brazil, September 2014

Barbosa, H. M. J.; Barja, B.; Pauliquevis, T. M.; Gouveia, D. A.; Artaxo, P.; Cirino, G. G.; Santos, R. M. N.; Oliveira, A. B.: Ground based lidar observations of aerossol and cirrus clouds optical properties in central Amazon during the dry season. In: 4th iLEAPS Science Conference, 2014, Nanjing.

Barja, B; Barbosa, HMJ; Gouveia D; Ground based remote sensing and in situ measurements of tropical and anvil cirrus properties. Radiative effects study in Amazonia during September-October 2014. In: International Workshop of ACRIDICONCHUVA Project, 2014, São José dos Campos.

D. Gouveia, H. M. J. Barbosa, B. Barja; Long-term measurements of base and top height, optical depth and extinction-to-backscattering ratio of high clouds with high vertical and temporal resolution using a ground-based lidar system in central Amazon. In: International Workshop of ACRIDICON-CHUVA Project, 2014, São José dos Campos. 



\section{APÊNDICE C - TRABALHOS PUBLICADOS OU SUBMETIDOS}

Foram 5 trabalhos científicos publicados durante o período do meu doutorado, dos quais fui primeiro autor de dois deles. Os três publicados em 2014, no primeiro ano do doutorado, foram iniciados durante o mestrado.

- Gouveia, D. A., Barja, B., Barbosa, H. M. J., Seifert, P., Baars, H., Pauliquevis, T., and Artaxo, P., 2017: Optical and Geometrical Properties of Cirrus Clouds in Amazonia Derived From 1-year of Ground-based Lidar Measurements, Atmos. Chem. Phys., 17, 3619-3636, doi:10.5194/acp-173619-2017, 2017.

- Guerrero-Rascado, J. L., E. Landulfo, J. C. Antuna, H. M. J. Barbosa, B. Barja, A. E. Bastidas, A. E. Bedoya, R. Costa, R. Estevan, R. N. Forno, D. A. Gouveia, C. Jimenez, E. G. Larroza, F. J. S. Lopes, E. Montilla-Rosero, G. A. Moreira, W. M. Nakaema, D. Nisperuza, D. Alegria, M. Manera, L. Otero, S. Papandrea, J. V. Pallota, E. Pawelko, E. J. Quel, P. Ristori, P. F. Rodrigues, J. Salvador, M. Sanchez, and A. Silva: Latin American Lidar Network (LALINET): diagnosis on network instrumentation, Journal of Atmospheric and Solar-Terrestrial Physics, 138-139 (2016) 112-120. doi:10.1016/j.jastp.2016.01.001

- Barbosa, H. M. J., Barja, B., Pauliquevis, T., Gouveia, D. A., Artaxo, P., Cirino, G. G., Santos, R. M. N., and Oliveira, A. B.: A permanent raman lidar station in the Amazon: description, characterization and first results, Atmos. Meas. Tech., 7, 1745-1762, doi:10.5194/amt-7-1745-2014, 2014.

- D. A. Gouveia, B. Barja and H. M. J. Barbosa: Characterization of cirrus clouds in central Amazon (2.89 $\left.{ }^{\circ} \mathrm{S} 59.97^{\circ} \mathrm{W}\right)$ : Firsts results from six months of observations in 2011, Óptica Pura y Aplicada, 47 (2) 109-144 (2014). doi: 10.7149/OPA.47.2.109

- Barbosa, H. M. J., F. J. S. Lopes, A. Silva, D. Nisperuza, B. Barja, P. Ristori, D.A. Gouveia, C. Jimenez, E. Montilla, G.L. Mariano, E. Landulfo, A. Bastidas, E.J. Quel: The first ALINE measurements and intercomparison exercise on lidar inversion algorithms, Óptica Pura y Aplicada, 47 (2) 99-108 (2014). doi: 10.7149/OPA.47.2.99 